\title{
Brominated and Chlorinated Contaminants and Metabolites in Polar Bears: Levels, Patterns, Spatiotemporal Trends and the Relationship to Diet
}

\author{
by \\ Melissa A. McKinney \\ M.Sc., University of Windsor, 2004 \\ B.Sc. (Honours), University of British Columbia, 2002 \\ A thesis submitted to the Faculty of Graduate Studies and Research \\ in partial fulfillment of the requirements for the degree of \\ Doctor of Philosophy \\ in \\ Chemistry with Specialization in Chemical and Environmental Toxicology \\ Carleton University \\ Ottawa, Ontario, Canada \\ (C) 2010, Melissa A. McKinney
}


Library and Archives

Canada

Published Heritage

Branch

395 Wellington Street

Ottawa ON K1A ON4

Canada
Bibliotheque et

Archives Canada

Direction du

Patrimoine de l'édition

395 , rue Wellington

Ottawa ON K1A ON4

Canada
Your file Votre référence

ISBN: 978-0-494-70533-9

Our file Notre référence

ISBN: 978-0-494-70533-9
NOTICE:

The author has granted a nonexclusive license allowing Library and Archives Canada to reproduce, publish, archive, preserve, conserve, communicate to the public by telecommunication or on the Internet, loan, distribute and sell theses worldwide, for commercial or noncommercial purposes, in microform, paper, electronic and/or any other formats.

The author retains copyright ownership and moral rights in this thesis. Neither the thesis nor substantial extracts from it may be printed or otherwise reproduced without the author's permission.
AVIS:

L'auteur a accordé une licence non exclusive permettant à la Bibliothèque et Archives Canada de reproduire, publier, archiver, sauvegarder, conserver, transmettre au public par télécommunication ou par l'Internet, prêter, distribuer et vendre des thèses partout dans le monde, à des fins commerciales ou autres, sur support microforme, papier, électronique et/ou autres formats.

L'auteur conserve la propriété du droit d'auteur et des droits moraux qui protège cette thèse. Ni la thèse ni des extraits substantiels de celle-ci ne doivent être imprimés ou autrement reproduits sans son autorisation.
In compliance with the Canadian Privacy Act some supporting forms may have been removed from this thesis.

While these forms may be included in the document page count, their removal does not represent any loss of content from the thesis.
Conformément à la loi canadienne sur la protection de la vie privée, quelques formulaires secondaires ont été enlevés de cette thèse.

Bien que ces formulaires aient inclus dans la pagination, il n'y aura aucun contenu manquant. 


\section{Abstract}

High levels of legacy contaminants including polychlorinated biphenyls (PCBs) and organochlorine pesticides (OCPs) occur in polar bears (Ursus maritimus) relative to species lower in the arctic marine food web; yet, levels and patterns vary within and among circumpolar subpopulations. Less is known regarding recent-/current-use organohalogens including brominated flame retardants (BFRs) in polar bears and their food webs. In this thesis, spatiotemporal variation in BFR, PCB and OCP levels and patterns was characterized in polar bears, and explanatory factors were investigated, particularly in relation to diet. Adipose tissues were collected in 2005-2008 from 11 subpopulations in Alaska (AL), Canada including subarctic western and southern Hudson Bay (WHB, SHB), East Greenland (EG) and Svalbard (SV). Although several BFRs were screened, only polybrominated diphenyl ethers (PBDEs), total-( $\alpha$ )hexabromocyclododecane (HBCD), and the polybrominated biphenyl 2,2',4,4',5,5'hexabromobiphenyl (BB153) were consistently found. Levels of these BFRs increased from west (AL) to east (EG and SV), and were also elevated in WHB and SHB, but remained low in all subpopulations relative to predominant legacy contaminants. $\Sigma$ PCB levels were high compared to all monitored contaminants and increased from west to east. $\sum$ Chlordane levels were highest among OCPs, but relatively spatially uniform. Diet variation among subpopulations was examined using nitrogen and carbon stable isotopes and fatty acids. Variation in PCB and PBDE, but not OCP, levels was significantly explained by diet. Therefore, geographic variation in levels of more persistent contaminants was mediated by both regional contamination and diet differences. From 
1991-2007, PBDE levels in WHB increased, whereas legacy contaminant levels generally decreased or showed non-significant trends. Sea ice-associated diet changes influenced temporal trends in WHB contaminant levels, resulting in higher levels over time than if the diet had not changed. Thus, climate changes are additionally a concern to northern ecosystems through altered contaminant exposures. Finally, comparison of BFR patterns in polar bear and marine mammals by hepatic microsomal biotransformation assay demonstrated greater depletion of BDE209 and decabromodiphenyl ethane (DBDPE) occurred in all species relative to lower brominated PBDEs. Characterizing these factors modulating contaminant levels in this sentinel species is critical to understanding the state of, and risks posed by, arctic contamination. 


\section{List of Publications associated with Thesis}

\section{Refereed Journal Publications}

McKinney, M.A., Dietz, R., Sonne, C., De Guise, S., Skirnisson, K., Karlsson, K., Steingrímsson, E., Letcher, R.J., 2010. Comparative hepatic microsomal biotransformation of selected polybrominated diphenyl ether, including decabromodiphenyl ether, and decabromodiphenyl ethane flame retardants in arctic marine-feeding mammals. Environ. Toxicol. Chem. In preparation. (Chapter 7)

McKinney, M.A., Letcher, R.J., Aars, J., Born, E.W., Branigan, M., Dietz, R., Evans, T.J., Gabrielsen, G.W., Muir, D.C.G., Peacock, E., Sonne, C., 2010. Regional contamination versus regional diet differences: understanding geographic variation in brominated and chlorinated contaminant levels in polar bears. Environ. Sci. Technol. Submitted. (Chapter 4)

McKinney, M.A., Letcher, R.J., Aars, J., Born, E.W., Branigan, M., Dietz, R., Evans, T.J., Gabrielsen, G.W., Peacock, E., Sonne, C., 2010. Flame retardants and legacy contaminants in polar bears from Alaska, Canada, East Greenland and Svalbard, 20052008. Environ. Int. Submitted. (Chapter 3)

McKinney, M.A, Stirling, I., Lunn, N.J., Peacock, E., Letcher, R.J., 2010. The role of diet on long-term (1991-2007) concentration and pattern trends of brominated and chlorinated contaminants in western Hudson Bay polar bears. Sci. Total Environ. In press. (Chapter 6)

Letcher, R.J., Gebbink, W.A., Sonne, C., Born, E.W., McKinney, M.A., and Dietz, R., 2009. Bioaccumulation and biotransformation of brominated and chlorinated contaminants and their metabolites in ringed seals (Pusa hispida) and polar bears (Ursus maritimus) from East Greenland. Environ. Int. 35: 1118-1124.

McKinney, M.A., Peacock, E., Letcher, R.J., 2009. Sea ice-associated diet change increases the levels of chlorinated and brominated contaminants in polar bears. Environ. Sci. Technol. 43: 4334-4339. (Chapter 5)

\section{Refereed Conference Abstracts and Proceedings}

McKinney, M.A., Letcher, R.J., Born, E.W., Branigan, M., Dietz, R., Evans, T.J., Gabrielsen, G.W., Peacock, E., Muir, D.C.G., Sonne, C., 2010. Flame retardants and legacy contaminants in polar bears from Alaska, Canada, East Greenland and Svalbard: spatiotemporal trends and the role of diet. 30th International Symposium on Halogenated Persistent Organic Pollutants (DIOXIN 2010), Sept. 12-17, San Antonio, TX, USA.

MacInnis, G.A., Letcher, R.J., McKinney, M.A., Tomy, G.T., Lebeuf, M., Fång, J., Bergman, A., Marvin, C.H., 2010. Investigation of HBCD metabolism in marine mammals using in vitro bioassays. 30th International Symposium on Halogenated Persistent Organic Pollutants (DIOXIN 2010), Sept. 12-17, San Antonio, TX, USA.

McKinney, M.A., Letcher, R.J., Born, E.W., Branigan, M., Dietz, R., Evans, T.J., Gabrielsen, G.W., Lunn, N., Muir, D.C.G., Peacock, E., Sonne, C., Stirling, I., 2010. Regional Differences, Temporal Trends and the Influence of Diet in Organohalogen 
Contaminants in Polar Bears. International Polar Year: Oslo Science Conference, June 8-12, Oslo, Norway.

Ross, M.S., Letcher, R.J., McKinney, M.A., Sonne, C., Dietz, R., Wong C.S. Comparison of the enantiomer distribution of chiral organochlorine contaminants in captive West Greenland sledge dogs and East Greenland polar bears. $30^{\text {th }}$ Annual North America Meeting of the Society of Environmental Toxicology and Chemistry (SETAC), Nov. 19-23, New Orleans, LA, USA.

McKinney, M.A., Dietz, R., Sonne, C., Skirnisson, K., Karlsson, K., Steingrímsson, E., Letcher, R.J., 2009. Comparative hepatic microsomal metabolism of PBDE (including BDE209) and DBDPE flame retardants in arctic marine top predators. $30^{\text {th }}$ Annual North America Meeting of the Society of Environmental Toxicology and Chemistry (SETAC), Nov. 19-23, New Orleans, LA, USA.

McKinney, M.A., Peacock, E., Branigan, M., Evans, T.J., Gabrielsen, G.W., Dietz, R., Sonne, C., Born, E.W., Stirling, I., Lunn, N., Letcher, R.J., 2009. Chemical contaminants in polar bears can be influenced by location, time and the diet they eat. 2009 Northern Contaminants Program Results Workshop, Sept. 29-30, Ottawa, ON, Canada.

McKinney, M.A., Peacock, E., Branigan, M., Evans, T.J., Gabrielsen, G.W., Dietz, R., Sonne, C., Born, E.W., Letcher, R.J., 2009. Regional differences and temporal patterns of brominated flame retardants in polar bears from Alaska, Canada, Greenland and Svalbard. $11^{\text {th }}$ Annual Workshop on Brominated Flame Retardants, May 19-20, Ottawa, ON, Canada.

McKinney, M.A., Peacock, E., Letcher, R.J., 2008. Does sea ice-associated variation in diet influence the temporal trends of organohalogen concentrations in Western Hudson Bay polar bears? International Arctic Change Conference, Dec. 9-12, Québec, QC, Canada.

Dietz, R., Rigét, F.F., Forchammer, M., Sonne, C., Aubail, A., Born, E.W., Letcher, R.J., McKinney, M.A., Muir, D., Bossi, R., Aars, J., Andersen, M., Wiig, Ø., Caurant, F., Grandjean, P. Contaminant linkages to climate parameters in polar bears (Ursus maritimus) from Greenland and Svalbard. International Arctic Change Conference, Dec. 9-12, Québec, QC, Canada.

McKinney, M.A., Peacock, E., Dyck, M., Branigan, M., Evans, T.J., Gabrielsen, G.W., Dietz, R., Sonne, C., Rigét, F., Muir, D.C.G., Letcher, R.J., 2008. Use of dietary tracers in the interpretation of current organohalogen contaminant spatial trends in polar bears. $5^{\text {th }}$ SETAC World Congress, Aug. 3-7, Sydney, NSW, Australia.

McKinney, M.A., Peacock, E., Dyck, M., Branigan, M., Evans, T.J., Gabrielsen, G.W., Dietz, R., Sonne, C., Rigét, F., Letcher, R.J., 2008. Temporal patterns of chlorinated and brominated contaminants in polar bears from western Hudson Bay, Canada and other circumpolar populations. $5^{\text {th }}$ SETAC World Congress, Aug. 3-7, Sydney, NSW, Australia.

Letcher, R.J., Chu, S., Peacock, E., Dietz, R., Sonne, C., Gabrielsen, G.W., McKinney, M.A., Branigan, M., Evans, T.J., 2008. Associations between perfluorinated carboxylate and sulfonate contaminants and precursors in polar bears from circumpolar populations. $5^{\text {th }}$ SETAC World Congress, Aug. 3-7, Sydney, NSW, Australia. 
Letcher, R.J., Chu, S., Peacock, E., Dietz, R., Sonne, C., Gabrielsen, G.W., McKinney, M.A., Branigan, M., Evans, T.J., 2008. Spatial distribution and temporal comparisons of bioaccumulative polyfluoroalkyl contaminants in polar bears from circumpolar populations. $5^{\text {th }}$ SETAC World Congress, Aug. 3-7, Sydney, NSW, Australia.

Dietz, R., Rigét, F.F., Letcher, R.J., Muir, D.C.G., Bossi, R., Vorkamp, K., McKinney, M.A., Born, E.W., 2008. Temporal trends and bioaccumulation of selected contaminants in East Greenland ringed seals and polar bears. $5^{\text {th }}$ SETAC World Congress, Aug. 3-7, Sydney, NSW, Australia.

McKinney, M.A., Peacock, E., Dyck, M., Gabrielsen, G.W., Sonne, C., Dietz, R., Letcher, R.J., 2007. Recent findings on the spatial and temporal trends of legacy chlorinated and recent-use/current-use brominated contaminants in polar bears. 2007 Northern Contaminants Program Results Workshop, Oct. 2-4, 2007, Lake Louise, AB, Canada. 


\section{Acknowledgements}

This project would not have been possible except for the help, expertise and involvement of many individuals. First, I would like to thank my supervisor, Robert Letcher, for providing me with such a great opportunity and for fully supporting and encouraging my progress along the way. Second, I would like to acknowledge all of the collaborators involved in the separate studies that comprise this thesis, specifically, Rune Dietz, Christian Sonne, Geir Gabrielsen, Elizabeth Peacock, Thomas J. Evans, Derek Muir, Erik Born, Marsha Branigan, Nick Lunn, Ian Stirling, Jon Aars, Sylvain De Guise, Karl Skirnisson, Karl Karlsson and Egill Steingrímsson.

For Canadian polar bear sampling and assistance, I thank Nunavut Hunters and Trappers Organizations, Nunavut Department of Environment conservation officers and lab technicians (A. Coxon, F. Piugattuk, A. Niptanatiak, D. Fredlund, J. Ashevak, J. Savikataaq, J. Qaunaq, A. Williams, P. Prefontaine, K. Nogier, A. Nakashuk, L. Kudluk, N. Nakoolik, E. Qaggutaq, T. Palluq, N. Amarualik, T. Mullin, B. J. Hainnu, G. Koonoo, T. Palluq, J. Coutu-Autut) and Environment Canada staff at NWRC (G. Savard, A. Idrissi, P. Dunlop, R. Lima, C. McClelland, K. Timm, M. Asrat, L. Periard) in the Wildlife Specimen Bank and Lab Services staff. Thanks also to A. Coxon for tooth aging of Nunavut bears. Thanks to the University of Waterloo Environmental Isotopes Laboratory (W. Mark) for stable isotopes analysis. Thanks to R. Pugh (Hollings Marine Laboratory, NIST) for assistance with the Alaskan samples. For Svalbard sampling, M. Andersen is acknowledged. East Greenland sampling and assistance was provided by local hunters, J. Brønlund, M. Kierkegaard, S. Joensen and L. Bruun. For the 
biotransformation studies, thanks to H. Guðmundsson, P. Sæmundsson, P. Jakobsson, C. Grøndahl, H. Magnason and J. Rothenborg for logistical support and tissue collection of the Iceland polar bear, to M. Levin and M. Eetak for involvement in beluga whale sampling and to G. Tomy for generous provision of the ringed seal liver samples.

I thank all of the present and past people in my lab group, in particular Lewis, Wouter, Francisco, Soheila and Shaogang. I also appreciate the great group of people at the NWRC, and especially the hockey "team". To my partner, Denis, whose patience, encouragement and assistance was invaluable. I also appreciate the support of my family.

In Canada, this study was funded by the Northern Contaminants Program (Department of Indian and Northern Affairs Canada) (R. Letcher), the Canadian International Polar Year Secretariat (E. Peacock, R. Letcher), the Molson Foundation (R. Letcher) and the Natural Sciences and Engineering Research Council of Canada (NSERC) by a Discovery Grant (R. Letcher) and an NSERC Canada Graduate Scholarship (M. McKinney). Greenland program funding was from the IPY program "BearHealth" by KVUG, the Danish Cooperation for Environment in the Arctic under the Danish Ministry of Environment and the Prince Albert Foundation. US Fish and Wildlife Service Marine Mammals Management contributed to Alaskan funding and the Norwegian Polar Institute contributed to the Norwegian funding. The beluga sampling was supported by a grant from the US EPA STAR Program (S. De Guise).

viii 


\section{Table of Contents}

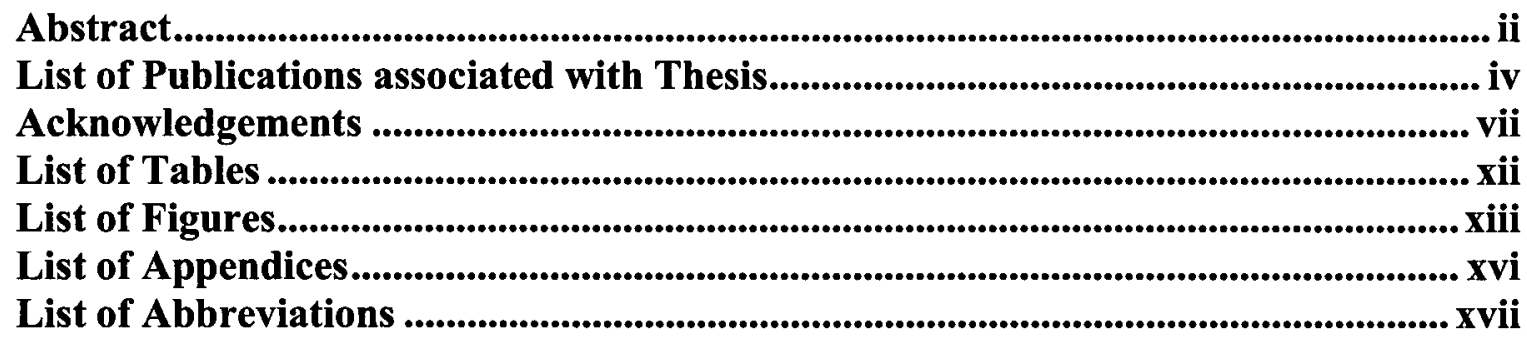

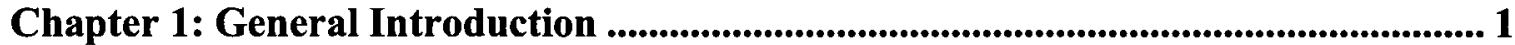

1.1 Contamination of the Arctic Environment by Organohalogens ............................. 1

1.1.1 Organohalogen Sources, Production, and Regulation .................................. 1

1.1.2 Pathways and Long-Range Transport ....................................................... 4

1.1.3 Bioaccumulation and Biomagnification in Arctic Marine Food Webs ................ 4

1.2 Organohalogens in Polar Bears ....................................................................... 5

1.2.1 Polar Bears as Biomonitors of Arctic Marine Ecosystem Contamination ........... 5

1.2.2 Factors affecting Organohalogen Levels in Polar Bears ............................... 12

1.2.2.1 Biological Factors ................................................................................ 12

1.2.2.2 Abiotic Factors .............................................................................. 15

1.2.2.3 Diet/Food Web Factors ........................................................................ 16

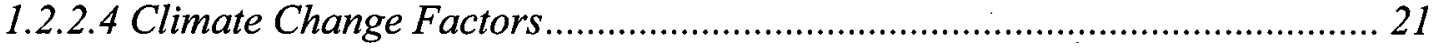

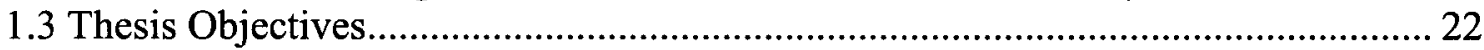

Chapter 2: Materials and Methods ................................................................ 27

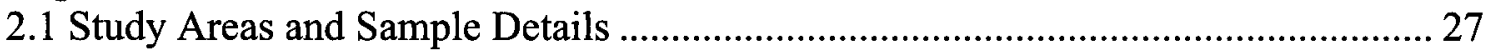

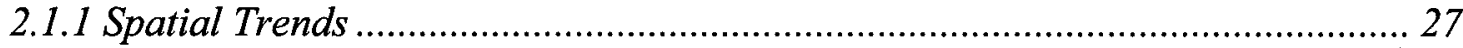

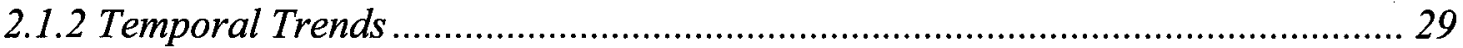

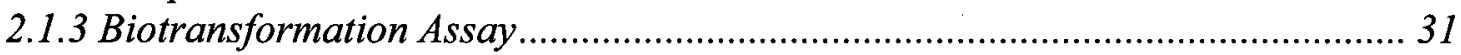

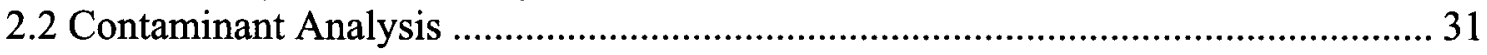

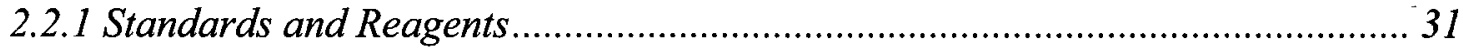

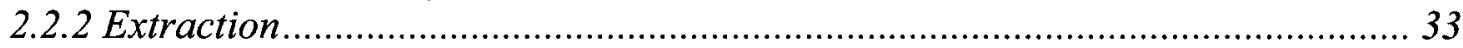

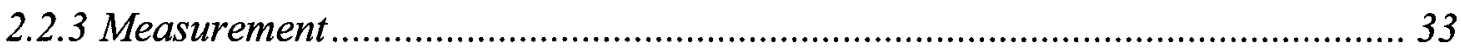

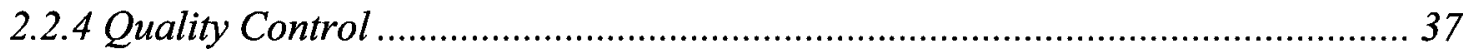

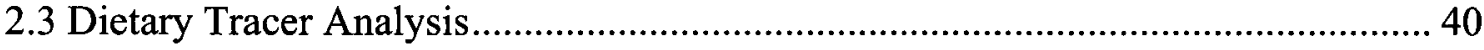

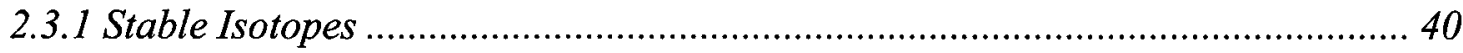

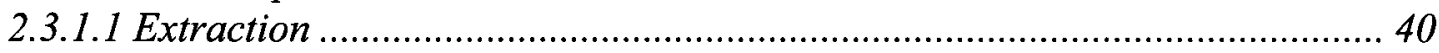

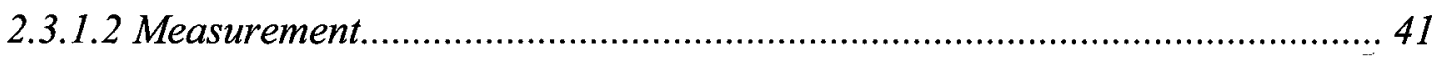

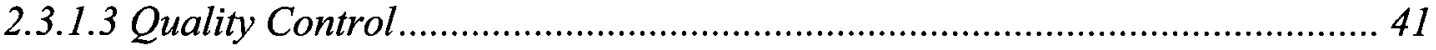

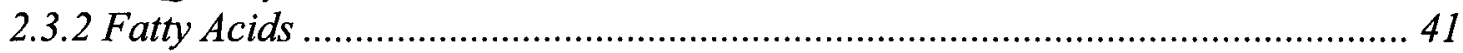

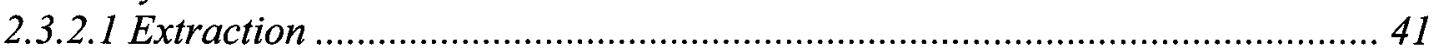

2.3.2.2 Measurement .................................................................................... 42

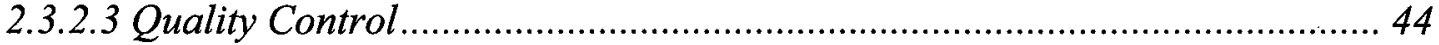

2.4 Western Hudson Bay Sea Ice Breakup Analysis.............................................. 44

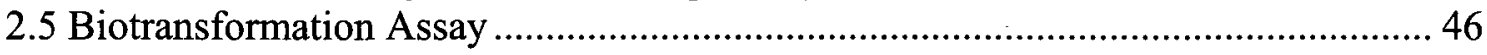




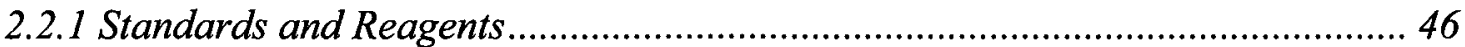

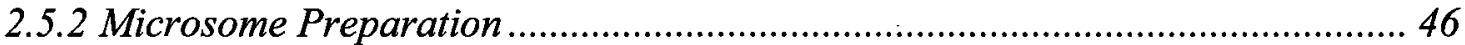

2.5.3 Microsomal Protein Content and Catalytic Activity ..................................... 47

2.5.4 In Vitro Biotransformation Assay Procedure .............................................. 47

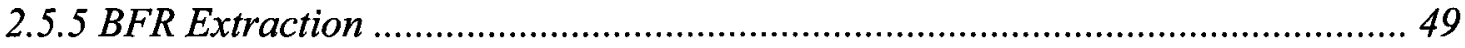

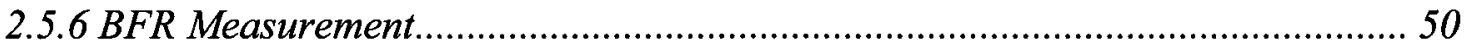

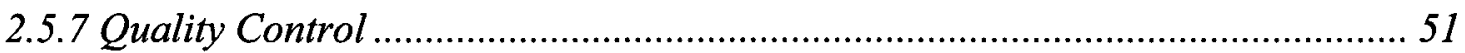

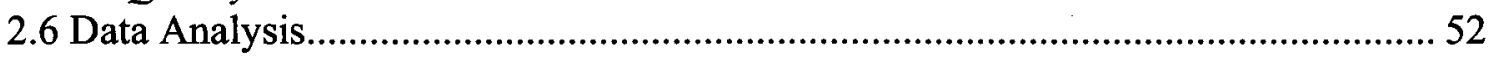

2.6.1 Contaminant Spatial Trends (Chapter 3).......................................................... 53

2.6.2 Relationship of Diet to Contaminant Spatial Trends (Chapter 4) ..................... 55

2.6.3 Relationship of Sea-Ice and Diet to Contaminant Temporal Trends (Chapter 5)

2.6.4 Relationship of Diet to Detailed Contaminant Temporal Trends and Patterns

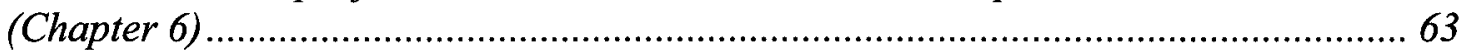

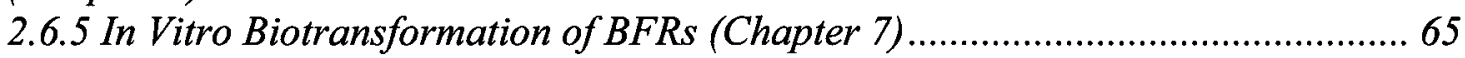

Chapter 3: Flame Retardants and Legacy Contaminants in Polar Bears from Alaska, Canada, East Greenland and Svalbard, 2005-2008 ............................................ 66

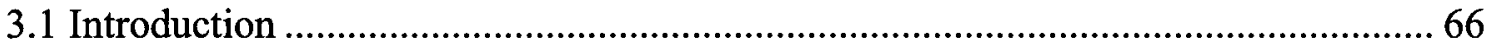

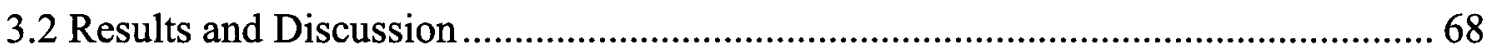

3.2.1 Influence of Biological Factors on Organohalogen Levels ................................ 68

3.2.2 Spatial Trends in BFR Levels and Patterns ................................................... 71

3.2.3 Spatial Trends in PCB and OCP Levels and Patterns................................... 78

3.2.4 Temporal Contaminant Comparisons .............................................................. 81

Chapter 4: Regional Contamination versus Regional Diet Differences: Understanding Geographic Variation in Brominated and Chlorinated Contaminant

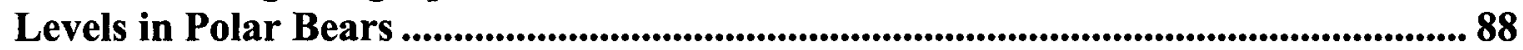

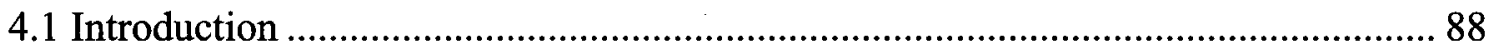

4.2 Results and Discussion.................................................................................... 90

4.2.1 Stable Isotope and Fatty Acid Signatures in Polar Bears and Ringed Seals..... 90

4.2.2 Geographic Variation in Polar Bear Diets...................................................... 92

4.2.3 Influence of Diet on Contaminant Concentrations ........................................... 97

4.2.4 Influence of Diet on Geographic Contaminant Trends.................................. 104

Chapter 5: Sea Ice-associated Diet Change Increases the Levels of Chlorinated and Brominated Contaminants in Polar Bears .................................................................. 109

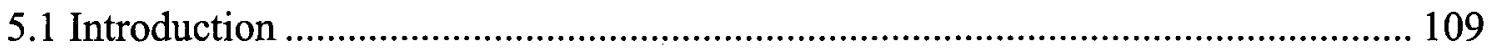

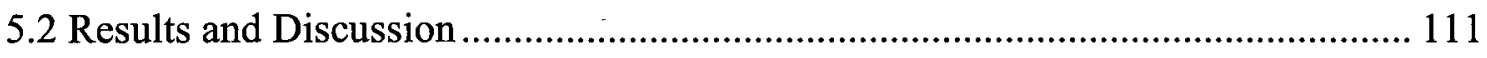

5.2.1 Relationship of Diet to Ice Breakup Date ...................................................... 111

5.2.2 Influence of Diet Change on Chlorinated and Brominated Contaminant

Concentrations .......................................................................................... 115 
Chapter 6: The Role of Diet on Long-Term (1991-2007) Concentration and Pattern Trends of Brominated and Chlorinated Contaminants in Western Hudson Bay

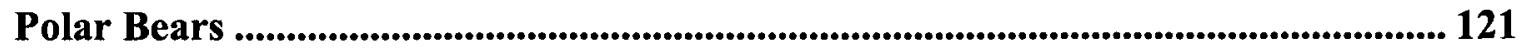

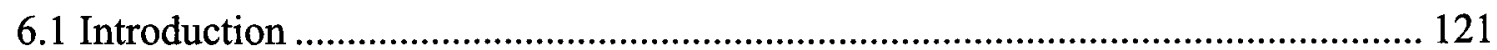

6.2 Results and Discussion ............................................................................... 124

6.2.1 Influence of Biological Factors on Organohalogen Concentrations................ 124

6.2.2 Legacy Contaminant Levels and Trends................................................... 130

6.2.3 Flame Retardant Levels and Trends ......................................................... 136

6.2.4 Contaminant Patterns in Relation to Diet, Year and Biological Group.......... 138

Chapter 7: Comparative Hepatic Microsomal Biotransformation of Selected Polybrominated Diphenyl Ether, including Decabromodiphenyl Ether, and Decabromodiphenyl Ethane Flame Retardants in Arctic Marine-Feeding Mammals

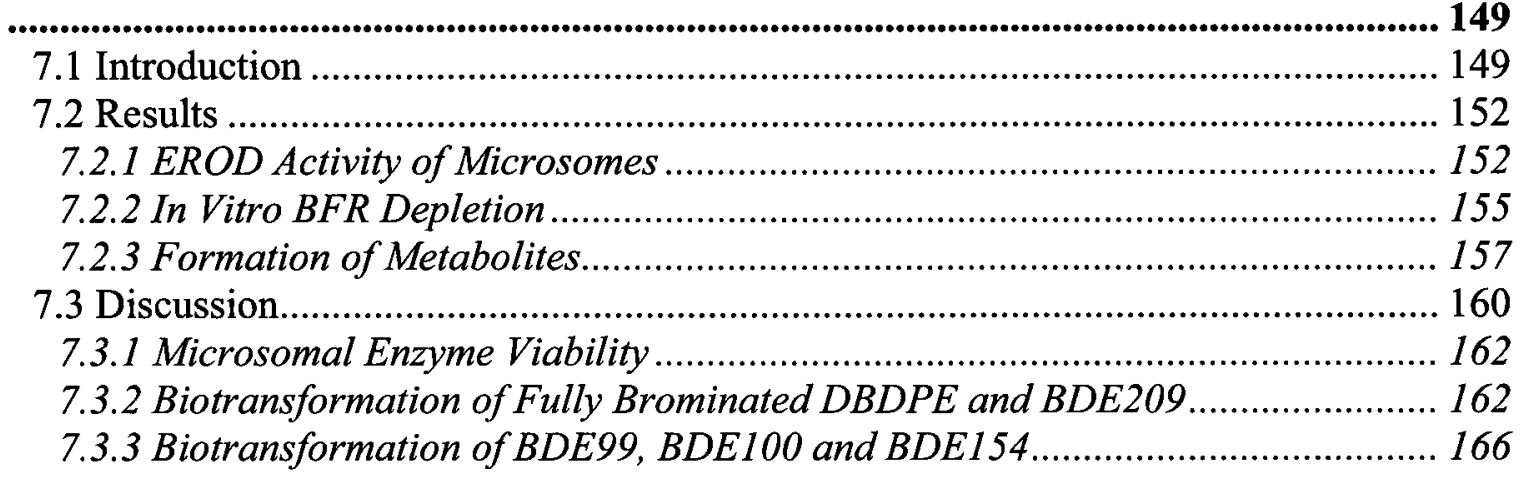

Chapter 8: Conclusions, Implications and Future Directions .............................. 169

8.1 Conclusions and Implications.................................................................... 169

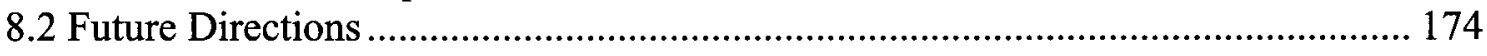

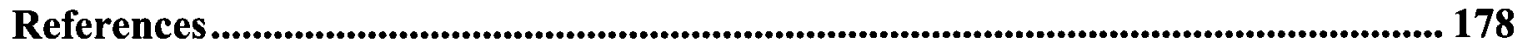




\section{List of Tables}

Table 2.1. Collection and biometric data for polar bears sampled in 2005-2008 from 11 subpopulations spanning Alaska east to Svalbard ............................................................ 28

Table 2.2. Biometric data of WHB polar bears sampled from 1991-2007 ....................... 30

Table 2.3. Sample collection location and date and biological data ................................ 32

Table 2.4. GC-MS conditions for analysis of PCB, OCP, BFR and $\mathrm{MeSO}_{2}$-DDE/PCB contaminants

Table 2.5. The 161 individual contaminants, congeners and metabolites analyzed in adipose tissue of polar bears from 11 subpopulations sampled in 2005-2008 and from archived adipose tissue of WHB polar bears from 1991-2007 ..................................... 37

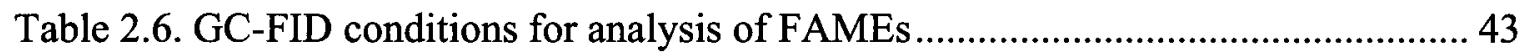

Table 2.7. SI and FA details for 2005-2008 polar bear samples from 11 subpopulations from Alaska, Canada, East Greenland and Svalbard ........................................................ 58

Table 3.1. Geometric means and 95\% confidence intervals $(95 \% \mathrm{CI})(\mathrm{ng} / \mathrm{g} \mathrm{lw})$ of brominated and chlorinated contaminants and metabolites in adipose of polar bears from 11 subpopulations collected from 2005-2008. .72

Table 4.1. GLM results testing subpopulation, Diet-Index and demographic effects on brominated and chlorinated contaminant concentrations (as $\sum$-contaminant class) in polar bear adipose from 10 subpopulations from Alaska, Canada and East Greenland .......... 101

Table 5.1. Contaminant temporal trends in WHB polar bears with and without correction for diet.

Table 6.1. Results ( $p$-values) from an ANCOVA testing the influence of biological group (adult female/adult male/subadult) and year on adipose organohalogen concentrations in polar bears from western Hudson Bay, 1991-2007 126

Table 6.2. Levels (ng/g lw) and temporal trends of BFRs detected in adipose of western Hudson Bay polar bears, 1991-2007. 127

Table 6.3. Levels (ng/g lw) and temporal trends of PCBs and $\mathrm{MeSO}_{2}-\mathrm{PCBs}$ in adipose of western Hudson Bay polar bears, 1991-2007 128

Table 6.4. Levels (ng/g lw) and temporal trends of OCPs in adipose of western Hudson Bay polar bears, 1991-2007. 129

Table 6.5. Influence of year, biological group and the dietary tracers, $\delta^{13} \mathrm{C}$, FA-Index1, FA-Index2, on contaminant patterns in adipose of polar bears from western Hudson Bay 144

Table 7.1. Polar bear (PB), beluga whale (BW), ringed seal (RS) and rat (RAT) liver microsomal protein content and EROD activity... 154 


\section{List of Figures}

Fig. 1.1. Simplified arctic marine food web. Modified graphic from Arctic Monitoring and Assessment (AMAP) Assessment Report: Arctic Pollution Issues (25).

Fig. 1.2. Polar bear subpopulations, or management zones, located throughout the circumpolar basin: Alaska- Bering-Chukchi Sea (AL), southern Beaufort Sea (SBS), northern Beaufort Sea (NBS), Viscount Melville Sound (VM), Norwegian Bay (NW), Lancaster/Jones Sound (LJS), M'Clintock Channel (MC), Gulf of Boothia (GB), Foxe Basin (FB), western Hudson Bay (WHB), southern Hudson Bay (SHB), Kane Basin (KB), Baffin Bay (BB), Davis Strait (DS), East Greenland (EG), Svalbard- Barents Sea (SV), Kara Sea and Laptev Sea. KB and BB have been found to be genetically similar enough to be considered as a single management zone (31). The same is true for the designated SV and Franz Josef Land subpopulations (shown as SV), collectively referred to as the Barents Sea subpopulation (3I). Subpopulations labeled on a black background indicate those examined in this thesis. Modified graphic from (42).

Fig. 1.3. Air current, transpolar ice movement, river outflow and ocean current pathways by which POPs move to and around the Arctic. The numbered boxes refer to the predominant air pathways of organohalogens to the Arctic. Modified graphic from AMAP Assessment 2002: Persistent organic pollutants in the Arctic (3).

Fig. 2.1. Flow diagram of $\mathrm{PCB}, \mathrm{OCP}, \mathrm{BFR}$ and $\mathrm{MeSO}_{2}-\mathrm{PCB} / \mathrm{DDE}$ extraction from polar bear adipose tissue. 34

Fig. 2.2. Western Hudson Bay sea ice break-up determination. (a) Example of weekly sea ice data from the Canadian Ice Service (http://ice-glaces.ec.gc.ca), (b) with overlaid sampling grid. (c) Weekly average ice concentration versus ordinal date. 45

Fig. 3.1. Correlations of adipose concentrations (log-scale) of $\beta-\mathrm{HCH}, \Sigma \mathrm{CHL}$ and $\sum \mathrm{MeSO}_{2}-\mathrm{PCB}$ with age for male and female polar bears sampled in 11 subpopulations from 2005-2008. Solid trend lines indicate significant $(p<0.05)$ correlations. Dashed lines indicate non-significant correlations.

Fig. 3.2. Percent composition (+SE) of individual contaminant concentrations to $\sum$-class for major contaminant classes determined in adipose from 11 polar bear subpopulations sampled in 2005-2008 (left to right): AL, SBS, NBS, GB, LJS, BB, DS, WHB, SHB, EG and SV. PCB, $\mathrm{MeSO}_{2}-\mathrm{PCB}$ and PBDE congener labels are further abbreviations from those listed in Table 2.5. 73

Fig. 3.3. Frequency of detection of non-PBDE BFRs in polar bear adipose in 2005-2008 from 4 regions (left to right): Alaska, the Canadian Arctic, Hudson Bay and the European Arctic. BB153 values are from detection of the coeluting BB153/BDE154, of which BB153 contributed on average $96 \%$. .77

Fig. 3.4. Spatiotemporal patterns in geometric mean $( \pm 95 \% \mathrm{CI})$ levels of major BFRs in adipose of polar bears from 11 subpopulations collected from 1996-2002 (white bars; from 35) and from 2005-2008 (crosshatched bars; present study). The 1996-2002 study 
did not report BB153/BDE154, and 1996-2002 SBS data shown was from NBS and SBS. Satellite map adapted from www.nasa.gov.

Fig. 3.5. Temporal comparisons of legacy contaminants in 10 polar bear subpopulations collected in 1989-1993 (black bars; from 26, 37), 1996-2002 (white bars; from 39) and 2005-2008 (crosshatched bars; current study). Beaufort Sea (BS) samples were from SBS and NBS. Blank values indicated a contaminant that was not analyzed from the location/time point, with the following exceptions in which the contaminant was below the MLOQ for a majority of samples: OCS in 1996-2002 in BS, GB, LJS, BB, DS, WHB; mirex in 1996-2002 in EG; 3-MeSO $2-p, p^{\prime}-\mathrm{DDE}$ in 1996-2002 in BB, SV and in 20052008 in all except BB and SHB. 83

Fig. 4.1. Mean $( \pm 95 \% \mathrm{CI})(\mathrm{a})$ muscle SI ratios of nitrogen $\left(\delta^{15} \mathrm{~N}\right)$ versus carbon $\left(\delta^{13} \mathrm{C}\right)$ and (b) adipose FA-Index 1 versus FA-Index 2 in ringed seals $(0)$ and polar bears $(\bullet)$ sampled within 10 (11 for FA) polar bear subpopulation regions. Ringed seal SI samples were not lipid-extracted, and Alaskan and Canadian Arctic values were from refs (141, 142). (c) Adjusted mean $( \pm 95 \% \mathrm{CI})$ trophic level (TL) versus $\delta^{13} \mathrm{C}^{\prime}$ and (d) $\mathrm{FA}_{\mathrm{adj}}$-Index 1 versus $\mathrm{FA}_{\mathrm{adj}}$-Index 2 in polar bear $(\bullet)$ subpopulations. $\mathrm{FA}_{\mathrm{adj}}$-Index1 is referred to as $\mathrm{FA}_{\mathrm{adj}}-$ Index elsewhere and used in subsequent analyses. Error bars for DS polar bear FAIndices were omitted for clarity. 91

Fig. 4.2. HCA (top panel) of the standardized (mean of zero, unit variance) means of trophic level, $\delta^{13} \mathrm{C}_{\text {adj }}$ and $12 \mathrm{FA}_{\text {adj }}$ in 10 polar bear subpopulations from $\mathrm{AL}$ east to EG. Clusters were generated using the squared Euclidean distance measure and the unweighted pair-group average linkage method. DFA (bottom panel) (ellipses enclose $95 \%$ data ranges) of TL, $\delta^{13} \mathrm{C}_{\text {adj }}$ and 4 dietary $\mathrm{FA}_{\text {adj }}$ in 10 polar bear subpopulations. The first two discriminant functions accounted for $81 \%$ of the total variance. Polar bears were $79 \%$ correctly classified by subpopulation. 94

Fig. 4.3. Mean $( \pm 95 \% \mathrm{CI})$ (a) trophic level (TL), (b) $\delta^{13} \mathrm{C}_{\mathrm{adj}}$ and (c) $\mathrm{FA}_{\mathrm{adj}}-$ Index signatures in 11 polar bear subpopulations. TL and $\delta^{13} C_{\text {adj }}$ were not available in SV..... 96

Fig. 4.4. Mean $( \pm 95 \% \mathrm{CI})$ (a) trophic level and (b) carbon stable isotope ratios $\left(\delta^{13} \mathrm{C}_{\mathrm{adj}}\right)$ versus $F A_{\text {adj }}$ Index in 10 polar bear subpopulations from $A L$ east to EG. ...................... 100

Fig. 4.5. Relationship of adipose $\Sigma$ PCB levels and Diet-Index in polar bears from 20052008 in 10 subpopulations from AL east to EG.

Fig. 4.6. Mean ( $\pm 95 \%$ CI) (a) $\sum$ PCB and (b) $\sum$ PBDE levels before ( $(\circ)$ and after (•) adjusting for the influence of Diet-Index in 11 polar bear subpopulations from AL east to SV. Adjusted levels were not available for SV.

Fig. 4.7. Mean ( $\pm 95 \% \mathrm{CI})$ FA-Index 1 and FA-Index2 values (PC1 and PC2) for 20052008 polar bear adipose from 11 subpopulations from AL east to SV (•) and for 19912007 from the WHB subpopulation (0). 108

Fig. 5.1. Mean ( $\pm \mathrm{SE})$ annual polar bear dietary tracer values versus ordinal date (01 Jan = ordinal date 1) of annual sea ice breakup in western Hudson Bay from 1991 to 2007. (a) Carbon stable isotopes $\left(\delta^{13} \mathrm{C}\right)$. (b) FA-Index $1(\bullet$, solid line) and FA-Index $2(\mathrm{O}$, dashed line). 112 
Fig. 5.2. Annual \% change $( \pm \mathrm{SE})$ in the concentrations of persistent organic contaminants in WHB polar bears, controlling for diet (white bars) and with the influence of diet included, i.e. the actual temporal trends (crosshatched bars). 118

Fig. 6.1. Levels (geometric mean $+95 \% \mathrm{CI}$ ) of PCBs and OCPs in adipose of polar bears from western Hudson Bay collected in 1968-2007. Figure adapted from de Wit et al. (3) with permission. White bars are from de Wit et al. (3) with original data from Norstrom et al. (43) and Verreault et al. (39). Overlaid black bars are from the current study..... 131

Fig. 6.2. Percent composition ( $+\mathrm{SE})$ of major contaminant classes in adipose of polar bears from western Hudson Bay (left to right): 1991 (first white bars), 1992 (first black bars), 1994 (first striped bars), 1995 (second white bars), 2001 (second black bars), 2003 (second striped bars) and 2007 (third white bars). PCB, $\mathrm{MeSO}_{2}$-PCB and PBDE congener labels are further abbreviations from those listed in Table 2.5. 139

Fig. 6.3. Factor loadings from principal components analyses on the percent (\%) composition of major contaminant classes in adipose of polar bears from western Hudson Bay sampled in 1991-2007. Encircled clusters contained compounds that loaded significantly (critical value of the correlation $>0.54$ ) on the same $\mathrm{PC}$, but were not significant on any other PCs. PCB and $\mathrm{MeSO}_{2}-\mathrm{PCB}$ congener labels are further abbreviations from those listed in Table 6.3. 142

Fig. 7.1. Structures of the BFRs investigated in the current biotransformation study. Hydrogen atoms have been omitted for clarity. 153

Fig. 7.2. Fraction of BFR concentrations, dosed as a mixture (A) or dosed as individual chemicals (B), remaining after $90 \mathrm{~min}$ incubation with hepatic microsomes from individual polar bear (PB1; cross-hatched bars), beluga whale (BW1 and BW2; white bars) and ringed seal (RS1 and RS2; dotted bars) and pooled ( $n=17)$ rat (RAT; black bars). Error bars represent \pm SD for the mixed BFR ( $n=4$ sample and control replicates) and individual BFR ( $n=3$ replicates) assays. The heavy dotted line denotes no depletion. Significant depletion at the $95 \%(p \leq 0.05)$ and the $99 \%(p \leq 0.01)$ confidence levels are indicated by single and double asterisks, respectively. 156

Fig. 7.3. Representative electron capture negative ionization, selected ion monitoring ([Br $\left.]^{-}, m / z 79\right)$ mass chromatograms of extracts from an in vitro biotransformation assay using polar bear (PB1) hepatic microsomes incubated with individual BFRs: (A) BDE154, (B) BDE209 and (C) DBDPE. Control microsomes were inactivated by $\mathrm{MeOH}$ treatment prior to the assay, whereas sample microsomes were viable and were incubated with the cofactors NADPH and DTT. Subsequent to initial screening for parent compound and possible neutral (debrominated) metabolites, controls and samples were derivatized to detect possible phenolic metabolites as their methoxylated analogues. Replicate control and sample $m / z 79$ chromatograms as well as all $\mathrm{m} / \mathrm{z} 81$ chromatograms gave the same results. 158 


\section{List of Appendices}

Appendix A. Analytical Details for Stable Isotopes Determinations from EIL ............. 195 Appendix B. Temporal comparisons of legacy contaminants and metabolites in adult male, adult female and subadult polar bears from 10 subpopulations from 1989-1993, 1996-2002 and 2005-2008

Appendix C. Nitrogen and carbon stable isotope ratios and FA composition in 2005-2008 polar bears from 11 subpopulations from Alaska east to Svalbard

Appendix D. Results of the ranked correlation analysis of WHB polar bear dietary tracers with ice breakup date in western Hudson Bay..... 201

Appendix E. Brominated and chlorinated contaminant and metabolite concentrations in adipose tissue of adult male, adult female and subadult polar bears from 11 subpopulations sampled in 2005-2008. 202

Appendix F. FA profiles and dietary tracer values in WHB polar bear adipose and sea ice breakup dates in western Hudson Bay from 1991-2007. 205 


\section{List of Abbreviations}

\section{$18: 2 \mathrm{n}-6$ \\ $18: 3 n-6$ \\ 20:1n-9 \\ 18:3n-3; ALA \\ $20: 2 \mathrm{n}-6$ \\ $20: 3 \mathrm{n}-6$ \\ $22: 1 \mathrm{n}-9$ \\ 20:3n-3; ETA \\ 20:4n-6; ARA \\ 20:5n-3; EPA \\ 22:5n-3; DPA \\ 22:6n-3; DHA \\ $95 \% \mathrm{CI}$ \\ $\delta^{13} \mathrm{C}$ \\ $\delta^{15} \mathrm{~N}$ \\ $\Delta \delta^{13} \mathrm{C}$ \\ $\Delta \delta^{15} \mathrm{~N}$}

AIC

AL

AMAP

ANCOVA

ANOVA

BB

BB\#

BDE\#

BFR

BMF

BTBPE

CB\#

CHL

$\mathrm{ClBz}$

CYP

DBDPE

DFA

DS

DTT

EG

EIL

EROD

FA linoleic acid

$\gamma$-linolenic acid

cis-11-eicosenoic acid

$\alpha$-linolenic acid

cis-11,14-eicosadienoic acid

cis-8,11,14-eicosatrienoic acid

erucic acid

cis-11,14,17-eicosatrienoic acid

arachidonic acid

cis-5,8,11,14,17-eicosapentaenoic acid

cis-7,10,13,16,19-docasapentaenoic acid

cis-4,7,10,13,16,19-docasahexaenoic acid

$95 \%$ confidence interval

carbon stable isotope ratio

nitrogen stable isotope ratio

carbon stable isotope ratio trophic enrichment factor

nitrogen stable isotope ratio trophic enrichment factor

Akaike's information criteria

Alaska polar bear subpopulation

Arctic Monitoring and Assessment Program

analysis of covariance

analysis of variance

Baffin Bay polar bear subpopulation

bromobiphenyl, numbered according to ref (l) rules for polychlorinated biphenyls

bromodiphenyl ether, numbered according to ref (1) rules for polychlorinated biphenyls

brominated flame retardant

biomagnification factor

1,2-bis(2,4,6-tribromophenoxy)ethane

chlorobiphenyl, numbered according to ref (1)

chlordane

chlorobenzene

cytochrome $\mathrm{P} 450$ isozyme

decabromodiphenyl ethane

discriminant function analysis

Davis Strait polar bear subpopulation

dithiothreitol

East Greenland polar bear subpopulation

Environmental Isotopes Laboratory

ethoxyresorufin $O$-deethylase

fatty acid 


\begin{tabular}{|c|c|}
\hline FAME & fatty acid methyl ester \\
\hline GB & Gulf of Boothia polar bear subpopulation \\
\hline GC-FID & gas chromatography-flame ionization detection \\
\hline GC-MS(ECNI) & $\begin{array}{l}\text { gas chromatography-mass spectrometry (electron capture negative } \\
\text { ionization mode) }\end{array}$ \\
\hline GC-MS(EI) & $\begin{array}{l}\text { gas chromatography-mass spectrometry (electron impact ionization } \\
\text { mode) }\end{array}$ \\
\hline GLM & general linear model \\
\hline HBB & hexabromobenzene \\
\hline $\mathrm{HBCD}$ & hexabromocyclododecane \\
\hline HCA & hierarchical cluster analysis \\
\hline HCB & hexachlorobenzene \\
\hline $\mathrm{HCH}$ & hexachlorocyclohexane \\
\hline IS & internal standard \\
\hline LJS & Lancaster/Jones Sound polar bear subpopulation \\
\hline LOEL & lowest observable effects level \\
\hline $\operatorname{lw}$ & lipid weight \\
\hline MeO-PBDE & methoxy-polybrominated diphenyl ether \\
\hline $\mathrm{MeSO}_{2}$-PCB & methyl sulfonyl polychlorinated biphenyl \\
\hline MLOQ & method limit of quantification \\
\hline MUFA & monounsaturated fatty acid \\
\hline NADPH & nicotinamide adenine dinucleotide phosphate \\
\hline NBS & northern Beaufort Sea polar bear subpopulation \\
\hline NIST & National Institute of Standards and Technology \\
\hline NOEL & no observed effects level \\
\hline NWRC & National Wildlife Research Centre \\
\hline OCP & organochlorine pesticide \\
\hline OCS & octachlorostyrene \\
\hline OH-PBDE & hydroxy-polybrominated diphenyl ether \\
\hline $\mathrm{OH}-\mathrm{PCB}$ & hydroxy-polychlorinated biphenyl \\
\hline PBB & polybrominated biphenyl \\
\hline PBDE & polybrominated diphenyl ether \\
\hline PBEB & pentabromoethylbenzene \\
\hline PBT & pentabromotoluene \\
\hline PCA & principal components analysis \\
\hline PCB & polychlorinated biphenyl \\
\hline PFC & perfluorinated compounds \\
\hline POP & persistent organic pollutant \\
\hline$p, p^{\prime}-\mathrm{DDD}$ & bis-2,2-(4-chlorophenyl)-1,1-dichloroethane \\
\hline$p, p^{\prime}-\mathrm{DDE}$ & bis-2,2-(4-chlorophenyl)-1,1-dichloroethene \\
\hline$p, p^{\prime}$-DDT & bis-2,2-(4-chlorophenyl)-1,1,1-trichloroethane \\
\hline PUFA & polyunsaturated fatty acid \\
\hline RSD & relative standard deviation \\
\hline SBS & southern Beaufort Sea polar bear subpopulation \\
\hline
\end{tabular}


SD

SE

SHB

SI

SIM

SV

$\mathrm{T}_{3}$

$\mathrm{T}_{4}$

TL

Tukey's HSD

WHB standard deviation

standard error of the mean

southern Hudson Bay polar bear subpopulation

stable isotope

selected ion monitoring

Svalbard polar bear subpopulation

triiodothyronine

thyroxine

trophic level

Tukey's honestly significant difference

western Hudson Bay polar bear subpopulation

xix 


\section{Chapter 1: General Introduction}

\subsection{Contamination of the Arctic Environment by Organohalogens}

Despite long distances from source regions, arctic environments and ecosystems are subject to contamination by a complex suite of persistent organic pollutants (POPs), collectively classified as organohalogen chemicals, as well as other anthropogenicallysourced pollutants including heavy metals, radionuclides and other organic chemicals (2). Organohalogen uptake into arctic marine food webs and elevated levels in species occupying upper trophic positions present a health concern for wildlife such as polar bears (Ursus maritimus) and for northern people subsisting on a locally-derived diet (3).

\subsubsection{Organohalogen Sources, Production, and Regulation}

The predominant source of POPs and other contaminants to the Arctic is emission from more populated, industrialized regions further south (3). Organohalogens consist of a wide array of industrial and agricultural chemicals and by-products. Regarded as an environmental concern for approximately the last five decades, the original or "legacy" organohalogens include the polychlorinated biphenyls (PCBs) and various organochlorine pesticides (OCPs). PCBs found use mainly as electrical insulators. In general, for all OCPs in question, they were applied as insecticides for agriculture and to control insect vectors of disease. Due to their characteristic persistence, potential for long-range transport, bioaccumulation and human and environmental health risks, 12 of 
these chlorinated chemicals or chemical classes have been designated as POPs, namely, dichlorodiphenyltrichloroethane (DDT), aldrin, dieldrin, endrin, chlordane (CHL), heptachlor, hexachlorobenzene (HCB), mirex, toxaphene, PCBs, polychlorinated dibenzo-p-dioxins and dibenzofurans. In 2004 (earlier in some countries), these legacy POPs were banned or severely restricted in more than 130 countries that ratified the Stockholm Convention on Persistent Organic Pollutants (http://www.pops.int; United Nations Environment Program). Yet, some of these identified POPs are still manufactured, while for others, substantial stockpiles continue to be an environmental health concern. For instance, DDT production and use has been exempted in effort to control vector borne diseases such as malaria (4). Emissions of PCBs from in-use materials, landfills and remaining stocks, in addition to re-emissions from sediment and soil reservoirs, remain substantial enough that despite declines after initial restrictions, recent environmental trends tend to be stable or show only slow declines (5).

There are also numerous recent- or current-use chemicals released into the environment intentionally or by accidental leakage, some of which have been found to be accumulating in the Arctic and its biota. Examples include the current-use pesticide endosulfan as well as chemicals used in consumer products, such as those classified as poly- and perfluorinated compounds (PFCs) and brominated flame retardants (BFRs) (69). Recent- and current-use BFRs include but are not limited to polybrominated biphenyls (PBBs), polybrominated diphenyl ethers (PBDEs), hexabromocyclododecane (HBCD) isomers, tetrabromobisphenol A (TBBPA), pentabromotoluene (PBT), 
pentabromoethylbenzene (PBEB), hexabromobenzene (HBB), 1,2-bis(2,4,6tribromophenoxy)ethane (BTBPE), $\quad \beta$-1,2-dibromo-4-(1,2-dibromoethyl)cyclohexane (TBECH) and decabromodiphenyl ethane (DBDPE). PBBs have not been used in North America since the 1970s; however, the DecaBB product was produced until 2000 in France (10). The PBDE products, PentaBDE and OctaPBDE, have been phased out of use in the European Union and were voluntarily withdrawn from production in North America in 2004. In 2009, tetra- through hepta-brominated PBDEs, hexa-brominated PBBs, and several other chemicals were additionally listed under the Stockholm Convention. BTBPE has been marketed for use as a replacement for OctaBDE, and DPDPE is considered an alternative to DecaBDE (6). DecaBDE is still produced, however, with a worldwide market demand of $56400 \mathrm{t}$ in 2003 (6), despite evidence that the primary component, $2,2^{\prime}, 3,3^{\prime}, 4,4^{\prime}, 5,5^{\prime}, 6,6^{\prime}$-hexabromodiphenyl ether (BDE209; PBDE and PCB numbering system as per ref $l$ ), is a potential source of currently banned lower brominated congeners to the environment through photolytic and metabolic debromination (11-13). There are currently no restrictions on the production or use of $\mathrm{HBCD}$, although it has been proposed for addition to the Stockholm Convention (6). PBT, PBEB, HBB, BTBPE and DPDPE remain unregulated. In a larger context, there are an estimated 9 thousand organic chemicals used in the United States at volumes greater than $4.5 \mathrm{t} / \mathrm{yr}$, and over 30 thousand chemicals used in Europe at volumes exceeding $1 \mathrm{t} / \mathrm{yr}$, the vast majority for which no data has been reported on their emissions or their environmental fate (14). 


\subsubsection{Pathways and Long-Range Transport}

The presence of organohalogens in the Arctic is generally due to long-range transport from lower latitude sources, although local sources have also been reported (3). Pathways to and fate within the arctic environment and its biota are dependent in part on the physico-chemical properties of a given contaminant including stability, volatility, solubility and hydrophobicity (2). Although variable, POP or POP-like organohalogens are generally stable with long half-lives in abiotic and biological matrices, resulting in their persistence in the environment, wildlife and humans. Gas phase, dissolved or particle-bound persistent contaminants can be transported to the Arctic by wind and ocean currents, riverine inputs, ice flows and migratory species $(3,15-17)$. For most semi-volatile organohalogens, the predominant pathway to the Arctic is through volatilization to the air at lower latitudes, transport and re-deposition, reaching the Arctic through single or multiple "hops" (18). However, certain organohalogens that have lower air-water partition coefficients, such as $\beta$-hexachlorocyclohexane $(\beta-\mathrm{HCH})$, are largely transported through aquatic pathways (18). For larger, less volatile organohalogens like BDE209 and DBDPE, particle-bound transport likely predominates (19).

\subsubsection{Bioaccumulation and Biomagnification in Arctic Marine Food Webs}

Organohalogen levels tend to be higher in marine versus terrestrial or freshwater arctic environments (3). Several PCBs, OCPs and PBDEs readily bioconcentrate directly 
through passive transport from water into lower trophic level marine organisms due to their hydrophobicity $(20,21)$. Such organisms can also be exposed through marine sediments and food, whereas diet is the major route of exposure for higher trophic level species including fish, seabirds and marine-feeding mammals (22). These higher organohalogen levels in lower trophic level biota than in seawater may further increase through the food web $(23,24)$. This organohalogen biomagnification through the relatively long arctic marine food chains results in the highest arctic levels in top trophic feeding marine species such as sea birds, marine mammals and polar bears (Fig. 1.1; 3, 25). Nonetheless, a variety of biological and ecological factors influence organohalogen accumulation and associated health risks in these arctic marine species, many of which will be discussed here with regard to polar bears (Section 1.2.2) including diet, trophic level, habitat use, seasonal fasting, body size, lipid content, sex, age, reproductive status and biotransformation (26-30).

\subsection{Organohalogens in Polar Bears}

\subsubsection{Polar Bears as Biomonitors of Arctic Marine Ecosystem Contamination}

The polar bear is considered an important sentinel species in contaminant biomonitoring. This Ursid species is circumpolarly distributed, but genetic, movement and geographical features have indicated distinct subpopulation structure (Fig. 1.2; 31, 32). Polar bears are opportunistic but typically represent the top trophic position of the marine food web and often feed preferentially on fat, resulting in high organohalogen 


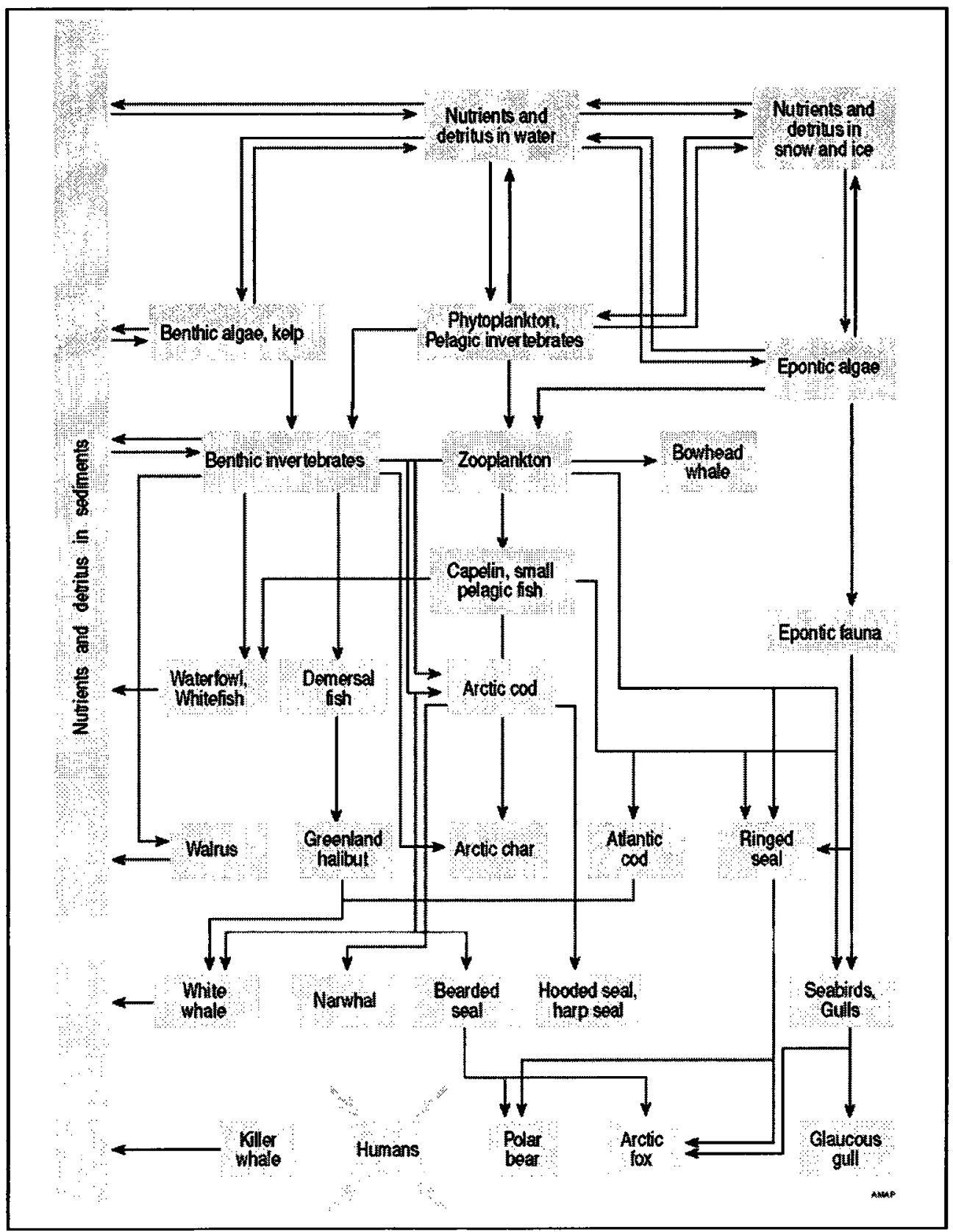

Fig. 1.1. Simplified arctic marine food web. Modified graphic from Arctic Monitoring and Assessment (AMAP) Assessment Report: Arctic Pollution Issues (25). 


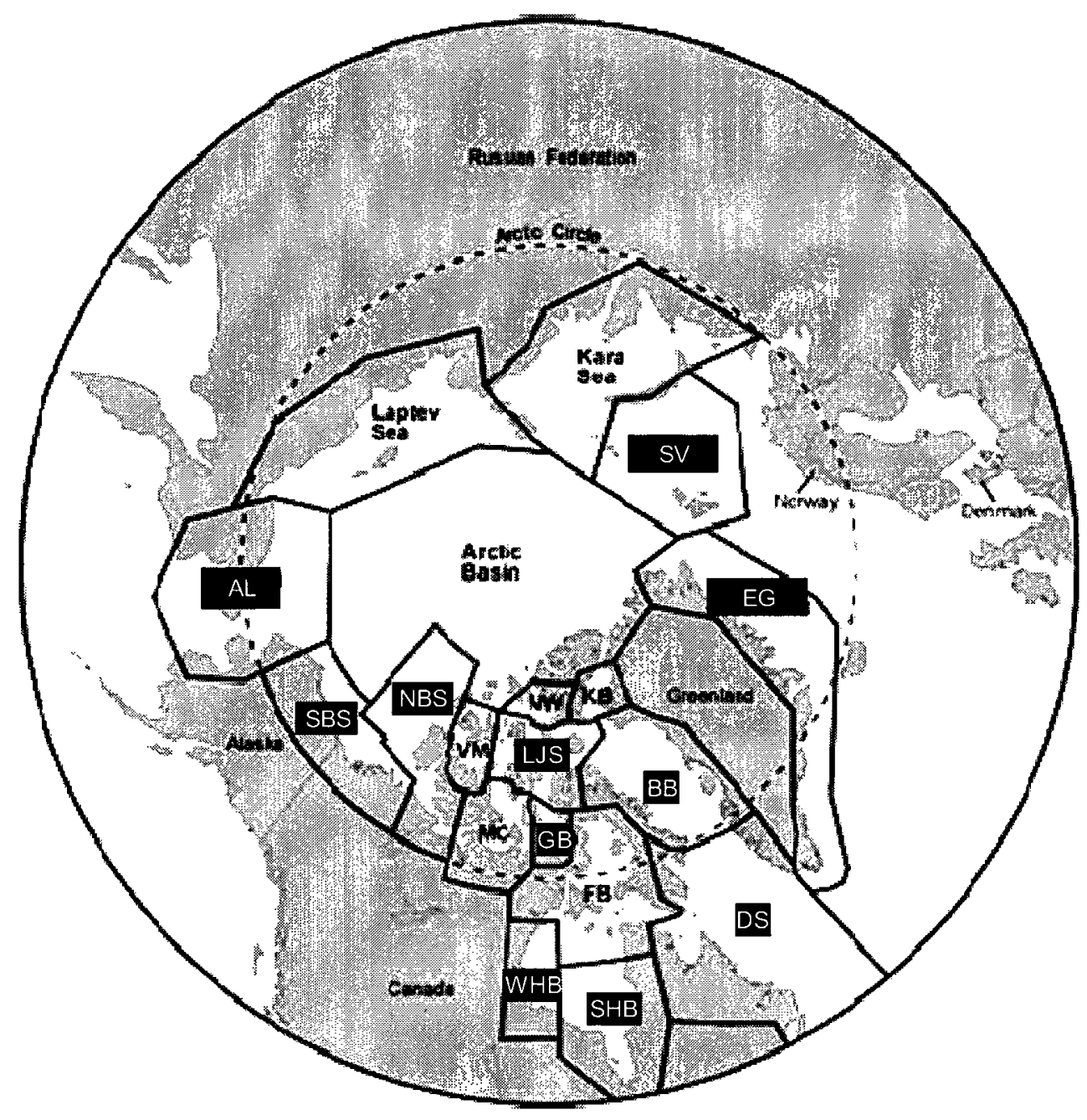

Fig. 1.2. Polar bear subpopulations, or management zones, located throughout the circumpolar basin: Alaska- Bering-Chukchi Sea (AL), southern Beaufort Sea (SBS), northern Beaufort Sea (NBS), Viscount Melville Sound (VM), Norwegian Bay (NW), Lancaster/Jones Sound (LJS), M'Clintock Channel (MC), Gulf of Boothia (GB), Foxe Basin (FB), western Hudson Bay (WHB), southern Hudson Bay (SHB), Kane Basin (KB), Baffin Bay (BB), Davis Strait (DS), East Greenland (EG), Svalbard- Barents Sea (SV), Kara Sea and Laptev Sea. KB and BB have been found to be genetically similar enough to be considered as a single management zone (31). The same is true for the designated SV and Franz Josef Land subpopulations (shown as SV), collectively referred to as the Barents Sea subpopulation (31). Subpopulations labeled on a black background indicate those examined in this thesis. Modified graphic from (42). 
levels in their tissues $(9,33)$. Given high contaminant biotransformation capacities (Section 1.2.2.1), polar bears also exhibit elevated tissue levels of persistent metabolites, including oxychlordane, hydroxy-(OH-)PCBs and methylsulfone-( $\left.\mathrm{MeSO}_{2}-\right) \mathrm{PCBs}$, relative to their prey $(23,34)$. Nonetheless, legacy contaminant and metabolite levels and patterns vary within and among subpopulations $(26,35-39)$. Several studies have reported correlations between contaminant levels and chemical biomarkers of endocrine, immune and reproductive function in some subpopulations $(40,41)$. These potential health effects have been supported by controlled studies on model Canoidea species, specifically, Greenland sledge dog (Canis familiaris) and Norwegian Arctic fox (Vulpes lagopus) (40). It has been suggested that polar bears are indeed the most sensitive species to potential health effects due to contaminant exposures $(40,41)$. Taken together, these studies indicate that polar bear contaminant burdens, in part, reflect the state of arctic marine ecosystem contamination and that this species may be a sensitive indicator of environmental health risks associated with such contamination.

Several studies have recently reviewed levels, patterns, spatial and temporal trends, and the potential toxicological significance of chlorinated and brominated contaminants in arctic biota including polar bears $(6,9,33,40,41)$. Only a brief overview is presented here. Verreault et al. (39) published the most comprehensive recent study of PCB and OCP spatial trends in female polar bear adipose tissues collected from AL, EG, SV and six regions of the Canadian Arctic in 1996-2002. Consistent with a previous 1989-1993 study (26), $\sum$ PCB and $\Sigma$ CHL were the predominant legacy POPs present in all 
subpopulations. These two contaminant classes along with $\sum \mathrm{DDT}$ and $\sum \mathrm{MeSO}_{2}-\mathrm{PCB}$ were generally at the highest levels in EG and SV. In contrast, $\Sigma \mathrm{HCH}$ levels were higher in Alaska and Canadian Arctic subpopulations. In a separate study, blood PCB and OCP levels in females from the Russian Arctic implied that Franz Josef Land and Kara Sea polar bears had the highest PCB, oxychlordane, $t$-nonachlor and $p, p^{\prime}$-DDE levels reported in any arctic biota $(36,38)$.

The presence of many BFRs in polar bears has not been reported, with the exception of PBDEs, HBCD and TBBPA (6), and comprehensive spatial trends have only been reported for PBDEs. Muir et al. (35) reported spatial trends of PBDEs in the same samples used in the Verreault et al. (39) study. The spatial pattern of $\sum$ PBDE levels tracked that of $\sum$ PCB, with the highest levels in EG and SV, suggesting similar source regions and pathways into the marine food web. The predominant PBDE, 2,2',4,4'tetrabromodiphenyl ether (BDE47), was at an even higher proportion of $\sum$ PBDE than reported for marine mammals such as ringed seals (blubber) (Pusa hispida), perhaps due to the higher bioaccumulation of BDE47 or greater debromination of higher brominated congeners in polar bears. The capacity of polar bears and other arctic species to metabolically debrominate BFRs remains unknown.

Verreault et al. (39) found in temporal comparisons of $\sum \mathrm{CHL}, \sum \mathrm{PCB}$ and $\sum \mathrm{MeSO}_{2}$ PCB that mean levels were generally lower (although statistical significance was not assessed) in 1996-2002 compared to 1989-1993 for most subpopulations $(26,37)$. Temporal comparisons for other legacy contaminants were either not as clear (e.g., $p, p^{\prime}-$ 
DDE) or not available. However, longer-term temporal trends for PCBs and OCPs are available for individual subpopulations, in particular, WHB. Analysis of archived WHB female adipose tissues collected in 1968, 1984 and most years from 1989-2002 demonstrated that levels of some, but not all, legacy organohalogens were highest in 1968 and/or $1984(33,39,43)$. From 1989-2002, levels either declined or showed no consistent trend. Shorter-term trends for PCBs and OCPs in EG and SV subpopulations, however, indicated faster declines in levels than those reported in WHB during the 1990s $(27,44)$. There are currently no published temporal comparative or trend studies of BFRs in polar bears, and variable trends have been reported in their main prey, ringed seals. In ringed seals from the western Canadian Arctic, $\sum$ PBDE levels exponentially increased from 1981-2000, but stabilized or declined from 2002-2003 $(45,46)$. In contrast, levels in East Greenland ringed seals showed no consistent trend from 1986-2004 (47).

Several studies have investigated the potential effects of organohalogen exposures in polar bears, particularly in relation to levels of thyroid hormones and vitamin A (retinol), which are important for growth and development (41). Lower thyroxine $\left(\mathrm{T}_{4}\right.$; the prohormone) and higher triiodothyronine $\left(\mathrm{T}_{3}\right.$; the active hormone) levels were found in the more exposed SV individuals relative to less exposed bears from LJS (48). Levels of $T_{4}$ and the total $T_{4}$ :free $T_{4}$ ratio have shown negative correlations with $\sum$ PCB levels (48, 49). Retinol levels were negatively correlated with PCB levels and positively correlated with OH-PCB levels, possibly related to interference with retinol metabolism (48). Braathen et al. (50) found somewhat different correlations and that the relationships of 
PCBs to thyroid hormones were more important for female than for male polar bears. Inter-study variation may be related to biological differences among sampled bears which can affect biomarker levels (e.g., reproductive status, fasting condition among others). Relationships have also been documented in SV bears between $\sum$ PCB and progesterone levels in females, between $\Sigma$ PCB, $\Sigma$ OCP and testosterone levels in males, and between $\sum$ PCB and $\sum$ OCP and cortisol levels in both sexes (51-53). Additional studies have reported negative correlations between PCB levels and immune biomarkers in the SV subpopulation (54). Sonne et al. $(55,56)$ reported that bone mineral density and liver histopathology in EG polar bears may be affected by contaminant burdens. Some sexual organ parameters and levels of certain organohalogen classes including $\sum$ PBDE were also found to be correlated in EG bears, although correlations between organohalogens themselves is an issue in these types of studies (57). Assuming a diet of ringed seals, Fisk et al. (4I) determined that Canadian Arctic subpopulations ingested PCBs and DDTs at levels exceeding the Environment Canada safe consumption guidelines and that $\sum$ PCB levels were above the lowest observable effects level (LOEL) for neurobehavioural effects in rhesus monkeys and the no observable effects level (NOEL) for vitamin A reduction in otters (41). Comparisons of threshold levels of effects between polar bears and other species should be interpreted with caution, however. 


\subsubsection{Factors affecting Organohalogen Levels in Polar Bears}

Several factors influence organohalogen levels and patterns in polar bears, as well as other species. Here, the predominant and/or most studied abiotic (sources and transport) and biological (sex, reproductive status, age, fasting, biotransformation) factors, as well as the possible role of diet/food web and climate changes, are discussed. It should be noted that, although often discussed separately, many of these factors interact to determine contaminant burdens in individuals, subpopulations and the species as a whole.

\subsubsection{Biological Factors}

Lower levels of legacy contaminants have generally been reported in female polar bears than in males, related to placental and especially lactational transfer of contaminants to their young $(26,27,29)$. However, similar levels of most legacy contaminants and PBDEs have been reported between age/sex groups from EG, suggesting that these influences may be relatively small $(27,28)$. Reproductive status may also play a role, as higher adipose contaminant levels have been reported in WHB females with cubs than in solitary/pregnant females, presumably due to dilution in a larger adipose depot in the latter (58).

Organohalogen levels have also shown variation with age in polar bears $(26,39)$. Young of the year from WHB showed higher OCP levels than adult females (58), but PCB and PBDE age trends were not observed among adult females in several subpopulations $(26,35)$. Similarly, in EG, levels of $\sum$ PBDE were not correlated with age 
in either males or females (28). In contrast to this, a recent study on bears from the SBS subpopulation found that levels of PCBs and several OCPs decreased with age in females, while CHL levels decreased with age in males (30), possibly related to sexspecific metabolism of CHLs.

Seasonal variation has been observed in adipose tissue levels of $\sum$ PBDE and $\sum$ DDT in EG polar bears, with highest levels reported in May and June, respectively $(27,28)$. However, seasonality in $\Sigma$ PCB and other OCPs was less clear, suggesting a "spike" in the levels of more metabolizable contaminants from elevated consumption during hyperphagia in March-May. Adipose $\Sigma \mathrm{PCB}, \sum \mathrm{CHL}$ and $\sum$ chlorobenzene $\left(\sum \mathrm{ClBz}\right)$ levels in solitary/pregnant WHB females increased from September-October to FebruaryMarch, likely related to decreasing body fat, whereas $\sum \mathrm{DDT}$ and $\sum \mathrm{HCH}$ levels did not change (58). During an average of 56 days of fasting (July-August to SeptemberNovember), adipose levels of $\sum$ PCB significantly increased in WHB females but not males, whereas $\sum D D T$ and $\Sigma H C H$ generally decreased in both sexes (29). Levels of $\Sigma$ CHL only decreased in males, again, suggesting elevated CHL metabolism in male relative to female polar bears. The length of fasting in polar bears is related to coverage of sea ice, their platform for hunting marine mammals, and differs among subpopulations (59). Thus, the potential for seasonal alterations in contaminant levels may vary from one subpopulation to the next, as well as with longer-term changes in sea ice availability (Section 1.2.2.4). 
Through determination of contaminant patterns as well as the measurement of retained metabolites, evidence indicates that polar bears have a high capacity to biotransform organohalogens relative to arctic marine mammals and seabirds (23). More intense staining of cross-reactive proteins with anti-rat cytochrome P450 (CYP) 1A1 and CYP2B1 in male polar bears than in rats suggested high and likely induced CYP1A- and CYP2B-type enzyme activity (60). CYP1A-type PCB inducers have been correlated with CYP1A expression, and $\Sigma$ CHL and $\sum$ ortho-PCBs have been correlated with CYP2B expression (60). Meta-para unsubstituted PCBs have been found in the polar bear diet (ringed seal) but not in polar bears, suggesting that they are rapidly metabolized in polar bears. The 3- and 4- $\mathrm{MeSO}_{2}$-analogues of these $\mathrm{PCBs}$ are retained, although a number of other $\mathrm{MeSO}_{2}$ - $\mathrm{PCB}$ congeners may additionally be accumulated from diet sources (34). Although less is known regarding BFR biotransformation, in the case of PBDEs, oxidative metabolism to $\mathrm{OH}-$ and possibly methoxy-(MeO)-PBDEs may occur, as has been demonstrated in dosed lab rodents (61-65). Lower brominated PBDEs and sulfurcontaining metabolites have also been reported in these dosing studies. Yet, the importance of OH-PBDE formation is unclear, as only low levels have been found in arctic biota including polar bears (e.g., 66-69). Corroborating these studies, a hepatic microsomal oxidative biotransformation assay on polar bears found no measurable depletion of any environmentally relevant PBDE congeners, except minor depletion of BDE154 (70). Dehalogenation may be an important biotransformation pathway for 
PBDEs, as variable reductive debromination of BDE209 and some lower brominated BDEs has been observed in dosed rats, fish and birds $(13,71,72)$.

\subsubsection{Abiotic Factors}

Once the biological factors that influence organohalogen contaminant levels in polar bears have been considered, it has often been subsequently assumed that remaining spatial and temporal variation is largely related to abiotic factors, namely, variation in contaminant source regions and emissions and prevailing long-range transport pathways (e.g., 39). That is, it has long been considered that contaminant level differences between different arctic regions play a major role in regulating contaminant level variation between polar bear subpopulations. As mentioned (Section 1.1.1 and 1.1.2), local point sources of organohalogen pollution in the Arctic are minor, such as PCBs from old military bases in the Canadian Arctic and Alaska and from harbours in the Norwegian and Russian Arctic. It is still well accepted that the vast majority of contamination continues to be through long-range transport of organohalogens from lower latitudes (3). Nearly $70 \%$ of historic PCB usage was in the USA, Western Europe and Japan (3). The majority of PentaBDE use was in Canada and the USA, whereas OctaBDE and DecaBDE were and still are, respectively, used more widely across North America, Europe and Asia (73). Atmospheric transport is the predominant pathway for most semi-volatile organohalogens and occurs more in the winter months. This transport can be considered as three predominant pathways, all of which can substantially influence polar bear 
subpopulation exposures: 1) air masses from industrialized Siberia and Eastern Europe are taken north to the Russian Arctic, 2) air masses from eastern North America and Europe are taken east and north to East Greenland and Svalbard, and 3) air masses from Asia are taken east and north to the Bering Strait, Alaska and the western Canadian Arctic (Fig. 1.3).

\subsubsection{Diet/Food Web Factors}

As early as 2000, Muir and Norstrom (74) suggested that geographic variation in polar bear PCB levels may also be strongly influenced by regional food web variation. Higher PCB levels were associated with larger home ranges in SV polar bears, which was suggested to be related to prey selection, or possibly to greater energetic costs associated with greater travel distances (75). Yet, in previous spatial as well as temporal studies of polar bear contaminant levels, diet and food web factors were not determined. This is no doubt partly related to the difficulty of quantitatively determining the diets/food webs of this arctic predator. Previous studies have attempted to assess diets in a few subpopulations by observing polar bear kills (e.g., 76, 77). However, this method is difficult, does not provide an integrated signal of diet over time and very likely suffers from seasonal observation bias. These surveys may also be biased towards larger and more common kills that can be spotted by air. Further, such diet assessments do not provide a quantitative assessment of individual intake and provide little information on overall food web structure (77-79). 


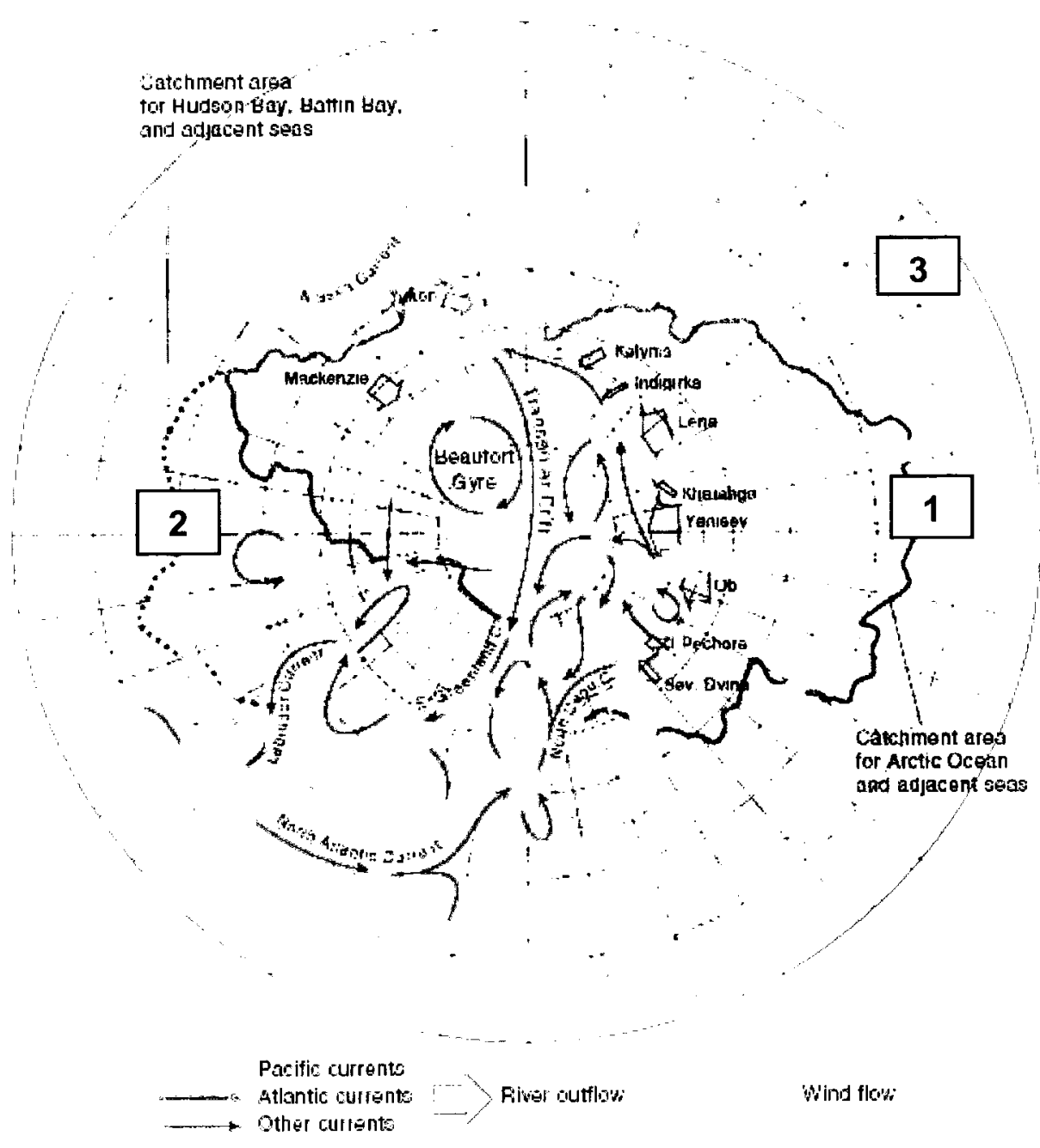

Fig. 1.3. Air current, transpolar ice movement, river outflow and ocean current pathways by which POPs move to and around the Arctic. The numbered boxes refer to the predominant air pathways of organohalogens to the Arctic. Modified graphic from AMAP Assessment 2002: Persistent organic pollutants in the Arctic (3). 
More recently, chemical tracers have instead been applied to clarify polar bear diets and food webs $(78,80-83)$. Stable isotopes (SI), particularly of nitrogen and carbon, have become useful and common tools to generate time integrated estimates of diet and trophic position (84-87). The SI of an element, and molecules containing such isotopes, react in the same way but at different rates, resulting in isotope fractionation during environmental and biological processes. SI data are reported as the delta $(\delta)$ value, representing the difference between the SI ratio in the sample and that in a universal standard. For example, the nitrogen SI ratio is denoted in per mil (\%o) as

$$
\delta^{15} \mathrm{~N}=\left[\left(\frac{{ }^{15} \mathrm{~N} /{ }^{14} \mathrm{~N}_{\text {sample }}}{{ }^{15} \mathrm{~N} /{ }^{14} \mathrm{~N}_{\text {standard }}}\right)-1\right] \times 1000 \% 0
$$

where atmospheric nitrogen is the global nitrogen isotope standard, with an atom $\%{ }^{15} \mathrm{~N}$ of 0.3663033. Since $\delta^{15} \mathrm{~N}$ enrichment occurs with increasing trophic level through a food web, it has been used to estimate the trophic positions of organisms (86). Pee Dee Belemnite is the global carbon isotope standard, with an atom $\%{ }^{13} \mathrm{C}$ of 1.1112328 . This Cretaceous marine fossil, Belemnitella americana, is from the Pee Dee formation in South Carolina and has a higher ${ }^{13} \mathrm{C} /{ }^{12} \mathrm{C}$ ratio than almost all other natural carbon-based substances. Because it changes minimally through food webs, $\delta^{13} \mathrm{C}$ has instead been used to determine carbon sources and thus provide information on feeding patterns, such as freshwater verses marine and pelagic verses benthic feeding $(88,89)$. 
Fatty acid (FA) analysis is also gaining acceptance as a dietary tracer, and can be used in conjunction with SI (90). FAs are straight hydrocarbon chains with zero to six double bonds and a carboxyl group at one end (91). They are abbreviated as $x: y: \mathrm{n}-z$, where $x$ refers to the hydrocarbon chain length, $y$ refers to the number of double bonds, and $z$ refers to the position of the first double bond from the methyl end of the FA. FAs comprise the majority of lipids in all organisms and are required for normal functioning (91). However, many higher trophic level organisms are not able to produce sufficient amounts of specific FAs and must therefore obtain these FAs from dietary sources. The profile of FAs of carbon chain length $\geq 14$ in a predator reflects that of its prey, with some predictable and correctable differences due to biosynthesis and metabolism (79, 91). General feeding patterns can be inferred from FA signatures; for instance, higher proportions of $\mathrm{C}_{18}$ polyunsaturated FAs (PUFAs) and lower proportions of $\mathrm{C}_{20}$ and $\mathrm{C}_{22}$ monounsaturated FAs (MUFAs) are typically more consistent with FA signatures of freshwater feeding mammals compared to marine feeding mammals (89). Indirect, but quantitative assessments of diet composition (i.e. prey species proportions) have also been performed by SI or FA modeling using tracer data from the predator and various potential prey species $(79,81,83)$.

Through observation of prey kills, it has generally been assumed that ringed seals are the predominant prey of polar bears, with some lower consumption of bearded seals (Erignathus barbatus) (76; Fig. 1.1). Yet, recent SI and FA research has suggested that polar bear diets and food webs likely vary among regions and over time. Bentzen et al. 
(83) used SI modeling to estimate that carcasses of subsistence-hunted bowhead whales (Balaena mysticetus) significantly contributed to the diet of the SBS polar bear subpopulation. Thiemann et al. (81) used FA modeling to estimate that Canadian Arctic subpopulations had varied diets consistent with feeding on several other marine mammal prey including harp seals (Phoca groenlandica), beluga whales (Delphinapterus leucas) and harbour seals (Phoca vitulina). This study further suggested considerable variation in diet composition between these subpopulations and to a lesser extent between bears of different sex and ages, as well as over seasons and between years.

Contaminant levels and patterns among marine mammal prey species has been shown to vary due to differences in prey-specific diets, trophic positions, fasting periods, foraging strategies, migration and biotransformation capacities and other biological factors $(9,92-94)$. For example, previous work has shown significant differences in organohalogen levels between different seal species within the same region (95-98). In one study, SV polar bears were observed feeding on an elevated number of harp seals, and significantly higher OCP levels were found in harp seals relative to ringed seals in that region (99). Therefore, spatial and temporal variation in the proportions of various marine mammal species in polar bear diets may consequently affect their organohalogen levels. Of course, the diets of the individual prey themselves may also vary spatially, temporally or by demographic group (e.g., 100). Considering these findings, it has been hypothesized that large-scale spatial variation in polar bear contaminant levels and patterns is, in part, affected by regional food web and/or diet differences $(26,36)$. 
However, this remains an untested hypothesis, not only in terms of geographic variation in contaminants, but also regarding temporal changes in contaminant levels and patterns. This research may be especially critical to investigate in light of reported climate-related changes to arctic ecosystems and food webs (Section 1.2.2.4).

\subsubsection{Climate Change Factors}

Anthropogenic contamination is one of the paramount environmental concerns of our time; a second and arguably more important issue is climate change, and both are likely significant stressors to arctic ecosystems. It is also very likely that climate change will influence organohalogen exposure in polar bears. However, there is currently insufficient data to address the combined effects of these two stressors on polar bears and other arctic species. The amount and patterns of organohalogen transport to the Arctic, changes in precipitation patterns, release of contaminants from melting multi-year sea ice and permafrost, changes in primary production levels, food web pathways, migratory species movements and never before seen communities, as well as polar bear diet shifts and fasting behaviour comprise a list of just some climate change-related factors that may modulate organohalogen exposure and associated health risks in polar bears and throughout arctic marine food webs (101-107).

Recently, limited evidence has suggested that climate change-associated factors may already be having an effect on contaminant concentrations in arctic biota. For example, Gaden et al. (108) found that temporal trends (1973-2007) in mercury levels in western 
Canadian Arctic ringed seals were correlated not with year but with length of ice-free season. Increasing trends of PCBs and mercury in western Canadian Arctic burbot (Lota lota) were linked with increased primary productivity, likely as a result of warming temperatures (109). Recent and drastic climate-related shifts in the composition of arctic and subarctic marine ecosystems have been reported. For instance, there has been an increase in subarctic fish relative to arctic fish in northern Hudson Bay (110). Reduced sea ice, warmer air and ocean temperatures, have also shifted the previously benthicdominated Northern Bering Sea ecosystem to a more pelagic, Southern Bering Sea-type (subarctic) ecosystem (111).

It has already been documented that WHB polar bears have come ashore earlier and in poorer condition over the last two decades, corresponding to earlier summer breakup of the annual sea ice in Hudson Bay $(105,112)$. Based on FA signatures, diet shifts may also have occurred over time in this subpopulation $(78,81)$. Therefore, assessing the impact of diet and/or food web changes on organohalogen levels in polar bears is of mounting importance in the face of continued climate changes.

\subsection{Thesis Objectives}

Despite consideration of the aforementioned abiotic and biological factors, there remains considerable unexplained variation in polar bear contaminant levels among individuals, subpopulations and over time. The main aim of this thesis is to assess geographic and temporal variation in brominated and chlorinated contaminant levels and 
patterns across circumpolar polar bear subpopulations and to test the overall hypothesis that dietary factors modulate contaminant spatial and temporal trends in polar bears. The separate sub-objectives investigated, and hypotheses tested, in the five individual studies are described here.

Objective 1. Excluding PBDEs, knowledge of BFR contamination in arctic ecosystems currently remains very limited. Determination of a broad suite of recent-use/current-use BFRs in a top predator such as the polar bear may provide an "early warning" of arctic accumulation issues (113). Current data on PCBs and OCPs in polar bears provides information on how well international controls on emissions are reflected in top trophic feeding arctic biota. In Chapter 3, I assess current (2005-2008) adipose levels and patterns of recently established as well as newly screened and identified BFRs, in addition to legacy organohalogen contaminants and metabolites, in 11 circumpolar subpopulations (Fig. 1.2). I also compare current contaminant levels and patterns to previous circumpolar assessments, as available, from 1989-1993 and 1996-2002 (26, 35, 39). This type of initial screening of potential "new" contaminants of concern, as well as continued monitoring of legacy contaminants, is important from a wildlife health perspective, as well as for people living in the Arctic.

Objective 2. Despite the commonly held notion that diet is perhaps the major contributing factor to organohalogen bioaccumulation in higher trophic level organisms (polar bears, marine mammals, seabirds) (e.g., 22), only rarely and recently have contaminant biomonitoring studies considered potential spatial differences or temporal 
changes in diet and/or food webs. Although long-range transport from differing point sources is likely influential in organohalogen spatial variation among polar bear subpopulations, the magnitude of this variation may be considerably different when diet is taken into account. In Chapter 4, I test the hypothesis that polar bear diets are different between circumpolar subpopulations spanning Alaska in the west to Svalbard in the east. I assess polar bear diet variation by examining SI and FA profiles between the circumpolar subpopulations and by using ringed seal SI and FA profiles as a type of baseline allowing inter-region comparisons. Second, I hypothesize that geographic variation in polar bear contaminant levels (as determined in Chapter 3) is due (in part) to diet variation. I test this hypothesis by examining whether organohalogen spatial trends in this sentinel species are significantly different when geographic variation in dietary factors is taken into consideration.

Objective 3. Having established the spatial patterns of organohalogens in polar bear subpopulations and the influence of diet, the next logical step is to investigate this relationship of polar bear diet to organohalogen levels over time. Here, I focus on the WHB polar bear subpopulation. This subpopulation has one of the most extensive tissue archives of any arctic marine or terrestrial mammal population and has elevated organohalogen contaminant levels relative to most circumpolar polar bear subpopulations (25), making it ideal for tracking temporal changes in the Arctic. WHB polar bears may be more susceptible to effects of climate-related changes in sea ice conditions than other subpopulations that live further north in areas where sea-ice dynamics do not currently 
include complete annual freeze-thaw cycles (78). Recent studies have demonstrated that increasingly earlier annual sea ice breakup timing in this region (one of the most noticeable climate-associated changes) has been correlated with lower body condition, birthrate and survival rate in WHB polar bears $(78,112,114)$. In Chapter 5 , I test the hypothesis that changes in seasonal sea ice coverage have also caused changes in WHB polar bear diets/food webs. I assess inter-annual diet variation from 1991-2007 using SI and FA profiles. If diet change is a result of sea ice changes, then dietary tracers should be correlated with annual sea ice breakup dates in the region. I also test whether diet change is consistent with a shift to higher proportions of open water-associated seal species versus ice-associated seal species, as previously hypothesized for diet shifts related to climate change (81). I also hypothesize that feeding changes, in turn, affect contaminant levels over time in WHB polar bears. I assess the temporal trends of selected $\sum$-classes of organohalogen contaminants in the WHB subpopulation with and without adjusting for the influence of diet factors.

Objective 4. As mentioned, legacy PCB and OCP time trends have been reported for the WHB subpopulation for the years 1968, 1984 and most years from 1989-2002. However, $\mathrm{MeSO}_{2}$-PCB and BFR changes have not been analyzed in WHB or in any other subpopulations. Moreover, other than for PBDEs and HBCD, there is no information on temporal trends of BFRs in any arctic species (6). In Chapter 6, I analyze the detailed temporal trends in levels and patterns of PCBs, OCPs, BFRs and $\mathrm{MeSO}_{2}-\mathrm{PCBs}$ in adipose tissues of WHB polar bears from 1991-2007. I compare, when possible, these 
levels to the earlier trends studies dating back to 1968 providing an exceptionally longterm dataset in comparison to most other arctic trend studies. As an expansion of Chapter 5, I also test the hypothesis that diet/food web changes affect contaminant congener/metabolite patterns. If contaminant patterns are influenced by diet, then dietary tracers should explain a significant amount of the variation in WHB contaminant patterns in a model incorporating dietary tracers as explanatory variables.

Objective 5. Finally, biotransformation is also an important factor influencing organohalogen contaminant levels in polar bears and other species. For BFRs, knowledge of biotransformation capacity and metabolite formation in polar bears and other arctic species is limited. Previous CYP-oxidative assay designs for arctic marine wildlife may not have adequately captured the metabolic potential towards BFRs, especially for fully brominated BFRs, which may be more subject to debromination $(13,71,72)$. Ecosystem exposure to highly brominated BFRs could be underestimated if these compounds are more readily metabolizable than lower brominated BFRs. In Chapter 7, I test the hypothesis that arctic species can biotransform higher brominated BFRs (BDE209 and DBDPE) relative to lower brominated BFRs (BDE99, BDE100, BDE154). I compare the in vitro oxidative transformation and/or reductive debromination of these BFRs using the hepatic microsomes of various arctic species including polar bear, beluga whale and ringed seal. I also examine the possibility that biotransformation plays a role in interspecies differences in BFR levels and patterns. 


\section{Chapter 2: Materials and Methods}

\subsection{Study Areas and Sample Details}

\subsubsection{Spatial Trends}

Polar bears (total $n=163$ ) were sampled from 2005-2008 in 11 subpopulations: Alaska - Chukchi/Bering Sea (AL), southern Beaufort Sea (SBS), northern Beaufort Sea (NBS), Gulf of Boothia (GB), Lancaster/Jones Sound (LJS), Baffin Bay (BB), Davis Strait (DS), western Hudson Bay (WHB), southern Hudson Bay (SHB), East Greenland (EG) and Svalbard (SV) (Fig. 1.2; Table 2.1). Adipose samples for contaminant and FA analysis and muscle samples for SI analysis were collected during native subsistence hunts. Only adipose biopsies were collected from the SV subpopulation. Collections occurred from October to mid-May. After sampling and during shipment, samples were kept frozen. Samples were stored at $-40^{\circ} \mathrm{C}$ at Environment Canada's National Wildlife Specimen Bank at the National Wildlife Research Centre (NWRC). Ages were determined by counting annual growth layer groups in the cementum of a vestigial premolar or lower right $\mathrm{I} 3$ tooth $(27,115)$. Polar bears were considered subadults if $\leq 4$ yr old and adults otherwise (26). Ringed seal blubber samples were obtained for FA analysis at similar locations over a similar time period ( $n \geq 10 /$ location; 2004-2006) through a parallel spatial contaminant monitoring project underway at Environment Canada (Burlington, ON). Muscle samples were also collected from ringed seals in East Greenland for SI 


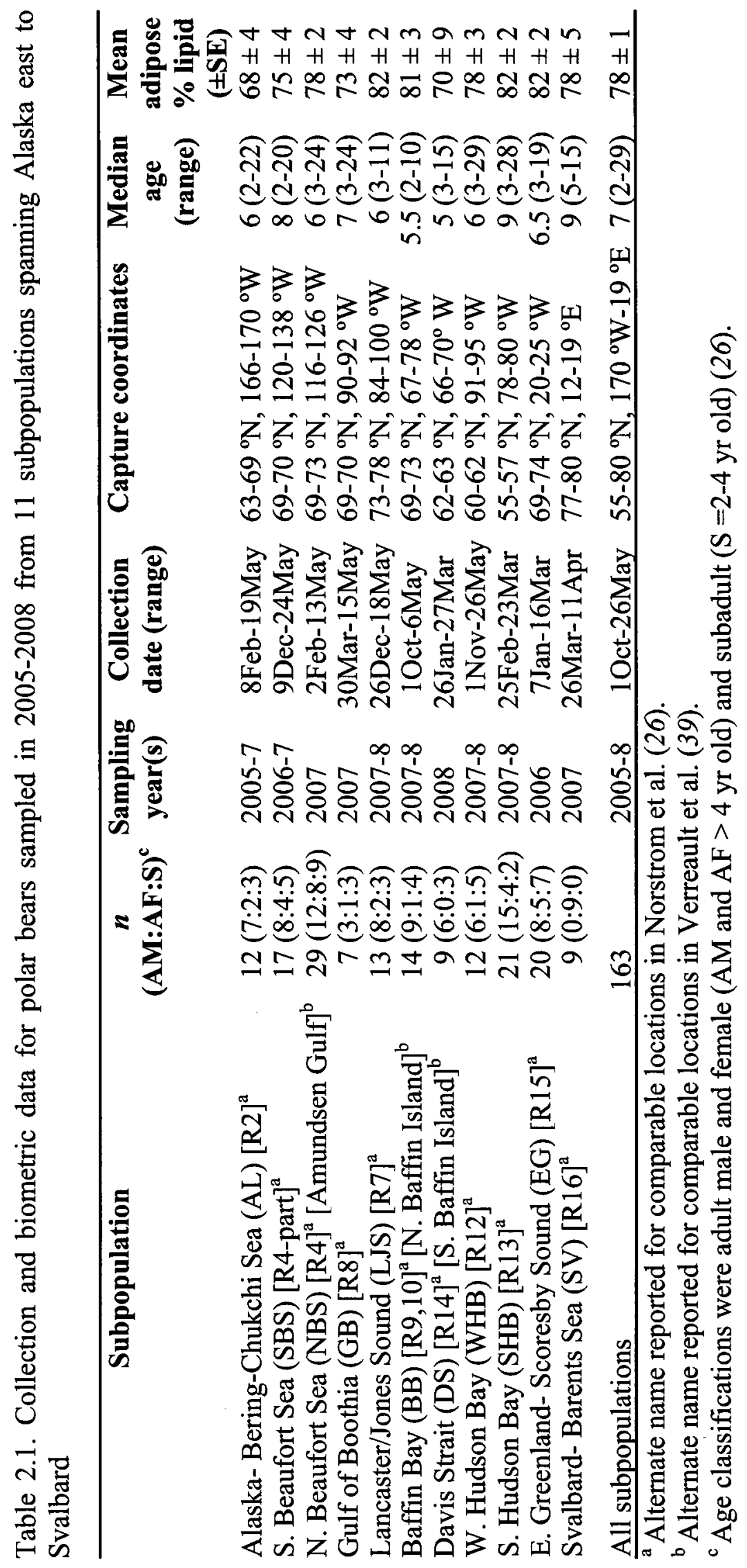


analysis. Remaining ringed seal muscle SI data was available from published studies. Ringed seal samples comprised both sexes and various ages.

\subsubsection{Temporal Trends}

The geographical location of the WHB polar bear subpopulation is bounded by $63.10^{\circ} \mathrm{N}, 88.30^{\circ} \mathrm{W}$, and by the western Hudson Bay coastal region (Fig. 1.2) We analyzed archived WHB polar bear adipose tissues (total $n=92$ ) from seven available years over the seventeen year period of 1991 to 2007 (Table 2.2). Samples from the 1990s were adipose biopsies taken during polar bear tagging operations, whereas the samples from the 2000s were mainly pieces of rump adipose tissue taken from bears harvested by Inuit hunters. There are no differences POPs patterns and concentrations or FA composition among major adipose depots in polar bear $(116,117)$. All samples were initially and during shipment kept frozen and stored at $-40^{\circ} \mathrm{C}$ in the long-term at Environment Canada's Wildlife Specimen Bank. There appears to be no change in FA concentrations and patterns between samples stored at $-40^{\circ} \mathrm{C}$ and $-80^{\circ} \mathrm{C}(118)$. To focus on the effect of diet on the contaminant concentrations over time, we selected and corrected (see also Section 2.6.3) the dataset to minimize confounding factors that could contribute to interindividual variation in contaminant levels. Samples chosen were mainly collected in September-November, which likely reduced seasonal variation in contaminant concentrations (27). Initial efforts focused on adult ( $>4 \mathrm{yr}$ old) females to minimize effects of sex-related variation in contaminant levels and because age effects on PCB, OCP and PBDE concentrations were shown to be minimal in adult females in previous 
studies $(26,35)$. However, the inclusion of samples from adult males and subadults (3-4 yr old) in years post-2000 was unavoidable in order to attain adequate sample sizes (44).

\subsubsection{Biotransformation Assay}

Fresh $(<60 \mathrm{~min}$ post-mortem) liver specimens were collected from a sacrificed individual subsistence-hunted polar bear from Canada, a stranded polar bear from Iceland, and subsistence-hunted beluga whales and ringed seals from Canada (Table 2.3). The liver tissues were immediately stored in a liquid nitrogen dry shipper preceding longterm storage at $\leq-80^{\circ} \mathrm{C}$. Hepatic microsomes from pooled $(n=17)$ adult male Wister Han rats (herein denoted RAT) were purchased from BD Gentest (Woburn, MA, USA).

\subsection{Contaminant Analysis}

\subsubsection{Standards and Reagents}

PCB and OCP standards were supplied by the Lab Services section of the Ecotoxicology and Wildlife Health Division at the NWRC (Ottawa, ON, Canada). Mass labeled ${ }^{13} \mathrm{C}$-PCB internal standards (ISs) for PCB and OCP analysis were purchased from Cambridge Isotope Laboratories (Andover, MA, USA). BFRs were purchased from Wellington Laboratories (Guelph, ON, Canada). $\mathrm{MeSO}_{2}-\mathrm{PCBs}$ were kindly supplied by

Dr. A. Bergman (Stockholm University, Sweden). All other reagents and solvents were of at least analytical grade purity. 
Table 2.3. Sample collection location and date and biological data

\begin{tabular}{|c|c|c|c|c|c|}
\hline $\begin{array}{l}\text { Sample } \\
\text { ID }^{\mathbf{a}}\end{array}$ & Species & Collection region & $\begin{array}{l}\text { Collection date } \\
(\text { yyyy } / \mathrm{mm})\end{array}$ & Sex & $\begin{array}{l}\text { Age } \\
\text { class }\end{array}$ \\
\hline PB1 & Polar bear & Iceland $^{\mathrm{b}}$ & $2008 / 06$ & $\mathrm{~F}$ & Adult \\
\hline PB2 & Polar bear & Lancaster/Jones Sound, Canada & 1993/04 & $\mathrm{M}$ & Adult \\
\hline BW1 & Beluga whale & Western Hudson Bay, Canada & 2003/08 & $\mathrm{M}$ & Adult \\
\hline BW2 & Beluga whale & Western Hudson Bay, Canada & $2003 / 08$ & $\mathrm{~F}$ & Adult \\
\hline RS1 & Ringed seal & Cumberland Sound, Canada & 2001/07 & $\mathrm{F}$ & Adult \\
\hline RS2 & Ringed seal & Cumberland Sound, Canada & $2001 / 07$ & $\mathrm{~F}$ & Adult \\
\hline
\end{tabular}




\subsubsection{Extraction}

Contaminants were extracted from approximately $0.5 \mathrm{~g}(0.2$ to $0.3 \mathrm{~g}$ for biopsies $)$ of polar bear adipose tissue as described previously (e.g., 39) and with modifications outlined here (Fig. 2.1). Samples were homogenized with sodium sulfate and spiked prior to extraction with ISs: a mixture of ${ }^{13} \mathrm{C}_{12}$-PCBs, ${ }^{13} \mathrm{C}_{6}$-ClBzs and ${ }^{13} \mathrm{C}_{12}-p$, $p$-DDE, as well as 3- $\mathrm{CH}_{3} \mathrm{SO}_{2}-2-\mathrm{CH}_{3}-2^{\prime}, 3^{\prime}, 4^{\prime}, 5,5^{\prime}-$ pentaCB $\left(\mathrm{MeSO}_{2}-\mathrm{PCB}\right.$ IS) and BDE30 (BFR IS).

Contaminants were extracted into 1:1 dichloromethane:hexane using an accelerated solvent extractor system at $100{ }^{\circ} \mathrm{C}$ and $1500 \mathrm{psi}$ for one cycle. A $10 \%$ portion of the extract was used for gravimetric determination of lipid content. From the remainder, lipids and other bioorganics were removed by automated gel permeation chromatography. The extract was separated into two fractions using a pre-conditioned (6 $\mathrm{ml}$ of $10 \%$ methanol in dichloromethane, followed by $8 \mathrm{ml}$ of $5 \%$ dichloromethane in hexane) silica LC-Si solid phase extraction cartridge $(500 \mathrm{mg} \times 6 \mathrm{ml}$; J.T. Baker, Phillipsburg, NJ, USA) on a vacuum manifold (121). The first fraction was eluted with 8 $\mathrm{mL}$ of $5 \%$ dichloromethane in hexane and contained (if present) all monitored PCBs, OCPs and BFRs. The second fraction was eluted with $8 \mathrm{ml}$ of $100 \%$ dichloromethane and contained (if present) $3-\mathrm{MeSO}_{2}-p, p^{\prime}-\mathrm{DDE}$ and all monitored $\mathrm{MeSO}_{2}-\mathrm{PCBs}$. Both fractions were spiked prior to analysis with a normalization standard, ${ }^{13} \mathrm{C}_{12}-\mathrm{CB} 138$.

\subsubsection{Measurement}

For all analyte classes, separation and quantification were performed on a $6890 \mathrm{~N}$ gas chromatograph (GC) - 5973N single quadrupole mass spectrometer (MS) (Agilent 
Extract from Tissue

$-0.5 \mathrm{~g}$ adipose homogenized and spiked with internal standard

-extracted with 1:1 dichloromethane:hexane using accelerated solvent extraction

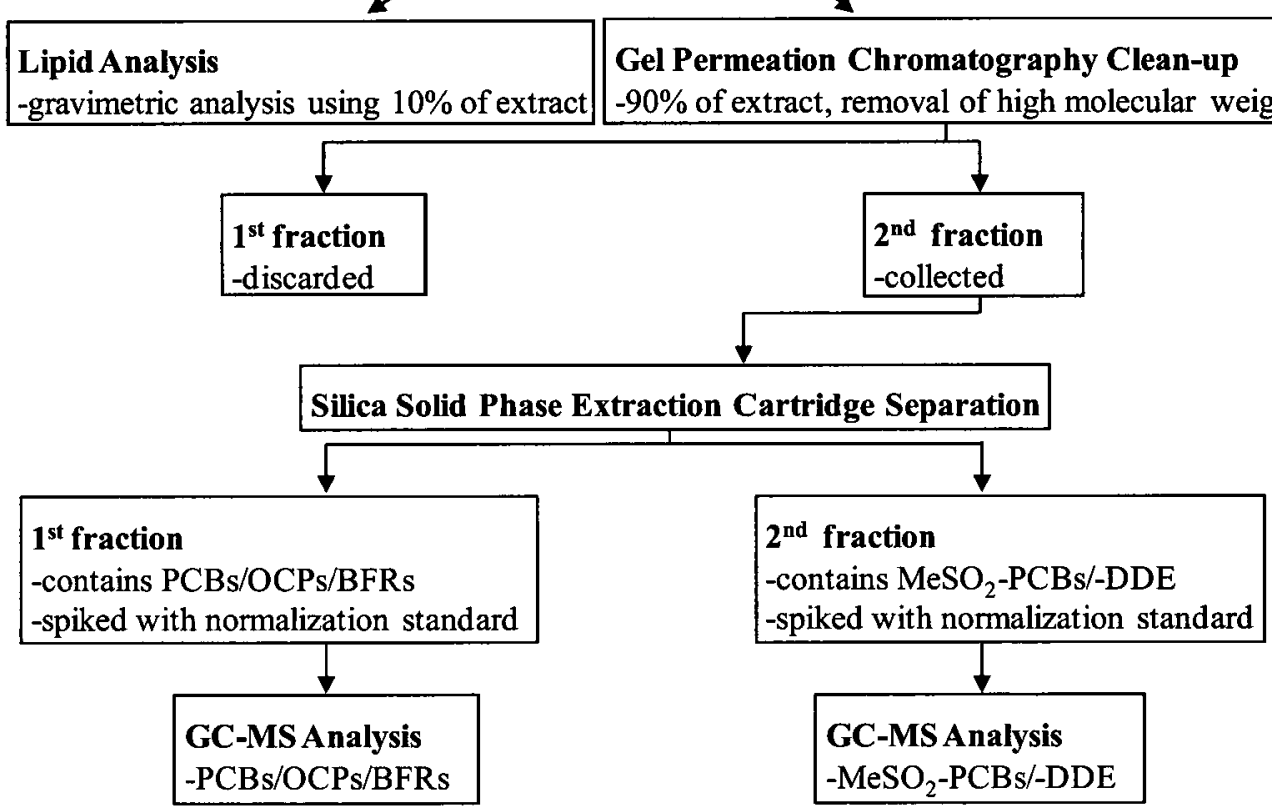

Fig. 2.1. Flow diagram of $\mathrm{PCB}, \mathrm{OCP}, \mathrm{BFR}$ and $\mathrm{MeSO}_{2}-\mathrm{PCB} / \mathrm{-DDE}$ extraction from polar bear adipose tissue. 
Technologies, Palo Alto, CA, USA) and based on previously published methods $(26,122$, 123). A $30 \mathrm{~m}$ length $\times 250 \mu \mathrm{m}$ i.d. fused silica DB-5 capillary column ((5\% phenyl-) methylpolysiloxane, $0.25 \mu \mathrm{m}$ film thickness; J \& W Scientific, Folsom, CA, USA) was used for GC separation of PCBs, OCPs and $\mathrm{MeSO}_{2}$-PCBs. For BFRs, a similar, but shorter $(15 \mathrm{~m})$ and thinner film thickness $(0.10 \mu \mathrm{m})$ column (DB5-HT) was used to minimize thermal decomposition and peak broadening of higher brominated BFRs (BDE209, DBDPE). An Agilent 7683 series injector and autosampler were used.

Details of the GC-MS conditions were provided in Table 2.4. For PCB and OCP analyses, the MS detector was used in the electron impact (EI) ionization mode. EI is a "hard" ionization technique whereby a beam of energetic $(70 \mathrm{eV})$ electrons ionize the analyte molecules. The cations generated were monitored by selected ion monitoring (SIM), wherein only ions of specific $\mathrm{m} / \mathrm{z}$ ratios are recorded, increasing the instrumental precision as well as sensitivity. Thus, e.g., for EI-MS analysis of PCBs, the $[\mathrm{M}]^{+}$and $[\mathrm{M}+2]^{+}$cations were monitored in designated chromatographic windows. For BFRs and $\mathrm{MeSO}_{2}-\mathrm{PCBs} /-\mathrm{DDE}$, the $\mathrm{MS}$ detector was used in the electron capture negative ionization mode $(\mathrm{ECNI})$, a soft ionization technique whereby the reagent gas slows down ("softens") the electrons in the electron beam thereby allowing them to be "captured" by the analyte. ECNI is useful for trace analysis of molecules containing halogen substituents, because of the high affinity of halogens for electrons. The $[\mathrm{M}]^{-}$and $[\mathrm{M}+2]^{-}$ anions were selectively monitored for tetra- to hepta-chlorinated $\mathrm{MeSO}_{2}$-PCBs. BFRs were mainly monitored using bromine isotopic anions. In addition, $\left[\mathrm{C}_{6} \mathrm{Br}_{5} \mathrm{O}\right]^{-}$anions 
Table 2.4. GC-MS conditions for analysis of PCB, OCP, BFR and $\mathrm{MeSO}_{2}$-DDE/PCB contaminants

\begin{tabular}{|c|c|c|c|c|}
\hline & PCBs & OCPs & BFRs & $\begin{array}{c}\mathrm{MeSO}_{2}-\mathrm{PCBs} /- \\
\text { DDE }\end{array}$ \\
\hline GC column length (m) & 30 & 30 & 15 & 30 \\
\hline Injector & splitless & splitless & splitless & splitless \\
\hline Injector temp $\left({ }^{\circ} \mathrm{C}\right)$ & 250 & 250 & 280 & 280 \\
\hline Injection volume $(\mu 1)$ & 1 & 1 & 1 & 1 \\
\hline Carrier gas & helium & helium & helium & helium \\
\hline Reagent gas & N/A & N/A & methane & methane \\
\hline Transfer line temp $\left({ }^{\circ} \mathrm{C}\right)$ & 280 & 280 & 280 & 280 \\
\hline Ionization mode & $\mathrm{EI}$ & EI & ECNI & ECNI \\
\hline Electron energy $(\mathrm{eV})$ & 70 & 70 & 70 & 70 \\
\hline Ion source temp $\left({ }^{\circ} \mathrm{C}\right)$ & 230 & 230 & 250 & 180 \\
\hline Quadrupole temp $\left({ }^{\circ} \mathrm{C}\right)$ & 150 & 150 & 150 & 150 \\
\hline Acquisition mode & SIM & SIM & SIM & SIM \\
\hline GC oven temperature & -Hold at $100^{\circ} \mathrm{C}$, & -Hold at $100^{\circ} \mathrm{C}$ & -Start at 90 & -Hold at $100^{\circ} \mathrm{C}$, \\
\hline ramping program & $3 \mathrm{~min}$ & $3 \mathrm{~min}$ & ${ }^{\circ} \mathrm{C}$ & $3 \mathrm{~min}$ \\
\hline & -Increase to 180 & -Increase to 180 & -Increase to & -Increase to 220 \\
\hline & ${ }^{\circ} \mathrm{C}$ at $20^{\circ} \mathrm{C} / \mathrm{min}$ & ${ }^{\circ} \mathrm{C}$ at $20^{\circ} \mathrm{C} / \mathrm{min}$ & $310^{\circ} \mathrm{C}$ at 20 & ${ }^{\circ} \mathrm{C}$ at $20^{\circ} \mathrm{C} / \mathrm{min}$ \\
\hline & -Increase to 300 & -Increase to 300 & ${ }^{\circ} \mathrm{C} / \mathrm{min}$ & -Hold for $1 \mathrm{~min}$ \\
\hline & ${ }^{\circ} \mathrm{C}$ at $2.5^{\circ} \mathrm{C} / \mathrm{min}$ & ${ }^{\circ} \mathrm{C}$ at $5^{\circ} \mathrm{C} / \mathrm{min}$ & $\begin{array}{l}\text {-Hold for } 15 \\
\text { min }\end{array}$ & $\begin{array}{l}\text {-Increase to } 280 \\
{ }^{\circ} \mathrm{C} \text { at } 3^{\circ} \mathrm{C} / \mathrm{min} \\
\text {-Hold for } 8 \mathrm{~min}\end{array}$ \\
\hline
\end{tabular}


were used to monitor nonaBDEs and BDE209 (124). To address the co-elution of BDE154 with BB153 with respect to analyte specific quantification, BDE154 was additionally monitored using $[\mathrm{M}-2 \mathrm{Br}]^{-}$anion isotopes, which were less abundant but allowed for mass spectral resolution, and thus separation from BB153. Total-( $\alpha-)$ HBCD was determined as $\mathrm{HBCD}$ diastereomers are subject to thermal re-arrangement at temperatures $>160^{\circ} \mathrm{C}$, and decomposition at $>240^{\circ} \mathrm{C}(125)$. All analyzed compounds were listed in Table 2.5 .

Identification and quantification was performed using MSD ChemStation (G1701DA D.01.00, Agilent Technologies). Each analyte was positively identified and quantified if (1) the retention time was within 0.03 min of that in the external standard, (2) the relative abundance of the qualifying ion to that of the quantifying ion was within $20 \%$ of the expected value and (3) the peak signal-to-noise ratio was at least 10. PCBs and OCPs were quantified by an external standard method, and ClBzs were also recovery corrected to account for volatility-related lower recoveries. $\mathrm{MeSO}_{2}-\mathrm{PCBs}$ and $\mathrm{BFRs}$ were quantified by an internal standard method based on the relative response factor of the analyte versus the appropriate internal standard, and thus concentrations were inherently recovery and performance corrected. Each contaminant concentration or $\sum$-contaminant class was calculated on a lipid weight (lw) basis.

\subsubsection{Quality Control}

For the spatial trends dataset, IS recoveries were $88 \pm 10 \%, 59 \pm 18 \%, 89 \pm 14 \%, 88 \pm$ $15 \%$ and $105 \pm 25 \%$ for $\mathrm{BDE} 30,{ }^{13} \mathrm{C}_{6}-\mathrm{ClBzs},{ }^{13} \mathrm{C}_{12}-\mathrm{PCBs},{ }^{13} \mathrm{C}_{12}-p, p$-DDE and 3- 
Table 2.5. The 161 individual contaminants, congeners and metabolites analyzed in adipose tissue of polar bears from 11 subpopulations sampled in 2005-2008 and from archived adipose tissue of WHB polar bears from 1991-2007

\begin{tabular}{|c|c|c|c|c|c|}
\hline 37 PBDEs & 8 Other BFRs & 741 & PCBs & 20 OCPs & $22 \mathrm{MeSO}_{2}-\mathrm{PCBS}$ \\
\hline BDE $28 / 33$ & PBT & CB18 & CB158 & ClBzs: & 3- $\mathrm{MeSO}_{2}-\mathrm{CB} 52$ \\
\hline BDE54 & PBEB & CB17 & CB128 & $1,2,4,5-\mathrm{TeClBz}$ & 3'- $\mathrm{MeSO}_{2}-\mathrm{CB} 49$ \\
\hline BDE75 & HBB & $\mathrm{CB} 16 / 32$ & $\mathrm{CB} 167$ & $1,2,3,4-\mathrm{TeClBz}$ & 4-MeSO ${ }_{2}-\mathrm{CB} 52$ \\
\hline BDE49 & BB101 & CB31 & CB156 & $\mathrm{PeClBz}$ & 4'--MeSO${ }_{2}-\mathrm{CB} 49$ \\
\hline BDE47 & $\mathrm{BB} 153^{\mathrm{a}}$ & CB28 & CB157 & HCB & 3- $\mathrm{MeSO}_{2}-\mathrm{CB} 64$ \\
\hline BDE66 & total- $(\alpha-) \mathrm{HBCD}$ & CB33/20 & CB179 & & $4-\mathrm{MeSO}_{2}-\mathrm{CB} 64$ \\
\hline BDE77 & ВТВРE & CB22 & CB176 & HCHs: & 4- $\mathrm{MeSO}_{2}-\mathrm{CB} 91$ \\
\hline BDE100 & DBDPE & CB52 & CB178 & $\alpha-\mathrm{HCH}$ & $3-\mathrm{MeSO}_{2}-\mathrm{CB} 70$ \\
\hline BDE119 & & CB49 & CB187/182 & $\beta-\mathrm{HCH}$ & $3^{\prime}-\mathrm{MeSO}_{2}-\mathrm{CB} 101$ \\
\hline BDE99 & & CB47/48 & CB183 & & $4-\mathrm{MeSO}_{2}-\mathrm{CB} 70$ \\
\hline BDE116 & & CB44 & CB174 & octachlorostyrene & 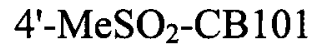 \\
\hline BDE85 & & CB42/59 & $\mathrm{CB} 177$ & & 3'- $\mathrm{MeSO}_{2}-\mathrm{CB} 87$ \\
\hline BDE155 & & CB64/41 & CB171 & CHLs: & $3-\mathrm{MeSO}_{2}-\mathrm{CB} 110$ \\
\hline $\mathrm{BDE} 154^{\mathrm{a}}$ & & CB74 & $\mathrm{CB} 172$ & heptachlor epoxide & 3- $\mathrm{MeSO}_{2}-\mathrm{CB} 149$ \\
\hline BDE153 & & CB70/76 & CB180 & oxychlordane & 4- $\mathrm{MeSO}_{2}-\mathrm{CB} 110$ \\
\hline BDE139 & & CB66 & CB170/190 & $t$-chlordane & 4'- $\mathrm{MeSO}_{2}-\mathrm{CB} 87$ \\
\hline BDE138 & & CB56/60 & CB189 & $c$-chlordane & $4-\mathrm{MeSO}_{2}-\mathrm{CB} 149$ \\
\hline BDE140 & & CB95 & CB202 & $t$-nonachlor & 3'- $\mathrm{MeSO}_{2}-\mathrm{CB} 132$ \\
\hline BDE156 & & CB92 & CB200 & $c$-nonachlor & 4'- $\mathrm{MeSO}_{2}-\mathrm{CB} 132$ \\
\hline BDE184 & & CB101/90 & CB199 & & 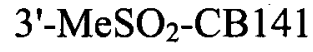 \\
\hline BDE183 & & CB99 & CB196/203 & $D D T_{s}$ & 4'- $\mathrm{MeSO}_{2}-\mathrm{CB} 141$ \\
\hline BDE191 & & CB97 & CB208 & $p, p^{\prime}-\mathrm{DDE}$ & 4'- $\mathrm{MeSO}_{2}-\mathrm{CB} 174$ \\
\hline BDE 180 & & CB87 & CB195 & $p, p^{\prime}$-DDD & \\
\hline BDE181 & & CB85 & CB207 & $p, p^{\prime}$-DDT & \\
\hline BDE190 & & CB110 & CB194 & & \\
\hline BDE171 & & CB118 & CB206 & 3- $\mathrm{MeSO}_{2}-p, p^{\prime}-\mathrm{DDE}$ & \\
\hline BDE202 & & CB114 & CB201 & dieldrin & \\
\hline BDE201 & & CB105 & & photomirex & \\
\hline BDE197 & & CB151 & & mirex & \\
\hline BDE203 & & CB149 & & & \\
\hline BDE196 & & CB146 & & & \\
\hline BDE205 & & CB153 & & & \\
\hline BDE208 & & CB141 & & & \\
\hline BDE207 & & CB130 & & & \\
\hline BDE206 & & CB137 & & & \\
\hline BDE209 & & CB138 & & & \\
\hline
\end{tabular}

${ }^{\mathrm{a}}$ Co-eluting compounds under optimized GC conditions. 
$\mathrm{CH}_{3} \mathrm{SO}_{2}-2-\mathrm{CH}_{3}-2,3^{\prime}, 4^{\prime}, 5,5^{\prime}-$ pentaCB, respectively. For the WHB temporal trends dataset, in the same order, IS recoveries were $87 \pm 12 \%, 59 \pm 7 \%, 85 \pm 5 \%, 88 \pm 8 \%$ and $91 \pm$ $17 \%$.

With each batch of 10 samples, a sodium sulfate method blank and the National Institute of Standards and Technology (NIST) Pilot Whale blubber SRM1945 were also extracted. Low and relatively constant blank responses were subtracted on a batch-bybatch basis. However, BDE209 and DBDPE blank values were variable and sometimes similar to sample values. Unlike for other compounds wherein method limits of quantification (MLOQs) were based on a signal-to-noise ratio of 10, MLOQs for BDE209 and DBDPE were set to the blank average plus $3 \times$ SD. MLOQs ranged from around $0.05 \mathrm{ng} / \mathrm{g} \mathrm{lw}$ for most BFRs to $0.3 \mathrm{ng} / \mathrm{g} \mathrm{lw}$ for total-( $\alpha-) \mathrm{HBCD}$ and $1 \mathrm{ng} / \mathrm{g}$ lw for BDE209 and DBDPE. To determine BDE154 separately from BB153, we monitored [M$2 \mathrm{Br}]^{-}$that had a higher MLOQ of $0.4 \mathrm{ng} / \mathrm{g} \mathrm{lw}$. The MLOQs were around $0.1 \mathrm{ng} / \mathrm{g}$ lw for PCBs and OCPs and 0.5 to $0.9 \mathrm{ng} / \mathrm{g}$ lw for $\mathrm{MeSO}_{2}-\mathrm{PCBs}$ and 3-MeSO $2-p, p^{\prime}-\mathrm{DDE}$.

In 19 repeated analyses of SRM1945 extracted with the spatial trends dataset, $\Sigma$ PCB, $\sum$ OCP and $\sum$ PBDE levels were within $7 \pm 5 \%, 11 \pm 6 \%$ and $16 \pm 11 \%$ of the NIST certified values $(126,127)$, respectively. In 12 repeated analyses of SRM1945 extracted with the temporal trends dataset, $\sum \mathrm{PCB}, \sum \mathrm{OCP}$ and $\sum \mathrm{PBDE}$ levels were within $5 \pm 4 \%, 7$ $\pm 3 \%$ and $14 \pm 7 \%$, respectively, of the certified values. SRM1945 does not currently have certified values for $\mathrm{MeSO}_{2}-\mathrm{PCBs}$ or for any non-PBDE BFRs.

The relative standard deviation (RSD) between duplicate analyses of polar bear samples in the spatial trends dataset were on average $6 \%, 7 \%, 13 \%$ and $13 \%$ for $\sum \mathrm{PCB}, \sum \mathrm{OCP}$, 
$\sum$ PBDE and $\sum \mathrm{MeSO}_{2}$-PCB concentrations, respectively. In the same order, duplicate analyses of polar bear samples in the temporal trends dataset showed RSDs on average of $7 \%, 15 \%, 21 \%$ and $12 \%$ different.

It bears noting that the error associated with mean concentrations in a given sample set was due largely to inter-individual variation in concentrations and did not include all sources of analytical error in the measurement (e.g., error associated with weighing the samples, error in external and internal standard concentrations). However, such residual analytical error was likely small relative to the inter-individual variation in concentrations.

\subsection{Dietary Tracer Analysis}

\subsubsection{Stable Isotopes}

\subsubsection{Extraction}

For the spatial dataset, polar bear muscle tissues were homogenized, lipid-removed and prepared for analysis by standard protocols (e.g., 128). Briefly, lipids were extracted with 2:1 chloroform:methanol. After centrifugation, solvent was discarded and tissues were rinsed with nanopure water, re-dried and re-homogenized. Samples (250-270 $\mu \mathrm{g})$ were accurately weighed into $5 \times 3.5 \mathrm{~mm}$ tin capsules. For comparability with published ringed seal muscle SI data in which lipids were not removed, East Greenland ringed seal samples were also not lipid-removed prior to SI analysis. For the temporal dataset, muscle samples were not available. Instead, the lipid extract from the gravimetric lipid 
determination (Section 2.2.2) was used for $\delta^{13} \mathrm{C}$ determination. Using the tip of a solventcleaned, unfolded paperclip, 150 to $300 \mu \mathrm{g}$ of lipid was weighed accurately into a $5 \times 3.5$ mm tin capsule.

\subsubsection{Measurement}

Carbon and nitrogen SIs were determined with an elemental analyzer coupled to a continuous flow isotope ratio mass spectrometer at the Environmental Isotope Laboratory (EIL; University of Waterloo, Waterloo, ON, Canada). Analytical details from EIL were provided in Appendix A.

\subsubsection{Quality Control}

For the spatial dataset, mean deviation of duplicate SI analysis on $10 \%$ of samples was $0.12 \%$ for $\delta^{15} \mathrm{~N}$ and $0.07 \%$ for $\delta^{13} \mathrm{C}$. For the temporal dataset, mean deviation of duplicate $\delta^{13} \mathrm{C}$ analysis on $13 \%$ of samples was $0.16 \%$. Further quality control details from EIL are provided in Appendix A.

\subsubsection{Fatty Acids}

\subsubsection{Extraction}

FA analysis was performed on polar bear adipose and ringed seal blubber samples according to methods described previously $(91,118)$. In short, 10 to $20 \mathrm{mg}$ of inner adipose tissue was used to avoid potentially oxidized outer tissue (91). After spiking with 
5- $\alpha$-cholestane as IS, lipids were extracted thrice using 2:1 chloroform:methanol (129) containing $0.01 \% \quad 2,6$-di- $t$-butyl-4-methylphenol as antioxidant. The extract was evaporated to dryness under nitrogen, and lipid was re-dissolved in toluene. FAs were methylated via the Hilditch reagent (91). After addition of $2 \%$ potassium bicarbonate (aqueous) solution, the organic layer was collected and FA methyl esters (FAMEs) were completely collected by two further extractions with hexane. This extract was stored at $80^{\circ} \mathrm{C}$ until analysis.

\subsubsection{Measurement}

FAMEs were analyzed using an HP $6890 \mathrm{~N}$ GC equipped with a flame ionization detector (FID). A $100 \mathrm{~m}$ × $250 \mu \mathrm{m}$ i.d fused silica SP-2560 capillary column (biscyanopropyl, $0.2 \mu \mathrm{m}$ film thickness; Supelco (Sigma-Aldrich), St. Louis, MO, USA) was used. FAMEs were quantified against a Supelco 37 component FAME external standard (118). Details of the GC-FID conditions were provided in Table 2.6.

Identification and quantification was performed using HP ChemStation software (Hewlett-Packard). FAMEs were quantified by an internal standard method. Here, we report only on the "dietary" FAs (i.e., those that are incorporated relatively unchanged or predictably from prey to predator adipose tissues for a monogastric predator $(79,91)$ and that were available for quantification based on the external standard. Individual FAMEs were calculated as the $\%$ of total dietary FAME. 
Table 2.6. GC-FID conditions for analysis of FAMEs

\begin{tabular}{lc}
\hline & FAMEs \\
GC column length $(\mathrm{m})$ & 100 \\
Injector & split \\
Injector temp $\left({ }^{\circ} \mathrm{C}\right)$ & 260 \\
Injection volume $(\mu \mathrm{l})$ & 1 \\
Carrier gas & helium \\
Makeup gas & nitrogen \\
Detector temp $\left({ }^{\circ} \mathrm{C}\right)$ & 260 \\
GC oven temperature ramping program & -Hold at $140{ }^{\circ} \mathrm{C}, 5 \mathrm{~min}$ \\
& -Increase to $240^{\circ} \mathrm{C}$ at $4{ }^{\circ} \mathrm{C} / \mathrm{min}$ \\
\hline
\end{tabular}




\subsubsection{Quality Control}

Recovery of 5 - $\alpha$-chlolestane IS was $100 \pm 10 \%$ and $107 \pm 5 \%$ for the spatial and temporal datasets, respectively. A blank, duplicate and two reference materials, Great Lakes herring gull (Larus argentatus) egg pool and NIST Pilot Whale blubber SRM1945, were extracted with every batch of samples. The RSD of dietary FAs averaged $6 \%$ and $5 \%$ for the gull egg pool analyzed with the spatial and temporal datasets, respectively. SRM1945 dietary FA values were on average within 15\% RSD of our laboratory results from the 2007 NIST Interlaboratory Comparison Exercise Program for Organic Contaminants in Marine Mammal Tissues for both spatial and temporal datasets. Relative differences in duplicate analyses of polar bear and ringed seal samples were on average $6 \%$ and $7 \%$, respectively, for dietary FAs in the spatial dataset. The dietary FA values averaged $6 \%$ different for the polar bear duplicate analyses in the temporal trends dataset.

\subsection{Western Hudson Bay Sea Ice Breakup Analysis}

The timing of annual sea ice breakup was calculated using established methods (112, 130). Weekly sea ice data were examined (Fig. 2.2; Canadian Ice Service) in the region (Section 2.1.2) from the start of breakup until the region was ice-free (mid-June to midAugust). A grid of 128 sampling points at $0.5^{\circ}$ lat/long intervals was overlaid on the ice concentration maps for each week over this 10 week period. The sampling point average was plotted against ordinal date (e.g. $01 \mathrm{Jan}=$ ordinal date 1$)$. The date when the ice cover

in western Hudson Bay was at $50 \%(5 / 10)$ was determined by interpolation and considered the ice breakup date for that year. 

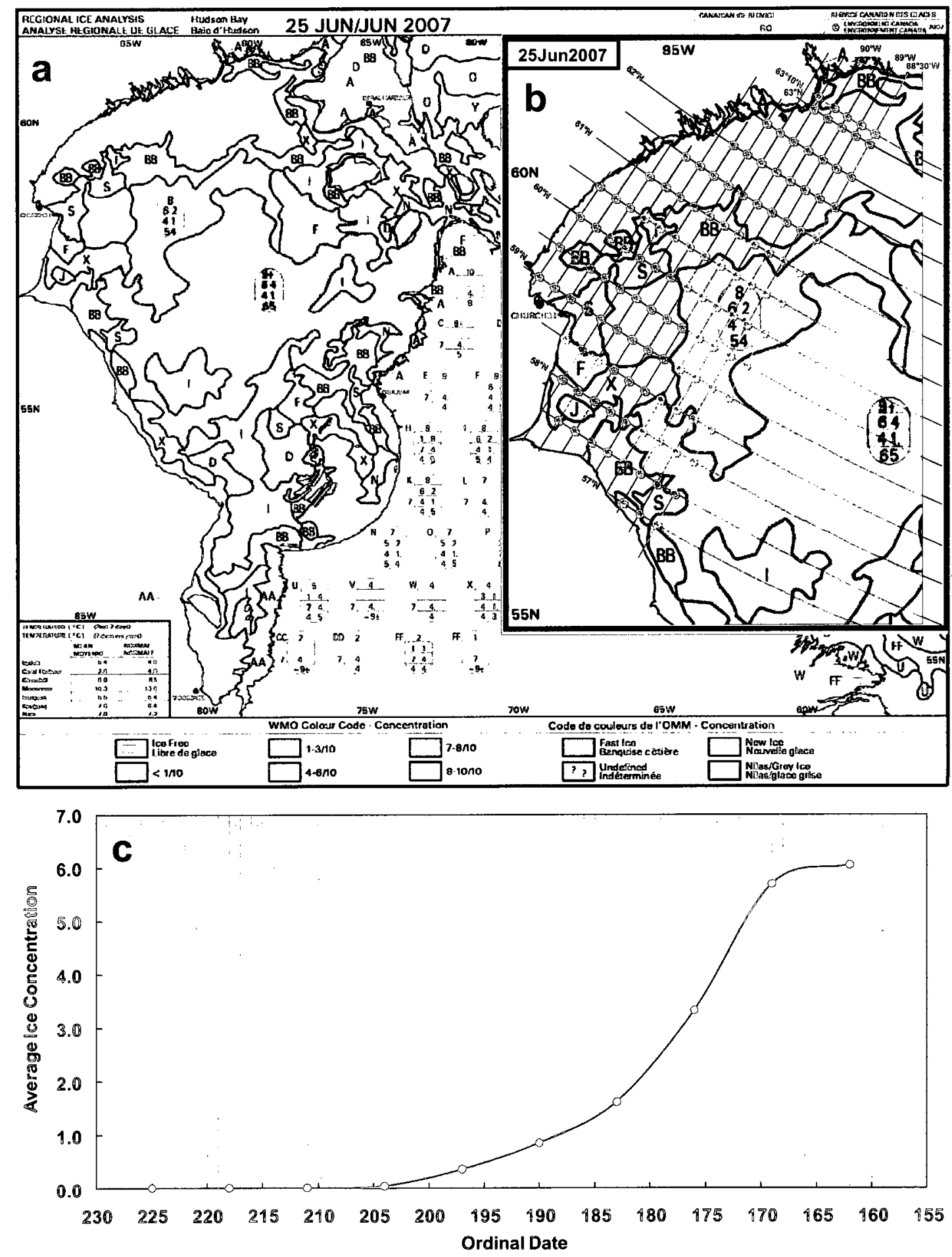

Fig. 2.2. Western Hudson Bay sea ice break-up determination for 2007. (a) Example of weekly sea ice data from the Canadian Ice Service (http://ice-glaces.ec.gc.ca), (b) with overlaid sampling grid. (c) Weekly average ice concentration versus ordinal date. 


\subsection{Biotransformation Assay}

\subsubsection{Standards and Reagents}

Dithiothreitol (DTT) and nicotinamide adenine dinucleotide phosphate (NADPH) regenerating system were purchased from Sigma-Aldrich and BD Gentest, respectively. Drs. G. Marsh and $\AA$. Bergman (Stockholm University, Sweden) generously provided OH-PBDE and MeO-PBDE standards. Water was supplied by a Milli-Q system (Millipore, San Jose, CA, USA) using a $0.22 \mu \mathrm{m}$ filter. All other reagents and solvents were of at least analytical grade purity.

\subsubsection{Microsome Preparation}

Hepatic microsome preparation has been described previously (120), except that the buffers used here had a higher DTT concentration $(10 \mathrm{mM})$ to preserve reductase and deiodinase enzyme activities (13). In brief, several grams of liver tissue were defrosted on ice. The sample was homogenized with approximately three volumes (w/v) of homogenization buffer ( $\mathrm{pH} 8.00$ ). The homogenate was centrifuged (12 $000 \mathrm{~g}, 20 \mathrm{~min}, 4$ $\left.{ }^{\circ} \mathrm{C}\right)$. The supernatant was collected and centrifuged $\left(100000 \mathrm{~g}, 60 \mathrm{~min}, 4{ }^{\circ} \mathrm{C}\right)$. The microsomal pellet was resuspended in resuspension buffer $(\mathrm{pH} 8.00)$ and washed of excess blood by re-centrifugation $\left(100000 \mathrm{~g}, 60 \mathrm{~min}, 4{ }^{\circ} \mathrm{C}\right)$. The pellet was resuspended, rehomogenized and stored at $-80^{\circ} \mathrm{C}$. 


\subsubsection{Microsomal Protein Content and Catalytic Activity}

Although catalyzed by CYP1A, 7-ethoxyresorufin- $O$-deethylase (EROD) activity was used as an overall direct microsome-associated indicator of enzymatic capacity. EROD activity and protein content were simultaneously determined using the fluorescence microplate assay of Kennedy and Jones (131), but the reaction was terminated after 2 min. Calibration curve stock standard concentrations were determined spectrophotometrically immediately prior to the assay. Bovine serum albumin was used as the protein standard. Resorufin was the standard for EROD measurements.

\subsubsection{In Vitro Biotransformation Assay Procedure}

Microsomes were incubated with either individual BFRs or a mixture of the BFRs. Without an internal standard to correct for (small) variation in spike volume, recovery and run-to-run instrument response, it may be difficult to conclusively detect slow depletion of a substrate in wildlife samples compared to controls. Therefore, we chose BDE153 as the IS to include in both the mixed and individual spiking standards, as it is monitored by isotopic $[\mathrm{Br}]^{-}$in ECNI-MS as are the other analytes, and preliminary work demonstrated negligible metabolic depletion of BDE153 under the present assay conditions. Two-tailed $t$-tests of BDE153 levels showed no statistical difference ( $p>$ 0.10) between all sample and control replicates for each individual animal. This is supported by previous in vitro oxidative biotransformation studies of BDE153 by our lab and others $(70,119,132)$, similar to studies on $\mathrm{CB} 153(119,133)$. As well, compared to 
other congeners investigated in the current study, minimal metabolism of BDE153 was observed in previous rat toxicokinetic dosing studies (134).

The standard mixture contained the BFRs: BDE99, BDE100, BDE154, BDE209 and DBDPE, as well the BDE153 IS. The original solvent (nonane for PBDEs; toluene for DBDPE) was evaporated under nitrogen flow, and the mixture was re-dissolved in acetone for a final $10 \mu \mathrm{M}$ concentration (30 pmol in the assay) for each BFR, except DBDPE which was set to $30 \mu \mathrm{M}$ (90 pmol in the assay) due to its low ECNI [Br] response. The $10 \mu \mathrm{M}$ concentration represented a compromise between being low enough to detect depletion within the short time-frame of the assay and being high enough to detect potential metabolites formed above the detection limits.

In the mixed BFR assay, possible debromination products could be masked by the presence of PBDEs of differing degrees of bromination in the original mixture and potential metabolites could not be unequivocally linked to a particular parent compound. Therefore, individual BFR standards (also containing BDE153) were prepared at the same concentrations as in the standard mixture for use in individual assays. These assays further served as replicates to confirm the depletion results from the mixed assays.

For assays using the BFR mixture, there were 4 control and 4 sample replicate tubes for individuals of each species (PB1, BW1, RS1 and RAT). For assays using the individual BFRs, there were 3 control and 3 sample replicates for all enzymatically viable specimens (i.e., including BW2 and RS2, as well). Control tubes contained the BFR spike (3 $\mu \mathrm{l})$ and buffer (80 mM NaH${ }_{2} \mathrm{PO}_{4}, 6.0 \mathrm{mM} \mathrm{MgCl}_{2}, 1.0 \mathrm{mM} \mathrm{Na}_{2}$ EDTA). Sample tubes 
were prepared similarly, but also contained $10 \mathrm{mM}$ DTT (non-native cofactor for reductases and deiodinases) and $1.6 \mathrm{mM}$ NADPH regenerating system (cofactor for oxidative CYPs). Preliminary tests on PB1 demonstrated that post-assay extracts from controls with and without cofactors showed no concentration differences, therefore cofactors were only added to the samples in subsequent assays. External standards were prepared containing the appropriate $3 \mu \mathrm{l} \mathrm{BFR} \mathrm{solution} \mathrm{in} \mathrm{order} \mathrm{to} \mathrm{monitor} \mathrm{recoveries.}$ Tubes were pre-incubated at $37^{\circ} \mathrm{C}$ for $5 \mathrm{~min}$. During this time, $1 \mathrm{ml}$ of ice-cold methanol was added to all control tubes to destroy enzyme activity upon addition of the microsomes. To start the assay, $1 \mathrm{mg}$ of microsomal protein was then added sequentially to all sample and control tubes ( $1 \mathrm{ml}$ final volume). Blanks containing only buffer and microsomes were also run, as well as a buffer blank containing buffer only. After 90 min in the shaking $(120 \mathrm{rpm}), 37^{\circ} \mathrm{C}$ water bath, $1 \mathrm{ml}$ of ice-cold methanol was added sequentially to all sample (and blank) tubes to stop the reaction.

\subsubsection{BFR Extraction}

After addition of hexane $(3 \mathrm{ml})$, tubes were mixed by vortex and centrifuged $(10 \mathrm{~min}$, $3000 \mathrm{rpm}$ ) and then the hexane layer was collected. Two further extractions with hexane were performed. Lipids were removed by treatment of the combined hexane extract with concentrated sulphuric acid, agitation, centrifugation and removal of the hexane layer. A further $3 \mathrm{ml}$ hexane rinse followed to ensure quantitative transfer of the analytes. The 
extract was evaporated and solvent-exchanged into a final $200 \mu$ l volume of 2,2,4trimethylpentane (isooctane).

After analysis of parent compound depletion and any neutral (debrominated) metabolite formation, some of the final extracts from the individual BFR assays were then derivatized to additionally investigate the possibility of oxidative metabolite formation. Treatment with diazomethane allowed for analysis of the extracts for methoxylated derivatives of any phenolic and/or phenolic debrominated metabolites (119). A separate test sample spiked with 2'-OH-2,4,4'-triBDE (2'-OH-BDE28) and 6-OH-2,2',4,4',5pentaBDE (6-OH-BDE99) and taken through the entire assay, extraction, and derivatization procedures, showed acceptable recoveries of $56 \%$ and $87 \%$, respectively.

\subsubsection{BFR Measurement}

Separation and quantification of all neutral BFR analytes followed the methods described in Section 2.2.3. Derivatized fractions were also analyzed for methoxylated BFRs under the same conditions and by monitoring $[\mathrm{Br}]^{-}$isotopes. Extracts were compared to available standards containing a suite of congeners that generally encompass the majority of known and environmentally relevant congeners, including a 49 PBDE congener plus DBDPE standard, and for derivatized phenolics, a 15 congener MeOPBDE standard. The PBDE standard contained BDEs 1, 2, 3, 10, 7, 15, 30, 17, 28, 54, 49, $71,47,66,77,100,119,99,85,155,154,153,139,140,138,156,188,184,179,183$, $182,191,180,181,190,171,170,202,201,197,203,196,205,194,195,208,207,206$, 
209 and DBDPE. The MeO-PBDE standard contained 6'-OH-BDE17, 2'-OH-BDE28, 4'OH-BDE17, 6'-OH-BDE49, 2'-OH-BDE68, 6-OH-BDE47, 3-OH-BDE47, 5-OH-BDE47, 4'-OH-BDE49，4-OH-BDE42，6-OH-BDE90，6-OH-BDE99，2-OH-BDE123，6-OHBDE85, and 6-OH-BDE137.

Based on a signal-to-noise ratio of 10 and the external standard response and correcting for non-quantitative recoveries where appropriate, the MLOQ was 0.04 to $0.09 \mathrm{nM}$ for brominated diphenyl ether compounds (from BDE99, BDE100, BDE154 and BDE209 responses) in the assay solution and $8 \mathrm{nM}$ for brominated diphenyl ethane compounds (based on DBDPE response). The MLOQ for derivatized phenolic brominated diphenyl ethers was 0.2 to $0.7 \mathrm{nM}$. In terms of metabolite formation, these MLOQ indicate that a single extractable debrominated BDE metabolite would be quantifiable if around $\geq 0.3 \%$ of the parent is converted. For debrominated BDPEs, around $\geq 9 \%$ conversion would result in a quantifiable metabolite and for phenolic BDEs around $\geq 2 \%$ conversion would be required. If two or more metabolites were formed, of course, greater conversion of the parent would be required to detect a given metabolite.

\subsubsection{Quality Control}

Recoveries were calculated by comparison of the analyte response in the controls to that in the appropriate spiked external standard. Recoveries for BDE99, BDE100, BDE154, BDE209 and DBDPE were $115 \pm 6 \%, 106 \pm 11 \%, 103 \pm 15 \%, 81 \pm 9 \%$ and 49 $\pm 23 \%$, respectively. 
The buffer blanks had trace levels of BDE47, 99 and/or 100 that were all below the MLOQ (signal-to-noise ratio of 10). Some of the microsome blanks had trace levels of BDE47, 99, 100, 153 and/or 154, but most were below the MLOQ, and the highest level $(0.12 \mathrm{nM})$ was still 260 times less than the concentration of the spike in the assay samples and controls.

\subsection{Data Analysis}

All tests were two-tailed with results considered significantly different at $p<0.05$, unless otherwise indicated. Statistical analyses were performed using Statistica (V6.0, StatSoft, 2003; Tulsa, OK, USA). In the spatial studies (Chapters 3 and 4), only individual or $\sum$-contaminants that were quantifiable in $>70 \%$ of the bears and in $>70 \%$ of the subpopulations were reported and subject to statistical analysis. In the temporal studies (Chapters 5 and 6 ), measures of central tendency were only calculated if $>70 \%$ of the values in a given year were above the MLOQ. Similarly, temporal trends were calculated only if $>70 \%$ of the values in every year were above the MLOQ. Within these subsets, concentrations $<$ MLOQ were assigned a random value between zero and onehalf the MLOQ for statistical analysis. Contaminant concentrations were $\log (x+1)$ transformed to better approximate normal distribution (Shapiro-Wilks $W$ test). 


\subsubsection{Contaminant Spatial Trends (Chapter 3)}

General linear models (GLM; type III) were used to determine the influence of sex, age and subpopulation on contaminant levels using the initial model: $\log ($ contaminant $)=$ subpopulation $+\operatorname{sex}+$ age + age $\times$ subpopulation + age $\times$ sex. The $\operatorname{sex} \times$ subpopulation term could not be tested as DS and SV comprised only males and only females, respectively. However, it was reasonable to assume that this term was negligible because this was the case in the 1989-1993 circumpolar study (26), and it was not significant in the model when DS and SV were excluded. Where age, sex, and interactions were not significant, a one-way analysis of variance (ANOVA) was used to test the reduced model, $\log ($ contaminant $)=$ subpopulation, followed by post hoc Tukey's HSD for unequal $n$.

Given significant heteroscedasticity (Browne-Forsythe test) for dieldrin and octachlorostyrene (OCS), non-parametric Kruskal-Wallis one-way ANOVA was performed followed by post hoc comparisons of mean ranks.

Ages were not determined for $6.6 \%$ of bears (4 BB, 1 DS, 1 LJS, 2 NBS, 1 SBS and 2 SHB). These missing ages were estimated using sex-specific $\sum$ CHL-age correlations generated from the entire dataset. Here and elsewhere $(26,39), \Sigma$ CHL levels varied minimally across subpopulations, such that the entire dataset could be used for imputation. Unlike other contaminants, $\Sigma$ CHL levels have also shown consistent trends with age (135). Although using the calculated values could artificially increase the correlations between $\Sigma$ CHL and age, we found no inflation of $r^{2}$-values $(0.13$ to 0.14 for males, 0.10 to 0.10 for females, respectively). To check that the age estimation procedure 
did not bias the results, we re-analyzed the dataset excluding the estimated-age bears for all contaminants. Initial GLMs for contaminants originally only significantly explained by subpopulation, also showed only subpopulation was significant when run excluding the estimated-age bears. Therefore, age was not included in the reduced models, and there was no reason to exclude the estimated-age bears. Contaminants originally explained by sex/age factors (and subpopulation, in most cases) $\left(\beta-\mathrm{HCH}, \Sigma \mathrm{CHL}, \sum \mathrm{MeSO}_{2}-\mathrm{PCB}\right.$; Section 3.2.1), were also explained by these factors in the models excluding the estimated-age bears. To ensure that the spatial results were not biased due to the presence of the estimated-age bears for these contaminants, we also re-calculated the spatial trends excluding these bears. The adjusted least-squares means (Section 3.2.1) were similar to the means including the estimated-age bears and the statistical results of betweenpopulation comparisons were identical.

As BDE47, BDE99, BDE100 and BDE153 were the only consistently detected PBDEs in the samples, we focused on these 4 congeners to ensure reliability of spatial comparisons. For $\mathrm{PCB}$ and $\mathrm{MeSO}_{2}-\mathrm{PCB}$ patterns, we focused on the 15 major congeners (or coeluting congeners) which represented $88-99 \%$ and $92-98 \%$ of $\sum \mathrm{PCB}$ and $\sum \mathrm{MeSO}_{2}-$ PCB, respectively.

Limited temporal comparisons were made between levels in the current 2005-2008 dataset and those reported across similar locations in 1989-1993 and 1996-2002 (26, 35, 37, 39). The 1989-1993 study reported adult male and female data, given sex-differences in certain contaminant levels (26). However, only adult male samples were screened for 
$\mathrm{MeSO}_{2}-\mathrm{PCBs}$ and 3-MeSO $2-p, p^{\prime}-\mathrm{DDE}$ in the 1989-1993 dataset (37). The 1996-2002 study reported female data, both adult and sub-adult (39). Age-adjusted female data were reported for a subset of contaminants to compare to the 1989-1993 study, but this adjustment resulted in only minor changes in mean levels. We compared the current 2005-2008 dataset to 1989-1993 adult females (except $\sum \mathrm{MeSO}_{2}-\mathrm{PCB}$ and 3-MeSO${ }_{2}-p, p^{\prime}-$ DDE) and 1996-2002 age-unadjusted females to maximize the breadth of contaminant temporal data. However, comparisons of all available data, including 1989-1993 males and 1996-2002 age-adjusted females were additionally provided (Appendix B). It is unlikely that quantitative temporal trends would be reliable given limited available time points, as well as inter-study biological and possible analytical variation (44). Instead, we considered qualitative consistency in patterns of temporal comparisons across subpopulations (increases/decreases) and with longer-term studies in WHB from 19681999 and/or 1991-2007 (Chapter 6 and ref 43).

\subsubsection{Relationship of Diet to Contaminant Spatial Trends (Chapter 4)}

We considered only FAs that were detected in all samples, were present in the external standard and resulted primarily or solely from dietary accumulation, i.e., the "dietary" FAs (79). These final 12 FAs, calculated as the mass \% of total dietary FAs, were linoleic acid (18:2n-6), $\gamma$-linolenic acid (18:3n-6), cis-11-eicosenoic acid (20:1n-9), $\alpha$-linolenic acid (ALA; 18:3n-3), cis-11,14-eicosadienoic acid (20:2n-6), cis-8,11,14-eicosatrienoic acid (20:3n-6), erucic acid (22:1n-9), cis-11,14,17-eicosatrienoic acid (ETA; 20:3n-3), 
arachidonic acid (ARA; 20:4n-6), cis-5,8,11,14,17-eicosapentaenoic acid (EPA; 20:5n-3), cis-7,10,13,16,19-docasapentaenoic acid (DPA; 22:5n-3) and cis-4,7,10,13,16,19docasahexaenoic acid (DHA; 22:6n-3).

Polar bear SI and FA signatures not only reflect the polar bear food web, which includes their diet (e.g., marine mammal prey species) and the lower food web (e.g., phytoplankton, zooplankton, fish species), but also region-specific baseline tracer values. Primary producer (and primary consumer) SI values, especially $\delta^{15} \mathrm{~N}$, vary across systems and over time (136). Plankton $\delta^{13} \mathrm{C}$ decreases with increasing latitude (137). Phytoplankton FA composition at the base of the food web has also shown large variation inter-annually and between organisms (138). Therefore, direct comparison of raw polar bear FA and SI (Appendix C) was not a valid indicator of polar bear food webs without considering region-specific and temporally comparable SI and FA values for an appropriate baseline organism. Since such baseline tracers were not available, we generated and/or used published region-specific SI and FA values from ringed seal collected in similar years as a pseudo-baseline. Ringed seal adjustment also normalizes any variation in tracer signatures due to variation in the phytoplankton-to-ringed seal portion of the food web. Thus, adjusted values were more representative of tracer variation due to polar bear diets and not overall food webs. We acknowledge that this is less ideal than comparisons of overall food web differences across regions in terms of understanding contaminant accumulation. We used tracer data from ringed seals collected within the region of the appropriate polar bear subpopulation or within the closest 
adjacent polar bear subpopulation region (Table 2.7), since FA signatures among Canadian Arctic ringed seals are most similar between adjacent locations (139). With the exception of SV, muscle samples were not available for $2.5 \%$ of the dataset. These missing $\delta^{15} \mathrm{~N}$ and $\delta^{13} \mathrm{C}$ values (1 BB, 1 NBS and 2 SBS bears) were estimated using subpopulation-specific means, as subpopulation membership was a better predictor of SI values than the biological variables, i.e., sex, age. Since muscle samples were not available for SV at all, this subpopulation was excluded from analyses involving SI data. Prior to comparison of polar bear FA signatures with ringed seal FA signatures, differential metabolism and deposition of individual FA in the polar bear, which result in differences between its FA signature and that of its diet, were accounted for using published calibration coefficients. To generate calibration coefficients for polar bears, previous feeding studies used mink (Mustela vison) as a model terrestrial carnivore fed a marine diet of herring supplemented with grey seal (Halichoerus grypus) oil $(79,81)$. Calibration coefficients were generated from the ratio of the individual FA abundance in the mink to that in its diet. We thus multiplied the polar bear FA abundances by the appropriate calibration coefficient and renormalized the FA to sum to unity (79).

A modified version of the standard trophic level (TL) equation was used to adjust polar bear $\delta^{15} \mathrm{~N}$ values (128). We used a trophic enrichment factor, $\Delta \delta^{15} \mathrm{~N}$, of $3.8 \%$ reported for the Lancaster/Jones Sound marine food web (82) and the tertiary consumer ringed seal to adjust for baseline variation among sites. For an individual bear from a given 
Table 2.7. SI and FA details for 2005-2008 polar bear samples from 11 subpopulations from Alaska, Canada, East Greenland and Svalbard

\begin{tabular}{lccc}
\hline \multicolumn{1}{c}{ Polar bear subpopulation } & $\begin{array}{c}\text { FA/SI } \\
\text { data }\end{array}$ & $\begin{array}{c}\text { Collection region of ringed seal } \\
\text { samples used to adjust polar bear } \\
\text { FA and SI data (listed by polar } \\
\text { bear subpopulation region) }\end{array}$ \\
\cline { 2 - 4 } for SI $\left.\boldsymbol{\delta}^{\mathbf{1 5}} \mathbf{N}^{\mathbf{1 3}} \mathbf{C}\right)$ \\
Alaska- Bering-Chukchi Sea (AL) & $\mathrm{Y} / \mathrm{Y}$ & $\mathrm{NBS}$ & $\mathrm{AL}^{\mathrm{a}}$ \\
S. Beaufort Sea (SBS) & $\mathrm{Y} / \mathrm{Y}$ & $\mathrm{NBS}$ & $\mathrm{NBS}^{\mathrm{b}}$ \\
N. Beaufort Sea (NBS) & $\mathrm{Y} / \mathrm{Y}$ & $\mathrm{NBS}$ & $\mathrm{NBS}^{\mathrm{b}}$ \\
Gulf of Boothia (GB) & $\mathrm{Y} / \mathrm{Y}$ & $\mathrm{LJS}$ & $\mathrm{LJS}^{\mathrm{b}}$ \\
Lancaster/Jones Sound (LJS) & $\mathrm{Y} / \mathrm{Y}$ & $\mathrm{LJS}$ & $\mathrm{LJS}^{\mathrm{b}}$ \\
Baffin Bay- N.E. Baffin Island (BB) & $\mathrm{Y} / \mathrm{Y}$ & $\mathrm{BB}$ & $\mathrm{BB}^{\mathrm{b}}$ \\
Davis Strait- S.E. Baffin Island (DS) & $\mathrm{Y} / \mathrm{Y}$ & $\mathrm{DS}$ & $\mathrm{DS}^{\mathrm{b}}$ \\
W. Hudson Bay (WHB) & $\mathrm{Y} / \mathrm{Y}$ & $\mathrm{WHB}$ & $\mathrm{WHB}^{\mathrm{b}}$ \\
S. Hudson Bay (SHB) & $\mathrm{Y} / \mathrm{Y}$ & $\mathrm{WHB}$ & $\mathrm{WHB}^{\mathrm{b}}$ \\
E. Greenland- Scoresby Sound (EG) & $\mathrm{Y} / \mathrm{Y}$ & $\mathrm{EG}$ & $\mathrm{EG}^{\mathrm{b}}$ \\
Svalbard- Barents Sea (SV) & $\mathrm{Y} / \mathrm{N}^{\mathrm{c}}$ & $\mathrm{EG}$ & $\mathrm{N}^{\mathrm{A}}$ \\
\hline
\end{tabular}

${ }^{a}$ Data were from ref (141), which reported $\delta^{15} \mathrm{~N}$ and $\delta^{13} \mathrm{C}$ in ringed seals from Barrow (Alaska), at which polar bears have a 50:50 chance of being from AL or SBS subpopulations $(83)$.

${ }^{\mathrm{b}}$ Data were from ref (142).

${ }^{\mathrm{c}}$ Muscle tissue was not collected for SI analysis. 
subpopulation

$$
\mathrm{TL}=4+\left[\frac{\left(\delta^{15} \mathrm{~N}_{\text {bear }}-\delta^{15} \mathrm{~N}_{\text {seal }}\right)}{3.8}\right]
$$

assuming ringed seal are at TL $=4$ and where $\delta^{15} \mathrm{~N}_{\text {seal }}$ was the mean $\delta^{15} \mathrm{~N}$ value of ringed seal collected within that polar bear subpopulation region (or adjacent region). Similarly, adjusted $\delta^{13} \mathrm{C}$ for a bear from a given subpopulation was calculated as

$$
\delta^{13} \mathrm{C}_{\text {adj }}=\delta^{13} \mathrm{C}_{\text {bear }}+\left[\delta^{13} \mathrm{C}_{\text {seal-all regions }}-\delta^{13} \mathrm{C}_{\text {seal }}\right]
$$

where $\delta^{13} \mathrm{C}_{\text {seal }}$ was the mean $\delta^{13} \mathrm{C}$ value of ringed seal collected within that polar bear

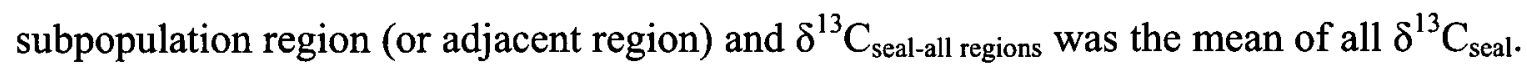
Similar to the TL calculation, this equation adjusted $\delta^{13} \mathrm{C}_{\text {bear }}$ to account for any spatial $\delta^{13} \mathrm{C}$ variation among ringed seals, and thus $\delta^{13} \mathrm{C}_{\text {adj }}$ was used to infer regional differences in polar bear feeding patterns, e.g., benthic- versus pelagic-foraging prey. For each FA, FA $_{\text {adj }}$ was similarly calculated. Based on these calculations, polar bears with exclusively ringed seal diets would occupy TL 5 . As $\Delta \delta^{13} \mathrm{C}$ is minimal within food webs $(140)$, bears feeding only on ringed seals would be expected to have a $\delta^{13} \mathrm{C}_{\text {adj }}$ nearly equal to that of ringed seal. However, we observed an increase in $\delta^{13} \mathrm{C}$ from seals to bears, likely related to the presence of non-extracted lipids in the seals (140). Thus, we could not reliably estimate a $\delta^{13} \mathrm{C}_{\mathrm{adj}}$ for polar bears feeding exclusively on ringed seal. 
Overall geographic variation in polar bear diet tracers was visualized by hierarchical cluster analysis (HCA) and discriminant function analysis (DFA) using TL, $\delta^{13} \mathrm{C}_{\text {adj }}$ and FA $_{\text {adj }}$ signatures (81). All tracer values were used in HCA as only variable means are used for each group. However, a reduced set of 6 tracers $\left(T L, \delta^{13} C_{a d j}\right.$, and the highest proportion and most variable $F_{A_{a d j}}: 18: 2 n-6,20: 1 n-9,22: 5 n-3$ and $\left.22: 6 n-3\right)$ were used in DFA so the sample number in the smallest group exceeded the number of variables $(81)$. Principal components analysis (PCA) was performed on the correlation matrix of FAadj values, as advocated for compositional data by Baxter et al. (143). The first PC (PC1), which accounted for $41 \%$ of the variation, was considered representative of the FA variation in the polar bears and the individual factor scores from this are referred to herein as the overall $F A_{a d j}-I n d e x(90)$. Subpopulation variation in $T L, \delta^{13} C_{\text {adj }}$ and $F A_{\text {adj- }}$ Index were examined to infer geographic differences in polar bear diets. A second PCA was performed on $\mathrm{TL}, \delta^{13} \mathrm{C}_{\mathrm{adj}}$ and $\mathrm{FA}_{\mathrm{adj}}$-Index to generate an overall Diet-Index (PC1, which accounted for $60 \%$ of the variation). This approach for creating an overall DietIndex using both SI and FA data was adopted from Hebert et al. (90). The influence of age, sex, subpopulation and all available first-order interactions on $\mathrm{TL}, \delta^{13} \mathrm{C}_{\mathrm{adj}}, \mathrm{FA}_{\mathrm{adj}}{ }^{-}$ Index and Diet-Index was determined by GLM (Type III). Sex $\times$ subpopulation could not be explicitly tested as only one sex was sampled in DS and SV. However, this interaction term was not significant when the model was run excluding these two subpopulations.

We studied contaminants known to be recalcitrant and to biomagnify in polar bears or their prey and thus most likely to be influenced by diet (30): $\Sigma$ PCB, $\Sigma C H L, \Sigma D D T$, 
$\sum \mathrm{PBDE}$ and the individual contaminants CB153, CB180, oxychlordane, $p, p^{\prime}-\mathrm{DDE}$, BDE47, BDE153, $\alpha-\mathrm{HCH}$ and $\beta-\mathrm{HCH}$. Detailed brominated and chlorinated contaminant concentration and pattern trends are reported separately (Chapter 3). The best subset of variables to model each contaminant was selected by Akaike's information criteria (AIC) generated from the variables: subpopulation, Diet-Index, sex, age and all first order interactions. The resulting best subset model was tested by GLM (Type III). Finally, for selected contaminants, we compared subpopulation differences in contaminant concentrations before and after adjusting for the influence of Diet-Index. Statistical differences in the adjusted least-squares subpopulation means were compared post hoc using Bonferroni correction.

\subsubsection{Relationship of Sea-Ice and Diet to Contaminant Temporal Trends (Chapter 5)}

As it is the overall pattern of FA that provides diet information (79), we performed principal components analysis on a suite of dietary FAs: 18:2n-6, 18:3n-6, ALA/18:3n-3, ETA/20:3n-3, ARA/20:4n-6, EPA/20:5n-3, DPA/22:5n-3 and DHA/22:6n-3. The factor scores along $\mathrm{PC} 1$ and $\mathrm{PC} 2$, which accounted for $51 \%$ of the total $\mathrm{FA}$ variation, were referred to as FA-Index1 and FA-Index2. These indices were considered representative of the FA variation in WHB polar bears and used in subsequent analyses.

We used simple correlation analysis to investigate the relationship of the dietary tracers $\left(\delta^{13} \mathrm{C}\right.$, FA-Index 1 and FA-Index 2$)$ to ice breakup date. However, due to the limited 
number of years of available data, we also tested these associations by performing correlation analysis on the ranked data (Appendix D).

We then determined the impact of dietary changes on the concentrations of POPs in WHB bears by comparing the annual \% change in the concentration of each contaminant before and after diet correction. Prior to these analyses, for contaminants consistently observed to differ in concentration between sexes ( $\Sigma \mathrm{PCB}, \Sigma \mathrm{CHL}, \Sigma \mathrm{DDT}$ ), data from the small number of male samples was converted to female equivalents (26). Although the use of male and female samples was unavoidable and the contaminant concentration differences between males and females were generally small both before and after sexadjustment (see Section 6.2.1), it must be noted that the possible influence of demographic variation on contaminant and dietary tracer results cannot be entirely ruled out. Annual $\%$ change controlling for diet was calculated as $\left(1-10^{b}\right) \times 100 \%$, where $b$ is the slope of the relationship between the contaminant concentration and the year from a multiple regression of the log-transformed contaminant concentration versus the dependent variables, $\delta^{13} \mathrm{C}$, FA-Index 1 , FA-Index 2 and year. Actual annual \% change (i.e. without diet correction) was calculated as $\left(1-10^{b}\right) \times 100 \%$, where $b$ is the slope of the simple regression of the log-transformed contaminant concentration versus year. To determine whether the diet-controlled versus actual annual \% change for each contaminant were significantly different, we compared the two $b$-values (slopes) using a Student's $t$-test. All tests were deemed statistically significant at $p<0.05$, marginally significant at $p<0.10$. Here, we reported only on the change in contaminant 
concentrations; actual contaminant concentrations and congener patterns were reported in Chapter 6.

\subsubsection{Relationship of Diet to Detailed Contaminant Temporal Trends and Patterns (Chapter 6)}

To minimize sex-related variation prior to statistical analyses, $\mathrm{PCB}, \mathrm{CHL}$ and DDT concentrations (which consistently vary between sexes) in males were converted to female equivalents (26).

Temporal trends were based on the analytical approach of the International Council for the Exploration of the Sea (ICES) (144) and calculated by the PIA temporal trends statistical application (A. Bignert, 2007; developed for use by AMAP; available at www.amap.no). PIA analyzes the annual index values for $(\log )$ linear and non-linear (3year running-mean smoother) trends. Medians were chosen as annual index values due to insensitivity to low numbers of extreme values and non-detects. Geometric means were additionally reported for selected contaminants for comparison to previous contaminant datasets for WHB bears. PIA also tests trends using the non-parametric Mann-Kendall test, which is less affected by endpoint values in the time series but has lower power to detect trends. Thus, trend direction was reported, and the $p$-value marked by an asterisk, only if at least a marginally significant trend $(p<0.10)$ was also indicated by the nonparametric test. Annual $\%$ change $\left(\left(1-10^{b}\right) \times 100 \%\right.$, where $b$ is the slope), $r^{2}$ and $p$-values from the linear regression portion were reported for reference even if there was no 
significant trend, a non-monotonic trend or a non-linear trend, but should not be considered meaningful in a quantitative sense.

For all contaminants, we tested whether the PIA trend results were confounded by effects of age/sex group (i.e., subadult/adult male/adult female; hereafter referred to as biological group) by analysis of covariance (ANCOVA) with year and biological group (adjusted to female equivalents for PCBs, CHLs, DDTs). For contaminants known to vary between biological groups and for those where biological group was significant in the ANCOVA, annual median values for the 2000 s years were also reported separately for each biological group and time trends were repeated on the adult female group. Time trend analyses repeated using PIA on the annual geometric mean and by simple linear regression on the individual concentration values using Statistica were consistent with the reported trends.

For contaminant classes that comprised a mixture of individual compounds, contaminant patterns were investigated using the percent $(\%)$ composition of the major individual compounds to $\sum_{15} \mathrm{PCB}, \sum_{15} \mathrm{MeSO}_{2}$-PCB, $\Sigma \mathrm{CHL}, \sum \mathrm{DDT}$ or $\sum_{4} \mathrm{PBDE}$. The $\%$ composition values were examined by PCA to determine correlations between congener proportions and to reduce congener patterns to a small number of representative variables, the significant PCs. Since most \% composition values were normally distributed, PCA is quite robust to deviations from normality (145), and to aid in subsequent interpretations, the analysis was performed on the untransformed values. The covariance matrix was used as all data were in the same units and had similar variance. 
To address possible factors contributing to variation in contaminant patterns, we performed a multiple regression of individual PC factor scores with year, biological group and the three dietary tracers $\left(\delta^{13} \mathrm{C}\right.$, FA-Index1 and FA-Index2, as per Section 2.6.3)

\subsubsection{In Vitro Biotransformation of BFRs (Chapter 7)}

Extent of depletion was reported as the fraction of the BFR remaining in the samples compared to the controls after the assay (i.e. the unmetabolized fraction), using internal standard normalization $(119,133)$

$$
\text { fraction remaining }=\frac{\text { ratio }_{\mathrm{BDE} 153}(\text { sample })}{\text { ratio }_{\mathrm{BDE} 153}(\text { control })}
$$

where ratio ${ }_{\mathrm{BDE} 153}$ is the ratio of the peak area of the BFR of interest to the peak area of the internal standard, BDE153, in a given chromatogram. This calculation thus inherently corrects for any variation in recoveries. Statistical significance of the depletion was considered by comparison of the sample and control groups using Student's $t$-test. By considering (the average unmetabolized fraction values of) all specimens as a group, the difference in the extent of depletion that occurred in the individual assay versus the mixed assay for each compound was compared using a paired $t$-test. Again considering all specimens together, differences in the extent of depletion among the different BFRs were tested using ANOVA (followed by post hoc Tukey's HSD). 


\section{Chapter 3: Flame Retardants and Legacy Contaminants in Polar Bears from Alaska, Canada, East Greenland and Svalbard, 2005-2008*}

\subsection{Introduction}

The polar bear is an important species for assessing the state of POP contamination within arctic marine ecosystems (26). Circumpolar distribution, regional subpopulations and ongoing studies securing samples from live or subsistence hunted bears makes this species ideal for studying spatiotemporal contaminant trends across the Arctic. As top trophic feeding predators of arctic and subarctic marine food webs, polar bears accumulate high levels of legacy POPs, especially PCBs and CHLs and may therefore be sensitive to potential health effects $(9,40,146)$. Given high contaminant biotransformation capacities, polar bears also have elevated tissue levels of persistent metabolites, including oxychlordane and $\mathrm{MeSO}_{2}-\mathrm{PCBs}$, relative to their prey $(23,34)$.

Previous studies of PCBs and OCPs in polar bears have been among the most extensive in spatiotemporal coverage available for any arctic species, except for the Russian subpopulations. In the first hemispheric-scale spatial comparison of selected chlorinated contaminants between subpopulations, adipose samples collected from 1989-1993 showed an increasing trend in $\sum \mathrm{PCB}, p, p^{\prime}-\mathrm{DDE}, \sum \mathrm{MeSO}_{2}-\mathrm{PCB}$ and to a lesser

*Submitted to Environ. Int., 2010. 
extent $\sum$ CHL levels going from $\mathrm{AL}$ east to $\mathrm{EG}$ and $\mathrm{SV}$ subpopulations $(26,37)$. Relatively elevated levels were also found in subarctic WHB and SHB subpopulations. Subsequently, polar bears sampled in 1987-1995 from the western Russian Arctic (Franz Josef Land and Kara Sea) had higher $\sum$ PCB levels than reported previously in other circumpolar subpopulations (36). Samples collected in 1996-2002 again showed increasing trends in PCB and DDT levels from AL east to EG and SV, but a reversed gradient for HCHs (39). For this 1996-2002 dataset, lower absolute levels but similar spatial patterns to PCBs were found for PBDEs (35). However, to our knowledge there have been few or no geographic comparisons in any arctic biota for other "new" or replacement BFRs including $\mathrm{HBCD}$, PBT, PBEB, HBB, BTBPE and DBDPE (6).

In addition to regional variation, polar bear contaminant levels are influenced by sex, age, seasonal fasting, body condition, reproductive status, biotransformation, diet and trophic level (26-30). Some of these factors confound spatial comparisons. However, consideration of ecological factors (diet, trophic level) may indicate subpopulations at greater risk from contaminant exposure than suggested by air, seawater or lower trophic level measurements alone. Furthermore, recent studies have reported changes in arctic and subarctic marine ecosystems in response to recently warming temperatures and changing sea ice conditions (e.g., Chapter 5). Continued monitoring of contaminants in circumpolar top trophic marine feeding polar bear subpopulations is important under changing conditions in the Arctic. Here, we assessed levels and patterns of several environmentally-relevant BFRs in polar bear adipose sampled from subarctic and arctic 
subpopulations spanning $189^{\circ}$ in longitude from $\mathrm{AL}$ to $\mathrm{SV}$. This assessment provided a large-scale picture of the current state of northern marine ecosystem contamination by these recent- and current-use BFRs. We also determined and compared the brominated contaminant patterns to current spatial trends of legacy chlorinated contaminants and metabolites. Further, we made two- and three-point temporal comparisons with previous assessments to understand how and suggest possible reasons why geographic variation in levels and patterns may be changing over time in arctic ecosystems.

\subsection{Results and Discussion}

\subsubsection{Influence of Biological Factors on Organohalogen Levels}

Age, sex, age $\times$ subpopulation and age $\times$ sex did not generally significantly explain contaminant level variation in the dataset. However, age and age $\times$ sex significantly explained $\beta-\mathrm{HCH}, \Sigma \mathrm{CHL}$ and $\sum \mathrm{MeSO}_{2}$-PCB levels. For these contaminants, the model was reduced to $\log ($ contaminant $)=$ subpopulation + sex + age + age $\times$ sex. Weak but significant negative correlations of $\beta-\mathrm{HCH}$ and $\sum \mathrm{MeSO}_{2}-\mathrm{PCB}$ levels with age occurred in female, but not male polar bears (Fig. 3.1). $\sum$ CHL levels were weakly but significantly negatively correlated with age in male and female polar bears (Fig. 3.1). We reported adjusted $\beta-\mathrm{HCH}, \Sigma \mathrm{CHL}$ and $\sum \mathrm{MeSO}_{2}$-PCB levels normalized to a $7 \mathrm{yr}$ old (median age) female. Declining contaminant levels with age in female polar bears is best explained by contaminant transfer to offspring through lactation. Polischuk et al. (29) found elevated milk:adipose concentration ratios $(>1)$ for $\sum \mathrm{ClBz}, \sum \mathrm{CHL}$ and $\sum \mathrm{HCH}$, implying 


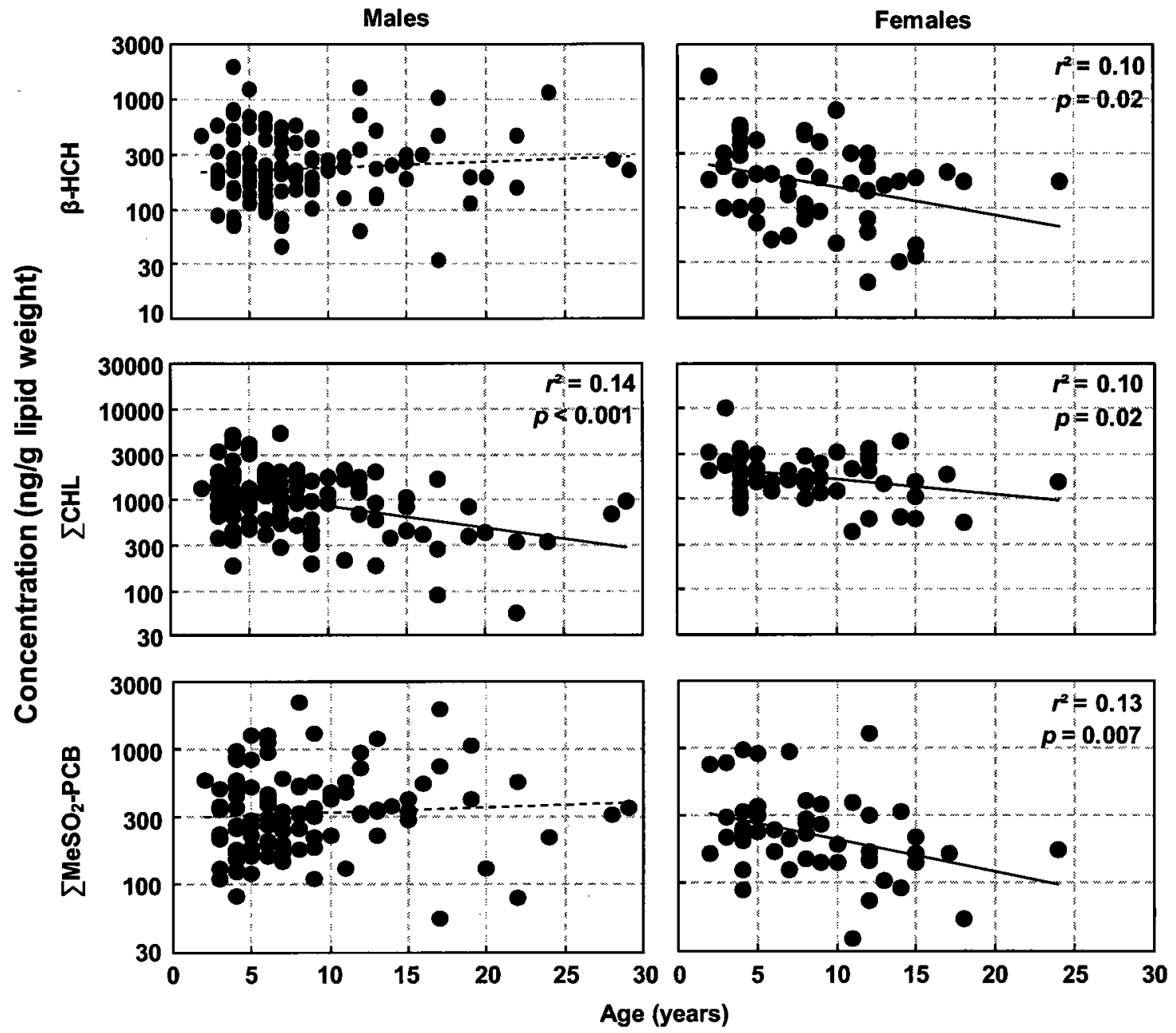

Fig. 3.1. Correlations of adipose concentrations (log-scale) of $\beta-H C H, \Sigma C H L$ and $\sum \mathrm{MeSO}_{2}-\mathrm{PCB}$ with age for male and female polar bears sampled in 11 subpopulations from 2005-2008. Solid trend lines indicate significant $(p<0.05)$ correlations. Dashed lines indicate non-significant correlations. 
preferential loss of these compounds from females through nursing. Although not investigated in that study, similarly elevated lactational transfer of $\mathrm{MeSO}_{2}-\mathrm{PCBs}$ to polar bear cubs was thus suggested from the current results. Declining male $\sum$ CHL levels with age were likely related to superior metabolism of CHLs in male polar bears, which is consistent with reports of lower CHL levels in males than females in several studies (26, $27,29,60)$. It has been proposed that adult females be used to monitor contaminants in polar bears due to a lack of age effects in this demographic group (e.g., 39). In contrast and in agreement with the current results for certain contaminants, decreasing levels of PCBs and several OCPs were recently found with age in female SBS polar bears, but only decreasing CHL levels with age in males (30).

It is unlikely that sample sizes (total $n=163$ ) were too low to detect demographic variation for contaminants with relatively small demographic differences in levels (subpopulation contaminant concentrations listed by demographic group in Appendix E). Norstrom et al. (26) found with a larger dataset ( $n=320$ adults) that although $\sum \mathrm{CHL}$ levels showed clear sex/age effects, $\sum \mathrm{PCB}, p, p^{\prime}$-DDE and dieldrin levels did not. Nonetheless, that study found higher $\sum$ PCB levels in adult males than females, which we and others $(27,30)$ did not observe. Previous reports of PBDEs in polar bears also did not find age or sex effects $(28,35)$. In addition to age and/or sex, other biological or ecological factors may have contributed to contaminant level variation. As sample collection was limited to just over half of the year, seasonal variation was likely reduced but not entirely eliminated. The influence of seasonal fasting may vary by demographic 
group (27-29) and also geographically, given spatial differences in year-round availability of sea ice on which polar bears hunt for marine mammals (59). Habitat use variation may also have influenced contaminant levels within subpopulations (75). Variation in diet or trophic level has been reported between subpopulations $(81)$.

\subsubsection{Spatial Trends in BFR Levels and Patterns}

$\sum$ PBDE and BB153/BDE154 were the highest level BFRs in all subpopulations (Table 3.1), but were around two to three orders of magnitude lower than levels of the predominant legacy contaminant class, $\sum$ PCB, consistent with earlier studies (9). Significant variation in $\sum$ PBDE levels between subpopulations showed higher levels in SHB followed by WHB, EG and SV, intermediate levels in the eastern Canadian Arctic, and lower levels in the western Canadian Arctic and AL. Subpopulation mean $\sum$ PBDE levels hence decreased with increasing longitude (i.e., east to west; $r=-0.70, p=0.02$ ). Given that the detected congeners mainly originated from pentaBDE products $(6)$, and that most pentaBDE use was in North America, higher levels in subarctic subpopulations (SHB, WHB) were likely related to closer proximity to North American source regions.

Higher levels in EG and SV may also have been related to prevailing atmospheric transport from eastern North America. Except for notably elevated SHB and WHB $\sum$ PBDE levels, spatial variation was similar to the first geographic PBDE study on polar bears sampled in 1996-2002 (35). Similar to that study, BDE47 generally predominated, ranging from $46-76 \%$ of $\sum$ PBDE (Fig. 3.2). However, proportions of 


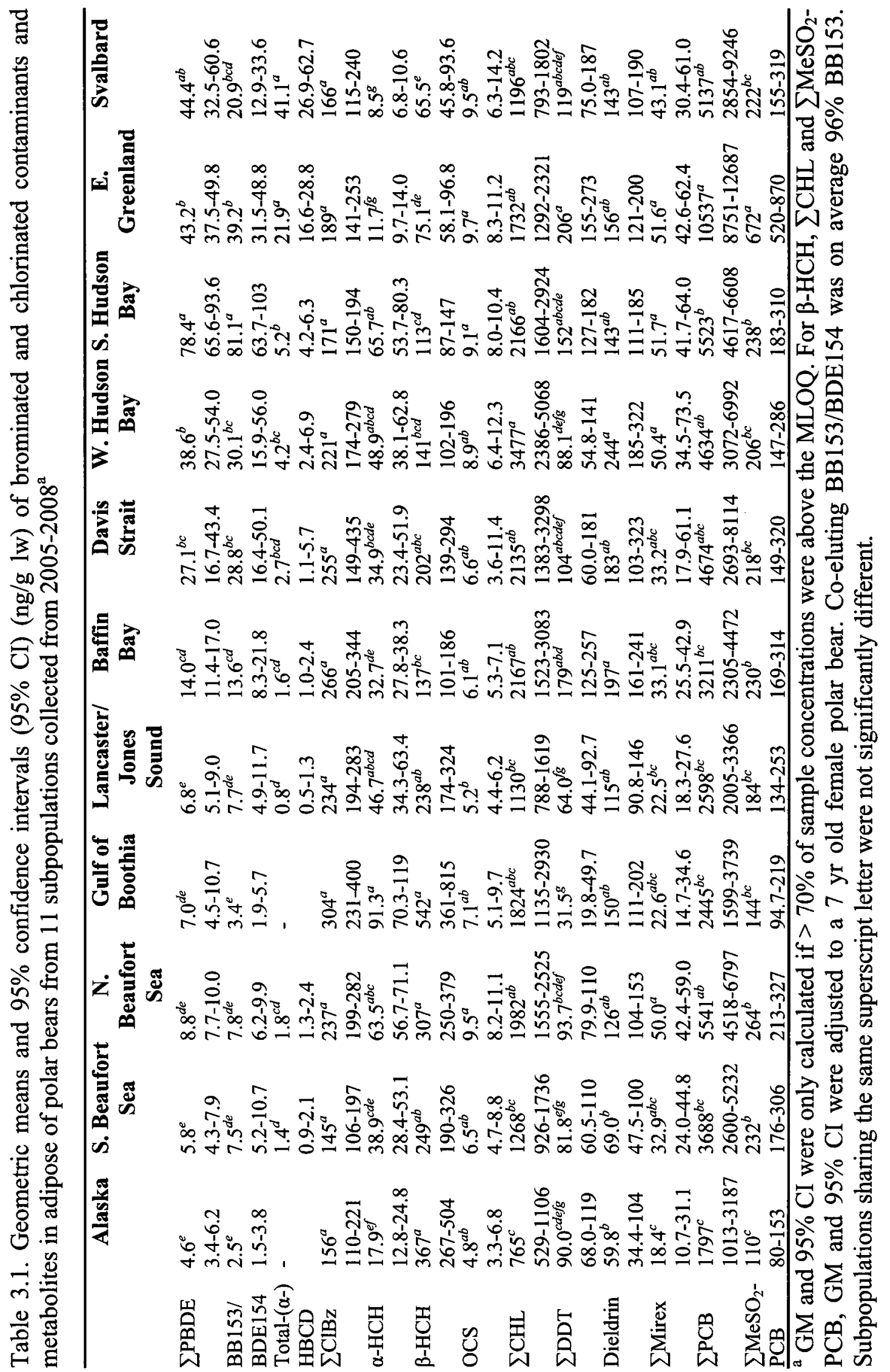


Fig. 3.2. Percent composition (+SE) of individual contaminant concentrations to $\sum$-class for major contaminant classes determined in adipose from 11 polar bear subpopulations sampled in 2005-2008 (left to right): AL, SBS, NBS, GB, LJS, BB, DS, WHB, SHB, EG and SV. $\mathrm{PCB}, \mathrm{MeSO}_{2}-\mathrm{PCB}$ and $\mathrm{PBDE}$ congener labels are further abbreviations from those listed in Table 2.5. 


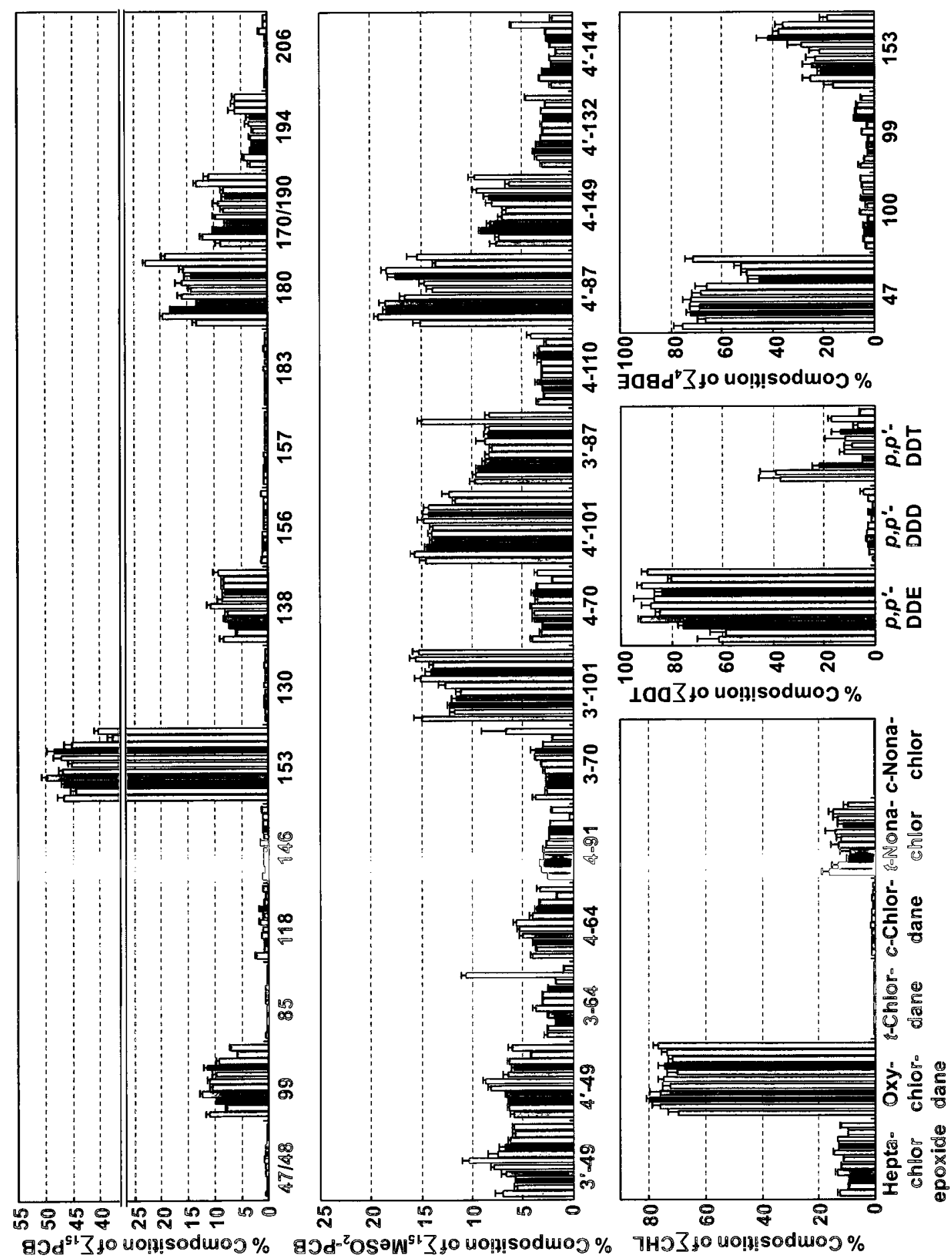


BDE153 (16-42\%) approximately doubled and proportions of BDE99 fell by around half relative to bears from the same regions in the 1996-2002 study. Like CB153, BDE153 may be a recalcitrant congener relative to other PBDEs such as BDE99. Further monitoring is necessary to confirm these temporal patterns, though; such a "weathered" or aged PBDE pattern shift was not identified in WHB polar bears sampled over 19912007 (Chapter 6). Mean BDE153 proportions were significantly negatively correlated with mean latitude $(r=-0.65, p=0.03$ ), whereas BDE47 proportions were significantly positively correlated $(r=0.64, p=0.04)$. For these two apparently more persistent congeners, proportions in polar bears reflect less discrimination of the more volatile BDE47 relative to BDE153 during long-range transport (147). Yet, the reason for higher BDE153 proportions (and lower BDE47 proportions) in the higher latitude EG subpopulation was unclear.

Several non-PBDE BFRs were also screened, but only total-( $\alpha$ )-HBCD and BB153/BDE154 were consistently detected. Total-( $\alpha$ )-HBCD was not quantifiable in > $70 \%$ of $\mathrm{AL}$ and GB polar bears. Significant level differences were observed between remaining subpopulations (Table 3.1). Highest total-( $\alpha)$-HBCD levels, comparable to $\sum$ PBDE, were found in EG and SV. Mean total-( $\alpha$ )-HBCD levels in SV were 15 to 51 times higher than in Canadian Arctic subpopulations. This finding implies large differences in source inputs between regions. These findings were consistent with much higher market demand for HBCD in Europe than in North America and Asia, versus greater use of the pentaBDE formulation in North America ( 6$)$. Total-( $\alpha)$-HBCD levels were higher in SHB and WHB than in central and western Canadian Arctic and AL 
subpopulations. However, this difference was not nearly as pronounced as for $\sum$ PBDE. Subpopulation mean levels of total-( $\alpha)$-HBCD were highly significantly negatively correlated with longitude $(r=-0.89, p=0.001)$. Separate detection and quantification of BDE154 from BB153 using [M-2Br] anions of BDE154 was possible in $24 \%$ of samples wherein these anions were above the MLOQ. We estimated that BDE154 comprised on average only $4 \%$ (range: 0.5 to $13 \%$ ) of the combined BB153/BDE154 concentration in these polar bear samples. Thus, BB153/BDE154 concentrations were a reasonable approximation of BB153 in polar bears, and implied that BB153 was at the highest concentration of any individual BFR across regions. This is an interesting finding given that HexaBB production was much lower than that of PBDE products and that HexaBB production ceased in the 1970s (148) and suggests that BB153 is highly recalcitrant. Spatial patterns in mean BB153 levels were similar to $\sum$ PBDE, significantly negatively correlated with longitude $(r=-0.60, p=0.05)$.

Other BFRs were infrequently identified ( $<14 \%$ of all samples) including PBEB, BTBPE and DBDPE (Fig. 3.3). HBB and BB101 were identified more frequently (50$60 \%$ of all samples), but at low levels ( $<3 \mathrm{ng} / \mathrm{g} \mathrm{lw}$ ). Similarly low and/or non-detectable levels of these BFRs were reported in Norwegian Arctic glaucous gull (Larus hyperboreus) plasma and eggs (149). Overall, tetra- to hexa-PBDEs (and BB153) remained the main BFRs detected across subpopulations despite their phase out and subsequent use of replacement BFRs. 


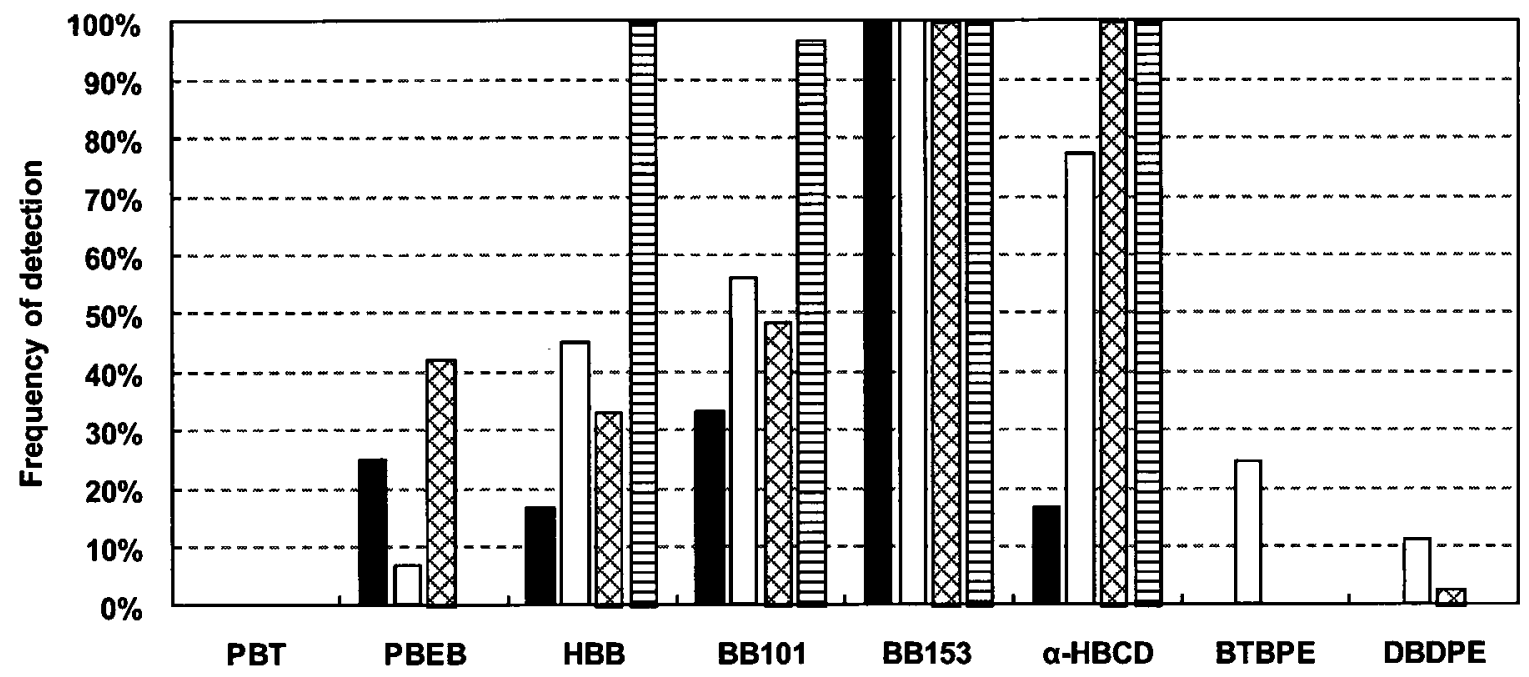

Fig. 3.3. Frequency of detection of non-PBDE BFRs in polar bear adipose in 2005-2008 from 4 regions (left to right): Alaska, the Canadian Arctic, Hudson Bay and the European Arctic. BB153 values are from detection of the coeluting BB153/BDE154, of which BB 153 contributed on average $96 \%$. 


\subsubsection{Spatial Trends in PCB and OCP Levels and Patterns}

Across subpopulations, $\Sigma$ PCB levels were highest among legacy contaminants (Table 3.1). $\sum$ PCB levels were significantly different between subpopulations, with highest levels in EG and lowest levels in AL. Non-significantly lower $\sum$ PCB levels were observed in GB, LJS and BB relative to SBS, NBS, WHB, SHB and SV. Consistent with previous studies (39), mean $\sum$ PCB levels were negatively correlated with longitude ( $r=-$ $0.62, p=0.04)$. As similar spatial differences were found for $\sum \mathrm{MeSO}_{2}-\mathrm{PCB}$ levels (longitudinal gradient: $r=-0.56, p=0.07$ ), the remaining discussion focuses on PCBs. Besides east-west variation, other geographic variation in levels and patterns occurred. Elevated $\sum$ PCB in EG relative to all other subpopulations was in agreement with the 1989-1993 study (20), but not the 1996-2002 study (39). This may be related to inter-year variation in availability of differentially-contaminated prey. For instance, within the adjacent SV subpopulation, seasonally preferential consumption of migratory and more contaminated harp seal versus ringed seal led to the hypothesis that harp seal are a vector of contaminant transport to this subpopulation (99). Breeding patches of harp and hooded seals (Cystophora cristata) are accessible to EG polar bears in March-April (R. Dietz, E. Born, personal observations). In all subpopulations, the congener contribution to $\sum$ PCB was $\mathrm{CB} 153>>\mathrm{CB} 180>\mathrm{CB} 99, \mathrm{CB} 138, \mathrm{CB} 170 / 190>\mathrm{CB} 194$, with much lower to nondetectable levels of all remaining congeners (Fig. 3.2). Higher proportions of highly chlorinated CB180 and CB170/190 and lower proportions of CB153 and CB99 in EG and to a lesser extent SV were possibly related to historic differences in PCB product use 
between lower latitude source regions (36). Similarly elevated CB180 and CB170/190 proportions and $\sum$ PCB levels were observed in SBS and NBS relative to adjacent subpopulations. It was hypothesized that such variation was related to a preponderance of more sympagic (ice-associated) versus pelagic phytoplankton and zooplankton in the lower food webs of this region (26). However, more recently it was shown that only levels of more water-associated contaminants like $\alpha-\mathrm{HCH}$ and HCB were elevated in sympagic amphipods versus pelagic zooplankton (150). Perhaps higher levels of PCBs (and proportions of highly chlorinated congeners) and other more particle-associated contaminants in Beaufort Sea subpopulations were more related to the large input of suspended particulate matter from the Mackenzie River (2). This river flows northward from regions much further south and represents by far the largest riverine input to the Arctic Ocean within the Canadian Arctic (2).

Levels of $\sum$ DDT were relatively low in all subpopulations and showed no longitudinal gradient. Yet, mean $p, p^{\prime}$-DDE levels decreased significantly with increasing longitude ( $r$ $=-0.64, p=0.04)$, similar to $\sum \mathrm{PCB}$ and likely reflected historic geographic patterns in DDT use. Elevated proportions of $p, p^{\prime}-\mathrm{DDT}$ in AL, SBS and to a lesser extent NBS (22$39 \%$ of $\left.\sum D D T\right)$ were not consistent with the 1996-2002 study. The current DDT pattern in these western subpopulations appears to reflect a substantial contribution of fresh DDT inputs. DDT was recently reintroduced for vector control in some Asian and African countries (6300 t produced in India alone in 2007) (4), which could explain elevated $p, p^{\prime}-$ DDT proportions in 2005-2007 western North American Arctic polar bears (Table 3.1). 
Nonetheless, SDDT remained at similar or lower levels in AL, SBS and NBS than in the historically more polluted EG and SV subpopulations (Table 3.1). Further monitoring of DDT levels and patterns in other Alaskan and western Canadian Arctic species should be pursued to understand whether this permitted vector control exemption under the Stockholm Convention may be changing DDT patterns and possibly levels within these remote ecosystems.

Findings of relatively spatially uniform and higher $\Sigma$ CHL levels than all other OCPs were consistent with earlier studies (39). Oxychlordane predominated $(\geq 70 \%$ in all subpopulations) even more so than in the 1996-2002 study (39), suggesting continued weathering of CHL patterns. Unlike most contaminants and consistent with the 19962002 study, mean $\sum \mathrm{HCH}$ and $\beta-\mathrm{HCH}$ levels were both strongly positively correlated with increasing longitude ( $r=0.81, p=0.002$ and $r=0.79, p=0.004$, respectively). In AL, $\sum \mathrm{HCH}$ levels approached those of $\Sigma \mathrm{CHL}$. In all subpopulations, mean $\beta-\mathrm{HCH}$ proportions to $\Sigma \mathrm{HCH}$ were higher than $\alpha-\mathrm{HCH}$, ranging from $66 \%$ to $77 \%$ in WHB and SHB to $94 \%$ in AL. Overall, these findings likely reflect greater use of technical $\mathrm{HCH}$ in Asia, increased $\alpha-\mathrm{HCH}$ levels in air with latitude, and the importance of oceanic transport, particularly for $\beta-\mathrm{HCH}$, from the North Pacific through the Bering Strait (2). $\sum \mathrm{ClBz}$, OCS, dieldrin and $\sum$ mirex levels were relatively low and spatially uniform, consistent with the 1996-2002 study. 


\subsubsection{Temporal Contaminant Comparisons}

BFRs were not assessed in the 1989-1993 study and only PBDEs were comprehensively determined in the 1996-2002 study (35). PPBDE levels were lower in 2005-2008 than in 1996-2002 for 7 of 9 subpopulations, but higher in WHB and similar in DS (Fig. 3.4). In SHB, 1996-2002 levels were unavailable. In a study on WHB polar bears from 1991-2007, ¿PBDE levels increased significantly, although levels in 2007 were lower than in 2003 (Chapter 6). Taken together, these findings suggest that $\Sigma$ PBDE levels in arctic marine ecosystems may have recently started to reflect the circa 2004 PentaBDE and OctaBDE phase-outs (6). The 1989-1993 and 1996-2002 studies did not report BB153 levels. Given comparable 2005-2008 BB153 levels to $\mathrm{PBBDE}$, lower production and earlier discontinuation of HexaBB (148), BB153 levels have likely declined only very slowly. Total-( $\alpha)$-HBCD levels were lower in 2005-2008 relative to 1996-2002 levels reported for AL, EG and SV. Apparent HBCD decreases in polar bears may reflect decreased manufacture and/or improved controls on HBCD emissions recently implemented by the bromine industry (151).

Regarding legacy contaminants, $\Sigma \mathrm{CHL}$ and $p, p^{\prime}$-DDE levels decreased consecutively from $1989-1993$ to $1996-2002$ to $2005-2008$ in most subpopulations. The $2005-2008$ levels were lower relative to $1989-1993$ levels in all subpopulations (Fig. 3.5). The only exception was $\Sigma$ CHL levels in WHB. Non-declining $\Sigma$ CHL levels in WHB were also reported in the longer-term studies, although levels may have peaked in the 1980s (ref43;

Chapter 6). Concentrations may have leveled off in this region (39); however, we 
= 응

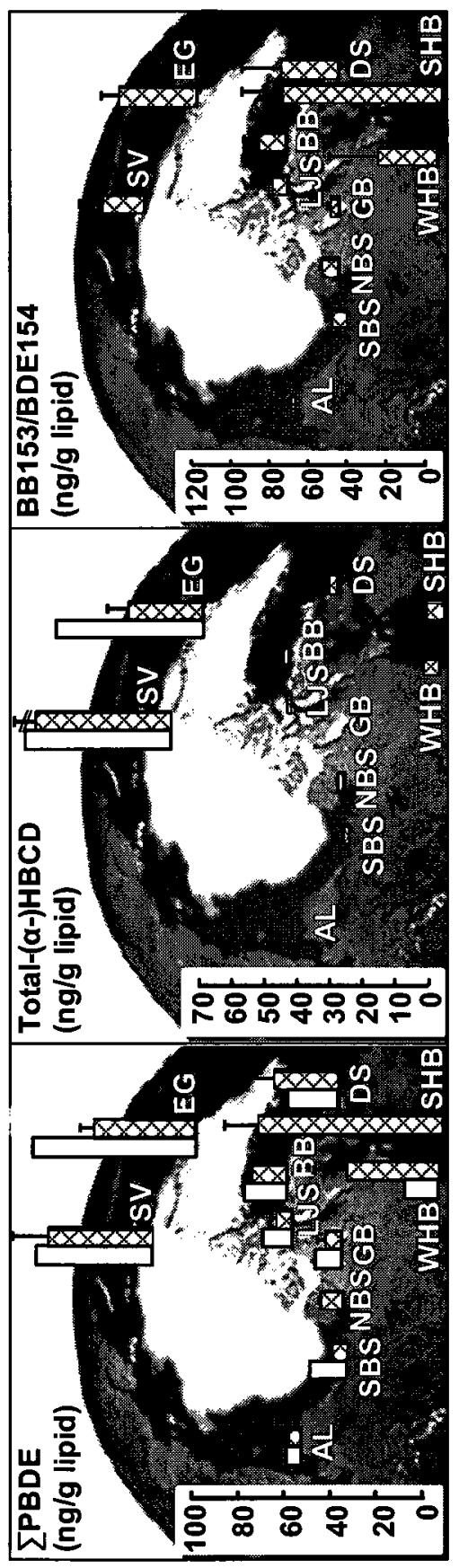

음

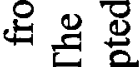

象完

ذั

文点

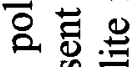

4 岕㐫

的

高鬲

\%

. 웡 명

2) 贾

品 突

.

豆

แั่

๑

잉

已苛

ลูกิ ติ

푱 용

的

ฮึ శ్

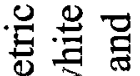

ह

¿ 는

$\exists$ ํํ

응

艺

든

전 ఫ్ 융

원

흉

की

的吾吾焉

ه 육 용 
Fig. 3.5. Temporal comparisons of legacy contaminants in 10 polar bear subpopulations collected in 1989-1993 (black bars; from 26, 37), 1996-2002 (white bars; from 39) and 2005-2008 (crosshatched bars; current study). Beaufort Sea (BS) samples were from SBS and NBS. Blank values indicated a contaminant that was not analyzed from the location/time point, with the following exceptions in which the contaminant was below the MLOQ for a majority of samples: OCS in 1996-2002 in BS, GB, LJS, BB, DS, WHB; mirex in 1996-2002 in EG; 3-MeSO $2-p, p^{\prime}-\mathrm{DDE}$ in 1996-2002 in BB, SV and in 20052008 in all except BB and SHB. 

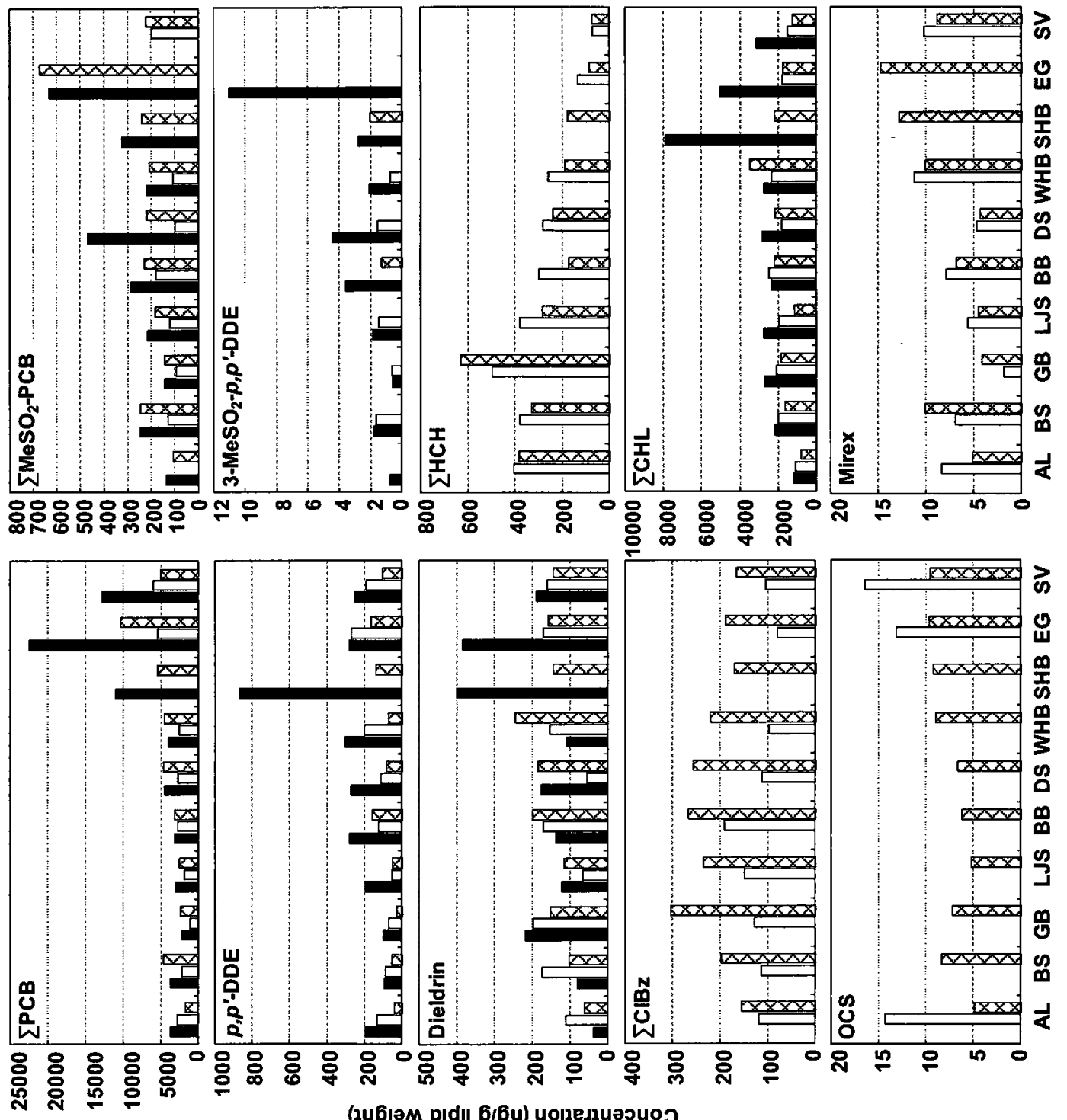

(746!̣м p!d!! 6/6u) uo!̣eมquәsuoว 
observed a nearly 4-fold drop in ECHL levels in SHB in the current 2005-2008 study relative to the 1989-1993 study. One hypothesis is that relatively stable $\Sigma$ CHL levels in WHB are more related to diet/food web changes within this region as indicated by carbon SI ratio and FA profile changes that have been correlated with sea ice changes in Hudson Bay (Chapter 5). In contrast, WHB $p, p^{\prime}$-DDE levels substantially decreased compared to temporal patterns in most subpopulations and in agreement with the 1991-2007 $\sum$ DDT (and $p, p^{\prime}$-DDE) trends (Chapter 6). This may be related to a previous local source and contrasting ecological distribution of DDT in this region relative to other contaminants (Chapter 5). Although it was difficult to compare 3- $\mathrm{MeSO}_{2}-p, p^{\prime}-\mathrm{DDE}$ trends due to missing data for some subpopulations in earlier studies and the high number of nondetects, it appeared that levels generally decreased, consistent with $p, p^{\prime}$-DDE trends.

Temporal patterns in $\sum$ PCB levels varied among subpopulations and between studies. It was previously reported that mean $\sum$ PCB levels decreased across subpopulations from 1996-2002 in comparison to 1989-1993 (39). Henriksen et al. (44) reported decreasing CB153 levels throughout the 1990s in SV. Decreasing $\sum$ PCB levels were also reported in the 1990s in WHB (43). However, when the current 2005-2008 data were compared to the 1996-2002 study, the decreasing pattern continued only in AL and SV. Similar nondeclining patterns were observed for $\sum \mathrm{MeSO}_{2}-\mathrm{PCB}$. $\sum$ PCB levels may have leveled off in the 2000 s in most subpopulations, subsequent to the declines observed in the $1990 \mathrm{~s}$. In agreement, there was no detectable (declining) trend reported in the 1991-2007 WHB study (Chapter 6). Alternatively, these discrepancies may be related to inter-year 
variability effects on such short-term, limited comparisons, or possibly to changes in trends linked to climate and/or ecological changes (Chapter 5).

Dieldrin levels were variable and showed no declines, consistent with other temporal studies $(39,43)$. The only available comparisons for $\sum \mathrm{HCH}, \Sigma \mathrm{ClBz}, \mathrm{OCS}$ and mirex were between 2005-2008 and 1996-2002. Unfortunately, previous studies found that analytical variation associated with recovery losses of relatively volatile $\alpha-\mathrm{HCH}$ and ClBzs led to erroneously lower adipose levels, confounding temporal comparisons between studies (Chapter 6). However, in the 1991-2007 WHB study the samples from all years were simultaneously analyzed and showed decreasing $\alpha-\mathrm{HCH}$ levels, increasing $\beta-\mathrm{HCH}$ levels and no change in $\sum \mathrm{ClBz}$ levels (Chapter 6). Lower OCS levels were found in 2005-2008 relative to $1996-2002$ in AL, EG and SV. For other subpopulations, OCS was largely not detected in 1996-2002, whereas OCS was detected in all 2005-2008 samples, pointing again to the difficulty of between-study comparisons. Mirex levels were lower in 6 of 9 subpopulations in 2005-2008 versus 1996-2002.

Some legacy contaminant levels appeared to decline in arctic marine ecosystems as inferred from polar bears, but this pattern was not universal. Non-declining PCB levels may be related to continued emissions from in-use materials and stored waste, despite previously declining environmental levels after product discontinuation in the 19701980s (5). Another explanation for non-declining levels may be exemptions to international regulations including the use of DDT for vector control. In addition to continuing high levels of some historic pollutants, the increasingly complex mixture of 
"new" chemicals such as BFRs implies that these organohalogen pollution issues will remain an environmental concern in arctic ecosystems in years to come. 


\title{
Chapter 4: Regional Contamination versus Regional Diet Differences:
}

\section{Understanding Geographic Variation in Brominated and Chlorinated Contaminant}

\author{
Levels in Polar Bears*
}

\subsection{Introduction}

Studies over the last decade have found associations between high levels of legacy chlorinated contaminants in certain polar bear subpopulations and biomarkers of toxic effects on, e.g., endocrine, immune and reproductive function (9). Currently, PCBs, OCPs, as well as BFRs like PBDEs, continue to be present at concentrations of concern, although levels and patterns vary widely within and among subpopulations across the circumpolar Arctic (Chapter 3). In order to improve reliability of reported contaminant trends, previous studies have considered confounding biological variation related to adipose tissue lipid content, sex, age and season $(26-28,39,44)$. Contaminant trends have additionally been discussed in relation to variation in source inputs, distances from source regions and physicochemical behaviour dictating the fate and transport of individual contaminants to and within the Arctic (Chapter 3). However, these specific biological and abiotic factors may not fully explain geographic differences in levels among subpopulations. Variation in other ecological factors like diet/food web may also

*Submitted to Environ. Sci. Technol., 2010. 
contribute to differences in contaminant levels, as has been observed within individual regions (30, 99; Chapter 5).

General information on polar bear diets from observations of prey kills has consistently shown that ringed seals are the predominant prey, followed by bearded seals $(76,77)$. Yet, polar bears are opportunistic and consumption is influenced by spatiotemporal variability in prey abundance and accessibility. Predation or scavenging on harp seals, Atlantic and Pacific walruses (Odobenus rosmarus), narwhals (Monodon monoceros), beluga, bowhead and sperm whales (Physeter macrocephalus) have also been documented $(77,83,152,153)$. Large size differences between these marine mammal prey implies that prey larger than ringed seals, but less frequently consumed, may still represent important dietary items on a biomass basis. Contaminant levels and patterns among prey species may vary due to differences in prey-specific trophic positions, fasting periods, foraging strategies, biotransformation capacities and other biological factors ( 9 , 92-94). Thus, it has been hypothesized that large-scale spatial variation in polar bear contaminant levels and patterns is, in part, affected by regional food web and/or diet differences $(26,36)$.

Previous spatial assessments of contaminant trends (including Chapter 3) in polar bears have not determined the influence of diet due to difficulties in quantifying individual diets. Nitrogen and carbon SI ratios $\left(\delta^{15} \mathrm{~N}, \delta^{13} \mathrm{C}\right)$ and FA composition, however, are increasingly used as chemical tracers of food web pathways and structure. Recently, these tracers have provided inferences regarding the time-integrated diets of individual bears $(81,83)$. Relative trophic positions of species within food webs have been estimated 
using $\delta^{15} \mathrm{~N}$, whereas nearshore/offshore, benthic/pelagic, sympagic (iceassociated)/pelagic, freshwater/marine, terrestrial/freshwater and terrestrial/marine feeding strategies have been differentiated by $\delta^{13} \mathrm{C}(82,86,88-90,94,154)$. FA signatures have also proven useful in distinguishing feeding strategies. Distinct FA signatures in several marine mammal species were recently used to estimate prey species composition in diets of Canadian polar bear subpopulations $(81,139,155)$. In the present study, we first hypothesized that polar bear diets, inferred from SI and FA signatures in bears relative to their main prey ringed seals, vary spatially in subpopulations from Alaska, Canada, East Greenland and Svalbard. Secondly, we hypothesized that diet variation contributes in part to spatial variation in chlorinated and brominated contaminant levels between subpopulations.

\subsection{Results and Discussion}

\subsubsection{Stable Isotope and Fatty Acid Signatures in Polar Bears and Ringed Seals}

Most SI and FA variation occurred between ringed seals and polar bears and also between polar bear subpopulations (Fig. 4.1). Less variation was generally observed between ringed seals from different regions. Furthermore, individual instances of more divergent ringed seal tracer values were more likely related to baseline variation between regions rather than considerably divergent ringed seal diets or lower food web structures in these regions. Specifically, ringed seals sampled within the northern Beaufort Sea (and NBS and SBS polar bears) had depleted $\delta^{13} \mathrm{C}$ signatures (Fig. 4.1a). This finding was probably related to $\delta^{13} \mathrm{C}$ depleted freshwater/terrestrial inputs into the eastern Beaufort 

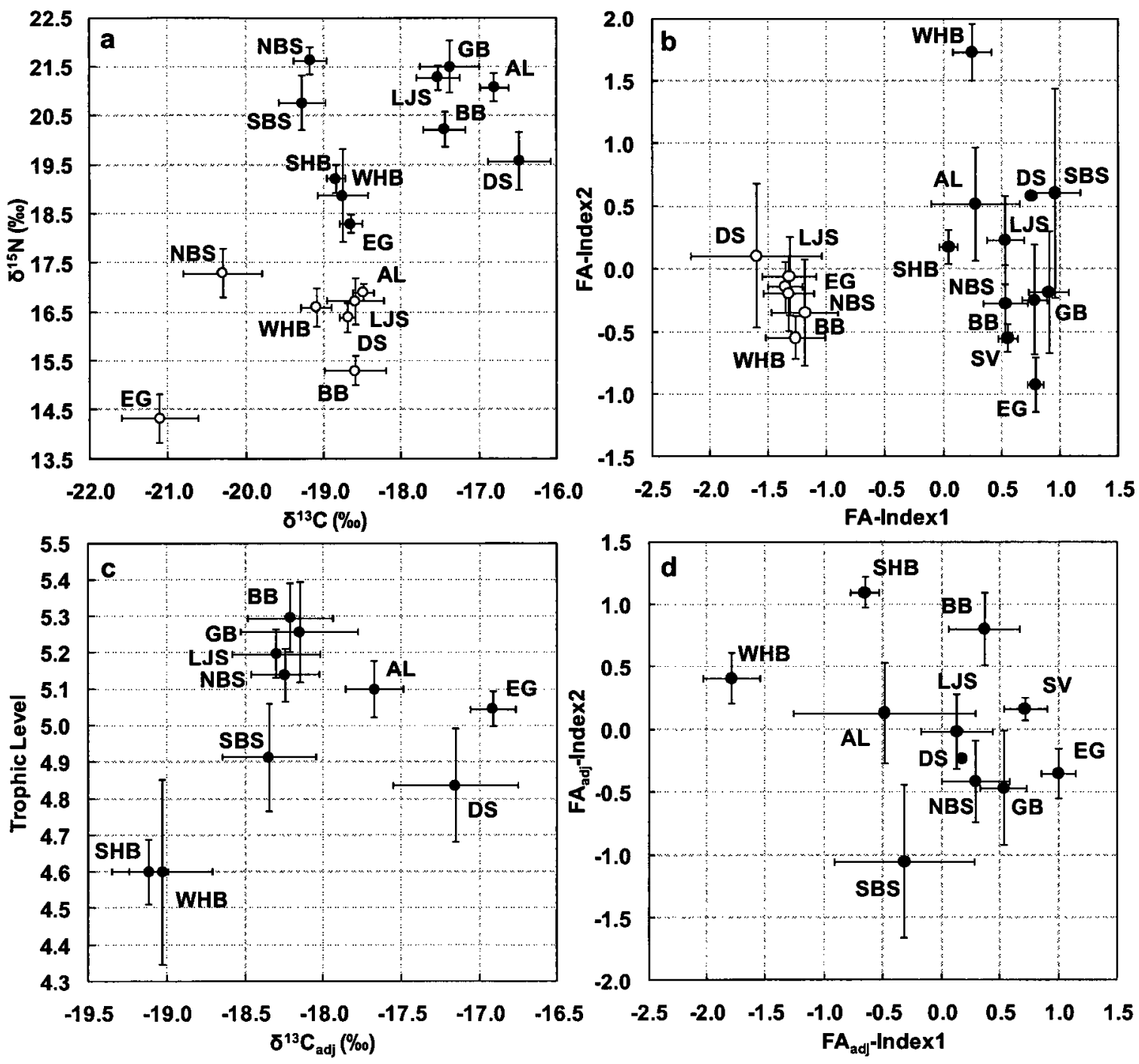

Fig. 4.1. Mean $( \pm 95 \% \mathrm{CI})$ (a) muscle SI ratios of nitrogen $\left(\delta^{15} \mathrm{~N}\right)$ versus carbon $\left(\delta^{13} \mathrm{C}\right)$ and (b) adipose FA-Index 1 versus FA-Index 2 in ringed seals $(0)$ and polar bears $(\bullet)$ sampled within 10 (11 for FA) polar bear subpopulation regions. Ringed seal SI samples were not lipid-extracted, and Alaskan and Canadian Arctic values were from refs (141, 142). (c) Adjusted mean ( $\pm 95 \% \mathrm{CI})$ trophic level versus $\delta^{13} \mathrm{C}^{\prime}$ and $(\mathrm{d}) \mathrm{FA}_{\text {adj-Index }}$

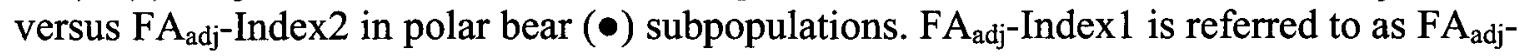
Index elsewhere and used in subsequent analyses. Error bars for DS polar bear FAIndices were omitted for clarity. 
Sea, mainly from the Mackenzie River (156). Depleted East Greenland ringed seal SI signatures were likely also related to depleted baseline values in this region $(154,156)$. These regional differences in seal SI values were not likely considerably influenced by variation in collection years, as recent sampling of ringed seals at various Canadian Arctic locations found generally low ( 1\%) inter-annual variation in $\delta^{15} \mathrm{~N}$ and $\delta^{13} \mathrm{C}$ (D. Muir, personnel communication). After considering baseline-associated variation, relatively similar ringed seal signatures across locations were consistent with previous reports of similarity among pelagic marine food webs from primary to tertiary consumers across geographically diverse arctic regions (94). These observations did not, however, imply that the ringed seal diets (or food webs from phytoplankton to ringed seal) were identical across locations, as indeed SI and FA signatures did vary regionally in ringed seals studied here and previously $(100,139,142,157,158)$. Thus, ringed seal diets likely do vary geographically, and to a lesser extent with age, sex, season and year. Overall, however, the current ringed seal and polar bear SI and FA signatures suggested that geographic variation in polar bear feeding ecology was greater than ringed seal diet and/or lower food web variation.

To compare polar bear feeding based on tracer signatures, we adjusted polar bear SI and FA values by normalization with the appropriate ringed seal data (Table 2.7). Notably, this adjustment corrected for the influence of likely baseline-associated SI variation within NBS, SBS and EG (Fig. 4.1c). Calculated mean TLs were in good agreement with previous estimates for SBS, LJS and EG polar bears using particulate 
organic matter or primary consumers for baseline adjustment $(82,83,154)$ and support our use of ringed seal as a pseudo-baseline.

\subsubsection{Geographic Variation in Polar Bear Diets}

Taken together, adjusted SI and FA signatures indicated diet differences among polar bear subpopulations. HCA and DFA showed that neighboring subpopulation dietary tracer signatures were more similar than those of geographically distant subpopulations (Fig. 4.2). On average, Subarctic WHB and SHB as well eastern Arctic DS and EG subpopulations had the most distinct signatures. Signatures were most similar among central and western Canadian Arctic subpopulations. DFA classified $79 \%$ of bears to the correct subpopulation. The only individual subpopulations in which less than $70 \%$ of bears were classified correctly were AL (67\%) and SBS (29\%), most frequently misclassified as NBS. These results were in good agreement with previous FA analyses of Canadian Arctic subpopulations (81).

TL varied significantly by polar bear subpopulation $(p<0.001)$, but not by age, sex or interaction terms $(p>0.29)$. Age (partial $\left.\eta^{2}=0.08, p<0.001\right)$ and age $\times \operatorname{sex}\left(\eta^{2}=0.03, p\right.$ $=0.04$ ) explained a significant but small amount of $\delta^{13} \mathrm{C}_{\mathrm{adj}}$ variation, whereas the effect of subpopulation predominated $\left(\eta^{2}=0.43, p<0.001\right)$. Significant but small age $\left(\eta^{2}=\right.$ 0.03, $p=0.04)$ and age $\times$ subpopulation $\left(\eta^{2}=0.14, p=0.02\right)$ effects were also found for $\mathrm{FA}_{\mathrm{adj}}$-Index, with a larger effect of subpopulation $\left(\eta^{2}=0.35, p<0.001\right)$. Taken together, these findings suggested that persistent regional diet differences were more important for SI and FA signatures than inter-annual, seasonal or demographic variation. 

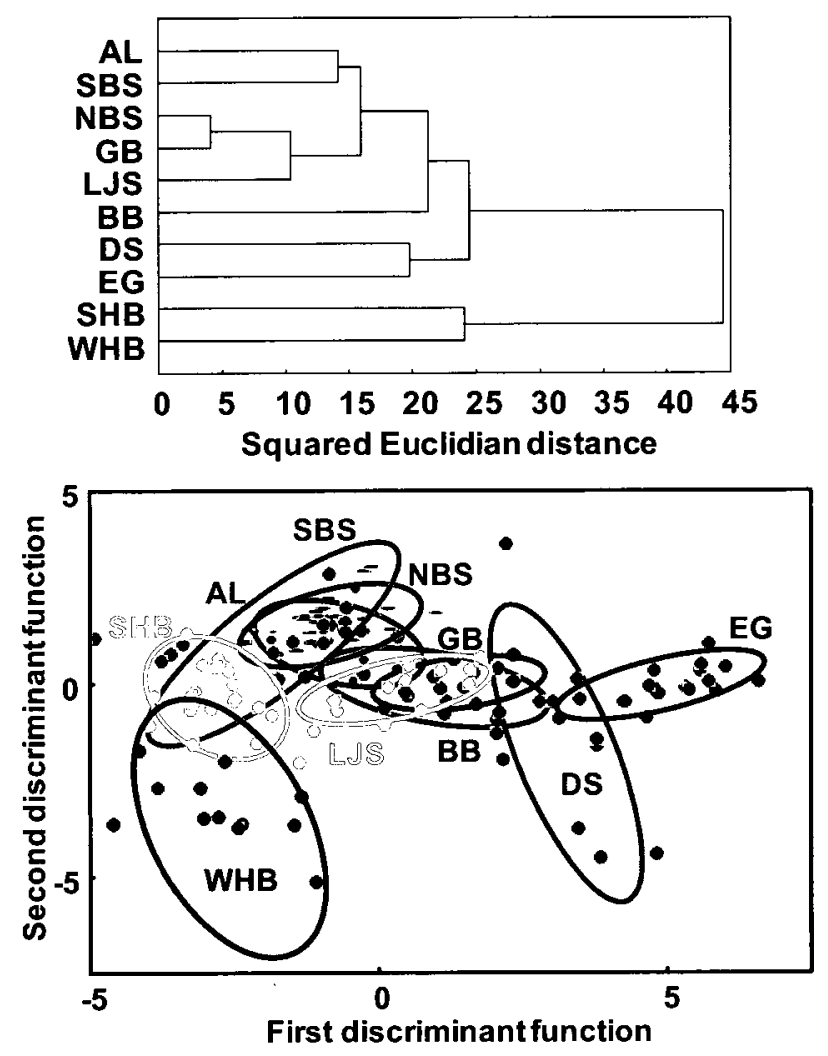

Fig. 4.2. HCA (top panel) of the standardized (mean of zero, unit variance) means of trophic level, $\delta^{13} \mathrm{C}_{\text {adj }}$ and $12 \mathrm{FA}_{\mathrm{adj}}$ in 10 polar bear subpopulations from $\mathrm{AL}$ east to $\mathrm{EG}$. Clusters were generated using the squared Euclidean distance measure and the unweighted pair-group average linkage method. DFA (bottom panel) (ellipses enclose $95 \%$ data ranges) of TL, $\delta^{13} \mathrm{C}_{\text {adj }}$ and 4 dietary $\mathrm{FA}_{\mathrm{adj}}$ in 10 polar bear subpopulations. The first two discriminant functions accounted for $81 \%$ of the total variance. Polar bears were $79 \%$ correctly classified by subpopulation. 
Individual examination of $\mathrm{TL}, \delta^{13} \mathrm{C}_{\mathrm{adj}}$ and $\mathrm{FA}_{\mathrm{adj}}$-Index provided insight into the types of feeding differences between subpopulations (Fig. 4.3). Polar bears are considered top trophic marine predators across their circumpolar distribution. In agreement, we found that subpopulation mean TLs straddled those estimated for an entirely ringed seal based diet (TL 5). Relatively narrow ranges were observed of $0.70 \mathrm{TL}$ units (or $2.66 \%$ in $\delta^{15} \mathrm{~N}$ ) and $2.20 \%$ in $\delta^{13} \mathrm{C}_{\text {adj. }}$. Yet, there were clear subpopulation differences in TL and $\delta^{13} \mathrm{C}_{\mathrm{adj}}$ and relative to a ringed seal diet (based on TL). Elevated proportions of higher TL prey (relative to ringed seal) were suggested in GB, LJS and BB (mean TLs 5.20 to 5.30). The identities of such prey were uncertain since other potential marine mammal prey species feed at TLs similar to or lower than ringed seals $(82,94)$. Elevated TLs could be related to body condition or cannibalism/scavenging on other bear carcasses. Trophic enrichment of $\delta^{15} \mathrm{~N}$ may also occur in nursing seal pups, on which polar bears feed heavily (141, 159). Elevated proportions of lower TL prey could be inferred for clearly TL depleted WHB and SHB (TL 4.60), but perhaps also in SBS and DS (TLs 4.84-4.91). This interpretation was consistent with greater availability and/or consumption of lower TL prey in the latter subpopulations, including scavenged bowhead whales in SBS and Atlantic walrus in DS $(83,155)$. Surprisingly, one third of WHB TLs were actually closer to TL 4 than 5.

SHB and WHB mean $\delta^{13} \mathrm{C}_{\mathrm{adj}}$ signatures (-19.12 to $-19.03 \%$ ) were also more depleted than other subpopulations. Since ringed seals are mainly pelagic foragers (155), the TL and $\delta^{13} \mathrm{C}_{\mathrm{adj}}$ findings together suggested elevated proportions of lower TL, more freshwater or terrestrially-associated prey in SHB and WHB bears than in other 

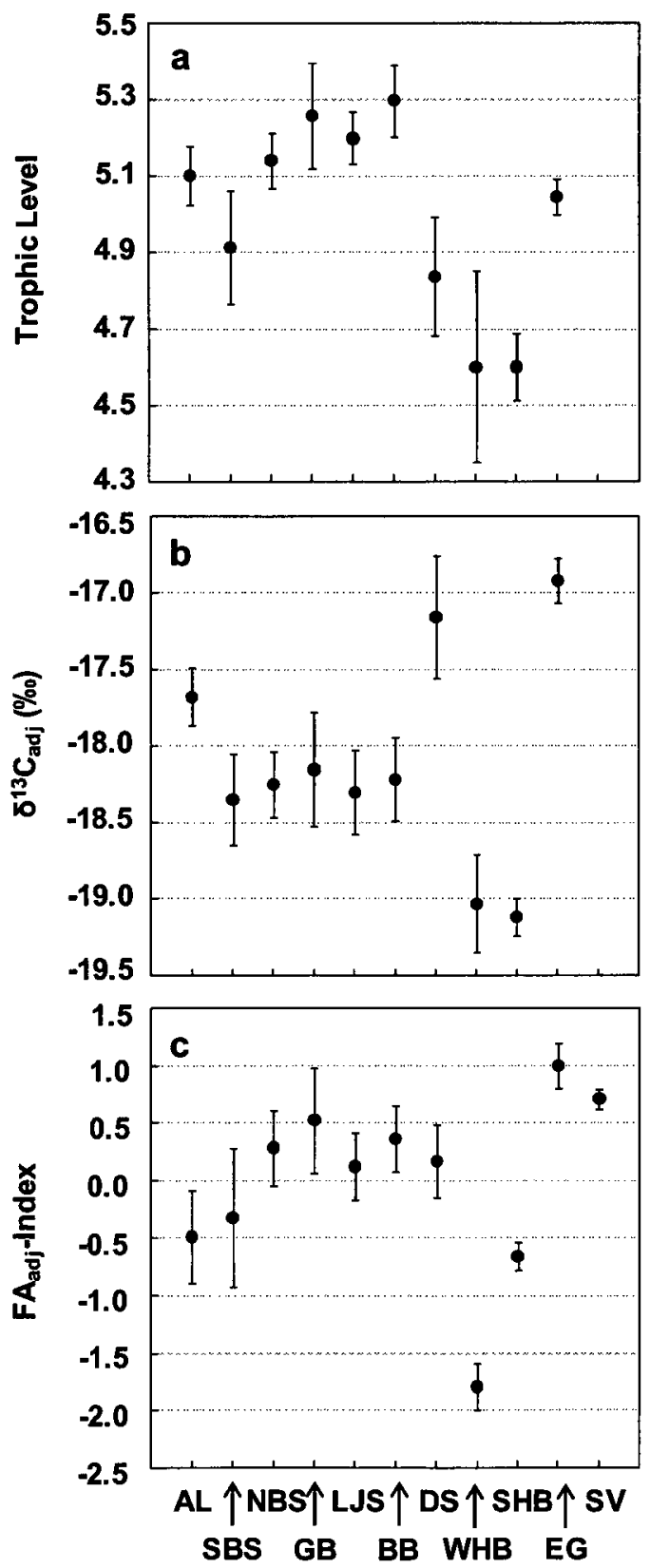

Fig. 4.3. Mean ( $\pm 95 \% \mathrm{CI}$ ) (a) trophic level (TL), (b) $\delta^{13} \mathrm{C}_{\mathrm{adj}}$ and (c) $\mathrm{FA}_{\mathrm{adj}}$-Index signatures in 11 polar bear subpopulations. TL and $\delta^{13} \mathrm{C}_{\text {adj }}$ were not available in $\mathrm{SV}$. 
subpopulations. However, significant terrestrial feeding has consistently been discounted in WHB, despite long ice-free periods in Hudson Bay during which the bears are forced on land (160). Perhaps the unknown prey were more freshwater-associated harbour seals and/or ringed seals from other regions within the ranges of these polar bear subpopulations that exploited freshwater resources to a greater extent than the ringed seal used as a reference in this study. Indeed, other studies have reported more depleted $\delta^{13} \mathrm{C}$ values in Hudson Bay ringed seals than the values we used $(158,161)$, suggesting substantial spatial or temporal variation in freshwater-associated food web inputs within Hudson Bay. It is unfortunate that Hudson Bay food web studies are lacking, especially given indirect indications of sea ice-associated ecosystem changes recently reported in this region (110; Chapter 5).

Enriched mean $\delta^{13} \mathrm{C}_{\mathrm{adj}}$ signatures in EG (-17.68\%) and DS (-17.15\%) implied higher proportions of primarily benthic foraging prey compared to other subpopulations, possibly bearded seals and/or walruses (141). SV bears had a similar diet to adjacent EG based on $\mathrm{FA}_{\mathrm{adj}}$-Index signatures and previous reports estimated $55 \%$ (biomass) bearded seal consumption in SV (77). Somewhat elevated $\delta^{13} \mathrm{C}_{\text {adj }}$ signatures in $\mathrm{AL}$ may have been related to availability of a wider variety of prey items within the Chukchi-Bering Seas; however, AL variation could have been associated with baseline differences. Our use of Barrow ringed seal to adjust AL SI signatures may not have been adequate, given spatial heterogeneity in baseline SI ratios from the Bering Sea northeast to the eastern Beaufort Sea $(83,156)$. Western and central Canadian Arctic subpopulations had similar $\delta^{13} \mathrm{C}_{\text {adj }}$ signatures. Unequivocal identification of prey items or quantification of proportional prey 
biomass was not possible from polar bear SI signatures, yet subpopulation variation likely represented substantial diet differences. For example, since bearded seal $\delta^{13} \mathrm{C}$ signatures are around $1 \%$ enriched $c f$. ringed seal $(82,141)$, the $>1 \%$ o higher $\delta^{13} \mathrm{C}_{\mathrm{adj}}$ in EG than in central Canadian Arctic subpopulations likely reflected ecologically significant feeding differences.

Mean FA $_{\text {adj }}$-Index separated polar bear subpopulations on different proportions of $\mathrm{C}_{20}$ and $\mathrm{C}_{22}$ MUFAs versus proportions of $\mathrm{C}_{18}$ and longer chain PUFAs. That is, 20:1n-9 and

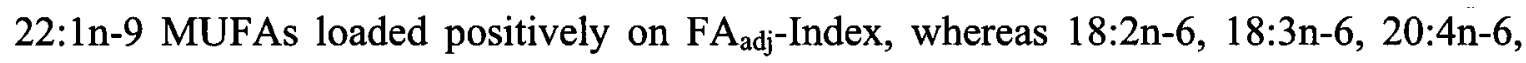
20:5n-3 and 22:5n-3 PUFAs loaded negatively (Fig. 4.3c). Higher proportions of $\mathrm{C}_{18}$ PUFAs and 20:4n-6 as well as lower proportions of $C_{20}$ and $C_{22}$ MUFAs are typical of freshwater feeding mammals compared to marine feeding mammals (e.g., 89). Consistent with $\delta^{13} \mathrm{C}_{\mathrm{adj}}$, this $\mathrm{FA}$ signature implied higher proportions of freshwater-foraging prey items from low $\mathrm{FA}_{\mathrm{adj}}$-Index values in SHB and WHB. Among marine mammals sampled in 1992-2004 and that range within Hudson Bay, lowest proportions of $20: 1 \mathrm{n}-9$ and $22: 1 n-9$ and highest proportions of $18: 2 n-6$ and $18: 3 n-6$ were found in harbour seals; yet, lower proportions of 20:1n-9 and 22:1n-9 were also found in Hudson Bay ringed seals compared to ringed seals in Canadian Arctic locations $(139,155)$. Consistent with kill observations in adjacent SV and with FA-based diet estimations in adjacent DS (77, 81), the reversed FA pattern in $\mathrm{EG}$, and to a lesser extent in $\mathrm{SV}$, may in part have reflected significant harp seal consumptions, which was not apparent from SI signatures alone. The highest proportions of $\mathrm{C}_{20}$ and $\mathrm{C}_{22}$ MUFAs have been reported for harp seals relative to other potential marine mammal prey (155). Similar to ringed seal, harp seal abundance is 
very high compared to other arctic marine mammals. However, harp seals are highly migratory and their distribution is concentrated in the North Atlantic and adjacent arctic waters including Davis Strait, Greenland Sea and Barents Sea, which overlap only the currently studied bear subpopulations of DS, EG and SV (59). Similar and intermediate

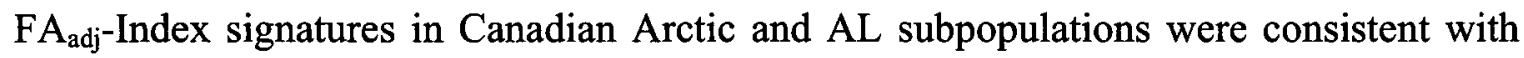
their more similar SI signatures relative to Hudson Bay and eastern arctic subpopulations. Intermediate DS FA adj-Index signatures were unexpected given varied SI signatures. These findings suggest a more varied diet in DS (consistent with ref 81 ) that on average resulted in similar FA signatures to other subpopulations.

\subsubsection{Influence of Diet on Contaminant Concentrations}

We investigated the relationship between diet and contaminant levels by combining TL, $\delta^{13} \mathrm{C}_{\mathrm{adj}}$ and $\mathrm{FA}_{\mathrm{adj}}$-Index into an overall Diet-Index (Section 2.6.2). $\mathrm{FA}_{\mathrm{adj}}$-Index was positively correlated with TL $(r=0.72, p=0.02)$ and $\delta^{13} \mathrm{C}_{\mathrm{adj}}(r=0.69, p=0.03)$ (Fig. 4.4). So, decreasing Diet-Index reflected increasing TL, $\delta^{13} C_{a d j}, C_{20}$ and $C_{22}$ MUFAs and decreasing $\mathrm{C}_{18}$ and longer chain PUFAs. Diet-Index varied significantly by polar bear subpopulation $(p<0.001)$, but not by age, sex or interaction terms $(p>0.37)$.

As hypothesized, Diet-Index significantly explained variation in polar bear contaminant levels (Table 4.1). Thus, contaminant concentrations increased with $\mathrm{TL}, \delta^{13} \mathrm{C}_{\mathrm{adj}}$ and proportions of $\mathrm{C}_{20}$ and $\mathrm{C}_{22}$ MUFAs and decreased with proportions of $\mathrm{C}_{18}$ and longer chain PUFAs. Considering all variables, effect sizes were largest for subpopulation, 


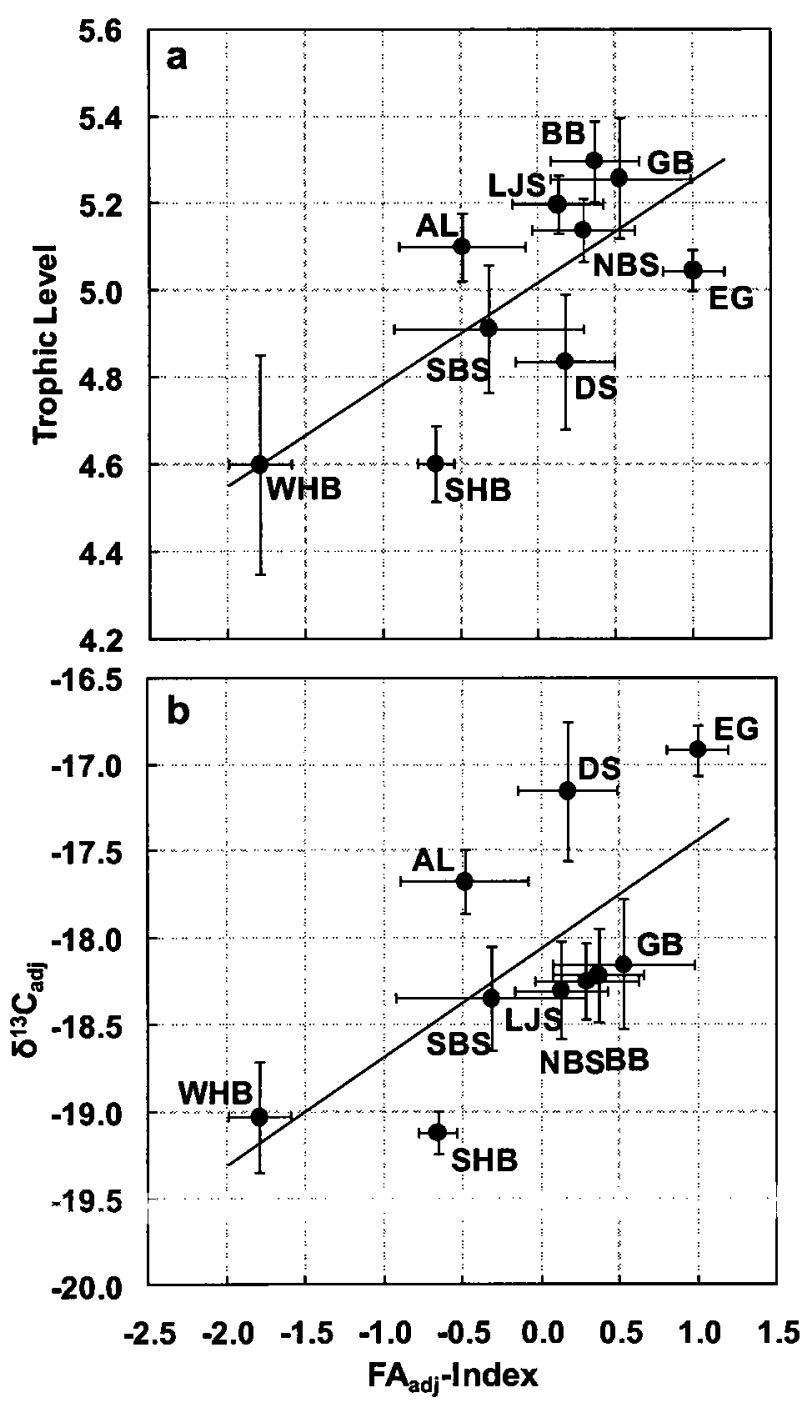

Fig. 4.4. Mean ( $\pm 95 \% \mathrm{CI})$ (a) trophic level and (b) carbon stable isotope ratios $\left(\delta^{13} \mathrm{C}_{\text {adj }}\right)$ versus $\mathrm{FA}_{\text {adj-Index in }} 10$ polar bear subpopulations from AL east to EG. 
Table 4.1. GLM results testing subpopulation, Diet-Index and demographic effects on brominated and chlorinated contaminant concentrations in polar bear adipose from 10 subpopulations from Alaska, Canada and East Greenland ${ }^{\mathrm{a}}$

\begin{tabular}{|c|c|c|c|c|c|}
\hline \multirow[t]{2}{*}{ Contaminant $^{b}$} & \multirow{2}{*}{$\begin{array}{c}\text { Whole } \\
\text { model } r^{2}, p\end{array}$} & \multicolumn{4}{|c|}{$\begin{array}{c}\text { Independent variables } \\
\text { partial } \eta^{2}, p\end{array}$} \\
\hline & & Subpopulation & Diet-Index & Age & Sex $\times$ age \\
\hline$\sum \mathrm{PCB}$ & $0.52,<0.001$ & $0.49,<0.001$ & $0.21,<0.001$ & - & - \\
\hline CB153 & $0.45,<0.001$ & $0.42,<0.001$ & $0.18,<0.001$ & - & - \\
\hline CB180 & $0.57,<0.001$ & $0.53,<0.001$ & $0.18,<0.001$ & - & $0.04,0.02$ \\
\hline$\sum \mathrm{CHL}$ & $0.48,<0.001$ & $0.31,<0.001$ & $0.06,0.003$ & $0.24,<0.001$ & $0.24,<0.001$ \\
\hline Oxychlordane & $0.51,<0.001$ & $0.30,<0.001$ & $0.05,0.01$ & $0.29,<0.001$ & $0.28,<0.001$ \\
\hline$\sum \mathrm{DDT}$ & $0.40,<0.001$ & $0.39,<0.001$ & $0.04,0.01$ & - & - \\
\hline$p, p^{\prime}-\mathrm{DDE}$ & $0.41,<0.001$ & $0.41,<0.001$ & - & - & - \\
\hline$\sum \mathrm{PBDE}$ & $0.85,<0.001$ & $0.84,<0.001$ & $0.15,<0.001$ & $0.04,0.02$ & - \\
\hline BDE47 & $0.77,<0.001$ & $0.77,<0.001$ & - & $0.04,0.02$ & - \\
\hline BDE153 & $0.81,<0.001$ & $0.79,<0.001$ & $0.14,<0.001$ & - & - \\
\hline$\beta-\mathrm{HCH}$ & $0.60,<0.001$ & $0.58,<0.001$ & $0.10,<0.001$ & $0.08,<0.001$ & $0.08,<0.001$ \\
\hline$\alpha-\mathrm{HCH}$ & $0.64,<0.001$ & $0.63,<0.001$ & - & - & - \\
\hline \multicolumn{6}{|c|}{$\begin{array}{l}{ }^{a} \text { For each contaminant, the best subset from the possible variables subpopulation, sex, } \\
\text { age, Diet-Index and all testable first-order interactions was selected for inclusion in the } \\
\text { model using the lowest AIC value. } \\
\text { mo } \\
{ }^{b} \text { Considered as } \log (x+1) \text {-transformed lw concentrations. } \\
\text { Partial } \eta^{2}\left(\mathrm{SS}_{\text {effect }} / \mathrm{SS}_{\text {effect }}+\mathrm{SS}_{\text {error }}\right) \text { is a measure of the effect size for each independent } \\
\text { variable. Blank cells indicated variables not selected by AIC or not significant in the } \\
\text { GLM }(p>0.05) \text {. }\end{array}$} \\
\hline
\end{tabular}


followed by Diet-Index. Age and sex $\times$ age effects were low or non-significant, except for $\sum \mathrm{CHL}$ and oxychlordane levels (discussed in Chapter 3). Additionally, measurements of rump fat thickness as an indicator of body condition were collected for $29 \%$ of bears, but within this sample subset did not significantly explain contaminant concentrations. The effect of Diet-Index was largest for PCBs, accounting by itself for $21 \%, 18 \%$ and $18 \%$ of the overall variance in $\sum \mathrm{PCB}, \mathrm{CB} 153$ and $\mathrm{CB} 180$ concentrations, respectively (Table 4.1, Fig. 4.5). Levels of $\sum$ PBDE and BDE153 (but not BDE47) were also significantly explained by Diet-Index (14-15\%), but not as strongly as for PCBs. Although Diet-Index explained $10 \%$ of variation in $\beta-\mathrm{HCH}$ levels, the effect was low or non-significant $(\leq 6 \%)$ for all other OCPs. Similarly the relative effect of $T L\left(\delta^{15} \mathrm{~N}\right)$ on chlorinated contaminant level variation among SBS bears was found to be highest for PCBs and low or nonsignificant for $\mathrm{CHL}, \mathrm{HCH}$ and DDT compounds (30). Differences in Diet-Index effects for individual contaminant (e.g., significant for $\beta-\mathrm{HCH}$ but not $\alpha-\mathrm{HCH}$ and significant for BDE153 but not BDE47) implicates diet as a factor in contaminant patterns as well. Sea ice-associated diet change in WHB bears from 1991-2007 similarly had a higher impact on $\sum \mathrm{PCB}$ and $\sum \mathrm{PBDE}$ than on $\sum \mathrm{CHL}, \alpha-\mathrm{HCH}$ and $\beta-\mathrm{HCH}$ levels (Chapter 5).

As a marine-feeding but terrestrial mammal, polar bears are uniquely efficient at metabolizing certain contaminants which are recalcitrant in marine mammals and seabirds (23). Although exposure to different contaminant levels and patterns may result from diet, exceptional biotransformation abilities may mitigate the influence of diet on levels of less recalcitrant OCPs in polar bears (30). Therefore, for certain contaminants, 


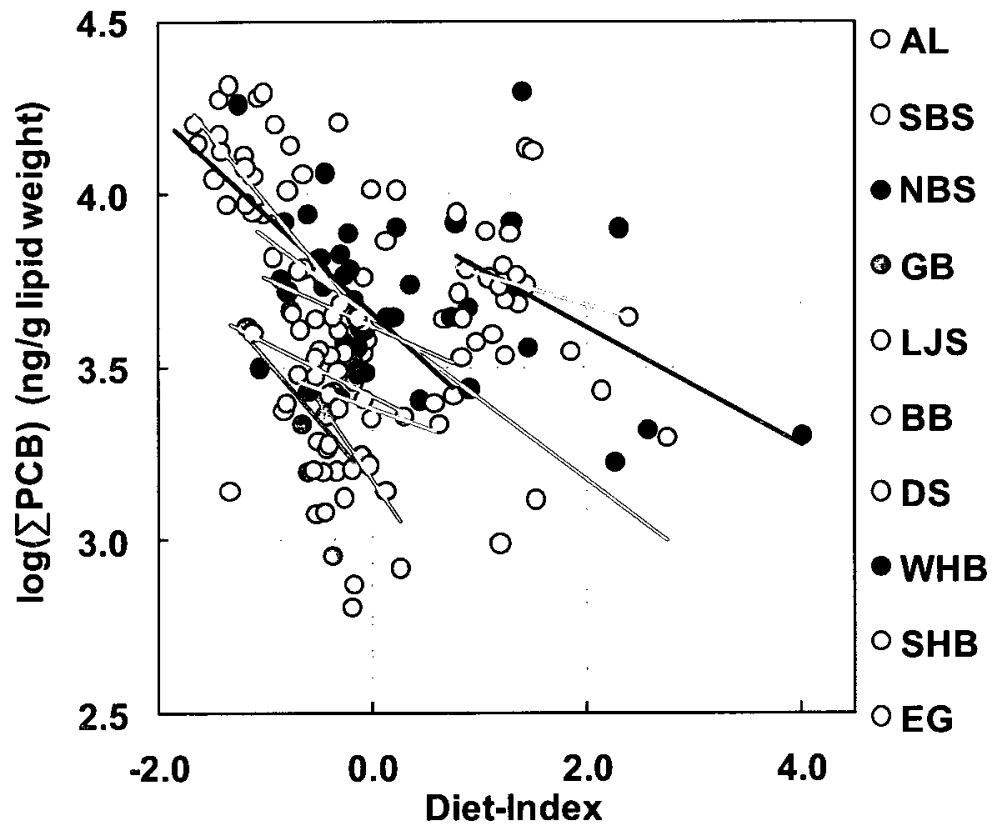

Fig. 4.5. Relationship of adipose $\sum$ PCB levels and Diet-Index in polar bears from 20052008 in 10 subpopulations from $\mathrm{AL}$ east to EG. 
polar bear burdens may not fully describe a spatiotemporally variable relationship between food web structure and arctic marine food web contamination. Contaminant studies within changing arctic ecosystems should consider the idiosyncratic nature of monitoring individual species, and would likely benefit from adopting a more holistic food web approach.

\subsubsection{Influence of Diet on Geographic Contaminant Trends}

To investigate the effect of diet variation on geographic contaminant trends in polar bears, we calculated subpopulation contaminant levels adjusting for Diet-Index (adjusted to mean of zero) and compared the levels to those we reported previously (Chapter 3). Here, we focused on $\Sigma \mathrm{PCB}$ and $\sum \mathrm{PBDE}$, since these contaminants were most strongly associated with Diet-Index and would thus best capture the influence of geographic variation in diet. Not surprisingly, Diet-Index adjustment had the largest effects on EG, SHB and WHB levels (Fig. 4.6), as these subpopulations had the most divergent SI and FA signatures. Prior to adjustment, EG polar bears had the highest $\sum$ PCB concentrations and WHB and SHB bears had intermediate $\Sigma$ PCB concentrations. After adjustment, $\sum$ PCB levels were $76 \%$ lower in EG and $137 \%$ and $91 \%$ higher in WHB and SHB bears, respectively, resulting in higher levels in WHB and SHB relative to other subpopulations $(p<0.001)$ except EG ( $p=0.03$ and 0.02 , respectively). $\sum$ PBDE levels were higher in EG, WHB and particularly SHB relative to most other subpopulations prior to diet adjustment. After adjustment, $\sum$ PBDE levels were $76 \%$ and $57 \%$ higher in WHB and 

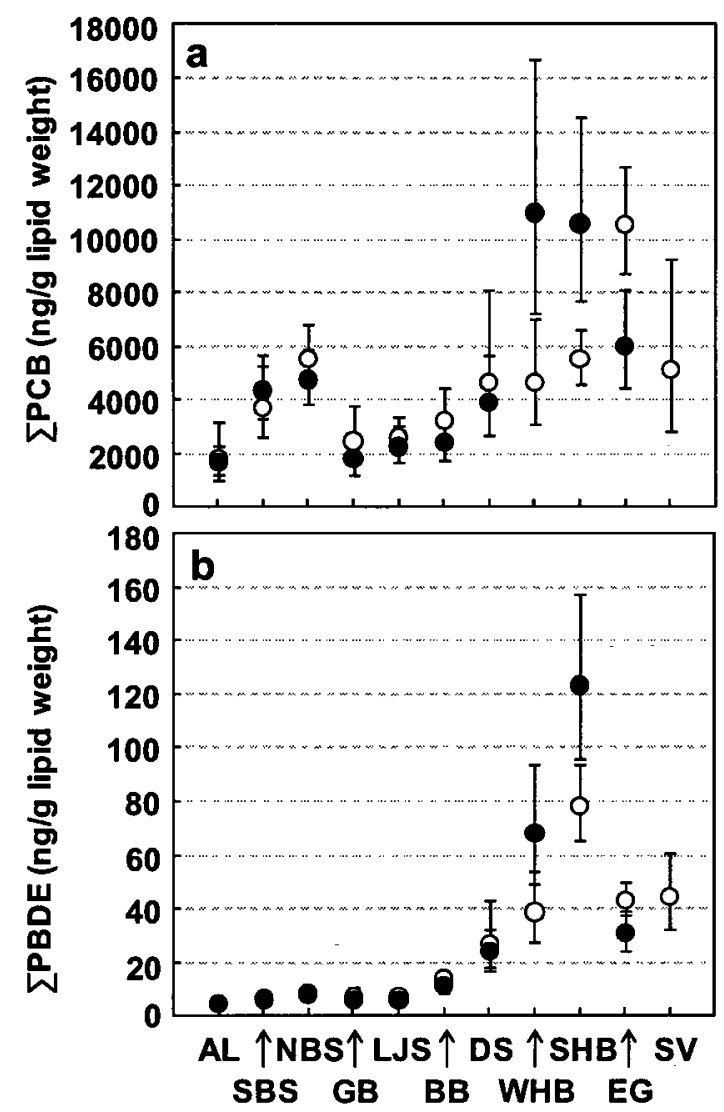

Fig. 4.6. Mean $\left( \pm 95 \%\right.$ CI) (a) $\sum$ PCB and (b) $\sum$ PBDE levels before ( $\circ$ ) and after ( $\bullet$ ) adjusting for the influence of Diet-Index in 11 polar bear subpopulations from AL east to SV. Adjusted levels were not available for SV. 
SHB, respectively, and $40 \%$ lower in EG bears. That is, diet-controlled $\sum$ PBDE levels were statistically higher in WHB and SHB than in all other subpopulations including EG $(p<0.001)$. Diet effects could not be quantified in SV bears in the absence of SI values. However, their Diet-Index may be similar to EG based on FAadj-Index values. Thus, dietadjusted $\sum$ PCB and $\sum$ PBDE levels in SV bears are hypothesized to also be lower, although perhaps less so than in EG bears. These results provide the first preliminary evidence that, relative to circumpolar subpopulations excluding SHB and WHB, higher PCB contamination in EG and SV subpopulations are influenced not just by proximity to sources but also by diet differences, as was previously hypothesized elsewhere (74). Based on the $\mathrm{FA}_{\mathrm{adj}}$-Index, this finding may be partly related to consumption of harp seals, and although only suggestive, is consistent with the hypothesis that harp seals are a vector for transport of contaminants to these polar bear subpopulations (99). More research into eastern Canadian Arctic, Greenland and Svalbard polar bear reliance on very (seasonally) abundant harp seal populations and the potential impact on contaminant exposure appears to be warranted.

In contrast to EG bears, diet may actually have reduced contaminant exposure for SHB and particularly WHB polar bears relative to other subpopulations, as adjusting for diet showed higher levels (Fig. 4.6). We hypothesized that the currently divergent dietary tracer signature in WHB bears compared to other subpopulations (except SHB) could be a result of recent sea ice-associated dietary and/or food web changes we previously reported (Chapter 5). To test this hypothesis we compared, by PCA, dietary FAs from the various subpopulations (muscle SI values were not available in the WHB study) to those 
in 1991-2007 in WHB (Fig. 4.7). There were clear inter-year differences in WHB FA signatures. However, in all years, WHB was distinguished from the other subpopulations. Separation along the first PC was, similar to previously, between $20: 1 \mathrm{n}-9$ and $22: \ln -9$ loading positively and $18: 2 n-6,18: 3 n-6,20: 5 n-3$ and $22: 5 n-3$ loading negatively. Thus, currently divergent WHB FA signatures $c f$. other subpopulations were not simply due to recent changes. Continued monitoring of dietary tracers in these apex arctic predators would contribute to understanding spatiotemporal variation in arctic marine food web structure and how it influences contaminant levels and patterns.

In this study, we were unable to factor the influence of overall food web differences on polar bear contaminant concentrations across subpopulations, due to lack of spatially and temporally comparable baseline SI and FA values. Although spatial variation in baseline SI values has been "mapped" over limited arctic marine regions (156), there is no overall characterization for the Arctic or a complete understanding of why such variation occurs, e.g. nutrient variation, growth rates, freshwater inputs, etc. (156). From a contaminant perspective, Hudson Bay appears to be most influenced by dietary factors, and would thus be an ideal arctic/subarctic marine ecosystem to "map" the lower food web using chemical tracers and thus better understand the overall food web influence on contaminant levels in polar bears. Application of these chemical tracers to the study of geographic and temporal variation in marine food webs and contaminant pathways remains a challenge and greater food web research is necessary, particular under changing temperatures, sea ice conditions and ecosystem structures in the Arctic (110). 


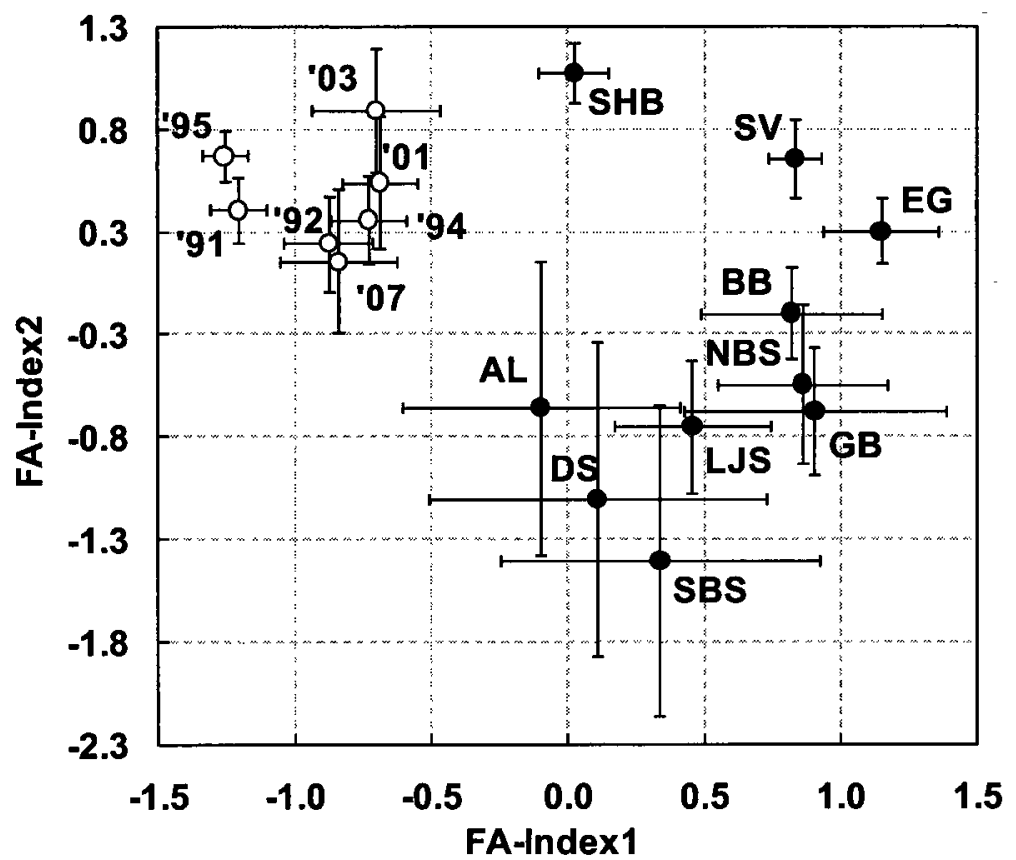

Fig. 4.7. Mean $( \pm 95 \% \mathrm{CI}) \mathrm{FA}-$ Index1 and FA-Index2 values (PC1 and PC2) for 20052008 polar bear adipose from 11 subpopulations from AL east to SV $(\bullet)$ and for 19912007 from the WHB subpopulation (0). For WHB, the year of sample collection is indicated is abbreviated as, e.g., ' $95=1995$. 


\section{Chapter 5: Sea Ice-associated Diet Change Increases the Levels of Chlorinated and Brominated Contaminants in Polar Bears*}

\subsection{Introduction}

There is an established link between recent climate change and phenological, geographical and compositional changes to ecosystems across many regions of the world $(162,163)$. The magnitude of warming is regionally variable, though, and is nearly twice the global average in the Arctic $(164,165)$. There are reports of recent and drastic climate-related shifts in the composition of arctic and subarctic marine ecosystems. In northern Hudson Bay, there has been an increase in subarctic fish relative to arctic fish (as measured by the diet of thick-billed murre (Uria lomvia)) with decreasing July ice cover from 1980 to 2002 (110). Reduced sea ice, along with warmer air and ocean temperatures, has shifted the previously benthic-dominated Northern Bering Sea ecosystem to a more pelagic, Southern Bering Sea-type (subarctic) ecosystem (111).

Environmental contamination by POPs is also a major concern for northern ecosystems, despite substantial distances from source regions further south $(147,166)$. Contamination of subarctic and arctic regions by POPs occurs mainly through long-range transport from

\footnotetext{
*Reproduced with permission from McKinney, M.A., Peacock, E., Letcher, R.J. Environ. Sci. Technol. 2009, 43, 4334-4339. Copyright 2009 American Chemical Society.
} 
lower latitudes (2). PCBs as well as OCPs including DDT, HCH and CHL have long been observed as contaminants in northern biota $(167,168)$. Lesser known, more recently monitored chemicals such as BFRs and PFCs are now also a concern in the Arctic (169, 170). As upper trophic level consumers, polar bears, as well as humans consuming a local diet, accumulate high tissue concentrations of, e.g., PCB and CHL contaminants, which have been related to biological effects $(9,41,171)$. For instance, endocrine, immune and reproductive biomarkers have been correlated with tissue levels of PCBs and certain OCPs in polar bears $(9,41$ and references therein).

Polar bears from the WHB subpopulation exist near the southern limit of the range of this species (Fig. 1.2) and appear to be more affected by recent climate warming than their more northerly located conspecifics (172). Hudson Bay polar bears (as well as those from the European Arctic) also have generally elevated adipose concentrations of organohalogen contaminants relative to other circumpolar populations (25). For this subpopulation, movement, mating and feeding depends in part on the timing and conditions of seasonal sea ice in the Hudson Bay (112). In this region, the mean annual air temperature is on average about $1.5^{\circ} \mathrm{C}$ warmer (as measured at Churchill, Manitoba, $\left.58.3^{\circ} \mathrm{N}, 93.8^{\circ} \mathrm{W}\right)(20)$, and the summer sea ice breakup is around three weeks earlier (173), than thirty years ago in the western part of the bay. Over the same period, there was no significant trend in the timing of fall sea ice freeze-up in western Hudson Bay (173). There were no significant trends in winter maximum land-fast ice thickness and timing at Churchill from 1960 to 1987 (174). The increasingly earlier breakup of the 
summer sea ice has been linked to lower body condition, birth and survival rates in WHB bears over the past two decades $(112,175)$. We hypothesized that this sea ice change is also affecting WHB polar bear feeding ecology, as measured by SI and FA dietary tracers. Since diet is the main route of exposure to the contaminants considered here, we also hypothesized that feeding changes would, in turn, affect their tissue contaminant levels.

\subsection{Results and Discussion}

\subsubsection{Relationship of Diet to Ice Breakup Date}

The mean annual $\delta^{13} \mathrm{C}$ values were significantly correlated with the annual ice breakup date $(r=0.92, p=0.004$; Fig. 5.1a). The timing of the ice breakup explained $84 \%$ of the variation in $\delta^{13} \mathrm{C}$ in WHB polar bears over the 1991 to 2007 time period. Decreasing (more negative) $\delta^{13} \mathrm{C}$ values, which suggest decreased proportions of benthic-foraging versus pelagic-foraging prey items in the polar bear diet, were associated with earlier ice breakup dates. Recent FA research has demonstrated that the WHB polar bear diet consists of two ice-associated prey, ringed seal and bearded seal, and two open waterassociated prey, harbour seal and harp seal $(81)$. As bearded seal is the only one of these seal species that forages predominately on benthic items (155), the change in polar bear $\delta^{13} \mathrm{C}$ suggested a lower consumption of bearded seals and consequently a relative increase in consumption of one or more of the other seals in years with a shortened period of ice cover. 

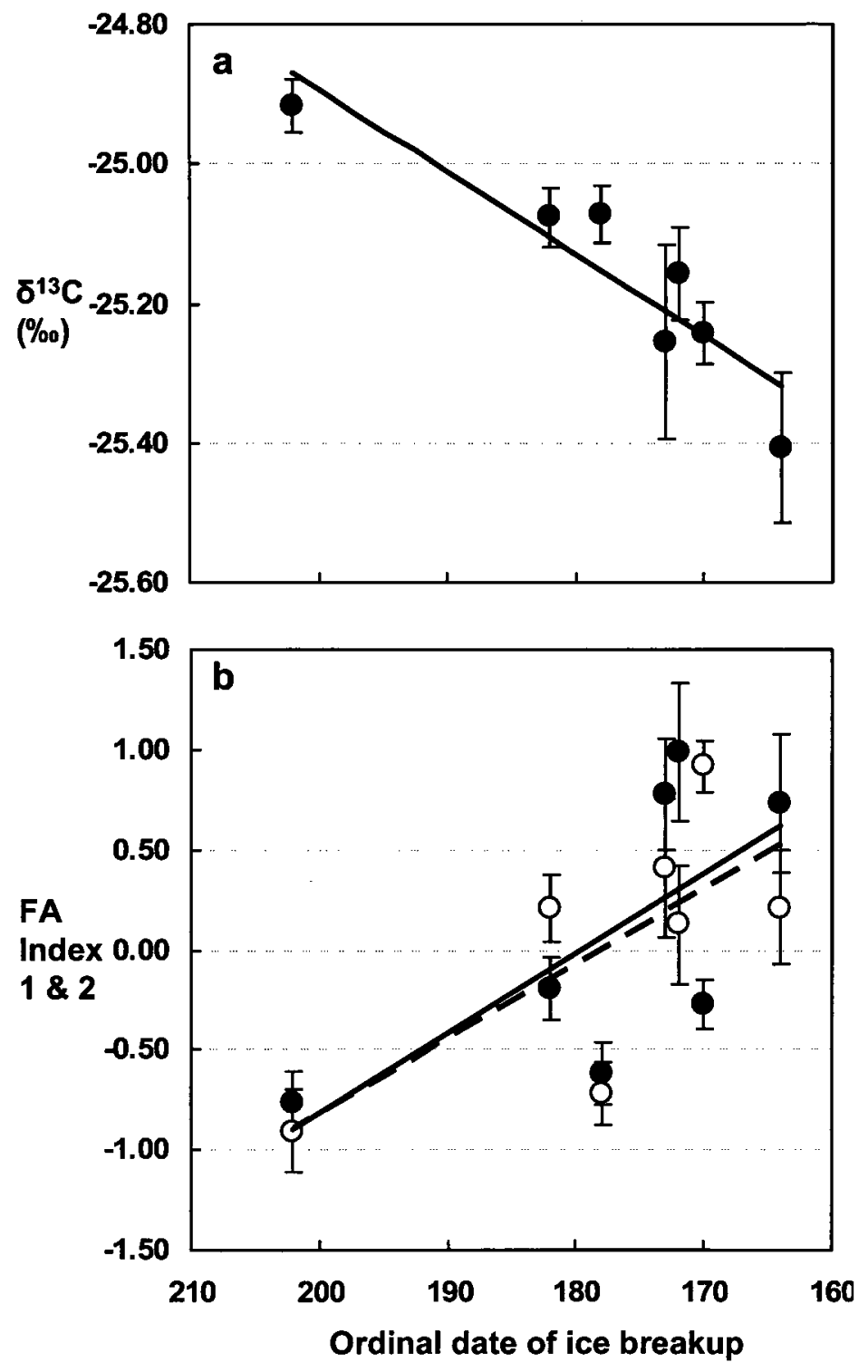

Fig. 5.1. Mean ( \pm SE) annual polar bear dietary tracer values versus ordinal date (01 Jan = ordinal date 1) of annual sea ice breakup in western Hudson Bay from 1991 to 2007. (a) Carbon stable isotopes $\left(\delta^{13} \mathrm{C}\right)$. (b) FA-Index $1(\bullet$, solid line) and FA-Index $2(O$, dashed line). 
Decreasing $\delta^{13} \mathrm{C}$ values with earlier breakup of the sea ice could also in part be influenced by other factors: increased terrestrial feeding, longer fasting, $\delta^{13} \mathrm{C}$ variation at the base of the food web or incorporation of $\delta^{13} \mathrm{C}$-depleted $\mathrm{CO}_{2}$ emitted from fossil fuel combustion into marine food chains. However, terrestrial feeding is an unlikely explanation, as although feeding on, e.g., berries, has been observed in WHB polar bears during the ice-free season, $\delta^{13} \mathrm{C}$ signatures in WHB bears, ringed seal and berries have consistently demonstrated that terrestrial input is not a significant contributor to the WHB bear diet (160). There are limited reports on the effects of fasting on dietary tracers. Yet, Polischuk et al. (176) found no difference in milk lipid $\delta^{13} \mathrm{C}$ values between WHB polar bear females between fall and spring (encapsulating our sample collection dates), although spring values were more variable. FA composition in black bear (Ursus americanus) milk was also relatively constant during and after winter dormancy (177). Taken together, these findings suggest that the dietary tracer changes with ice breakup are not largely driven by changes in fasting. Baseline food web $\delta^{13} \mathrm{C}$ changes due to variation in nutrients or productivity has been observed $(178,179)$, and without knowledge of possible temporal variation in baseline $\delta^{13} \mathrm{C}$, we cannot rule out that this could, in part, result in $\delta^{13} \mathrm{C}$ variation in the bears. Atmospheric $\mathrm{CO}_{2}$ has become depleted in $\delta^{13} \mathrm{C}$ due to the contribution of isotopically light $\mathrm{CO}_{2}$ from fossil fuel emissions (180). Relevant to this study, the depletion was around $0.4 \%$ over the period of 1991 to $2006(181)$. We found a non-significant decrease in WHB polar bear $\delta^{13} \mathrm{C}$ from 1991 to $2007(r=0.63, p$ $=0.13$ ). A correction factor for this confounding variation has been developed for 
temporal studies on terrestrial ecosystems, but the authors noted that this depletion would be less in marine systems, as dissolved inorganic carbon (DIC) is not in equilibrium with atmospheric $\mathrm{CO}_{2}$ and atmospheric $\mathrm{CO}_{2}$ is not the sole source of DIC to aquatic systems (182). Further research on the extent to which this confounding factor affects $\delta^{13} \mathrm{C}$ studies of marine food webs is warranted.

Given the variety of other factors that may affect $\delta^{13} \mathrm{C}$, we also studied FA patterns in WHB polar bears. Increasingly earlier ice breakup date explained $46 \%$ and $53 \%$ of the increases in FA-Index1 $(r=-0.68, p=0.09)$ and FA-Index2 $(r=-0.73, p=0.07)$, respectively (Fig. 5.1b; Appendix F). The main FAs that loaded positively on Index 1 (ALA and DPA) and Index2 (DHA) have been found in higher proportions in harbour and harp seal than in bearded seal (155). The main FAs that loaded negatively on FAIndex 1 (EPA, $\gamma$-linolenic acid) have been found at lower proportions in harbour and harp seal than in bearded seal (155). However, these FA patterns did not suggest changes in the proportion of ringed seal consumed. These results, in combination with the $\delta^{13} \mathrm{C}$ changes, suggest a relative decrease in the proportion of bearded seals consumed and increases in the proportion of harbour and harp seals consumed in years with a longer period of open water. This shift in the proportions of ice-associated to open-water associated prey is largely consistent with an observed diet shift for WHB bears using FA tracers of the bears and of their prey over the 1994 to 2004 period which, though, also found relatively constant ringed seal consumption $(81)$. 
Changes in WHB polar bear consumption patterns could be related to changes in accessibility to prey and/or prey abundance with altered ice conditions in the region. Ringed seals and bearded seals are considered ice-seals; yet, land-fast ice is more important habitat for ringed seals compared to pack ice habitat for bearded seals (59). Land-fast ice in the region appears to be stable, but pack ice conditions have changed $(173,174)$. It is possible that accessibility of WHB polar bears to bearded seals (but not ringed seals) has changed as a result. Harbour seals in Hudson Bay are year-round inhabitants, but stay in areas of open water (183). Harp seals are migratory, moving from the North Atlantic to, among other regions, Hudson Bay when open-water conditions prevail (59). Archaeological evidence from Inuit settlements in Labrador showed a higher ratio of harbour seal to ringed seal in centuries with lighter ice conditions (184), suggesting that open-water seals may be more abundant in northern regions in years of lighter ice conditions. Further study of polar bear prey in Hudson Bay is required to address these possible explanations. It is important to note, however, that the changes in polar bear dietary tracers may reflect not only shifts near the top of this food web, but also more extensive ecosystem composition changes in Hudson Bay (110).

\subsubsection{Influence of Diet Change on Chlorinated and Brominated Contaminant}

\section{Concentrations}

All contaminants (except $\alpha-\mathrm{HCH}$ ) were correlated with FA-Index1 and FA-Index2, and $\sum \mathrm{DDT}$ and $\sum \mathrm{PBDE}$ were also correlated with $\delta^{13} \mathrm{C}$, implying that diet explained a 
significant amount of the variation in WHB polar bear contaminant levels (Table 5.1). Similarly, Bentzen et al. $(30,83)$ used stable carbon and nitrogen isotopes to demonstrate that southern Beaufort Sea polar bears show inter-year differences in diet, and that $\delta^{15} \mathrm{~N}$ and to a lesser extent $\delta^{13} \mathrm{C}$ explained a significant proportion of the inter-individual variation in organochlorine concentrations.

To determine the effect of the measured feeding shift on the levels of contaminants in WHB polar bears, we compared the annual \% change in the concentration of each contaminant (or sum of contaminant class) before and after controlling for diet change (Fig. 5.2). When we controlled for diet change, the concentrations of $\Sigma \mathrm{PCB}, \Sigma \mathrm{CHL}$ and $\sum$ DDT decreased over time in WHB polar bears, whereas $\sum$ PBDE and $\beta$-HCH increased. However, when we examined the actual trends (i.e. not adjusted for diet change), the magnitude and in some cases direction of concentration changes over time was different. For $\sum \mathrm{PCB}, \Sigma \mathrm{CHL}, \sum \mathrm{PBDE}$ and $\beta-\mathrm{HCH}$, the diet change resulted in increased concentrations over time. This meant that the concentration of $\sum$ PBDE increased at a significantly $\left(\sum \mathrm{PBDE}, t_{0.05(2), 10}=2.45, p=0.03\right)$ and $28 \%$ faster rate than if the diet had not changed. $\beta-\mathrm{HCH}$ increased at a $20 \%$ faster rate (although not statistically faster than the diet corrected rate: $t=1.17, p=0.26$ ). For $\sum \mathrm{PCB}$ and $\sum \mathrm{CHL}$, the trends actually switched from decreasing to increasing concentrations over time due to the change in diet, though only the $\sum$ PCB switch was marginally statistically significant ( $\sum$ PCB: $t=$ 1.93, $p=0.08$; $\Sigma \mathrm{CHL}, t=0.95, p=0.36$ ). Overall, these trends towards higher actual 


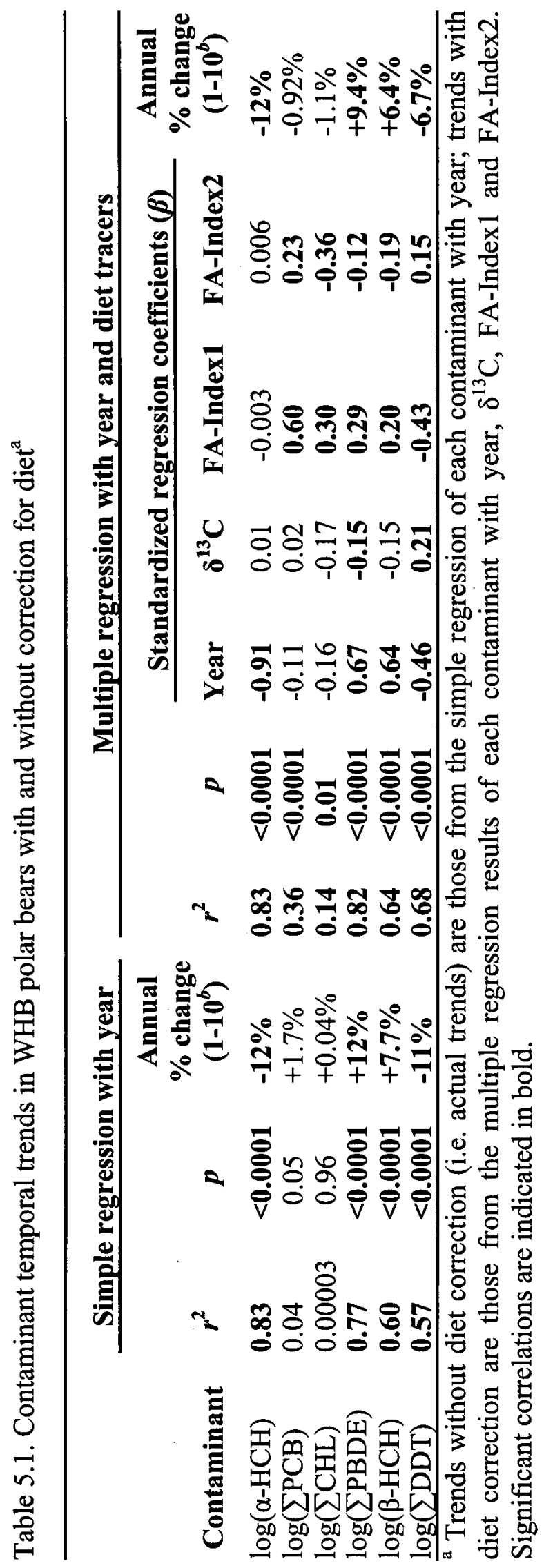




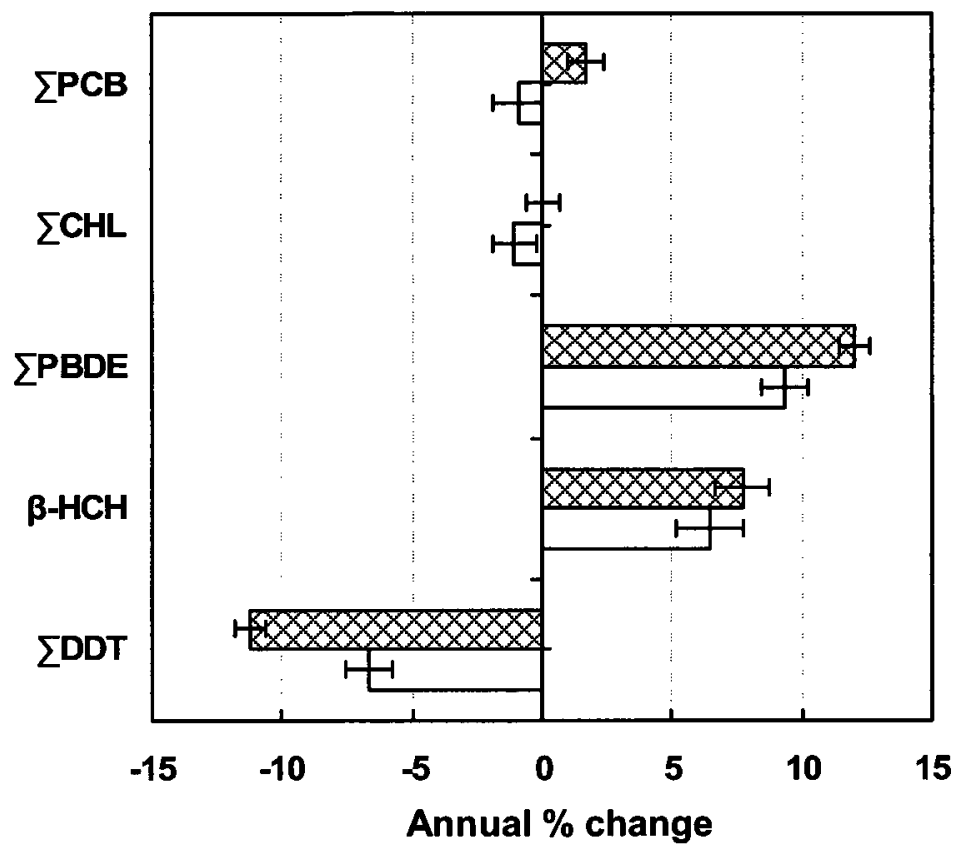

Fig. 5.2. Annual \% change $( \pm \mathrm{SE})$ in the concentrations of persistent organic contaminants in WHB polar bears, controlling for diet (white bars) and with the influence of diet included, i.e. the actual temporal trends (crosshatched bars). 
contaminant concentrations versus those if diet had remained constant are consistent with studies demonstrating lower contaminant levels in bearded seals relative to the other prey species $(92,94,96)$ and with the observed diet shift to less bearded seal consumption by WHB polar bears. Not unexpectedly, the diet shift had more impact on the concentrations of contaminants that are highly biomagnified in polar bears (e.g., $\sum$ PCB, $\sum$ PBDE) relative to contaminants that biomagnify to a lesser extent (e.g., $\beta-\mathrm{HCH})(35,185)$. Similarly, the change for $\alpha-\mathrm{HCH}$, which demonstrates relatively low persistence and bioaccumulation, remained at $-12 \%$ per year regardless of diet correction (Table 5.1 ).

Surprisingly, $\sum$ DDT concentrations decreased more rapidly $(64 \%$ faster; $t=2.69, p=$ 0.02 ) in response to the polar bear diet change. Although the major burden of POPs in northern regions is from long-range transport (2), DDT was also sprayed in the 1950s and 1960s at military installations and communities within our study site. Resulting terrestrial runoff likely led to DDT contamination of the local marine benthos. For example, PCB use at DEW-line sites in the Canadian Arctic resulted in elevated PCB concentrations in nearby marine sediments and benthic species (186). In addition, a study of the White Sea in the Russian Arctic, a region much closer to urban and industrial pollution sources than the Canadian Arctic, found that benthic foragers (bearded seals) had higher $\sum$ PCB and $\sum$ DDT concentrations than more pelagic foragers (ringed and harp seals) (98). Thus in our study, the more rapid decrease in polar bear $\sum$ DDT concentrations is consistent with the decreased contribution of benthic-foraging prey to their diet, as measured by $\delta^{13} \mathrm{C}$ changes. 
Adipose contaminant concentrations may be affected by decreased fatness (body condition), as has been documented in this subpopulation over the same time period (112). We were unable to investigate this possibility as accepted fatness indicators, e.g., Quetelet Index (mass/length ${ }^{2}$, were not available for most samples. However, we did measure adipose lipid content in our analyses, which has recently been suggested to be an adequate marker of fatness in polar bears (187). In contrast, other studies have demonstrated that an increase in fatness of a polar bear is due solely to an increase in adipocyte number not volume (188), which would not lead to an increase in adipose lipid content. Regardless, we did not find a significant correlation of adipose lipid content with year nor with ice breakup date.

We expect that this observed temporal change in the WHB polar bear diet/food web, which resulted in increased contaminant levels over the 1991 to 2007 period (relative to levels had diet not changed), may continue with increasingly warmer temperatures and diminished sea ice under predicted climate change scenarios (164). To date, the biological impact of climate change has largely focused on direct changes to ecosystems (163). Yet, our results indicate that there is a need to further investigate the interrelationships between climate change and other ecological stressors, and perhaps more urgently so in vulnerable populations and species of the Arctic and Subarctic. 


\section{Chapter 6: The Role of Diet on Long-Term (1991-2007) Concentration and Pattern Trends of Brominated and Chlorinated Contaminants in Western Hudson Bay Polar Bears*}

\subsection{Introduction}

POPs in the Arctic, such as PCBs and OCPs, are largely transported from lower latitudes and tend to accumulate in northern wildlife (9). Recent research has demonstrated increasing complexity in the organohalogen residues in these biota, including various BFRs, PFCs, current-use pesticides and persistent metabolites of legacy contaminants such as $\mathrm{MeSO}_{2}$-PCBs $(6,8,9)$. Regarding BFRs, PBBs, PBDEs and HBCD have been detected in various arctic and subarctic biota (6). However, less is known about the presence of new or replacement, BFRs, such as PBT, PBEB, HBB, BTBPE, and DBDPE (6).

The polar bear is a top predator in arctic and subarctic marine food webs. High levels of POPs in polar bears have been strongly implicated as health stressors in the subpopulations of EG, SV, SHB and WHB (9). Although cause-effect relationships have not been established, several contaminant-biomarker correlative studies on the former

\footnotetext{
*Sci. Total Environ., In press.
} 
two subpopulations have found associations between levels of certain organohalogens and, in particular, immune, reproductive and endocrine system biomarkers of effects (9). To address elevated exposures and associated risks from both legacy POPs and emerging chemicals of concern, it is important to monitor trends and effects in sentinel species including polar bears. Currently, temporal trends have not been reported for levels of any individual PBDEs or non-PBDE BFRs in polar bears. For PCBs and OCPs, the most extensive temporal trend datasets available are from the WHB subpopulation. Analysis of archived WHB female adipose tissues collected in 1968, 1984 and most years between 1989-2002 demonstrated that levels of certain chlorinated contaminants were highest in 1968 and/or 1984, and that levels of most contaminants either declined or remained unchanged from 1989-2002 $(33,39,43)$. Throughout the 1990 s, PCB and/or OCP levels in EG and SV polar bears declined somewhat faster than in WHB bears (27, 44). Extended temporal trends for polar bear subpopulations that encompass more recent time points are lacking. Recent meta-analysis of available time-series of PCBs and OCPs in arctic biota showed generally decreasing or not statistically changing trends, with more decreasing trends occurring east of the Canadian Arctic (189). These trends paralleled decreasing concentrations in arctic air, although more recently air concentrations appeared to be stabilizing (190).

Particularly for current and future arctic and subarctic trends studies, climate change may be an important factor influencing and confounding our interpretation of variation in POPs levels and patterns (107). Recent evidence has indicated that climate change- 
associated factors are already affecting contaminant concentrations in northern biota $(108,109)$. Regarding polar bears, recent temporal trends in $\sum$-concentrations of selected POPs in the WHB subpopulation were partially explained by sea ice-associated changes in the marine diet/food web (Chapter 5). Thus, contaminant levels in polar bears reflect not only altered atmospheric sources and releases over time, but also variation and potential long-term ecosystem changes due to climate change. Changes in the patterns of congeners/metabolites in relation to these $\operatorname{diet} /$ food web changes have not been investigated.

Here, we expand on our previous work on WHB contaminant trends, and in particular, the influence of diet/food web changes (Chapter 5). Previously, we reported the annual change for select contaminant classes and the relationship to sea ice-associated diet/food web changes. In the current study, our first objective was to assess the actual individual and $\sum$-contaminant concentrations, congener and metabolite patterns and temporal trends for a comprehensive suite of legacy chlorinated contaminants in WHB adipose tissues. We compared these findings to previous longer-term WHB trends to provide one of the longest-term temporal comparisons reported to date for any arctic species. Next, we reported for the first time on the concentrations and temporal trends of numerous BFRs in polar bears. Finally, we tested the hypothesis that contaminant congener/metabolite patterns are influenced not only by atmospheric sources and "weathering" (i.e., aging of the contaminant residue pattern), but also by diet/food web variation. 


\subsection{Results and Discussion}

\subsubsection{Influence of Biological Factors on Organohalogen Concentrations}

The influence of age and sex on organohalogen levels was assessed on $\sum$-contaminant classes except for $\mathrm{HCH}$, as $\alpha$ - and $\beta$-HCH possess differing physico-chemical properties that lead to differences in environmental persistence and biomagnification (33). The proportion of subadults, adult females and adult males varied among years (Table 2.2). Prior to sex-adjustment, the only significant within-year demographic difference was higher $\sum$ CHL $(p<0.001)$ in adult females than in adult males in 2003. With a larger circumpolar dataset, Norstrom et al. (26) previously reported significantly higher levels of $\sum$ CHL, but not $\sum$ PCB, $p, p^{\prime}-\mathrm{DDE}$ and dieldrin, in cubs/subadults (0-4 $\mathrm{yr}$ old) than in adults ( $>4 \mathrm{yr}$ old). That study and two smaller studies on SV and EG bears $(27,135)$ found higher $\Sigma \mathrm{CHL}$ levels in adult females than in adult males. Polischuk et al. (29) reported that subadult and adult male polar bear body burdens for $\Sigma$ CHL (driven by the metabolite oxychlordane) declined significantly during fasting, whereas those in females did not. The mechanism by which males are able to effectively metabolize CHLs is unknown, but may be related to male-specific CYPs or higher induction (or inducibility) of specific enzymes. $\sum$ PCB, $\Sigma$ CHL and $\sum D D T$ levels in males were adjusted to female equivalents prior to analysis, as they have consistently shown sex-related concentration differences in larger datasets (26). Although demographic differences were not generally significant prior to sex-adjustment, the adjustment generally reduced within-year contaminant concentration variation. All other $\mathrm{OCPs}, \mathrm{MeSO}_{2}-\mathrm{PCBs}$ and $\mathrm{PBDEs}$ were not 
sex-adjusted and showed no demographic differences, except for mirex levels, which were higher $(p=0.02)$ in females than in males in 2003.

To determine contaminant temporal trends, we wanted to assess confounding betweenyear variation as well. ANCOVA results (Table 6.1) generally showed significant effects of year for contaminants that also demonstrated significant time trends (i.e., in the PIA analysis) (Tables 6.2-6.4). That is, the time trends were not generally confounded by biological group differences. The exceptions to this were $\sum \mathrm{MeSO}_{2}-\mathrm{PCB}$ and dieldrin levels, which were not significant with year by ANCOVA, but showed significantly increasing and decreasing time trends, respectively. $\sum \mathrm{MeSO}_{2}-\mathrm{PCB}$ and dieldrin trends (Tables 6.3 and 6.4) were thus confounded by between-year biological differences, and should be regarded with caution. For $\sum$ PCB, $\sum$ PBDE and $\alpha-\mathrm{HCH}$ levels, although temporal trends were consistent, biological group and the interaction was also significant by ANCOVA (Table 6.1). Thus, the magnitude of the reported trends may have been influenced by biological group, and the annual median values were additionally reported separately for each biological group for years not exclusively comprised of adult female samples, and temporal trends were also calculated on adult females only (Tables 6.2-6.4). These additional values were also provided for $\sum \mathrm{CHL}$ and $\sum \mathrm{DDT}$ for reference (e.g., 26). However, they should be treated with caution due to very low adult female sample sizes in 2001, 2003 and 2007 ( $n=3,3$ and 1, respectively). 
Table 6.1. Results ( $p$-values ${ }^{\mathrm{a}}$ ) from an ANCOVA testing the influence of biological group (adult female/adult male/subadult) and year on adipose organohalogen concentrations in polar bears from western Hudson Bay, 1991-2007

\begin{tabular}{lccc}
\hline \multicolumn{1}{c}{ Contaminant } & Biological group & Year & Biological group $\times$ year \\
$\sum \mathrm{PBDE}$ & $<0.001^{*}$ & $0.01^{*}$ & $<0.001^{*}$ \\
$\sum \mathrm{PCB}$ & $0.02^{*}$ & 0.39 & $0.02^{*}$ \\
$\sum \mathrm{MeSO}_{2}-\mathrm{PCB}$ & 0.06 & 0.39 & 0.06 \\
$\sum \mathrm{ClBz}$ & 0.46 & 0.76 & 0.46 \\
$\alpha-\mathrm{HCH}$ & $0.01^{*}$ & $<0.001^{*}$ & $0.01^{*}$ \\
$\beta-\mathrm{HCH}$ & 0.07 & $0.05^{*}$ & 0.07 \\
$\sum \mathrm{CHL}$ & 0.71 & 0.35 & 0.70 \\
$\sum \mathrm{DDT}$ & 0.25 & $0.01^{*}$ & 0.25 \\
Dieldrin & 0.29 & 0.21 & 0.29 \\
$\sum$ Mirex & 0.08 & 0.63 & 0.08 \\
\hline
\end{tabular}

${ }^{a}$ Statistical significance $(p<0.05)$ is indicated by an asterisk. 


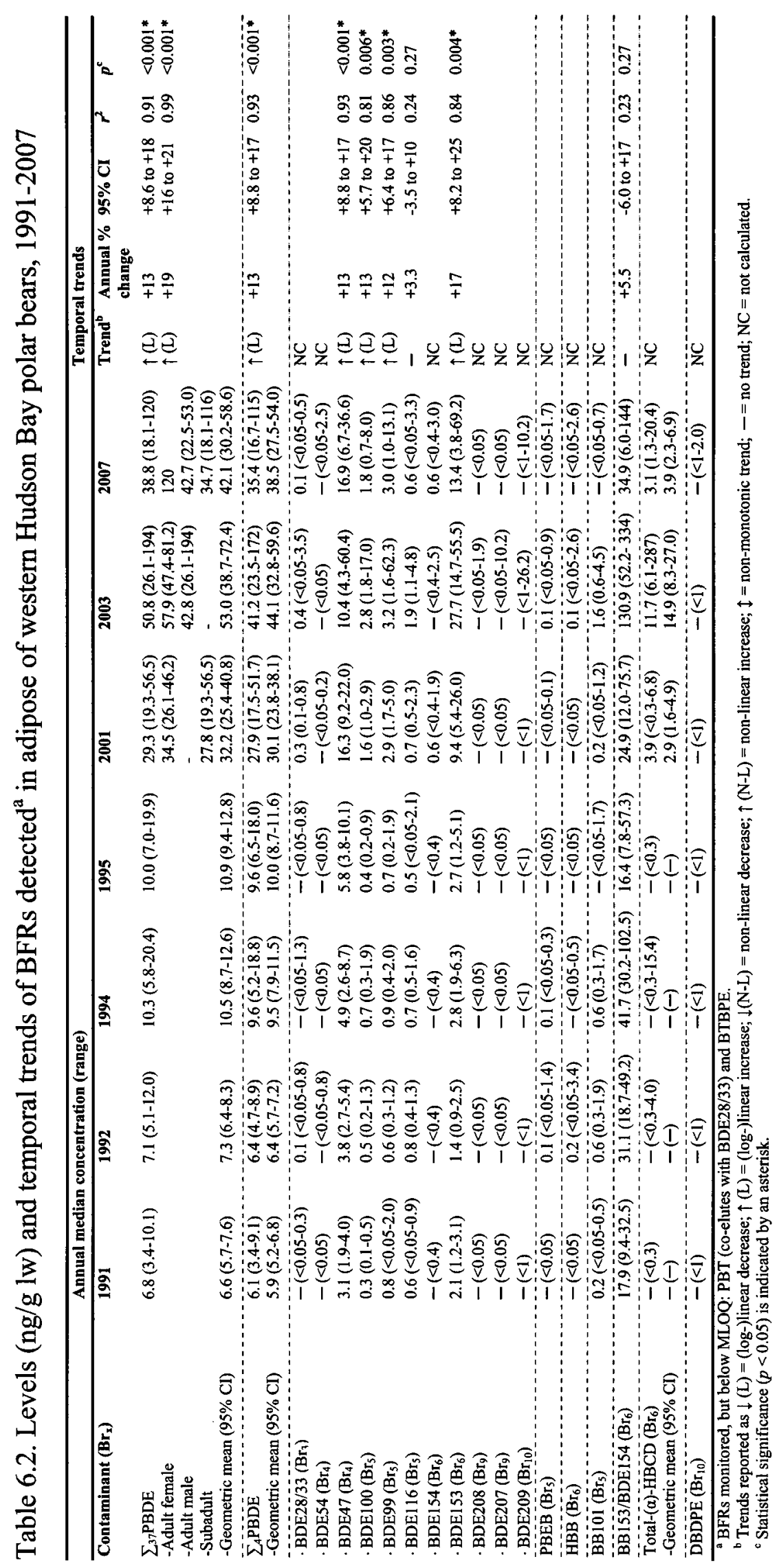




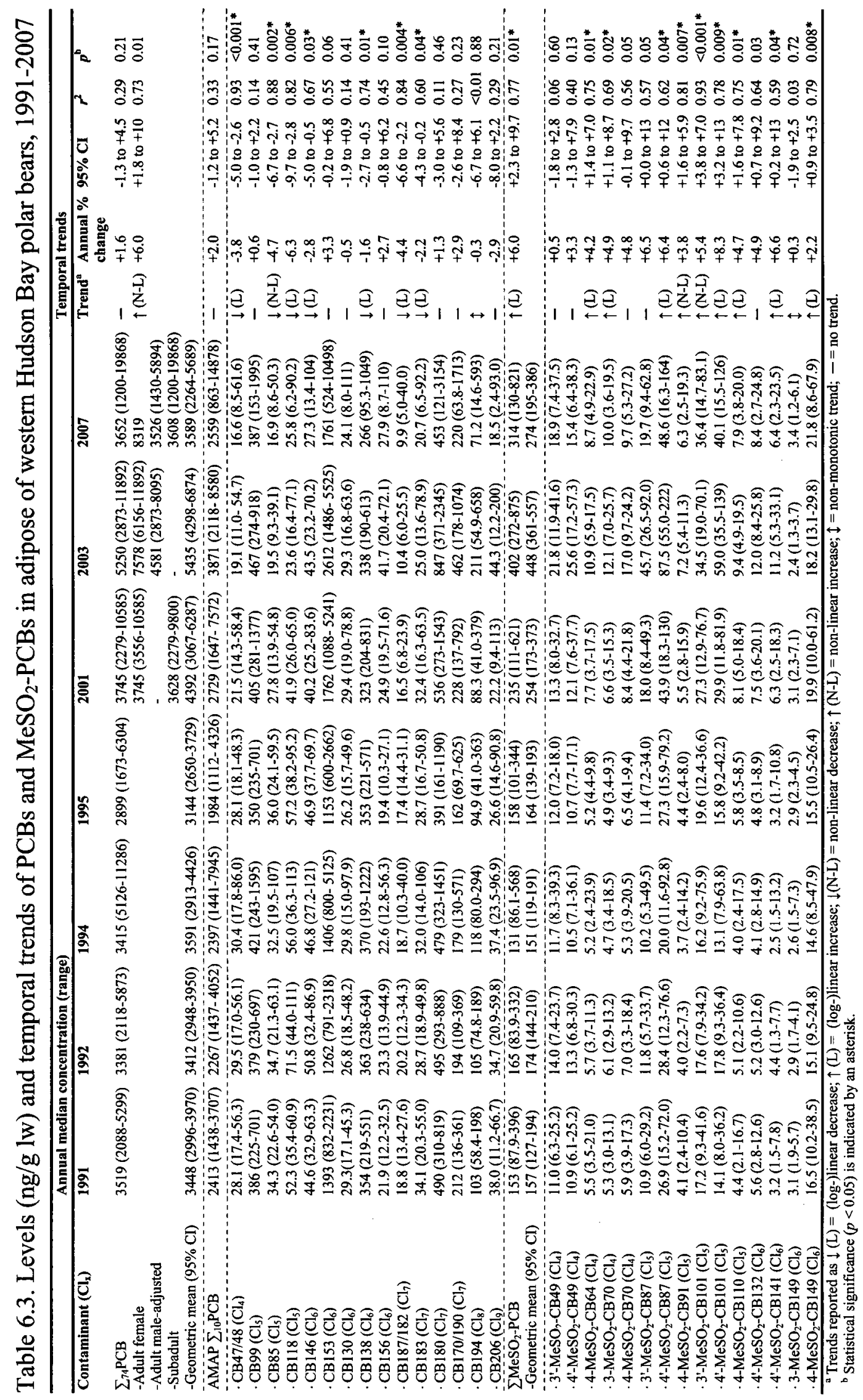




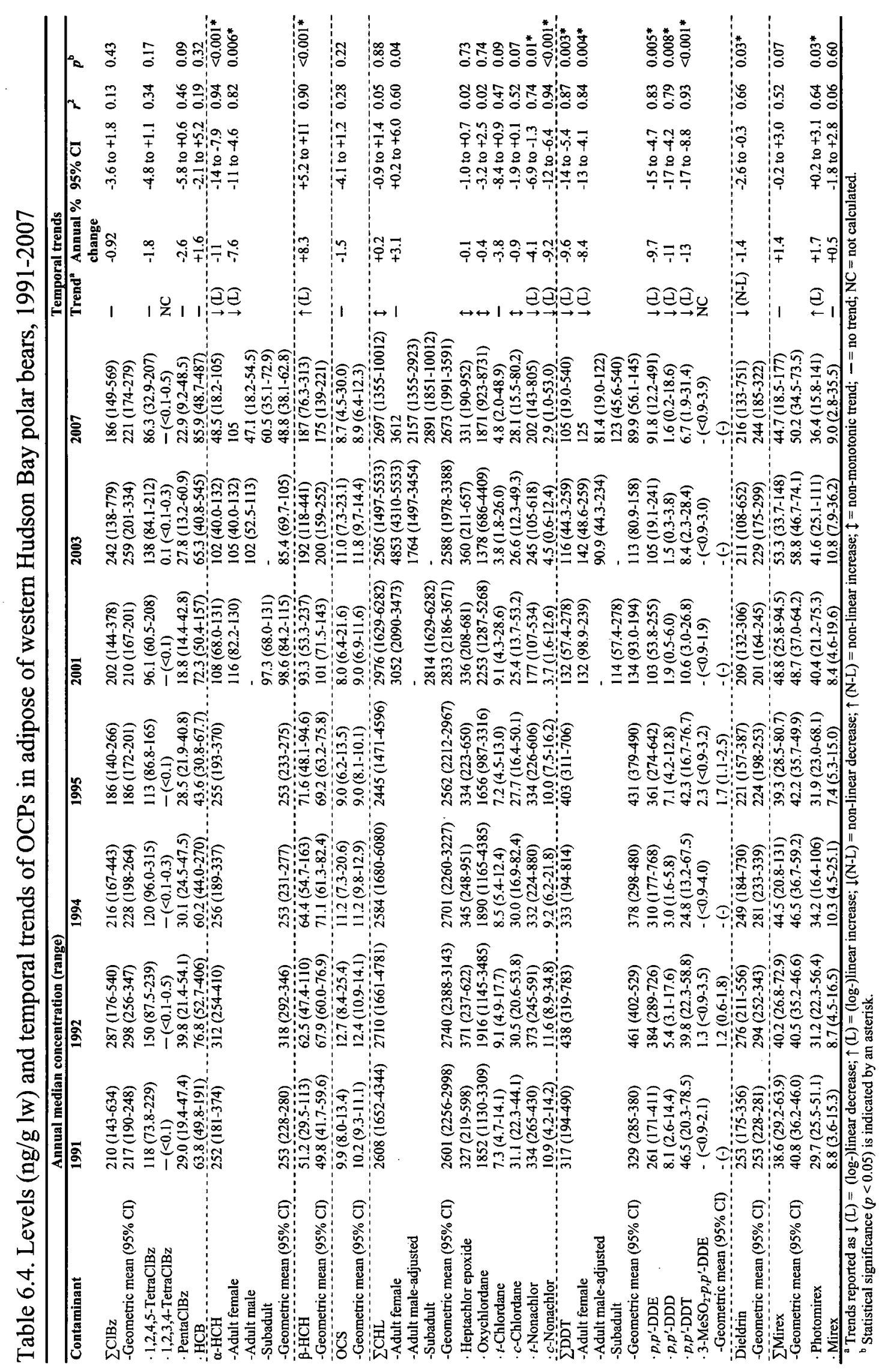




\subsubsection{Legacy Contaminant Levels and Trends}

In all years, the highest level legacy contaminants were $\Sigma$ PCB followed by $\Sigma$ CHL (both $>1 \mathrm{ppm}$ ) with at least an order of magnitude lower levels of $\sum \mathrm{DDT}, \Sigma \mathrm{ClBz}$, $\sum \mathrm{HCH}, \sum \mathrm{MeSO}_{2}-\mathrm{PCB}$, dieldrin, $\sum$ mirex and OCS (Table 6.3 and 6.4). This was consistent with recent reports on POPs in circumpolar polar bear populations (9). The DDT metabolite, 3- $\mathrm{MeSO}_{2}-p, p^{\prime}-\mathrm{DDE}$, was not consistently detected in the present bears. Levels of $\alpha-\mathrm{HCH}$ and $\sum \mathrm{DDT}$ decreased and $\beta-\mathrm{HCH}$ increased (log-linearly) from 19912007. There was no clear temporal trend for $\sum \mathrm{PCB}, \Sigma \mathrm{ClBz}$, OCS, $\Sigma \mathrm{CHL}$ and $\sum$ mirex. Since changes in dieldrin and $\sum \mathrm{MeSO}_{2}-\mathrm{PCB}$ levels were related to between-year biological group differences, they likely showed no significant time trends as well. The power to detect an annual concentration change of $5 \%$ with the number of years in the current time series was generally only between $13-27 \%$, although above $60 \%$ for $\sum \mathrm{CHL}$ and $\sum$ mirex. This low power was similar to other time series in a recent meta-analysis of temporal trends in arctic biota (189). Henriksen et al. (44) found the most effective action to improve the statistical power would be annual sampling. Nonetheless, combining existing data sets to provide long-term series may also clarify or substantiate increasing or decreasing time trends. The current results were compared to temporal trends of PCBs and OCPs in WHB polar bears from 1968-2002 (Fig. 6.1) (33, 39, 43). Generating quantitative overall trends was not warranted due to possible variation from differences in pre-analysis storage times, extraction and analytical techniques, and data analysis (191). 
Fig. 6.1. Levels (geometric mean $+95 \% \mathrm{CI}$ ) of PCBs and OCPs in adipose of polar bears from western Hudson Bay collected in 1968-2007. Figure adapted from de Wit et al. (3) with permission. White bars are from de Wit et al. (3) with original data from Norstrom et al. (43) and Verreault et al. (39). Overlaid black bars are from the current study. 


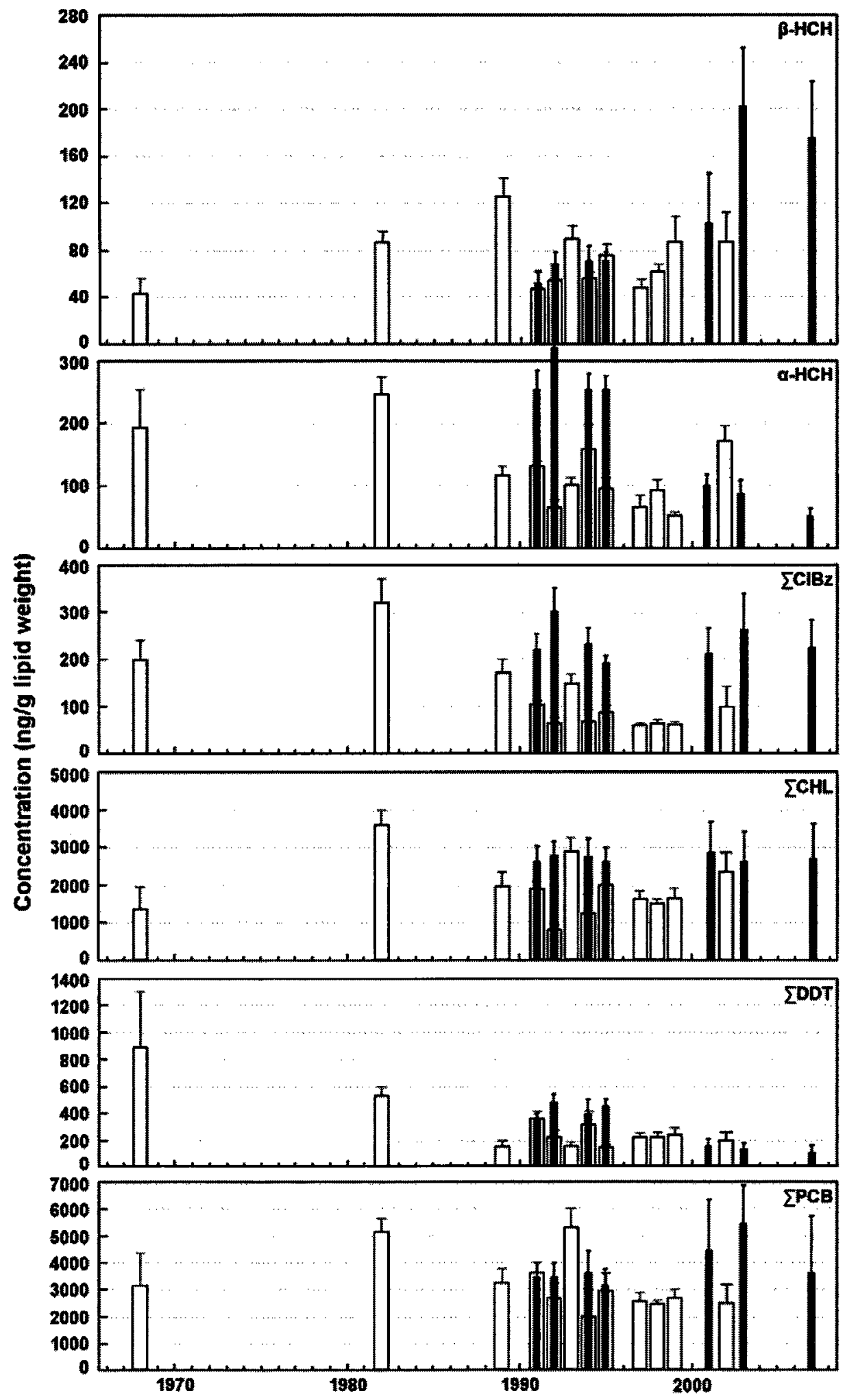


Nonetheless, when our 1990s data overlapped with the previous dataset, the same-year means generally agreed (Fig. 6.1). The major differences were for $\alpha-\mathrm{HCH}$ and $\Sigma \mathrm{ClBz}$, likely due to analytical variation from volatility-related recovery losses relative to other OCPs.

Over the four decades comprising the combined studies, there was a five-fold increase in $\beta$-HCH levels (Fig. 6.1). Decreasing $\beta-\mathrm{HCH}$ levels have been observed in other northern biota, but slower declines or sometimes increases have been observed west of the European Arctic (189). Although divergent same-year means prevented a long-term assessment, $\alpha-\mathrm{HCH}$ levels declined in this and previous polar bear studies, and thus likely declined overall. The difference in $\alpha-\mathrm{HCH}$ and $\beta-\mathrm{HCH}$ trends has resulted in a substantial shift in $\Sigma \mathrm{HCH}$ composition in WHB polar bears, from mainly $\alpha-\mathrm{HCH}$ in $1968(>80 \%)$ to mainly $\beta$-HCH in 2007 (78\%). This pattern has been reported in other northern wildlife (189). It is related to greater partitioning of $\beta-\mathrm{HCH}$ into water resulting in the slower arrival of this isomer to higher latitudes, and to $\alpha-\mathrm{HCH}$ being more readily metabolized and thus less bioaccumulative. We previously found that the rate of $\beta-\mathrm{HCH}$ increase (+8.3\%/year) from 1991-2007, which was higher than all other increasing $\beta$-HCH trends reviewed by Rigét et al. (189), was in part related to sea ice-associated diet/food web change (Chapter 5). This change did not influence the decline rate $(-11 \% /$ year) of the less recalcitrant $\alpha-\mathrm{HCH}$, which was similar to decline rates reported in other species (189).

Levels of $\sum D D T$ have declined substantially (by an order of magnitude) over the past four decades. From 1991-2007, the measured decline was fairly consistent across DDT 
compounds (Table 6.4$)$. The rate of decline of $\sum$ DDT $(-9.6 \% /$ year) was more than double the mean rate measured in other northern biota $(-4.4 \% /$ year; 189$)$. We have previously shown that this decline would have been slower if diet/food web changes had not occurred in WHB bears (Chapter 5). More rapid decline than in other regions may also have been related to local spraying of DDT in the 1950s and 1960s and more immediate subsequent declines (3).

¿CHL levels showed no directional changes from 1968-2007 (Fig. 6.1). Levels were highest in the early 1980 s, but our data and the data from Verreault et al. (39) indicated that there has been no unidirectional change over the past two decades. $\sum \mathrm{CHL}$ trends were not reflective of the behaviour of individual CHLs (Table 6.4). Within our dataset, the major CHL compound was oxychlordane, followed by lower levels of heptachlor epoxide and $t$-nonachlor. Oxychlordane and heptachlor epoxide, which are CHL metabolites, appeared to drive the lack of trend in $\mathrm{CH} H \mathrm{~L}$. In contrast, the parent compounds of oxychlordane, $t$-nonachlor and particularly $c$-nonachlor, both decreased significantly from 1991-2007. This increasingly weathered pattern suggested that recycled residues are responsible for sustained high inputs of CHL into this ecosystem. However, from 1986-2006, $\Sigma$ CHL levels decreased in ringed seals from four Canadian locations including western Hudson Bay (192). Verreault et al. (39) previously found lower $\sum$ CHL levels in limited two-point temporal comparisons of all examined polar bear subpopulations except WHB. This discrepancy may be related to recent feeding changes, as we previously found that after diet-adjustment, WHB polar bear $\sum$ CHL residues did in 
fact have a declining tendency (although not statistically significant) from 1991-2007 (Chapter 5). We hypothesized that the polar bear dietary tracer results indicated increased proportional consumption of harbour and harp seals and a relative decrease in bearded seals. Bearded seals in other regions have been relatively less contaminated than other seals (e.g., 94). Harp seals are migratory and may be a vector for transporting a more contaminated North Atlantic organohalogen signature to WHB polar bears (Chapter 5). A recent study using stable SI ratios and mercury as dietary tracers found that harbour seals in western Hudson Bay feed at a higher trophic level than ringed and bearded seals (158). Thus, proportionally less bearded seal and more harbour and/or harp seal consumption is consistent with the anomalous organohalogen time trends in WHB polar bears. This explanation remains speculative and could be addressed by the collection of dietary tracer and contaminant in western Hudson Bay food web studies.

Along with $\Sigma \mathrm{CHL}, \sum \mathrm{PCB}$ was the other organohalogen of most concern from a quantitative perspective. Levels of $\sum$ PCB showed no obvious trends over the four decades (Fig 6.1), other than a small and not significant increasing tendency from 19912007 (Table 6.3). The AMAP $\sum_{10}$ PCB (sum of CB28, CB31, CB52, CB101, CB105, CB118, CB138, CB153, CB156 and CB180) results were similar (Table 6.3). After considering the influence of biological group, it is likely that the $\sum \mathrm{MeSO}_{2}-\mathrm{PCB}$ levels were temporally unchanging as well. This stagnant temporal trend for $\sum \mathrm{PCB}$ and $\sum \mathrm{MeSO}_{2}$-PCB levels was not reflective of individual congener trends. The 15 highest concentration PCBs as well as $\mathrm{MeSO}_{2}$-PCBs comprised on average 96\% (range: 89-98\%) 
and $94 \%$ (range: $89-98 \%$ ) of $\sum_{74} \mathrm{PCB}$ and $\sum_{23} \mathrm{MeSO}_{2}-\mathrm{PCB}$, respectively (Table 6.3). Unchanged CB180 and CB194 levels paralleled the lack of $\sum$ PCB trends, but levels of congeners such as CB118 and CB138 declined from 1991-2007. Levels of CB153 showed an increasing tendency $(p=0.06)$. These changes indicate a shift to a more weathered PCB signature, but similar to $\Sigma \mathrm{CHL}$, there has been no concomitant drop in $\sum$ PCB levels, possibly in part related to diet and/or food web changes.

Temporal trends in $\Sigma \mathrm{ClBz}$ levels were unclear. Norstrom et al. (43) reported declines in the 1990s. Similar to the current study, Verreault et al. (39) found that 2002 levels were unchanged from the early 1990s. Individual $\mathrm{ClBz}$ levels were variable, but also showed non-significant temporal trends (Table 6.4). Consistent with our results, Norstrom et al. (43) did not detect a temporal change in dieldrin levels through the 1990s. Mirex and OCS levels were not reported in the earlier trend studies.

\subsubsection{Flame Retardant Levels and Trends}

Adipose $\sum_{37} \mathrm{PBDE}$ levels increased from 1991-2007 (Table 6.2). $\sum_{4} \mathrm{PBDE}$ was also reported as only $\mathrm{BDE} 47, \mathrm{BDE} 99, \mathrm{BDE} 100$ and $\mathrm{BDE} 153$ were consistently detected, comprising on average $90 \%$ of $\sum_{37} \mathrm{PBDE}$. These congeners and $\sum_{4} \mathrm{PBDE}$ increased similar to $\sum_{37} \mathrm{PBDE}$. Lower PBDE levels in 2007 cf. 2003 (except for BDE47) may have indicated recently stabilizing or declining trends related to the late-2004 North American phase-out of PentaBDE and OctaBDE. However, the levels of certain legacy contaminants such as $\sum$ PCB were also elevated in 2003 compared to 2001 and 2007, so 
apparent recent declines of $\sum$ PBDE may partially be attributed to inter-annual variation rather than a directional change in trends. PBDE levels in western Hudson Bay ringed seal blubber were shown to have increased from 1992-2006, but dropped in 2008 (193). To our knowledge, there are no published reports on PBDE temporal trends in other polar bear subpopulations, but ringed seals in other regions have been studied. There was no trend in East Greenland ringed seals from 1986-2004 (47). Levels increased in western Canadian Arctic ringed seals from 1981-2000, leveling off or declining in 2002-2003 (45). Most temporal trends studies on arctic air, sediment and biota have also demonstrated PBDE increases, but possible leveling off or declines in recent years (6). Regardless, $\sum$ PBDE levels in WHB bears were consistently two orders of magnitude lower than $\sum \mathrm{PCB}$ and $\Sigma \mathrm{CHL}$ levels.

Manufacture and use of DecaBDE (mainly comprising BDE209) is on-going in North America. Although BDE209 is a major congener in arctic air (190), BDE209 and nonaBDEs were not consistently detected in WHB bears ( $<9 \%$ of all samples). Similarly inconsistent detection and/or low levels of BDE209 and nonaBDEs have been reported in other northern wildlife including ringed seal (blubber; 192) and seabirds from northern Norway (eggs; 194). Low to non-detectable levels in biota versus the surrounding environment may be related to lower bioavailability (195) and/or greater metabolism of highly brominated PBDEs in biota (12).

To our knowledge, HBCD is the only other BFR for which temporal trends in arctic biota have been previously investigated. Total- $(\alpha)$-HBCD was largely not detected in 
WHB bears in the 1990s, but it was detected post-2000 at levels around five- to ten-fold lower than $\sum$ PBDE (Table 6.2). Similarly, most HBCD time series published to date in arctic biota could not determine trends due to large fluctuations in HBCD concentrations (6). The PBB, BB153 (co-eluting with BDE154), was detected at similar levels to $\sum$ PBDE. In the limited number of samples wherein BDE154 was quantifiable by [M$2 \mathrm{Br}]^{-}$anions, BDE154 comprised on average $4 \%$ (range: $1-13 \%$ ) of the coeluting BB153/BDE154 signal. Therefore, BB153 was the predominant (individual) brominated contaminant detected in all years. The lack of temporal decreases in BB153 attested to its persistence, as PBBs have not been used in North America since the 1970s (148). BB101 was infrequently found at low levels. PBEB, HBB and DBDPE were the only other BFRs detected, but detection was very infrequent and in the low- to sub-ppb range. PBEB and HBB were/are only low volume BFRs, whereas DBDPE is a current, high production product. Because of its large molecular size, DBDPE may not be very mobile or bioavailable or it may be readily degradable, perhaps similar to BDE209 (as reviewed by 6).

\subsubsection{Contaminant Patterns in Relation to Diet, Year and Biological Group}

Contaminant level and pattern trends (Fig. 6.2) in polar bears are partially due to changes in source signatures and pathways, as well as abiotic and biological weathering. Other recognized (confounding) factors include age, reproductive status, 
Fig. 6.2. Percent composition (+SE) of major contaminant classes in adipose of polar bears from western Hudson Bay (left to right): 1991 (first white bars), 1992 (first black bars), 1994 (first striped bars), 1995 (second white bars), 2001 (second black bars), 2003 (second striped bars) and 2007 (third white bars). PCB, $\mathrm{MeSO}_{2}$-PCB and PBDE congener labels are further abbreviations from those listed in Table 2.5. 


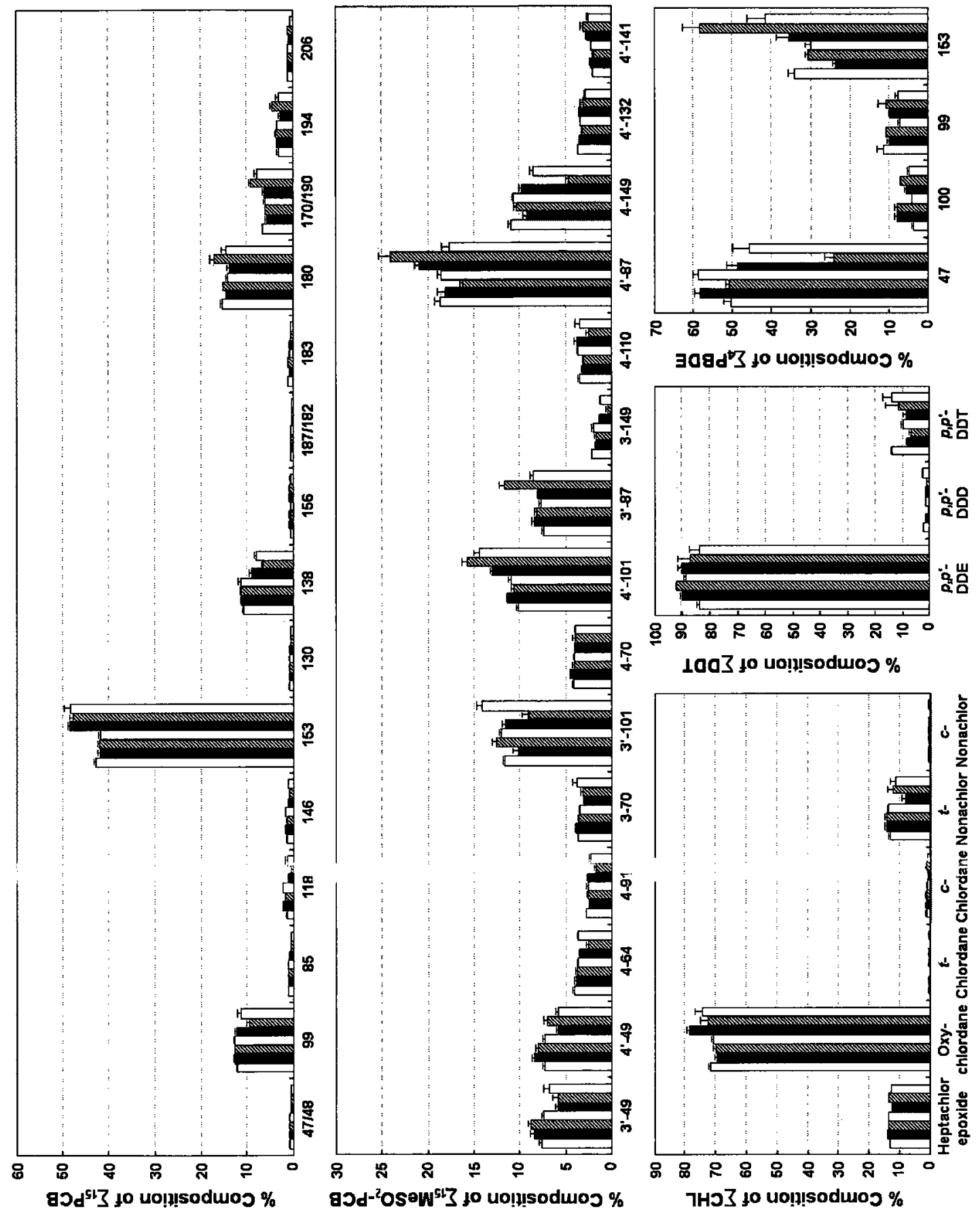


biotransformation capacity, lactation, seasonal fasting, body size, lipid content and habitat use (22). Trends may also be related to changes in food web pathways (Chapter 5). To address some of these possibilities, we performed PCAs on the congener/metabolite proportions for the major contaminant classes (Fig. 6.3). Multiple regression of PC factor scores with year, biological group and the three dietary tracers often resulted in low multiple $r^{2}$ values (below $0.5 ; 145$ ) (Table 6.5). So the explanatory variables were not always good predictors of contaminant patterns, but reasonable explanations for certain contaminant patterns could be discussed.

The PCA on PCB congener proportions showed four clusters across two significant PCs (Fig. 6.3). PC1 and PC2 accounted for $43 \%$ and $35 \%$ of the pattern variation, respectively. Congeners in cluster A loaded positively on PC1 and consisted mainly of lower (tetra- to hexa-) chlorinated PCBs. Cluster B loaded negatively on PCl and consisted of CB153. Polar bear PC1 factor scores were negatively correlated year and $\delta^{13} \mathrm{C}$ and positively correlated with FA-Indexl (Table 6.5). That is, a proportional increase in $\mathrm{CB} 153$ and decrease in lower chlorinated PCBs occurred over time (i.e., weathering) and was also related to diet, consistent with lower proportional consumption of bearded seals and higher proportions of harbor or harp seals (Chapter 5).

For PCB-PC2, four highly (hepta- to nona-) chlorinated congeners loaded negatively (cluster C) and CB99 loaded positively (cluster D). PC2 factor scores were related to $\delta^{13} \mathrm{C}, \mathrm{FA}-\mathrm{Index} 2$, biological group and their interactions. Highly chlorinated congener levels were thus influenced by dietary exposure in all demographic groups, but in females 
Fig. 6.3. Factor loadings from principal components analyses on the percent (\%) composition of major contaminant classes in adipose of polar bears from western Hudson Bay sampled in 1991-2007. Encircled clusters contained compounds that loaded significantly (critical value of the correlation $>0.54$ ) on the same PC, but were not significant on any other PCs. $\mathrm{PCB}$ and $\mathrm{MeSO}_{2}-\mathrm{PCB}$ congener labels are further abbreviations from those listed in Table 6.3. 


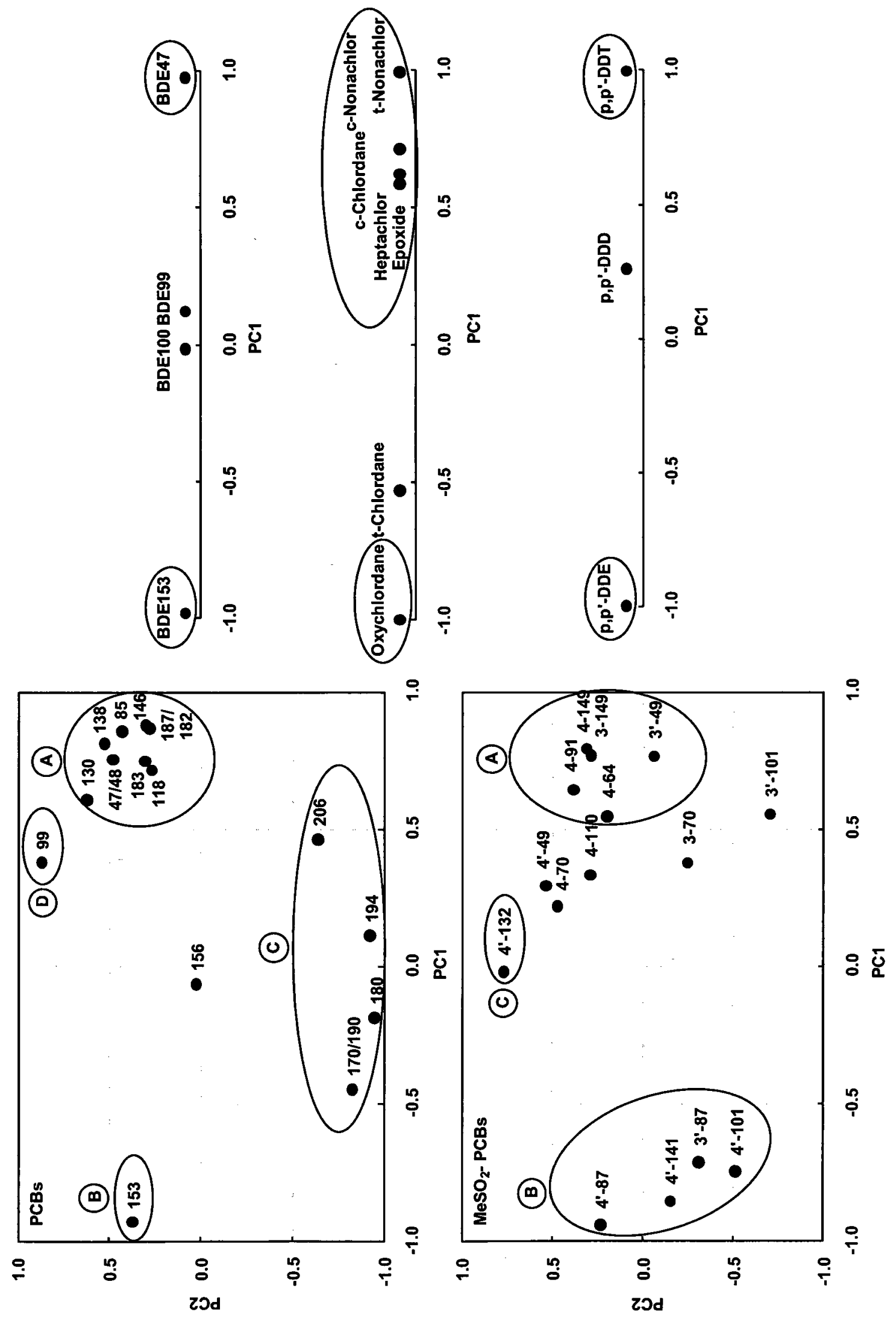


Table 6.5. Influence of year, biological group and the dietary tracers, $\delta^{13} \mathrm{C}$, FA-Index 1 , FA-Index2, on contaminant patterns in adipose of polar bears from western Hudson Bay

\begin{tabular}{|c|c|c|c|}
\hline \multirow[t]{2}{*}{$\begin{array}{c}\text { Contaminant } \\
\text { pattern }^{\mathrm{a}}\end{array}$} & \multicolumn{3}{|c|}{$\begin{array}{c}\text { Multiple regression with the main effects year, biological group }{ }^{b}, \\
\text { dietary tracers and first-order interactions of biological group and } \\
\text { dietary tracers }\end{array}$} \\
\hline & $\begin{array}{c}\overline{\text { Multiple }} \\
r^{2}\end{array}$ & e p & Significant explanatory variables (semipartial $r$ ) \\
\hline PCB-PC1 & 0.64 & $<0.001$ & main effects: $\delta^{13} \mathrm{C}(0.18)$, FA-Index $1(-0.14)$, year $(-0.18)$ \\
\hline PCB-PC2 & 0.34 & $<0.001$ & $\begin{array}{l}\text { main effects: biological group }(-0.25) \\
\text { interactions: biological group } \times \delta^{13} \mathrm{C}(-0.24) \text {, biological } \\
\text { group } \times \mathrm{FA} \text {-Index } 2(-0.24)\end{array}$ \\
\hline $\begin{array}{l}\mathrm{MeSO}_{2} \text {-PCB- } \\
\mathrm{PCl}\end{array}$ & 0.46 & $<0.001$ & none \\
\hline $\begin{array}{l}\mathrm{MeSO}_{2} \text {-PCB- } \\
\mathrm{PC} 2\end{array}$ & 0.48 & $<0.001$ & main effects: FA-Index $1(0.22), \delta^{13} \mathrm{C}(-0.16)$, year $(-0.32)$ \\
\hline $\begin{array}{l}\mathrm{MeSO}_{2} \text {-PCB- } \\
\mathrm{PC} 3\end{array}$ & 0.25 & 0.002 & none \\
\hline PBDE-PC1 & 0.66 & $<0.001$ & $\begin{array}{l}\text { main effects: biological group }(-0.18) \text {, FA-Index } 1(-0.21) \\
\text { interactions: biological group } \times \text { FA-Index } 1(0.16), \\
\text { biological group } \times \text { FA-Index }(-0.14) \text {, biological } \\
\text { group } \times \delta^{13} \mathrm{C}(-0.17)\end{array}$ \\
\hline CHL-PC1 & 0.47 & $<0.001$ & $\begin{array}{l}\text { main effects: biological group }(0.19) \text {, year }(-0.17), \delta^{13} \mathrm{C} \\
(0.36) \text {, FA-Index } 1(-0.41) \text {, } \\
\text { interactions: biological group } \times \delta^{13} \mathrm{C}(0.19) \text {, biological } \\
\text { group } \times \text { FA-Index } 1(-0.17)\end{array}$ \\
\hline DDT-PC1 & 0.34 & $<0.001$ & none \\
\hline
\end{tabular}

${ }^{a}$ Contaminant patterns were represented by the factor scores of individual polar bears from a PCA on \% composition of major individual contaminants to $\sum$-contaminant class. ${ }^{\mathrm{b}}$ Results shown above were from testing biological group coding $k-1$ ( $k=3$ groups: adult female, adult male and subadult) dummy variables, with adult female as the reference category. To test for adult male versus subadult, the analysis was repeated with subadult as the reference category. For PCB-PC2 and PBDE-PC1, biological group was significant for adult male versus adult female (and adult male versus subadult). For CHL-PC1, biological group was significant for subadult versus adult female. 
and subadults the influence of diet may be moderated by lactational transfer. Diet differences between male, female and subadult polar bears have been reported (81). Bernhoft et al. (135) found higher levels of these same four highly-chlorinated PCBs in adult male polar bears than in adult females/young/subadults from Svalbard. The proposed explanation was that lactational loss results in lower proportions of recalcitrant, highly chlorinated congeners in adult females versus males, but has less effect on more metabolizable, lower chlorinated PCBs. Lower proportions of highly chlorinated PCBs in subadults versus adult males may be because lactational transfer of highly chlorinated PCBs is limited.

BDE47 and BDE153 contributed to variation in PBDE-PC1, which accounted for $48 \%$ of the variance (Fig. 6.3). Higher and lower proportions of BDE153 and BDE47, respectively, were associated with adult males (versus adult females/subadults) and with higher FA-Index 1 (higher proportions of harp or harbour seals, and lower proportions of bearded seals). Interaction terms between biological group (adult males versus adult females) and $\delta^{13} \mathrm{C}, \mathrm{FA}-$ Index 1 and FA-Index2 were significant, implying that the influence of dietary uptake in females and subadults was moderated by lactational transfer. Similar to the PCB pattern explanation (135), greater lactational transfer of the lower brominated BDE47 versus the higher brominated BDE153 may have resulted in higher proportions of BDE47 in subadults. However, adult females still had relatively lower proportions of BDE153 than adult males because of lactational transfer. Year was not significant in explaining the PBDE congener pattern, suggesting that it is too early to 
detect weathering of the signature, i.e., increased proportions of the more persistent congener, BDE153 (35).

The CHL PCA (Fig. 6.3) found only one significant PC, accounting for $58 \%$ of the variation. CHL-PC1 separated oxychlordane from a cluster containing heptachlor epoxide, $c$-chlordane, $c$-nonachlor and $t$-nonachlor. Higher proportions of oxychlordane and lower proportions of the clustered compounds were best explained by individual diet differences (depleted $\delta^{13} \mathrm{C}$ and higher FA-Index1) (Table 6.5). Biological group and dietary tracers also contributed. Adult females had higher proportions of oxychlordane versus subadults and adult males. Polischuk et al. (29) found that oxychlordane significantly decreased in adult and subadult male polar bears during fasting, but not in adult females, indicating sex-specific metabolism. Higher oxychlordane proportions were also associated with later years, suggesting that the CHL pattern has changed due to weathering.

The $\mathrm{MeSO}_{2}$-PCB PCA (Fig. 6.3) found three significant PCs (PC1 and PC2 accounted for $39 \%$ and $17 \%$ of the variation in the $\mathrm{MeSO}_{2}-\mathrm{PCB}$ pattern, respectively). Two clusters of congeners (A and B) contributed to the variation along PC1. None of the explanatory variables (year, dietary tracers or biological group) significantly explained variation along this PC. Letcher et al. (34) have previously established that $\mathrm{MeSO}_{2}-\mathrm{PCBs}$ could be present in polar bears due to metabolic formation and/or accumulation from prey (specifically ringed seal blubber). As dietary tracers did not explain variation in PC1 factor scores, $\mathrm{MeSO}_{2}$-PCBs that loaded significantly on $\mathrm{PC1}$ were not simply 
bioaccumulated from their diet. Variation along PC1 may have been related to individual metabolic differences from, e.g., differences in exposure to enzyme-inducing contaminants or body condition, which were not considered in the model. Of the four $\mathrm{MeSO}_{2}$-PCBs that loaded negatively on PC1 (cluster B), Letcher et al. (34) demonstrated that 3'- and 4'- $\mathrm{MeSO}_{2}-\mathrm{CB} 87$ and 4'- $^{\prime} \mathrm{MeSO}_{2}-\mathrm{CB} 141$ were among the most likely congeners to be additionally present in polar bears due to biotransformation. On PC2, 4'$\mathrm{MeSO}_{2}-\mathrm{CB} 132$ loaded positively, one of the only $\mathrm{MeSO}_{2}-\mathrm{PCBs}$ present in polar bears solely due to bioaccumulation (34). Thus, it was not surprising that, in addition to being associated with year, higher scores on PC2 were significantly explained by dietary tracers. These findings suggested that some but not all $\mathrm{MeSO}_{2}-\mathrm{PCBs}$ may be influenced by long-term diet/food web changes.

The DDT PCA found one significant PC, accounting for $69 \%$ of the variation. DDTPC1 was distinguished by positive loading of $p, p^{\prime}$-DDT and negative loading of $p, p^{\prime}-$ DDE. None of the explanatory factors explained variation along DDT-PC1. Lack of biological group and dietary influences were consistent with substantial metabolism of DDTs in subadult, adult male and adult female polar bears (29). Like $\mathrm{MeSO}_{2}-\mathrm{PCB}-\mathrm{PC1}$, perhaps DDT patterns were partly associated with individual differences in metabolic potential towards DDTs. The DDT pattern was not associated with year, although a more weathered pattern (proportionally higher DDE) over time was expected. Continued exposures to a more "fresh" local source of DDT may be from spraying in the study region in the 1950s and 1960s (Chapter 5). 
Overall, chlorinated contaminant trends in WHB polar bears varied in comparison to those measured in other northern wildlife, for instance, more rapid DDT decline, more rapid $\beta-\mathrm{HCH}$ increase and no $\mathrm{CHL}$ decline. These unusual temporal trends may, in part, have been related to sea ice-associated diet and/or food web changes we previously reported in this subpopulation. Contaminant patterns were also suggestive of exposure changes that were related to source inputs and weathering and to diet/food web changes. 
Chapter 7: Comparative Hepatic Microsomal Biotransformation of Selected Polybrominated Diphenyl Ether, including Decabromodiphenyl Ether, and Decabromodiphenyl Ethane Flame Retardants in Arctic Marine-Feeding Mammals*

\subsection{Introduction}

BFRs comprise a diverse suite of commercially used chemicals that are additively- or reactively-integrated into consumer products to meet fire safety standards. Some BFRs, such as PBDEs, are established environmental contaminants, including in arctic wildlife and fish (9). Environmental behaviour as well as toxicological research has largely focussed on the lower brominated congeners, demonstrating bioaccumulation, long-range transport and potential for neurotoxic and endocrine-disrupting properties (73). Tetra- to hepta-brominated PBDEs were recently listed in Annex A of the Stockholm Convention on Persistent Organic Pollutants (www.pops.int). Yet, the fully-brominated BDE209, which constitutes $>90 \%$ of the high production volume DecaBDE products (196), has also been detected in non-source regions (197). BDE209 is also degraded to more persistent, lower brominated congeners by photolysis (11) and through biotransformation, as shown in dosing studies on some wildlife and fish $(13,72,198)$.

*In preparation for submission to Environ. Toxicol. Chem. 
As market demand for PBDE alternatives increases, other current-use BFRs are also being reported in environmental matrices. Notable is DBDPE, marketed as an alternative to DecaBDE. Available in the mid-1980s, limited production data indicates increasing DBDPE use in the past two decades in Japan, with the reverse trend observed for DecaBDE (199). In 2006, the estimated DBDPE production volume (12 000 metric tonnes) in China was similar to that of DecaBDE formulations (20 000 metric tonnes) (200). DBDPE has recently been reported in North American herring gulls and freshwater fish, and in Chinese waterbirds and captive pandas (200-204). In some instances, DBDPE was found at similar or higher parts-per-billion ( $\mathrm{ppb}$ ) levels than BDE209 and/or in non-source regions.

In the Arctic, BFR patterns vary between air and biological matrices, as well as between species within food webs. Whereas BDE209 is a major congener in arctic air (19), low to non-detectable levels of BDE209 have been found in tissues of mammals feeding at upper trophic levels of the arctic marine food web (e.g., Chapter 3). As well, the levels, patterns and prey-predator biomagnification of lower brominated PBDEs and other BFRs appear to vary significantly among, e.g., polar bears, ringed seals and beluga whales $(28,35,205)$. Such variations are due to factors such as regional and seasonal differences in dietary exposures, lactational transfer, as well as species-specific biotransformation capacities and substrate-selectivities towards individual contaminants. For instance, high phase I CYP activities and blood levels of OH-PCBs in polar bears imply an elevated ability to biotransform PCB congeners compared to beluga whales and 
ringed seals $(9,23,206)$. In contrast, low levels of OH-PBDEs and slow to nondetectable turnover of environmentally-relevant PBDE congeners during oxidative hepatic microsomal assays has suggested, at least from an CYP perspective, a low biotransformation potential towards PBDEs in these three high-trophic marine-feeding mammals $(66,68,70,119)$.

Nonetheless, studies on other species using different experimental designs have demonstrated varying congener-specific PBDE biotransformation results. Dosed rats were shown to metabolize BDE47, BDE99, BDE100, BDE154, and especially BDE209, but poorly metabolize $\operatorname{BDE} 153(61-65,134,207)$. Oxidation and oxidative debromination were predominant biotransformation pathways, the first step likely being CYP-mediated arene epoxide formation $(64,208)$. The fully brominated BDE209 is not likely metabolized directly by this pathway. Instead, varying rates and degrees of reductive debromination of BDE209 (and some other PBDEs) to lower brominated congeners has been found in dosed fish, birds and rats $(13,71,72)$. Results using hepatic microsomes from Chinook salmon (Onchorhynchus tshawytscha) and common carp (Cyprinus carpio) demonstrated that DTT but not NADPH was required for PBDE debromination, discounting CYP and suggesting involvement of other enzymes, possibly iodothyronine deiodinase(s) $(209,210)$. It is unknown whether DBDPE may undergo similar transformations as BDE209, but it is possible given their physico-chemical similarities. 
Greater understanding of the metabolic capacity towards highly brominated BFRs in wildlife species would contribute to assessing risks associated with, e.g., oxidative and reductive, biotransformation to potentially more toxic, lower brominated metabolites. The previous CYP-oxidative assay designs for arctic marine wildlife may not have adequately captured the metabolic potential towards BFRs, especially for fully brominated BFRs. In this study, we investigated metabolism of BDE209 and DBDPE in high-trophic feeding arctic marine wildlife, in comparison to relatively lower brominated PBDEs (BDE99, BDE100 and BDE154; Fig. 7.1) using an in vitro assay design that expanded the range of possible first step enzymatic transformations. We compared the BFR biotransformation capacity across arctic species including polar bear, beluga whale and ringed seal, as well as the laboratory rat as a mammalian model species.

\subsection{Results}

\subsubsection{EROD Activity of Microsomes}

The EROD activity among the arctic marine wildlife microsomes was highly variable (Table 7.1), but all individuals with one exception fell within a couple hundred to a couple thousand $\mathrm{pmol} / \mathrm{mg} / \mathrm{min}$ catalytic turnover rate. However, the low EROD activity of PB2 did not fit this pattern. The PB2 EROD activity (when extracted and analyzed) 15 years earlier was 35 times higher $(794 \mathrm{pmol} / \mathrm{mg} / \mathrm{min} ; 60)$ than the current measurement and just 2.7 times lower than the EROD activity of PB1. Thus, the current finding of only 


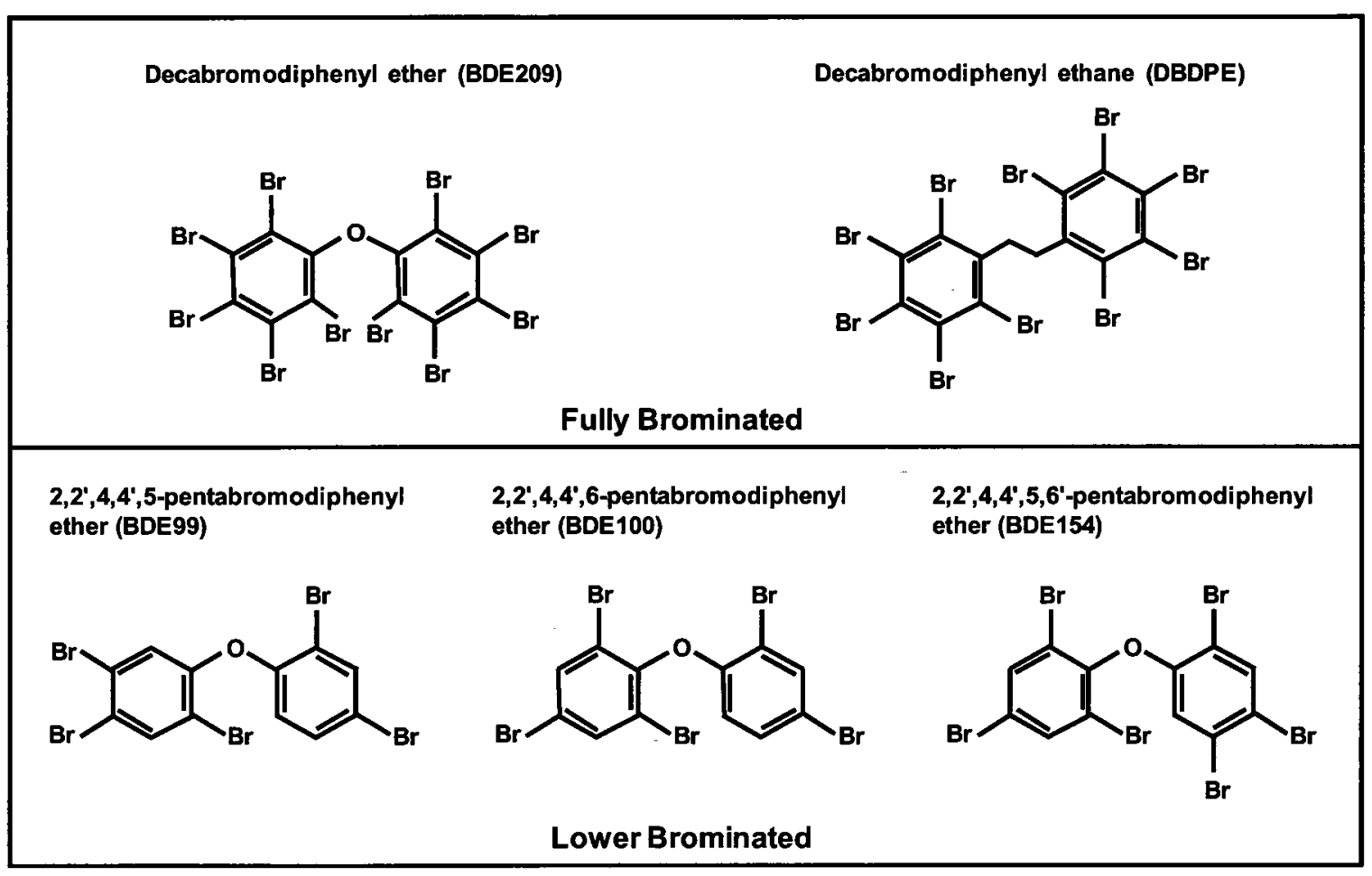

Fig. 7.1. Structures of the BFRs investigated in the current biotransformation study. Hydrogen atoms have been omitted for clarity. 
Table 7.1. Polar bear (PB), beluga whale (BW), ringed seal (RS) and rat (RAT) liver microsomal protein content and EROD activity

\begin{tabular}{lcc}
\hline Sample ID & $\begin{array}{c}\text { Microsomal yield }^{\mathbf{a}} \\
\text { (mg protein/g tissue) }\end{array}$ & $\begin{array}{c}\text { EROD }^{\mathbf{a}} \\
\text { (pmol/mg protein/min) }^{\text {(mg }}\end{array}$ \\
PB1 & $15(2)$ & $2167(99)$ \\
PB2 & $18(1)$ & $23(4)^{6}$ \\
BW1 & $7.3(0.3)$ & $694(41)$ \\
BW2 & $9.0(0.3)$ & $309(6)$ \\
RS1 & $18(1)$ & $397(15)$ \\
RS2 & $19.9(0.4)$ & $199(10)$ \\
RAT & NA & 120 \\
\hline
\end{tabular}

NA: not available.

${ }^{\text {a }}$ Mean ( \pm range) of inter-day duplicate assays ( $n=3$ replicates/assay), except RS2 microsomal yield is mean $( \pm \mathrm{SD})$ of single day replicates and RAT EROD data is from microsome provider (BD Gentest).

${ }^{\mathrm{b}}$ This value is approximately 35 times lower than the value $(794 \mathrm{pmol} / \mathrm{mg}$ protein $/ \mathrm{min}$; $60)$ determined in microsomes from this individual extracted and analyzed around 15 years earlier. 
residual EROD activity in PB2 microsomes was more than likely due to degradation of liver enzyme integrity during more than 15 years in long-term storage. We considered the PB2 microsomes too degraded and did not further use them in the BFR biotransformation assays.

\subsubsection{In Vitro BFR Depletion}

Generally, the PB, BW, RS and RAT microsomes substantially depleted the two fully brominated BFRs, BDE209 and particularly DBDPE, within the limited time frame of the in vitro assay (Fig. 7.2). In contrast, much lesser to non-significant depletion of the pentaand hexa-brominated BDE99, BDE100 and BDE154 occurred for all species. BFRs that were depleted in the mixture assays appeared to be depleted to a greater extent in the single BFR assays, but this was only significant for DBDPE $(p=0.05)$. In the BFR mixture assays, between $6 \%-17 \%$ of BDE209 was depleted and between $27 \%-59 \%$ of DBDPE was depleted. In the single BFR assays, BDE209 was depleted between 14\% $25 \%$ and DBDPE between $44 \%-74 \%$. For PB1, $1 \%$ of BDE154 was depleted in the BFR mixture, and $2 \%, 3 \%$ and a marginally significant $1 \%$ of BDE154, BDE100 and BDE99, respectively, were depleted in the individual BFR assays. In addition, $2 \%$ of BDE154 was depleted by RAT in the single BFR assay. The BW and RS microsomes did not significantly deplete any of the lower brominated PBDEs. Considering all specimens together, significant differences in the extent of depletion between BFRs occurred in both 

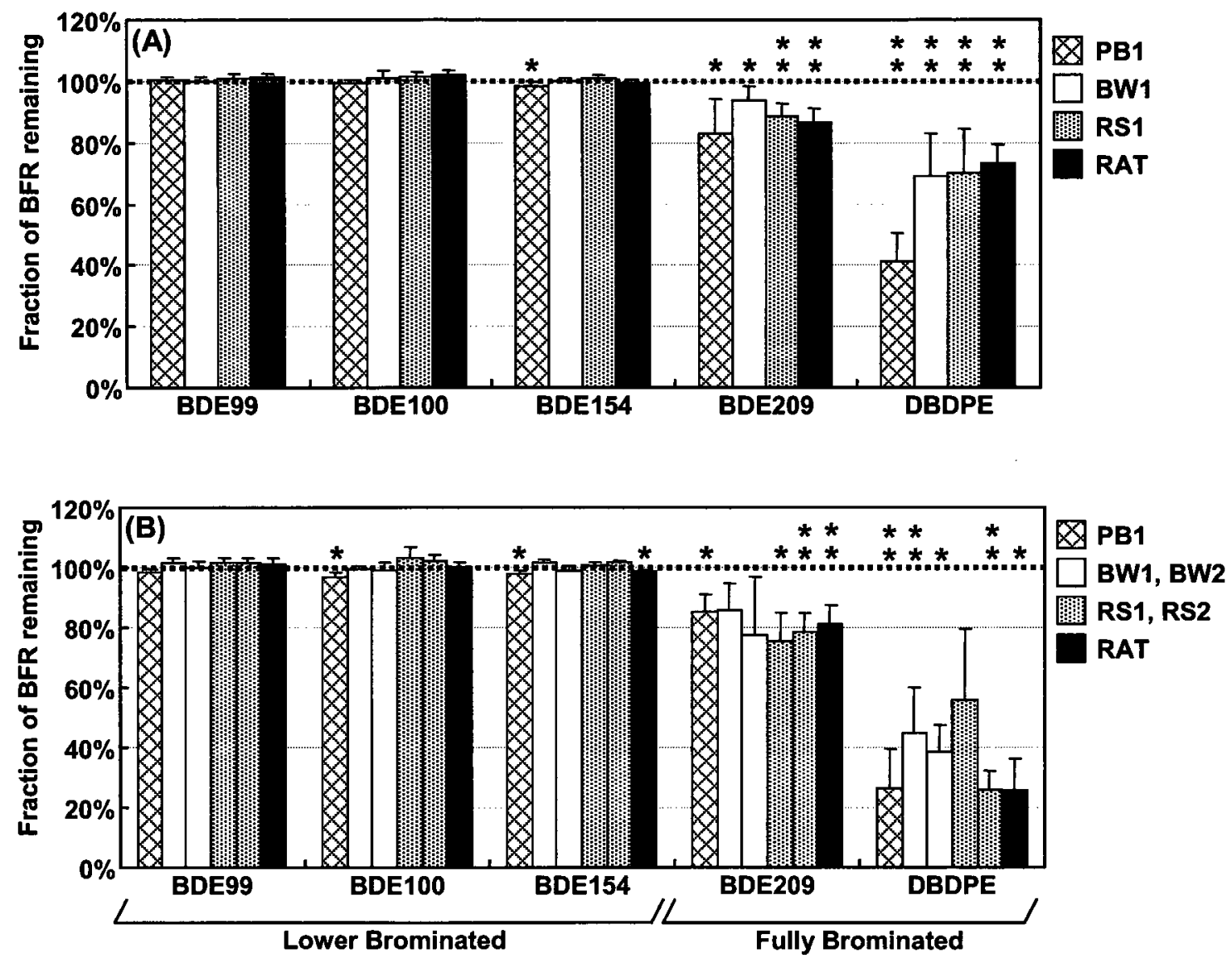

Fig. 7.2. Fraction of BFR concentrations, dosed as a mixture (A) or dosed as individual chemicals (B), remaining after $90 \mathrm{~min}$ incubation with hepatic microsomes from individual polar bear (PB1; cross-hatched bars), beluga whale (BW1 and BW2; white bars) and ringed seal (RS1 and RS2; dotted bars) and pooled ( $n=17)$ rat (RAT; black bars). Error bars represent \pm SD for the mixed BFR ( $n=4$ sample and control replicates) and individual BFR ( $n=3$ replicates) assays. The heavy dotted line denotes no depletion. Significant depletion at the 95\% $(p \leq 0.05)$ and the $99 \%(p \leq 0.01)$ confidence levels are indicated by single and double asterisks, respectively. 
the mixture and individual assays $(p<0.00001)$. Greater depletion of DBDPE than all PBDEs including BDE209 drove the differences in both the mixture assays and the individual assays, except that greater depletion of BDE209 than the lower brominated PBDEs also reached statistical significance in the individual assays (probably due to greater $n$ ).

\subsubsection{Formation of Metabolites}

The PB, BW and RS microsomes were prepared to preserve, and the biotransformation assays were designed to optimize, multiple enzyme systems. This approach was used to hopefully allow for both reductive and oxidative pathways to be substantial enough to observe the metabolism of BFRs in vitro. This was particularly critical to facilitate the metabolism of fully brominated BFRs, wherein a CYP-mediated direct hydroxy group insertion or arene-epoxide formation on a fully halogen-substituted aromatic as an initial metabolic step seems unlikely (65). Initially, the present study focussed on possible debrominated metabolites, given their apparently greater toxicity and environmental persistence (73), at least in the case of PBDEs. However, no clear evidence for formation of any debrominated PBDEs (or debrominated DBDPE metabolites) was observed (see Fig. 7.3 for BDE154, BDE209 and DBDPE metabolism in PB1; BDE99 and BDE100 not shown). For all BFRs studied, there were no peaks indicative of metabolites present in the sample chromatograms (Fig. 7.3; third chromatogram in each series) that were not also present in the control chromatograms (Fig. 7.3; fourth chromatogram in each series) at 
Fig. 7.3. Representative electron capture negative ionization, selected ion monitoring ([Br $\left.]^{-}, m / z 79\right)$ mass chromatograms of extracts from an in vitro biotransformation assay using polar bear (PB1) hepatic microsomes incubated with individual BFRs: (A) BDE154, (B) BDE209 and (C) DBDPE. Control microsomes were inactivated by $\mathrm{MeOH}$ treatment prior to the assay, whereas sample microsomes were viable and were incubated with the cofactors NADPH and DTT. Subsequent to initial screening for parent compound and possible neutral (debrominated) metabolites, controls and samples were derivatized to detect possible phenolic metabolites as their methoxylated analogues. Replicate control and sample $\mathrm{m} / \mathrm{z} 79$ chromatograms as well as all $\mathrm{m} / \mathrm{z} 81$ chromatograms gave the same results. 

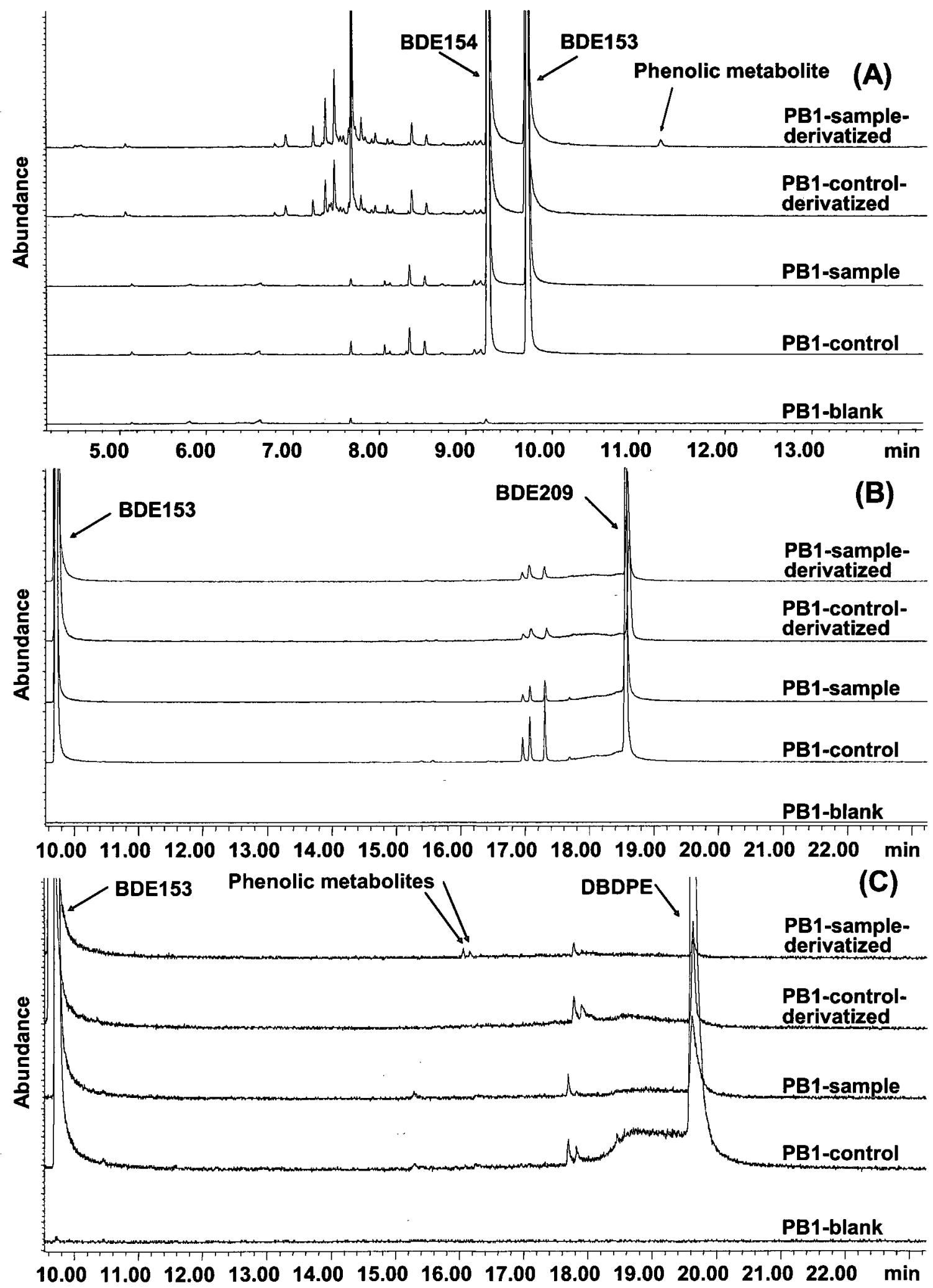
similar concentrations. Nonetheless, all three nonaBDEs (BDE206, BDE207 and BDE208) appeared in the BDE209 chromatograms, as well as two likely but unidentified nonaBDPEs (retention times between 17.6-18.0 $\mathrm{min}$ ) in the DBDPE chromatograms. No peaks were detected in the range that would be expected for octa- or hepta-BDE or BDPE metabolites. The debrominated analyte peaks observed may be present due to 1) minor contamination of the original standard, 2) breakdown of these BFRs in the GC injection port during analysis of the extracts, and/or 3) precursor BFR metabolism in the assays. Metabolism alone cannot fully explain these findings, as these peaks were also found in the controls. If they were present solely due to degradation in the injection port, their response would likely be proportional to the response of the BDE209 (or DBDPE). However, as is particularly noticeable in the case of DBDPE, wherein generally greater than half of the original concentration was metabolised, the response of the first eluting apparent nonaBDPE in the sample extracts was still similar to that in the controls (Fig. 7.3C). Thus, no definitive conclusion can be reached, but these observations suggest that both slight contamination of the original standard and metabolic debromination in the assays may explain the presence of proportionally low amounts of nona-BDPEs and BDEs in the case of DBDPE and possibly BDE209, respectively.

Regardless, given the apparent lack of substantial debrominated metabolites which would account for the extensive depletion of DBDPE and to a lesser extent BDE209, attempts to identify metabolites were expanded by derivatizing the extracts from some individuals, PB1 and the model RAT, to examine the possibility of phenolic and/or 
phenolic debrominated metabolite formation. No derivatized phenolic peaks were observed for BDE209 (Fig. 7.3B, first and second chromatograms in the series), BDE99 or BDE100 (data not shown).

Despite limited depletion of BDE154, a single derivatized phenolic peak was observed in both PB1 (Fig. 7.3A, first chromatogram in the series) and in RAT (data not shown) samples, that was not detectable in the controls (Fig. 7.3A, second chromatogram in the series). Although it did not match the retention time of any of the MeO-PBDE congeners in the standard, it was in the retention time range expected for a MeO-hexaBDE (derivatized $\mathrm{OH}-$ hexa-BDE). Based on the response of the single hexa-brominated congener in the standard, 2'-MeO-BDE123, the concentration of this metabolite after 90 min was $0.5 \pm 0.1 \mathrm{nM}$ in PB1. Given that $2 \%$ of BDE154 (30 $\mathrm{nM}$ original concentration) was transformed by PB1, nearly all of the BDE154 metabolized was accounted for by this single metabolite. The concentration of this metabolite was $0.11 \pm 0.01 \mathrm{nM}$ in the RAT, accounting for around one-fifth of the portion of metabolized BDE154.

In PB1, but not in RAT, two (likely multiply-debrominated, based on much earlier elution than DBDPE) phenolic metabolites were detected in the derivatized DBDPE samples (Fig. 7.3C, first chromatogram in the series) that were not detected in the derivatized controls (Fig. 7.3C, second chromatogram in the series). These metabolites were below the estimated MLOQ of $8 \mathrm{nM}$ for a BDPE-derivative (based on the MLOQ of DBDPE). However, if generously assumed to each be at the MLOQ of $8 \mathrm{nM}$, these 
metabolites would still only account for around one-fifth of the $74 \%$ of the DBDPE depleted by PB1 microsomes.

\subsection{Discussion}

\subsubsection{Microsomal Enzyme Viability}

The large variation in EROD activity observed between the specimens was expected, given that this catalytic activity is not only species-specific, but also dependant in part on sex, age, health status, differential exposure to enzyme-inducing chemicals, time span between death and liver sampling, and length of time the liver tissues were in long-term storage prior to microsome extraction and analysis $(93,120,211)$. Yet, despite the large number of confounding variables, the inter-species variation observed was not inconsistent with previous characterization of cetacean, pinniped and ursid CYP enzyme expression and activity (with the exception of PB2). Specifically, the elevated EROD activity of PB1 is in good agreement with higher CYP protein expression (60), higher levels of OH-PCB and $\mathrm{MeSO}_{2}$-PCB and -DDE metabolites $(9,34,212)$ and simpler PCB congener patterns (23) in polar bears in comparison to beluga whales and ringed seals.

\subsubsection{Biotransformation of Fully Brominated DBDPE and BDE209}

To our knowledge, the only previous study on metabolism of DBDPE (which also examined BDE209) in any species was a very recent dosing study in rats (213). In that study, the authors reported low tissue accumulation of DBDPE (compared to BDE209) 
and the detection of seven metabolites which did not appear to be formed from reductive debromination. In contrast, several debrominated metabolites of BDE209 were reported. BDE209 metabolism has been studied more extensively, both in vitro and in vivo in mammals (including humans), fish and birds. Here, we found consistent and rapid (relative to the other PBDEs studied) depletion of the fully brominated DBDPE and BDE209 by polar bear, beluga whale, ringed seal and rat hepatic microsomes. Hexabromobenzene, has also demonstrated rapid metabolism in a rat toxicokinetic dosing study (214), suggesting that this might be characteristic of fully brominated aromatic compounds. The significantly greater depletion of DBDPE compared to BDE209 may be related to the ethane linkage in DBDPE versus the ether linkage in BDE209 (Fig. 7.1). The saturated bonds of the DBDPE ethane linkage and the lack of unsaturated conjugation result in a low energetic barrier to rotation around these carbon-carbon bonds, whereas the ether linkage of BDE209 is more energetically constrained and the molecular structure more rigid. Such molecular flexibility for DBDPE may permit structural orientations that better facilitate enzyme-mediated metabolism. Further investigation of the comparative metabolic capacity towards these two BFRs, the mechanism(s) of their biotransformation and study of their metabolites in experimental animals is warranted, particularly in light of their large, and in the case of DBDPE likely growing, production volumes (199).

Consistent with the current findings, much more extensive metabolism of BDE209 (65, 71) than BDE47, BDE99, BDE100, BDE153 and BDE154 $(61-64,134,208)$ has been 
observed in rat dosing studies. In contrast, no detectable depletion of BDE209 was observed with phenobarbital-treated (CYP2B-induced) rat microsomes (132), archived polar bear microsomes (70), and various marine mammal microsomes (215) incubated with only NADPH as co-factor, suggesting the possibility that CYPs may not be involved at least in the initial biotransformation step of BDE209. Stapleton et al. (216) did not detect metabolism of BDE209 (in contrast to BDE99) on incubation with human hepatocytes either, but noted that this finding may have been due to low cellular BDE209 uptake. In vitro microsomal (dependant on DTT but not NADPH) and in vivo studies in fish found substantial (debrominative) metabolism of BDE209 in carp and to a much lesser extent rainbow trout. Taken together with the current findings, these results suggest that the metabolism of BDE209 (and possibly DBDPE) may be highly species-specific and/or quantitatively and possibly mechanistically different than that of the lower brominated compounds. Supporting this, the extent of BDE209 depletion was not statistically distinguishable between the individual and the mixed assays (although it was just significant $(p=0.05)$ for DBDPE). This finding suggests that BDE209 and the lower brominated PBDEs are not substrates for the same (iso)enzyme.

The present study did not detect debrominated and/or phenolic metabolites of BDE209, and could only account for a limited fraction of the depleted DBDPE by the detection of two phenolic metabolites (in PB1). Previous BDE209 rat dosing studies identified traces of octa- and nona-BDEs and thirteen debrominated phenolic metabolites, including a $\mathrm{OH}$ octa-BDE, a OH-nona-BDE and a OH-MeO-hexa-BDE $(65,71,195)$. Nonetheless, these 
studies also found that despite extensive metabolism, the majority of the original concentration could not be unaccounted for by the identified metabolites. Hakk et al. (63) noted that a characteristic of PBDE metabolism is the large proportion of non-extractable metabolites. This was also the case for BTBPE in dosed rats (217). Our results may be interpreted similarly or in combination with other possible explanations. For instance, several metabolites could have formed at concentrations below the limit of detection, as there are a large number of debrominated/phenolic metabolites that could be formed from BDE209 or DBDPE. As well, highly brominated phenolic metabolites may not have been effectively derivatized by the diazomethane treatment. Another alternative is low recovery of unknown major metabolites, such as conjugated, water-soluble metabolites that would have remained in the aqueous phase on extraction with hexane. From a toxicological perspective, the first mentioned explanation of high rates of formation of non-extractable metabolites may be a cause for concern, as they imply covalent-binding of reactive metabolites to macromolecules, (i.e., proteins and/or lipids: 63, 65). Future studies should perhaps use radiolabeled BDE209 and DBDPE to improve the ability to track loss of the parent compound.

Rapid depletion of BDE209 relative to the lower brominated PBDEs studied, taken together with the fish and rat laboratory experiments, has implications for the understanding of BDE209 contamination in the environment. The extent of wildlife (and likely human) exposure to BDE209 may not be fully realized by measurement of tissue levels of BDE209, which may be very low, highly affected by metabolism, and thus 
significantly underestimate the ecosystem burden of total BDE209 (BDE209 and its transformation products). As Ross et al. (218) have pointed out, increasing and substantial abiotic reservoirs of BDE209, despite possibly lower bioavailability than for other PBDEs, represent a serious concern for marine ecosystems. The same case may be made for DBDPE, given its obvious similarities to BDE209, the present results demonstrating depletion, and the apparently increasing use of DBDPE as a replacement for BDE209.

\subsubsection{Biotransformation of BDE99, BDE100 and BDE154}

The in vitro assay results indicated a slower rate of depletion (either oxidatively or by reductive debromination) of the lower brominated, environmentally-relevant BDE99, BDE100 and BDE154, in the studied species in comparison to the highly brominated BFRs. This is in agreement with previous NADPH-dependent microsomal assays showing non-detectable penta- and hexa-BDE depletion in beluga whale (119), archived polar bear (70) and various marine mammal (215) microsomes. Yet, species-specific differences do occur as exemplified by lower marine vertebrates, e.g., certain but not all fish species appear to be able to rapidly metabolize not only BDE209 (13), but also lower brominated PBDEs. For instance, carp liver microsomes completely metabolized BDE99 through debromination to BDE47 within 60 min (209), and the transformation was dependent on the presence of DTT but not NADPH, again suggesting the involvement of enzymes other than CYPs. Metabolism of BDE99 was very slow in a study on Chinook 
salmon hepatic microsomes, though, and BDE49 rather than BDE47 was the observed metabolite (210).

Slow but significant depletion of BDE154 was observed in the archived polar bear study (70), which was also observed in the current study (PB1 and RAT). Detection of a phenolic metabolite of BDE154 in PB1 (and RAT) likely accounted for a substantial portion of the BDE154 metabolism. Unlike DBDPE, this phenolic metabolite eluted after BDE154, suggesting no concomitant debromination of BDE154 in this transformation pathway or possibly debromination and multiple hydroxylation. Based on monitoring of the $[\mathrm{Br}]^{-}$anions only, this metabolite could be singly- or multiply-hydroxylated. MonoOH-tetra- to hexa-BDEs, as well as di-OH-penta- and hexa-BDEs were found in BDE154 dosed rats, yet high amounts of non-extractable metabolites were also noted (64).

Because of the low number available individuals from each species, it was not possible to assess the inter-species differences in metabolic capacity towards the various BFRs. Nonetheless, the present results indicated that all species investigated were able to rapidly deplete BDE209 and DBDPE relative to the lower brominated PBDEs studied. There may also be differences in the rate of metabolism among species, with a tendency for slower transformation in beluga whale, and faster transformation in rat and polar bear. This conclusion is tentative based on the small dataset and other potentially confounding variables (e.g., sex, age, tissue preservation), but is consistent with what is known of these species' metabolic capacities towards other xenobiotics (Section 7.3.1). 
This study found depletion of the fully brominated BDE209 and especially DBDPE in comparison to the lower brominated BDE99, BDE100 and BDE154 across a range of arctic marine-feeding mammals: polar bear, beluga whale, ringed seal, as well as the model, rat). Particularly for BDE209 and DBDPE, low to non-detectable levels of debrominated and/or phenolic metabolites, despite large depletion, suggested the possibility of bioactivation through covalent binding of reactive metabolites to macromolecules. Given the large environmental reservoirs of BDE209 and possibly DBDPE, and their apparently relatively rapid biotransformation, it is possible that despite low to moderate bioavailability, these species may be more or less continuously exposed to these BFRs. Our findings indicate that for highly brominated BFRs, further research into their environmental fate, abiotic and metabolic transformation products and interactions with biomacromolecules is required to understand their environmental risks. 


\section{Chapter 8: Conclusions, Implications and Future Directions}

\subsection{Conclusions and Implications}

Arctic environments and ecosystems were once considered pristine relative to more populated and industrialized temperate regions. However, it is now recognized that the Arctic is subject to contamination by a broad suite of mainly long-range transported chemicals that are used in agriculture, industry and several consumer products. For top trophic feeding arctic wildlife such as polar bears, a growing body of evidence suggests that current contamination levels are resulting in subtle health effects. Nevertheless, contaminant accumulation and associated health concerns in polar bears and other species depend on several abiotic, biological and ecological factors. Although it has been speculated that diet/food web factors influence polar bear contaminant trends, this hypothesis has not previously been empirically tested. In Chapters 3-6, I clearly demonstrated, for the first time, that geographic and temporal variation in "emerging" BFR and legacy contaminant levels and patterns in polar bears is partially attributable to diet factors. The main conclusions and broader implications from the studies in this thesis are detailed here.

Estimates of diet/food web parameters are necessary to accurately assess and interpret contaminant spatial and temporal trends. From the results of this thesis, I recommend consideration of diet (and overall food web) factors in the design of spatial and temporal contaminant trends studies. Given that polar bears are considered an 
important arctic sentinel species, a limited understanding of the biological and ecological factors that can confound spatial and temporal trends assessments may lead to erroneous conclusions. That is, differences in polar bear contamination levels among subpopulations and changes over time could be misinterpreted as being due solely to regional differences or temporal changes, respectively, in source emissions. This possibility has major regulatory and policy implications, in terms of accurately identifying, and in turn minimizing, regional sources and emissions. For instance, in Chapter 4, I showed that diet signatures in WHB and SHB were associated with lower PCB and PBDE levels, whereas EG and SV signatures were associated with higher levels. Therefore, reports of higher contaminant levels in European Arctic environments based on polar bear subpopulation assessments are partially related to significant diet differences expressed among sampled subpopulations. From a wildlife management perspective, these results also provide information on subpopulations (EG and SV) that are more susceptible to elevated contaminant levels based on their feeding strategies and regional availability of prey items. This is in addition to these subpopulations (EG and SV) being exposed to higher levels through differences in regional contamination loadings. The possibility that diet-related contaminant loads in EG and SV subpopulations were partially a result of elevated consumption of migratory and more contaminated harp seals could not be concluded with certainty. However, the dietary tracer results certainly indicate that further investigations along these lines are warranted. 
Polar bears may not be reliable biomonitors for certain contaminants. Like biological factors, the importance of diet/food web factors appears to vary by contaminant class (Chapters 4 and 5). In Chapter 4, I showed that Diet-Index explained a considerable proportion of the variation in PCB and PBDE levels, but only explained lower or non-significant proportions of the variation in OCP levels. These findings were likely due to the greater influence of metabolism and/or elimination of these less persistent (at least in polar bears) OCP contaminants. Similarly, in the biotransformation assays (Chapter 7), substantial BDE209 depletion suggested possible underestimation of the ecosystem burden of total BDE209 (BDE209 and its transformation products), and the need for further research to identify (and assess the persistence and toxicity of) major BDE209 metabolites. There may be a similar cause for concern regarding DBDPE, given its similarities to BDE209 in physico-chemical and environmental properties, current evidence of biotransformation, and its apparent increasing use as a replacement for BDE209. Taken together, these studies (Chapters 4 and 7 ) indicate that polar bears may only be a good reflection of arctic marine ecosystem contamination for the relatively more persistent contaminants. On the other hand, there may be a more immediate cause for concern for a contaminant that does accumulate in polar bears, given that this species appears to substantially accumulate only highly recalcitrant contaminants.

"New" chemicals continue to find their way into arctic environments and ecosystems, resulting in "new generations" of POPs. I reported the presence of novel BFRs in polar bear subpopulations (Chapters 3 and 6). The presence of PBEB, HBB, 
BTBPE and DBDPE in a minority of samples indicated that these "emerging" contaminants are transported to the Arctic and that their continued monitoring is warranted. Moreover, the detection of a chemical in a top trophic feeding arctic predator such as polar bears indicates that the POP criteria of persistence, bioaccumulation and long-range transport have been fulfilled. I also presented the first report of $\mathrm{MeSO}_{2}-\mathrm{PCB}$ and BFR temporal patterns (Chapter 6), and the first report of spatial BFR patterns (Chapter 3), in polar bears, with the exception of one previous spatial study on PBDEs (35). In addition to these "new" or more recently detected chemicals, I found that circumpolar subpopulations continued (as of 2005-2008; Chapter 3) to have high levels of certain historic pollutants. On a concentration basis, legacy contaminants, particularly PCBs and CHLs, remained of greatest concern, despite international regulations on their production and use. Overall, despite temporal decreases for some organohalogens, the findings in this thesis suggested that certain legacy organohalogens, as well as a complex mixture of emerging contaminants, will remain an environmental concern in arctic ecosystems in years to come. Current national and international regulations on these manufactured chemicals are mostly reactive in nature, responding through treaties and legislation only after chemicals have been identified as environmental contaminants. The results reported in this thesis further support increasing calls for the development of legislation that is more proactive, in an effort to curb and regulate the manufacture of further generations of POP-like (replacement) chemicals. Also of importance is the 
improvement of controls on the release of legacy contaminants from stockpiles and in-use materials.

Climate change-related effects on contaminant burdens in arctic wildlife are already occurring, and should be considered in contaminant accumulation and effects studies. Climate change and contamination by POPs are two global environmental issues that are major concerns for arctic ecosystems. Predictions have been made regarding the possible influence of climate changes on contaminant levels and pathways in arctic environments and ecosystems. Yet, to my knowledge, this thesis provided the first empirical evidence linking a climate associated change to actual changes in contaminant levels in an arctic wildlife species. I showed that climate change indirectly modulated contaminant levels and patterns through sea ice-associated diet change in the WHB polar bear subpopulation (Chapters 5 and 6). As expected from climate change predictions, this apparent diet change was consistent with an increase in the consumed proportions of open water-associated seal species compared to iceassociated seal species in years of earlier sea ice breakup. Polar bear diets in years with earlier sea ice breakup, in turn, were associated with higher contaminant burdens. These findings, along with other recent studies $(103,108,109)$, are the first indications that climate change-related shifts in contaminant levels and patterns in arctic food webs have already occurred. Thus, in addition to substantial shifts in phenology, geography and composition of ecosystems in the Arctic and many other regions of the world (102, 162, 
163), climate changes are altering, and likely will continue to alter, the ecosystem burdens and health risks posed by persistent organic pollutants.

\subsection{Future Directions}

Results from this thesis and their ensuing discussion make clear some avenues for future research, the most important of which are outlined below.

1. This thesis was a first attempt at incorporating diet/food web as an explanatory factor in polar bear contaminant levels both over spatial and temporal scales. The application of chemical tracers to diet/food web studies of contaminants is not new, yet so far it has generally been restricted to single systems and points in time. In this thesis, geographic comparisons and changes over time were investigated. This remains a challenging area of research due to a number of simplifying assumptions and unknowns that require refinement and characterization, respectively. One major issue identified by this work is a lack of circumpolar baseline SI and FA tracer data and a very limited understanding of potential baseline temporal variation. From a spatial aspect, this thesis used spatially and temporally comparable ringed seal SI and FA data to make polar bear tracer values more comparable across regions. However, baseline tracer data would have been more appropriate and would have allowed for comparison of integrated food web signatures. In the temporal work, the incorporation of baseline data was not possible and thus no baseline correction was applied. It remains to be seen whether temporal baseline variation may have been an influential factor. In general terms, for both spatial and 
temporal assessments, an appropriate baseline organism/species for circumpolar arctic marine ecosystem comparisons should be identified (136) making not only variation among arctic ecosystems more valid but also allowing comparisons to be made across multiple studies. Nonetheless, SI and FA variation at the base of the food web may still be relevant to contaminant accumulation. For instance, low $\delta^{13} \mathrm{C}$ values that indicate elevated terrestrial/freshwater inputs into a marine food web may actually reflect a contaminant source, especially for more water soluble contaminants such as certain PFCs (142). Thus, a better understanding of the reasons why baseline variation occurs across regions and over time should also be pursued, in order to determine the appropriateness of applying a baseline correction.

2. More holistic food web studies should be performed as opposed to single organism studies. In this thesis, it was demonstrated that the study of a single species suffers from species-specific idiosyncrasies; the high biotransformation capacity of polar bears resulted in their OCP levels not necessarily being a good reflection of ecosystem contamination. Incorporating more food web information could provide a more comprehensive comparison across polar bear subpopulations and over time, particularly as applied to understanding the effects of climate change-associated food web change on contaminant levels and pathways. For instance, Hudson Bay appears to be undergoing climate change-related food web changes and may be a good "indicator food web" for identifying climate related contaminant changes in future studies, rather than focusing on the often considered "indicator species". 
3. Several studies, including those in this thesis, have identified and/or examined a single or a few factors (e.g. demographic group, season, habitat use, reproductive status, body condition, diet/food web, induction status of biotransformation enzymes) that have correlated significantly with polar bear contaminant levels. However, the simultaneous consideration of all known and possibly inter-related factors has not been considered generally due to unknown factors, missing or incomplete values, and small datasets (often causing over-parameterization of complex models). Ideally, a large enough database, perhaps combined among polar bear researchers, could be generated and standardized for inter-study variation, and then mined to clarify the relative importance of many identified factors and their interactions to better understand polar bear and arctic marine ecosystem contamination. It is interesting to note that results from the spatial dietary tracer analyses (Chapter 4) using 2 SIs and 12 dietary FAs along with much lower sample sizes were consistent with a much larger FA study on Canadian Arctic subpopulations from 1972-2004 (81). This consistency suggested (1) a smaller subset of SI and/or FA tracers may be sufficient in future studies and (2) regional diet differences and possible future changes may be distinguished with an $n$ as low as around 10 individuals per subpopulation, similar to previous recommendations for POPs monitoring in polar bears (44).

4. In the temporal studies, the influence of diet/food web change on WHB contaminant levels and patterns was investigated. However, there are many other ways in which climate changes may influence contaminant levels in arctic and subarctic marine food 
webs, e.g., transport patterns and rates, temperature and primary production (Section 1.2.2.4). Currently, most potential factors have merely been predictions. More specific values and parameters from modeling and empirical studies are needed to examine the magnitude and direction of such effects on contaminant levels, and to assess which identified or currently unidentified factors may be more or less influential. It should be noted that the current (2005-2008) SI and FA dataset from the studied subpopulations (Chapter 4) represents a large spatial-scale reference dataset to which future studies could be compared in order assess climate change-associated diet/food web impacts on contaminant levels in and among arctic and subarctic regions.

5. In future BFR biotransformation studies, radio-labeled compounds could be used in order to avoid, or account for, recovery losses in conducted assays. Attempts to determine covalent-binding of metabolites, or perhaps suggest the identity of other metabolites, would thus be possible through identification of the fractions containing remaining radioactivity. 


\section{References}

(1) Ballschmiter, K.; Zell, M. Analysis of polychlorinated biphenyls (PCB) by glass capillary gas chromatography Fresenius $Z$. Anal. Chem. 1980, 302, 20-31.

(2) Macdonald, R. W.; Barrie, L. A.; Bidleman, T. F.; Diamond, M. L.; Gregor, D. J.; Semkin, R. G.; Strachan, W. M. J.; Li, Y. F.; Wania, F.; Alaee, M.; Alexeeva, L. B.; Backus, S. M.; Bailey, R.; Bewers, J. M.; Gobeil, C.; Halsall, C. J.; Harner, T.; Hoff, J. T.; Jantunen, L. M. M.; Lockhart, W. L.; Mackay, D.; Muir, D. C. G.; Pudykiewicz, J.; Reimer, K. J.; Smith, J. N.; Stern, G. A.; Schroeder, W. H.; Wagemann, R.; Yunker, M. B. Contaminants in the Canadian Arctic: 5 years of progress in understanding sources, occurrence and pathways Sci. Total Environ. 2000, 254, 93234.

(3) de Wit, C. A.; Fisk, A. T.; Hobbs, K. E.; Muir, D. C. G.; Gabrielsen, G. W.; Kallenborn, R.; Krahn, M. M.; Norstrom, R. J.; Skaare, J. U. AMAP Assessment 2002: Persistent organic pollutants in the Arctic.; Arctic Monitoring and Assessment Programme: Oslo, 2004.

(4) van den Berg, H. Global status of DDT and its alternatives for use in vector control to prevent disease; Stockholm Convention/United Nations Environment Programme: Geneva, 2008; pp 1-31.

(5) Diamond, M. L.; Melymuk, L.; Csiszar, S. A.; Robson, M. Estimation of PCB stocks, emissions, and urban fate: will our policies reduce concentrations and exposure? Environ. Sci. Technol. 2010, 44, 2777-2783.

(6) de Wit, C. A.; Herzke, D.; Vorkamp, K. Brominated flame retardants in the Arctic environment -- trends and new candidates Sci. Total Environ. 2010, 408, 2885-2918.

(7) Butt, C. M.; Berger, U.; Bossi, R.; Tomy, G. T. Levels and trends of poly- and perfluorinated compounds in the arctic environment Sci. Total Environ. 2010, 408, 2936-2965.

(8) Weber, J.; Halsall, C. J.; Muir, D.; Teixeira, C.; Small, J.; Solomon, K.; Hermanson, M.; Hung, H.; Bidleman, T. Endosulfan, a global pesticide: a review of its fate in the environment and occurrence in the Arctic Sci. Total Environ. 2010, 408, 2966-2984.

(9) Letcher, R. J.; Bustnes, J. O.; Dietz, R.; Jenssen, B. M.; Jørgensen, E. H.; Sonne, C.; Verreault, J.; Vijayan, M. M.; Gabrielsen, G. W. Exposure and effects assessment of persistent organohalogen contaminants in arctic wildlife and fish Sci. Total Environ. 2010, 408, 2995-3043.

(10) Darnerud, P. O. Toxic effects of brominated flame retardants in man and in wildlife Environ. Int. 2003, 29, 841-853.

(11) Söderström, G.; Sellström, U.; de Wit, C. A.; Tysklind, M. Photolytic debromination of decabromodiphenyl ether (BDE 209) Environ. Sci. Technol. 2004, 38, 127-132.

(12) Stapleton, H. M.; Alaee, M.; Letcher, R. J.; Baker, J. E. Debromination of the flame retardant decabromodiphenyl ether by juvenile carp (Cyprinus carpio) following dietary exposure Environ. Sci. Technol. 2004, 38, 112-119.

(13) Stapleton, H. M.; Brazil, B.; Holbrook, R. D.; Mitchelmore, C. L.; Benedict, R.; Konstantinov, A.; Potter, D. In vivo and in vitro debromination of decabromodiphenyl 
ether (BDE209) by juvenile rainbow trout and common carp Environ. Sci. Technol. 2006, 40, 4653-4658.

(14) Muir, D. C. G.; Howard, P. H. Are there other persistent organic pollutants? A challenge for environmental chemists Environ. Sci. Technol. 2006, 40, 7157-7166.

(15) Ballschmiter, K. Global distribution of organic compounds Environ. Carcinogen. Rev. C-J. Environ. Science Health 1991, 9, 1-46.

(16) Gouin, T.; Mackay, D.; Jones, K. C.; Harner, T.; Meijer, S. N. Evidence for the "grasshopper" effect and fractionation during long-range atmospheric transport of organic contaminants Environ. Pollut. 2004, 128, 139-148.

(17) Blais, J. M.; Kimpe, L. E.; McMahon, D.; Keatley, B. E.; Mattory, M. L.; Douglas, M. S. V.; Smol, J. P. Arctic seabirds transport marine-derived contaminants Science 2005, 309, 445.

(18) Wania, F. Potential of degradable organic chemicals for absolute and relative enrichment in the Arctic Environ. Sci. Technol. 2006, 40, 569-577.

(19) Su, Y.; Hung, H.; Sverko, E.; Fellin, P.; Li, H. Multi-year measurements of polybrominated diphenyl ethers (PBDEs) in the Arctic atmosphere Atmos. Environ. 2007, 41, 8725-8735.

(20) Thomann, R. V. Bioaccumulation model of organic chemical distribution in aquatic food chains Environ. Sci. Technol. 1989, 23, 699-707.

(21) Christensen, J. H.; Platz, J. Screening of polybrominated diphenyl ethers in blue mussels, marine and freshwater sediments in Denmark J. Environ. Monitor. 2001, 3, 543-547.

(22) Borgå, K.; Fisk, A. T.; Hoekstra, P. F.; Muir, D. C. G. Biological and chemical factors of importance in the bioaccumulation and trophic transfer of persistent organochlorine contaminants in Arctic marine food webs Environ. Toxicol. Chem. 2004, 23, 2367-2385.

(23) Norstrom, R. J.; Muir, D. C. G. Chlorinated hydrocarbon contaminants in arctic marine mammals Sci. Total Environ. 1994, 154, 107-128.

(24) Jones, K. C.; de Voogt, P. Persistent organic pollutants (POPs): state of the science Environ. Pollut. 1999, 100, 209-221.

(25) de March, B. G. E.; de Wit, C. A.; Muir, D. C. G.; Braune, B. M.; Gregor, D. J.; Norstrom, R. J.; Olsson, M.; Skaare, J. U.; Strange, K. Persistent organic pollutants. In AMAP Assessment Report, Arctic Pollution Issues; Arctic Monitoring and Assessment Programme: Oslo 1998; pp 183-372.

(26) Norstrom, R. J.; Belikov, S. E.; Born, E. W.; Garner, G. W.; Malone, B.; Olpinski, S.; Ramsay, M. A.; Schliebe, S.; Stirling, I.; Stishov, M. S.; Taylor, M. K.; Wiig, Ø. Chlorinated hydrocarbon contaminants in polar bears from eastern Russia, North America, Greenland, and Svalbard: biomonitoring of Arctic pollution Arch. Environ. Contam. Toxicol. 1998, 35, 354-367.

(27) Dietz, R.; Riget, F. F.; Sonne, C.; Letcher, R. J.; Born, E. W.; Muir, D. C. G. Seasonal and temporal trends in polychlorinated biphenyls and organochlorine 
pesticides in east Greenland polar bears (Ursus maritimus), 1990-2001 Sci. Total Environ. 2004, 331, 107-124.

(28) Dietz, R.; Rigét, F. F.; Sonne, C.; Letcher, R. J.; Backus, S.; Born, E. W.; Kirkegaard, M.; Muir, D. C. G. Age and seasonal variability of polybrominated diphenyl ethers in free-ranging east Greenland polar bears (Ursus maritimus) Environ. Pollut. 2007, 146, 166-173.

(29) Polischuk, S. C.; Norstrom, R. J.; Ramsay, M. A. Body burdens and tissue concentrations of organochlorines in polar bears (Ursus maritimus) vary during seasonal fasts Environ. Pollut. 2002, 118, 29-39.

(30) Bentzen, T. W.; Follmann, E. H.; Amstrup, S. C.; York, G. S.; Wooller, M. J.; Muir, D. C. G.; O'Hara, T. M. Dietary biomagnification of organochlorine contaminants in Alaskan polar bears Can. J. Zool. 2008, 86, 177-191.

(31) Paetkau, D.; Amstrup, S. C.; Born, E. W.; Calvert, W.; Derocher, A. E.; Garner, G. W.; Messier, F.; Stirling, I.; Taylor, M. K.; Wiig, Ø.; Strobeck, C. Genetic structure of the world's polar bear populations Mol. Ecol. 1999, 8, 1571-1584.

(32) Taylor, M. K.; Lee, J. Distribution and abundance of Canadian Polar Bear populations: a management perspective Arctic 1995, 48, 147-154.

(33) Braune, B. M.; Outridge, P. M.; Fisk, A. T.; Muir, D. C. G.; Helm, P. A.; Hobbs, K.; Hoekstra, P. F.; Kuzyk, Z. A.; Kwan, M.; Letcher, R. J.; Lockhart, W. L.; Norstrom, R. J.; Stern, G. A.; Stirling, I. Persistent organic pollutants and mercury in marine biota of the Canadian Arctic: an overview of spatial and temporal trends Sci. Total Environ. 2005, 351-352, 4-56.

(34) Letcher, R. J.; Norstrom, R. J.; Muir, D. C. G. Biotransformation versus bioaccumulation: sources of methyl sulfone PCB and 4,4'-DDE metabolites in the polar bears food chain Environ. Sci. Technol. 1998, 32, 1656-1661.

(35) Muir, D. C. G.; Backus, S.; Derocher, A. E.; Dietz, R.; Evans, T. J.; Gabrielsen, G. W.; Nagy, J.; Norstrom, R. J.; Sonne, C.; Stirling, I.; Taylor, M. K.; Letcher, R. J. Brominated flame retardants in polar bears (Ursus maritimus) from Alaska, the Canadian Arctic, east Greenland, and Svalbard Environ. Sci. Technol. 2006, 40, 449455.

(36) Andersen, M.; Lie, E.; Derocher, A. E.; Belikov, S. E.; Bernhoft, A.; Boltunov, A. N.; Garner, G. W.; Skaare, J. U.; Wiig, Ø. Geographic variation of PCB congeners in polar bears (Ursus maritimus) from Svalbard east to the Chukchi Sea Polar Biol. 2001, 24, 231-238.

(37) Letcher, R. J.; Norstrom, R. J.; Bergman, $\AA$. Geographical distribution and identification of methyl sulfone PCB and DDE metabolites in pooled polar bear (Ursus maritimus) adipose tissue from western hemisphere arctic and subarctic regions Sci. Total Environ. 1995, 160-161, 409-420.

(38) Lie, E.; Bernhoft, A.; Riget, F.; Belikov, S. E.; Boltunov, A. N.; Derocher, A. E.; Garner, G. W.; Wiig, Ø.; Skaare, J. U. Geographical distribution of organochlorine pesticides (OCPs) in polar bears (Ursus maritimus) in the Norwegian and Russian Arctic Sci. Total Environ. 2003, 306, 159-170. 
(39) Verreault, J.; Muir, D. C. G.; Norstrom, R. J.; Stirling, I.; Fisk, A. T.; Gabrielsen, G. W.; Derocher, A. E.; Evans, T. J.; Dietz, R.; Sonne, C.; Sandala, G. M.; Gebbink, W.; Riget, F. F.; Born, E. W.; Taylor, M. K.; Nagy, J.; Letcher, R. J. Chlorinated hydrocarbon contaminants and metabolites in polar bears (Ursus maritimus) from Alaska, Canada, east Greenland, and Svalbard: 1996-2002 Sci. Total Environ. 2005, 351, 369-390.

(40) Sonne, C. Health effects from long-range transported contaminants in Arctic top predators: An integrated review based on studies of polar bears and relevant model species Environ. Int. 2010, 36, 461-491.

(41) Fisk, A. T.; de Wit, C. A.; Wayland, M.; Kuzyk, Z. Z.; Burgess, N.; Letcher, R. J.; Braune, B.; Norstrom, R. J.; Polischuk Blum, S.; Sandau, C.; Lie, E.; Larsen, H. J. S.; Skaare, J. U.; Muir, D. C. G. An assessment of the toxicological significance of anthropogenic contaminants in Canadian arctic wildlife Sci. Total Environ. 2005, 351$352,57-93$.

(42) Aars, J.; Lunn, N. J.; Derocher, A. E. Polar Bears: Proceedings of the 14th Working Meeting of the IUCN/SSC Polar Bear Specialist Group. 2006. Gland, Switzerland, IUCN.

(43) Norstrom, R. J.; Moisey, J.; Stirling, I.; Lunn, N. J.; Sandau, C.; Bandiera, S. M.; Skaare, J. U.; Larsen, H. J.; Derocher, A. E.; Wiig, Ø. Effects and trends of POPs on polar bears. In Synopsis of research conducted under the 2000-2001 Northern Contaminants Program; Kalhok, S., Ed.; Department of Indian Affairs and Northern Development: Ottawa 2001; pp 215-226.

(44) Henriksen, E. O.; Wiig, Ø.; Skaare, J. U.; Gabrielsen, G. W.; Derocher, A. E. Monitoring PCBs in polar bears: lessons learned from Svalbard J. Environ. Monit. 2001, 3, 493-498.

(45) Ikonomou, M. G.; Kelly, B. C.; Stern, G. A. Spatial and temporal trends of PBDEs in biota from the Canadian Arctic marine environment Organohalog. Compd. 2005, 67, 950-953.

(46) Ikonomou, M. G.; Rayne, S. R.; Addison, R. F. Exponential increases of the brominated flame retardants, polybrominated diphenyl ethers, in the Canadian Arctic from 1981 to 2000 Environ. Sci. Technol. 2002, 36, 1886-1892.

(47) Rigét, F.; Vorkamp, K.; Dietz, R.; Rastogi, S. C. Temporal trend studies on polybrominated diphenyl ethers (PBDEs) and polychlorinated biphenyls (PCBs) in ringed seals from east Greenland J. Environ. Monitor. 2006, 8, 1000-1005.

(48) Sandau, C. D. Analytical chemistry of hydroxylated metabolites of PCBs and other halogenated phenolic compounds in blood and their relationship to thyroid hormone and retinol homeostasis in humans and polar bears. Ph.D. Dissertation, Carleton University, 2000.

(49) Skaare, J. U.; Bernhoft, A.; Wiig, Ø.; Norum, K. R.; Haug, E.; Eide, D. M.; Derocher, A. E. Relationships between plasma levels of organochlorines, retinol and thyroid hormones from polar bears (Ursus maritimus) at Svalbard J. Toxicol. Environ. Health, Part A 2001, 62, 101-115. 
(50) Braathen, M.; Derocher, A. E.; Wiig, Ø.; Sørmo, E. G.; Lie, E.; Skaare, J. U.; Jenssen, B. M. Relationship between PCBs and thyroid hormones and retinol in female and male polar bears Environ. Health Perspect. 2004, 112, 826-833.

(51) Haave, M.; Ropstad, E.; Derocher, A. E.; Lie, E.; Dahl, E.; Wiger, R.; Skaare, J. U.; Jenssen, B. M. Polychlorinated biphenyls and reproductive hormones in female polar bears at Svalbard Environ. Health Perspect. 2003, 111, 431-436.

(52) Oskam, I. C.; Ropstad, E.; Lie, E.; Derocher, A. E.; Wiig, Ø.; Dahl, E.; Larsen, S.; Skaare, J. U. Organochlorines affect the steroid hormone cortisol in free-ranging polar bears (Ursus maritimus) at Svalbard, Norway J. Toxicol. Environ. Health, Part A 2004, 67, 959-977.

(53) Oskam, I. C.; Ropstad, E.; Dahl, E.; Lie, E.; Derocher, A. E.; Wiig, Ø.; Larsen, S.; Wiger, R.; Skaare, J. U. Organochlorines affect the major androgenic hormone, testosterone, in male polar bears (Ursus maritimus) at Svalbard J. Toxicol. Environ. Health, Part A 2003, 66, 2119-2139.

(54) Lie, E.; Larsen, H. J. S.; Larsen, S.; Johansen, G. M.; Derocher, A. E.; Lunn, N. J.; Norstrom, R. J.; Wiig, Ø.; Skaare, J. U. Does high organochlorine (OC) exposure impair the resistance to infection in polar bears (Ursus maritimus)? Part I: effect of OCs on the humoral immunity $J$. Toxicol. Environ. Health, Part A 2004, 67, 555-582.

(55) Sonne, C.; Dietz, R.; Leifsson, P. S.; Born, E. W.; Letcher, R. J.; Kirkegaard, M.; Muir, D. C. G.; Riget, F. F.; Hyldstrup, L. Do organohalogen contaminants contribute to histopathology in liver from east Greenland polar bears (Ursus maritimus)? Environ. Health Perspect. 2005, 113, 1569-1574.

(56) Sonne, C.; Dietz, R.; Born, E. W.; Riget, F. F.; Kirkegaard, M.; Hyldstrup, L.; Letcher, R. J.; Muir, D. C. G. Is bone mineral composition disrupted by organochlorines in east Greenland polar bears (Ursus maritimus)? Environ. Health Perspect. 2004, 112, 1711-1716.

(57) Sonne, C.; Leifsson, P. S.; Dietz, R.; Born, E. W.; Letcher, R. J.; Hyldstrup, L.; Riget, F. F.; Kirkegaard, M.; Muir, D. C. G. Xenoendocrine pollutants may reduce size of sexual organs in east Greenland polar bears (Ursus maritimus) Environ. Sci. Technol. 2006, 40, 5668-5674.

(58) Polischuk, S. C.; Letcher, R. J.; Norstrom, R. J.; Ramsay, M. A. Preliminary results of fasting on the kinetics of organochlorines in polar bears (Ursus maritimus) Sci. Total Environ. 1995, 160-161, 465-472.

(59) Laidre, K. L.; Stirling, I.; Lowry, L. F.; Wiig, Ø.; Heide-Jorgensen, M. P.; Ferguson, S. H. Quantifying the sensitivity of arctic marine mammals to climate-induced habitat change Ecol. Appl. 2008, 18, S97-S125.

(60) Letcher, R. J.; Norstrom, R. J.; Lin, S.; Ramsay, M. A.; Bandiera, S. M. Immunoquantitation and microsomal monooxygenase activities of hepatic cytochromes P4501A and P4502B and chlorinated hydrocarbon contaminant levels in polar bear (Ursus maritimus) Toxicol. Appl. Pharmacol. 1996, 137, 127-140. 
(61) Hakk, H.; Larsen, G.; Klasson-Wehler, E. Tissue disposition, excretion and metabolism of 2,2',4,4',5-pentabromodiphenyl ether (BDE-99) in the male SpragueDawley rat Xenobiotica 2002, 32, 369-382.

(62) Örn, U.; Klasson-Wehler, E. Metabolism of 2,2',4,4'-tetrabromodiphenyl ether in rat and mouse Xenobiotica 1998, 28, 199-211.

(63) Hakk, H.; Huwe, J.; Low, M.; Rutherford, D.; Larsen, G. Tissue disposition, excretion and metabolism of 2,2',4,4',6-pentabromodiphenyl ether (BDE-100) in male Sprague-Dawley rats Xenobiotica 2006, 36, 79-94.

(64) Hakk, H.; Huwe, J. K.; Larsen, G. L. Absorption, distribution, metabolism and excretion (ADME) study with 2,2',4,4',5,6'-hexabromodiphenyl ether (BDE-154) in male Sprague-Dawley rats Xenobiotica 2009, 39, 46-56.

(65) Mörck, A.; Hakk, H.; Örn, U.; Klasson-Wehler, E. Decabromodiphenyl ether in the rat: absorption, distribution, metabolism, and excretion Drug Metab. Dispos. 2003, 31, 900-907.

(66) McKinney, M. A.; De Guise, S.; Martineau, D.; Béland, P.; Lebeuf, M.; Letcher, R. J. Organohalogen contaminants and metabolites in beluga whale (Delphinapterus leucas) liver from two Canadian populations Environ. Toxicol. Chem. 2006, 25, 12461257.

(67) Gebbink, W. A.; Sonne, C.; Dietz, R.; Kirkegaard, M.; Born, E. W.; Muir, D. C. G.; Letcher, R. J. Target tissue selectivity and burdens of diverse classes of brominated and chlorinated contaminants in polar bears (Ursus maritimus) from East Greenland Environ. Sci. Technol. 2008, 42, 752-759.

(68) Routti, H.; Letcher, R. J.; Chu, S.; van Bavel, B.; Gabrielsen, G. W. Polybrominated diphenyl ethers and their hydroxylated analogues in ringed seals (Phoca hispida) from Svalbard and the Baltic Sea Environ. Sci. Technol. 2009, 43, 3494-3499.

(69) Verreault, J.; Gabrielsen, G. W.; Chu, S. G.; Muir, D. C. G.; Andersen, M.; Hamaed, A.; Letcher, R. J. Flame retardants and methoxylated and hydroxylated polybrominated diphenyl ethers in two Norwegian arctic top predators: glaucous gulls and polar bears Environ. Sci. Technol. 2005, 39, 6021-6028.

(70) Letcher, R. J.; Gebbink, W. A.; Sonne, C.; Born, E. W.; McKinney, M. A.; Dietz, R. Bioaccumulation and biotransformation of brominated and chlorinated contaminants and their metabolites in ringed seals (Pusa hispida) and polar bears (Ursus maritimus) from East Greenland Environ. Int. 2009, 35, 1118-1124.

(71) Huwe, J. K.; Smith, D. J. Accumulation, whole-body depletion, and debromination of decabromodiphenyl ether in male Sprague-Dawley rats following dietary exposure Environ. Sci. Technol. 2007, 41, 2371-2377.

(72) Van den Steen, E.; Covaci, A.; Jaspers, V. L. B.; Dauwe, T.; Voorspoels, S.; Eens, M.; Pinxten, R. Accumulation, tissue-specific distribution and debromination of decabromodiphenyl ether (BDE 209) in European starlings (Sturnus vulgaris) Environ. Pollut. 2007, 148, 648-653.

(73) Birnbaum, L. S.; Staskal, D. F. Brominated flame retardants: cause for concern? Environ. Health Perspect. 2004, 112, 9-17. 
(74) Muir, D. C. G.; Norstrom, R. J. Geographical differences and time trends of persistent organic pollutants in the Arctic Toxicol. Lett. 2000, 112-113, 93-101.

(75) Olsen, G. H.; Mauritzen, M.; Derocher, A. E.; Sørmo, E. G.; Skaare, J. U.; Wiig, Ø.; Jenssen, B. M. Space-use strategy is an important determinant of PCB concentrations in female polar bears in the Barents Sea Environ. Sci. Technol. 2003, 37, 4919-4924.

(76) Stirling, I.; Archibald, W. R. Aspects of predation of seals by polar bears J. Fish. Res. Board Can. 1977, 34, 1126-1129.

(77) Derocher, A. E.; Wiig, Ø.; Andersen, M. Diet composition of polar bears in Svalbard and the western Barents Sea Polar Biol. 2002, 25, 448-452.

(78) Iverson, S. J.; Stirling, I.; Lang, S. L. C. Spatial and temporal variation in the diets of polar bears across the Canadian Arctic: indicators of changes in prey populations and environment. In Top Predators in Marine Ecosystems; Boyd, I. L., Wanless, S., Camphuysen, C. J., Eds.; Cambridge University Press: Cambridge 2006; pp 98-117.

(79) Iverson, S. J.; Field, C.; Bowen, W. D.; Blanchard, W. Quantitative fatty acid signature analysis: a new method of estimating predator diets Ecol. Monogr. 2004, 74, 211-235.

(80) Thiemann, G. W.; Budge, S. M.; Iverson, S. J.; Stirling, I. Unusual fatty acid biomarkers reveal age- and sex-specific foraging in polar bears (Ursus maritimus) Can. J. Zool. 2007, 85, 505-517.

(81) Thiemann, G. W.; Iverson, S. J.; Stirling, I. Polar bear diets and arctic marine food webs: insights from fatty acid analysis Ecol. Monogr. 2008, 78, 591-613.

(82) Hobson, K. A.; Welch, H. E. Determination of trophic relationships within a high arctic marine food web using $\delta^{13} \mathrm{C}$ and $\delta^{15} \mathrm{~N}$ analysis Mar. Ecol. Prog. Ser. 1992, 84, 9-18.

(83) Bentzen, T. W.; Follmann, E. H.; Amstrup, S. C.; York, G. S.; Wooller, M. J.; O'Hara, T. M. Variation in winter diet of southern Beaufort Sea polar bears inferred from stable isotope analysis Can. J. Zool. 2007, 85, 596-608.

(84) Kelly, J. F. Stable isotopes of carbon and nitrogen in the study of avian and mammalian trophic ecology Can. J. Zool. 2000, 78, 1-27.

(85) Peterson, B. J.; Fry, B. Stable isotopes in ecosystem studies Ann. Rev. Ecol. Syst. 1987, 18, 293-320.

(86) Post, D. M. Using stable isotopes to estimate trophic position: models, methods, and assumptions Ecology 2002, 83, 703-718.

(87) Hobson, K. A. Tracing origins and migration of wildlife using stable isotopes: a review Oecologia 1999, 120, 314-326.

(88) France, R. L. Carbon-13 enrichment in benthic compared to planktonic algae: foodweb implications Mar. Ecol. Prog. Ser. 1995, 124, 307-312.

(89) Smith, R. J.; Hobson, K. A.; Koopman, H. N.; Lavigne, D. M. Distinguishing between populations of fresh- and salt-water harbour seals (Phoca vitulina) using stable-isotope ratios and fatty acid profiles Can. J. Fish. Aquat. Sci. 1996, 53, 272279. 
(90) Hebert, C. E.; Weseloh, D. V. C.; Idrissi, A.; Arts, M. T.; O'Gorman, R.; Gorman, O. T.; Locke, B.; Madenjian, C. P.; Roseman, E. F. Restoring piscivorous fish populations in the Laurentian Great Lakes causes seabird dietary change Ecology 2008, 89, 891-897.

(91) Budge, S. M.; Iverson, S. J.; Koopman, H. N. Studying trophic ecology in marine ecosystems using fatty acids: a primer on analysis and interpretation Mar. Mammal Sci. 2006, 22, 759-801.

(92) Bang, K.; Jenssen, B. M.; Lydersen, C.; Skaare, J. U. Organochlorine burdens in blood of ringed and bearded seals from north-western Svalbard Chemosphere 2001, 44, 193-203.

(93) Boon, J. P.; van der Meer, J.; Allchin, C. R.; Law, R. J.; Klunsøyr, J.; Leonards, P. E. G.; Spliid, H.; Storr-Hansen, E.; Mckenzie, C.; Wells, D. E. Concentrationdependent changes of PCB patterns in fish-eating mammals: Structural evidence for induction of cytochrome P450 Arch. Environ. Contam. Toxicol. 1997, 33, 298-311.

(94) Hoekstra, P. F.; O'Hara, T. M.; Fisk, A. T.; Borgå, K.; Solomon, K. R.; Muir, D. C. G. Trophic transfer of persistent organochlorine contaminants (OCs) within an Arctic marine food web from the southern Beaufort-Chukchi Seas Environ. Pollut. 2003, 124, 509-522.

(95) Bernt, K. E.; Hammill, M. O.; Lebeuf, M.; Kovacs, K. M. Levels and patterns of PCBs and OC pesticides in harbour and grey seals from the St Lawrence Estuary, Canada Sci. Total Environ. 1999, 244, 243-262.

(96) Krahn, M. M.; Becker, P. R.; Tilbury, K. L.; Stein, J. E. Organochlorine contaminants in blubber of four seal species: Integrating biomonitoring and specimen banking Chemosphere 1997, 34, 2109-2121.

(97) Hobbs, K. E.; Lebeuf, M.; Hammill, M. O. PCBs and OCPs in male harbour, grey, harp and hooded seals from the Estuary and Gulf of St Lawrence, Canada Sci. Total Environ. 2002, 296, 1-18.

(98) Muir, D. C. G.; Savinova, T.; Savinov, V.; Alexeeva, L.; Potelov, V.; Svetochev, V. Bioaccumulation of PCBs and chlorinated pesticides in seals, fishes and invertebrates from the White Sea, Russia Sci. Total Environ. 2003, 306, 111-131.

(99) Kleivane, L.; Severinsen, T.; Skaare, J. U. Biological transport and mammal to mammal transfer of organochlorines in Arctic fauna Mar. Environ. Res. 2000, 49, 343-357.

(100) Holst, M.; Stirling, I.; Hobson, K. A. Diet of ringed seals (Phoca hispida) on the east and west sides of the North Water Polynya, northern Baffin Bay Mar. Mammal Sci. 2001, 17, 888-908.

(101) Jenssen, B. M. Endocrine-disrupting chemicals and climate change: a worst-case combination for arctic marine mammals and seabirds? Environ. Health Perspect. 2006, 114, 76-80.

(102) Williams, J. W.; Jackson, S. T.; Kutzbacht, J. E. Projected distributions of novel and disappearing climates by 2100 AD Proc. Natl. Acad. Sci. USA 2007, 104, 57385742 . 
(103) Bustnes, J. O.; Gabrielsen, G. W.; Verreault, J. Climate variability and temporal trends of persistent organic pollutants in the Arctic: a study of glaucous gulls Environ. Sci. Technol. 2010, 44, 3155-3161.

(104) Macdonald, R. W.; Mackay, D.; Li, Y.-F.; Hickie, B. How will global climate change affect risks from long-range transport of persistent organic pollutants? Hum. Ecol. Risk Assess. 2003, 9, 643-660.

(105) Stirling, I.; Parkinson, C. L. Possible effects of climate warming on selected populations of polar bears (Ursus maritimus) in the Canadian Arctic Arctic 2006, 59, 261-275.

(106) Macdonald, R. W. Climate change, risks and contaminants: a perspective from studying the Arctic Hum. Ecol. Risk Assess. 2005, 11, 1099-1104.

(107) Macdonald, R. W.; Harner, T.; Fyfe, J. Recent climate change in the Arctic and its impact on contaminant pathways and interpretation of temporal trend data Sci. Total Environ. 2005, 342, 5-86.

(108) Gaden, A.; Ferguson, S. H.; Harwood, L.; Melling, H.; Stern, G. A. Mercury trends in ringed seals (Phoca hispida) from the western Canadian Arctic since 1973: associations with length of ice-free season Environ. Sci. Technol. 2009, 43, 36463651.

(109) Carrie, J.; Wang, F.; Sanei, H.; Macdonald, R. W.; Outridge, P. M.; Stern, G. A. Increasing contaminant burdens in an arctic fish, burbot (Lota lota), in a warming climate Environ. Sci. Technol. 2010, 44, 316-322.

(110) Gaston, A. J.; Woo, K.; Hipfner, J. M. Trends in forage fish populations in Northern Hudson Bay since 1981, as determined from the diet of nestling thick-billed murres Uria lomvia Arctic 2003, 56, 227-233.

(111) Grebmeier, J. M.; Overland, J. E.; Moore, S. E.; Farley, E. V.; Carmack, E. C.; Cooper, L. W.; Frey, K. E.; Helle, J. H.; McLaughlin, F. A.; Mcnutt, S. L. A major ecosystem shift in the northern Bering Sea Science 2006, 311, 1461-1464.

(112) Stirling, I.; Lunn, N. J.; Iacozza, J. Long-term trends in the population ecology of polar bears in western Hudson Bay in relation to climate change Arctic 1999, 52, 294306.

(113) de Wit, C. A.; Fisk, A. T.; Hobbs, K. E.; Muir, D. C. G.; Gabrielsen, G. W.; Kallenborn, R.; Krahn, M. M.; Norstrom, R. J.; Skaare, J. U. AMAP Assessment 2002: Persistent organic pollutants in the Arctic; Arctic Monitoring and Assessment Programme: Oslo, 2004.

(114) Derocher, A. E.; Lunn, N. J.; Stirling, I. Polar bears in a warming climate Integr. Comp. Biol. 2004, 44, 163-176.

(115) Calvert, W.; Ramsay, M. A. Evaluation of age determination of polar bears by counts of cementum growth layer groups Ursus 1998, 10, 449-453.

(116) Thiemann, G. W.; Iverson, S. J.; Stirling, I. Seasonal, sexual and anatomical variability in the adipose tissue of polar bears (Ursus maritimus) J. Zool. 2006, 269, $65-76$. 
(117) Verreault, J.; Norstrom, R. J.; Ramsay, M. A.; Mulvihill, M.; Letcher, R. J. Composition of chlorinated hydrocarbon contaminants among major adipose tissue depots of polar bears (Ursus maritimus) from the Canadian high Arctic Sci. Total Environ. 2006, 370, 580-587.

(118) Hebert, C. E.; Arts, M. T.; Weseloh, D. V. C. Ecological tracers can quantify food web structure and change Environ. Sci. Technol. 2006, 40, 5618-5623.

(119) McKinney, M. A.; De Guise, S.; Martineau, D.; Béland, P.; Arukwe, A.; Letcher, R. J. Biotransformation of polybrominated diphenyl ethers and polychlorinated biphenyls in beluga whale (Delphinapterus leucas) and rat mammalian model using an in vitro hepatic microsomal assay Aquat. Toxicol. 2006, 77, 87-97.

(120) McKinney, M. A.; Arukwe, A.; De Guise, S.; Martineau, D.; Béland, P.; Dallaire, A.; Lair, S.; Lebeuf, M.; Letcher, R. J. Characterization and profiling of hepatic cytochromes P450 and phase II xenobiotic-metabolizing enzymes in beluga whales (Delphinapterus leucas) from the St. Lawrence River Estuary and the Canadian Arctic Aquat. Toxicol. 2004, 69, 35-49.

(121) Saito, K.; Sjödin, A.; Sandau, C. D.; Davis, M. D.; Nakazawa, H.; Matsuki, Y.; Patterson, D. G. Jr. Development of a accelerated solvent extraction and gel permeation chromatography analytical method for measuring persistent organohalogen compounds in adipose and organ tissue analysis Chemosphere 2004, $57,373-381$.

(122) Gauthier, L. T.; Hebert, C. E.; Weseloh, D. V. C.; Letcher, R. J. Current-use flame retardants in the eggs of herring gulls (Larus argentatus) from the Laurentian Great Lakes Environ. Sci. Technol. 2007, 41, 4561-4567.

(123) Letcher, R. J.; Norstrom, R. J. An integrated analytical method for determination of polychlorinated aryl methyl sulfone metabolites and polychlorinated hydrocarbon contaminant in biological matrices Anal. Chem. 1995, 67, 4155-4163.

(124) Bjorklund, J.; Tollback, P.; Hiarne, C.; Dyremark, E.; Ostman, C. Influence of the injection technique and the column system on gas chromatographic determination of polybrominated diphenyl ethers $J$. Chromatrogr. A 2004, 1041, 201-210.

(125) Barotini, F.; Cozzani, V.; Petarca, L. Thermal stability and decomposition products of HBCD Ind. Eng. Chem. Res. 2001, 40, 3270-3280.

(126) Schantz, M. M.; Koster, B. J.; Oakley, L. M.; Schiller, S. B.; Wise, S. A. Certification of polychlorinated biphenyl congeners and chlorinated pesticides in a whale blubber standard reference material Anal. Chem. 1995, 67, 901-910.

(127) Stapleton, H. M.; Keller, J. M.; Schantz, M. M.; Kucklick, J. R.; Leigh, S. D.; Wise, S. A. Determination of polybrominated diphenyl ethers in environmental standard reference materials Anal. Bioanal. Biochem. 2007, 387, 2365-2379.

(128) Hebert, C. E.; Shutt, J. L.; Hobson, K. A.; Weseloh, D. V. C. Spatial and temporal differences in the diet of Great Lakes herring gulls (Larus argentatus): evidence from stable isotope analysis Can. J. Fish. Aquat. Sci. 1999, 56, 323-338.

(129) Folch, J.; Lees, M.; Sloane-Stanley, G. H. A simple method for the isolation and purification of total lipides from animal tissues J. Biol. Chem. 1957, 226, 497-509. 
(130) Etkin, D. A. Break-up in Hudson Bay: its sensitivity to air temperatures and implications for climate warming Climatol. Bull. 1991, 25, 21-34.

(131) Kennedy, S. W.; Jones, S. P. Simultaneous measurement of cytochrome P4501A catalytic activity and total protein concentration with a fluorescence plate reader Anal. Biochem. 1994, 222, 217-223.

(132) Harju, M.; Hamers, T.; Kamstra, J. H.; Sonneveld, E.; Boon, J. P.; Tysklind, M.; Andersson, P. L. Quantitative structure-activity relationship modeling on in vitro endocrine effects and metabolic stability involving 26 selected brominated flame retardants Environ. Toxicol. Chem. 2007, 26, 816-826.

(133) Li, H. X.; Boon, J. P.; Lewis, W. E.; Van den Berg, M.; Nyman, M.; Letcher, R. J. Hepatic microsomal cytochrome P450 enzyme activity in relation to in vitro metabolism/inhibition of polychlorinated biphenyls and testosterone in Baltic grey seal (Halichoerus grypus) Environ. Toxicol. Chem. 2003, 22, 636-644.

(134) Sanders, J. M.; Lebetkin, E. H.; Chen, L. J.; Burka, L. T. Disposition of 2,2',4,4,5,5'-hexabromodiphenyl ether (BDE153) and its interaction with other polybrominated diphenyl ethers (PBDEs) in rodents Xenobiotica 2006, 36, 824-837.

(135) Bernhoft, A.; Wiig, Ø.; Skaare, J. U. Organochlorines in polar bears (Ursus maritimus) at Svalbard Environ. Pollut. 1997, 95, 159-175.

(136) Jardine, T. D.; Kidd, K. A.; Fisk, A. T. Applications, considerations and sources of uncertainty when using stable isotope analysis in ecotoxicology Environ. Sci. Technol. 2006, 40, 7501-7511.

(137) Rau, G. H.; Sweeney, R. E.; Kaplan, I. R. Plankton ${ }^{13} \mathrm{C}:{ }^{12} \mathrm{C}$ ratio changes with latitude: differences between northern and southern oceans Deep-Sea Res. 1982, 29, 1035-1039.

(138) Budge, S. M.; Springer, A. M.; Iverson, S. J.; Sheffield, G.; Rosa, C. Blubber fatty acid composition of bowhead whales, Balaena mysticetus: Implications for diet assessment and ecosystem monitoring J. Exp. Mar. Biol. Ecol. 2008, 359, 40-46.

(139) Thiemann, G. W.; Iverson, S. J.; Stirling, I. Variability in the blubber fatty acid composition of ringed seals (Phoca hispida) across the Canadian Arctic Mar. Mammal Sci. 2007, 23, 241-261.

(140) Post, D. M.; Layman, C. A.; Arrington, D. A.; Takimoto, G.; Quattrochi, J.; Montana, C. G. Getting to the fat of the matter: models, methods and assumptions for dealing with lipids in stable isotope analyses Oecologia 2007, 152, 179-189.

(141) Dehn, L. A.; Sheffield, G. G.; Follmann, E. H.; Duffy, L. K.; Thomas, D. L.; O'Hara, T. M. Feeding ecology of phocid seals and some walrus in the Alaskan and Canadian Arctic as determined by stomach contents and stable isotope analysis Polar Biology 2007, 30, 167-181.

(142) Butt, C. M.; Mabury, S. A.; Kwan, M.; Wang, X.; Muir, D. C. G. Spatial trends of perfluoroalkyl compounds in ringed seals (Phoca hispida) from the Canadian Arctic Environ. Toxicol. Chem. 2008, 27, 542-553.

(143) Baxter, M. J.; Beardah, C. C.; Cool, H. E. M.; Jackson, C. M. Compositional data analysis of some alkaline glasses Mathematical Geology 2005, 37, 183-196. 
(144) Nicholson, M. D.; Fryer, R. J.; Larsen, J. R. Temporal trend monitoring: robust method for analysing contaminant trend monitoring data. In Techniques in Environmental Sciences; Keizer, P. D., Ed.; ICES: 1998.

(145) Norman, G. R.; Streiner, D. L. Biostatistics- the bare essentials; BC Decker Inc.: Hamilton, 2000.

(146) Skaare, J. U.; Bernhoft, A.; Derocher, A.; Gabrielsen, G. W.; Goksoyr, A.; Henriksen, E.; Larsen, H. J.; Lie, E.; Wiig, O. Organochlorines in top predators at Svalbard - occurrence, levels and effects Toxicol. Lett. 2000, 112, 103-109.

(147) Wania, F.; Mackay, D. Global fractionation and cold condensation of low volatility organochlorine compounds in polar regions Ambio 1993, 22, 10-18.

(148) de Boer, J.; de Boer, K.; Boon, J. P. Polybrominated biphenyls and diphenyl ethers. In The Handbook of Environmental Chemistry; Paasivirta, J., Ed.; Springer-Verlag: Berlin 2000; pp 61-95.

(149) Verreault, J.; Gebbink, W. A.; Gauthier, L. T.; Gabrielsen, G. W.; Letcher, R. J. Brominated flame retardants in glaucous gulls from the Norwegian Arctic: more than just an issue of polybrominated diphenyl ethers Environ. Sci. Technol. 2007, 41, 4925-4931.

(150) Borgå, K.; Gabrielsen, G. W.; Skaare, J. U. Differences in contamination load between pelagic and sympagic invertebrates in the Arctic marginal ice zone: influence of habitat, diet and geography Mar. Ecol. Prog. Ser. 2002, 235, 157-169.

(151) Law, R. J.; Bersuder, P.; Barry, J.; Wilford, B. H.; Allchin, C. R.; Jepson, P. D. A significant downturn in levels of hexabromocyclododecane in the blubber of harbor porpoises (Phocoena phocoena) stranded or bycaught in the UK: an update to 2006 Environ. Sci. Technol. 2008, 42, 9104-9109.

(152) Calvert, W.; Stirling, I. Interactions between polar bears and overwintering walruses in the central Canadian High Arctic. In Bears- Their Biology and Management: Proceedings of the 8th International Conference on Bear Research and Management, 20-25 February 1989; Darling, L. M., Archibald, W. R., Eds.; International Association for Bear Research and Management: Victoria 1990; pp 351356.

(153) Smith, T. G.; Sjare, B. Predation of belugas and narwhals by polar bears in nearshore areas of the Canadian High Arctic Arctic 1990, 43, 99-102.

(154) Hobson, K. A.; Ambrose, W. G.; Renaud, P. E. Sources of primary production, benthic-pelagic coupling, and trophic relationships within the Northeast Water Polynya: Insights from $\delta^{13} \mathrm{C}$ and $\delta^{15} \mathrm{~N}$ analysis Mar. Ecol. Prog. Ser. 1995, 128, 1-10.

(155) Thiemann, G. W.; Iverson, S. J.; Stirling, I. Variation in blubber fatty acid composition among marine mammals in the Canadian Arctic Mar. Mammal Sci. 2008, 24, 91-111.

(156) Schell, D. M.; Barnett, B. A.; Vinette, K. A. Carbon and nitrogen isotope ratios in zooplankton of the Bering, Chukchi and Beaufort seas Mar. Ecol. Prog. Ser. 1998, $162,11-23$. 
(157) Riget, F. F.; Dietz, R.; Born, E. W.; Sonne, C.; Hobson, K. A. Temporal trends of mercury in marine biota of west and northwest Greenland Mar. Pollut. Bull. 2007, 54, $72-80$.

(158) Young, B. G.; Loseto, L. L.; Ferguson, S. H. Diet differences among age classes of Arctic seals: evidence from stable isotope and mercury biomarkers Polar Biol. 2010, $33,153-162$.

(159) Stirling, I.; Archibald, W. R. Aspects of Predation of Seals by Polar Bears Journal of the Fisheries Research Board of Canada 1977, 34, 1126-1129.

(160) Hobson, K. A.; Stirling, I.; Andriashek, D. S. Isotopic homogeneity of breath $\mathrm{CO}_{2}$ from fasting and berry-eating polar bears: implications for tracing reliance on terrestrial foods in a changing Arctic Can. J. Zool. 2009, 87, 50-55.

(161) Muir, D. C. G.; Segstro, M. D.; Hobson, K. A.; Ford, C. A.; Stewart, R. E. A.; Olpinski, S. Can seal eating explain elevated levels of PCBs and organochlorine pesticides in walrus blubber from eastern Hudson-Bay (Canada) Environ. Pollut. 1995, 90, 335-348.

(162) Walther, G. R.; Post, E.; Convey, P.; Menzel, A.; Parmesan, C.; Beebee, T. J. C.; Fromentin, J. M.; Hoegh-Guldberg, O.; Bairlein, F. Ecological responses to recent climate change Nature 2002, 416, 389-395.

(163) Parmesan, C.; Yohe, G. A globally coherent fingerprint of climate change impacts across natural systems Nature 2003, 421, 37-42.

(164) Johannessen, O. M.; Bengtsson, L.; Miles, M. W.; Kuzmina, S. I.; Semenov, V. A.; Alekseev, G. V.; Nagurnyi, A. P.; Zakharov, V. F.; Bobylev, L. P.; Pettersson, L. H.; Hasselmann, K.; Cattle, A. P. Arctic climate change: observed and modelled temperature and sea-ice variability Tellus $A$ 2004, 56, 328-341.

(165) Graversen, R. G.; Mauritsen, T.; Tjernstrom, M.; Kallen, E.; Svensson, G. Vertical structure of recent Arctic warming Nature 2008, 451, 53-56.

(166) Ottar, B. The transfer of airborne pollutants to the Arctic region Atmos. Environ. 1981, 15, 1439-1445.

(167) Jensen, S.; Johnels, A. G.; Olsson, M.; Otterlind, G. DDT and PCB in marine animals from Swedish waters Nature 1969, 224, 247-250.

(168) Muir, D. C. G.; Wagemann, R.; Hargrave, B. T.; Thomas, D. J.; Peakall, D. B.; Norstrom, R. J. Arctic marine ecosystem contamination Sci. Total Environ. 1992, $122,75-134$.

(169) de Wit, C. A.; Alaee, M.; Muir, D. C. G. Levels and trends of brominated flame retardants in the Arctic Chemosphere 2006, 64, 209-233.

(170) Houde, M.; Martin, J. W.; Letcher, R. J.; Solomon, K. R.; Muir, D. C. G. Biological monitoring of polyfluoroalkyl substances: a review Environ. Sci. Technol. 2006, 40, 3463-3473.

(171) Dewailly, E.; Nantel, A.; Weber, J. P.; Meyer, F. High-levels of PCBs in breastmilk of Inuit women from Arctic Quebec Bull. Environ. Contam. Toxicol. 1989, 43, 641-646. 
(172) Thiemann, G. W.; Derocher, A. E.; Stirling, I. Polar bear Ursus maritimus conservation in Canada: an ecological basis for identifying designatable units Oryx 2008, 42, 504-515.

(173) Gagnon, A. S.; Gough, W. A. Trends in the dates of ice freeze-up and breakup over Hudson Bay, Canada Arctic 2005, 58, 370-382.

(174) Gagnon, A. S.; Gough, W. A. East-west asymmetry in long-term trends of landfast ice thickness in the Hudson Bay region, Canada Climate Res. 2006, 32, 177-186.

(175) Regehr, E. V.; Lunn, N. J.; Amstrup, S. C.; Stirling, I. Effects of earlier sea ice breakup on survival and population size of polar bears in western Hudson Bay $J$. Wildl. Manage. 2007, 71, 2673-2683.

(176) Polischuk, S. C.; Hobson, K. A.; Ramsay, M. A. Use of stable-carbon and -nitrogen isotopes to assess weaning and fasting in female polar bears and their cubs Can. J. Zool. 2001, 79, 499-511.

(177) Iverson, S. J.; Oftedal, O. T. Fatty acid composition of black bear (Ursus americanus) milk during and after the period of winter dormancy Lipids 1992, 27, 940-943.

(178) Laws, E. A.; Popp, B. N.; Bidigare, R. R.; Kennicutt, M. C.; Macko, S. A. Dependence of phytoplankton carbon isotopic composition on growth-rate and $\left[\mathrm{CO}_{2}\right]_{\mathrm{aq}}$ : theoretical considerations and experimental results Geochim. Cosmochim. Acta 1995, 59, 1131-1138.

(179) O'Reilly, C. M.; Alin, S. R.; Plisnier, P. D.; Cohen, A. S.; Mckee, B. A. Climate change decreases aquatic ecosystem productivity of Lake Tanganyika, Africa Nature 2003, 424, 766-768.

(180) Francey, R. J.; Allison, C. E.; Etheridge, D. M.; Trudinger, C. M.; Enting, I. G.; Leuenberger, M.; Langenfelds, R. L.; Michel, E.; Steele, L. P. A 1000-year high precision record of $\delta^{13} \mathrm{C}$ in atmospheric $\mathrm{CO}_{2}$ Tellus Ser. $B$ 1999, 51, 170-193.

(181) Allison, C. E.; Francey, R. J. Verifying Southern Hemisphere trends in atmospheric carbon dioxide stable isotopes J. Geophys. Res. Atmos. 2007, 112, D21304.

(182) Long, E. S.; Sweitzer, R. A.; Diefenbach, D. R.; Ben David, M. Controlling for anthropogenically induced atmospheric variation in stable carbon isotope studies Oecologia 2005, 146, 148-156.

(183) Mansfield, A. W. Distribution of harbor seal, Phoca Vitulina Linnaeus, in Canadian Arctic waters J. Mammal. 1967, 48, 249-257.

(184) Woollett, J. M.; Henshaw, A. S.; Wake, C. P. Palaeoecological implications of archaeological seal bone assemblages: Case studies from Labrador and Baffin Island Arctic 2000, 53, 395-413.

(185) Muir, D. C. G.; Norstrom, R. J.; Simon, M. Organochlorine contaminants in arctic marine food chains: accumulation of specific polychlorinated biphenyls and chlordane-related compounds Environ. Sci. Technol. 1988, 22, 1071-1079.

(186) Bright, D. A.; Dushenko, W. T.; Grundy, S. L.; Reimer, K. J. Effects of local and distant contaminant sources: polychlorinated biphenyls and other organochlorines in 
bottom-dwelling animals from an Arctic estuary Sci. Total Environ. 1995, 160/161, 265-284.

(187) Stirling, I.; Thiemann, G. W.; Richardson, E. Quantitative support for a subjective fatness index for immobilized polar bears $J$. Wildl. Manage. 2008, 72, 568-574.

(188) Pond, C. M.; Mattacks, C. A.; Colby, R. H.; Ramsay, M. A. The anatomy, chemical composition, and metabolism of adipose tissue in wild polar bears (Ursus maritimus) Can. J. Zool. 1992, 70, 326-341.

(189) Rigét, F.; Bignert, A.; Braune, B.; Stow, J.; Wilson, S. Temporal trends of legacy POPs in Arctic biota, an update Sci. Total Environ. 2009, 408, 2874-2884.

(190) Hung, H.; Kallenborn, R.; Breivik, K.; Su, Y.; Brorström-Lundén, E.; Olafsdottir, K.; Thorlacius, J. M.; Leppänen, S.; Bossi, R.; Skov, H.; Manø, S.; Patton, G. W.; Stern, G.; Sverko, E.; Fellin, P. Atmospheric monitoring of organic pollutants in the Arctic under the Arctic Monitoring and Assessment Programme (AMAP): 1993-2006 Sci. Total Environ. 2010, 408, 2854-2873.

(191) de Solla, S. R.; Weseloh, D. V. C.; Letcher, R. J.; Hebert, C. E. Reconcilable differences: the use of reference material to reduce methodological artifacts in the reporting of organochlorine pesticides and polychlorinated biphenyls Environ. Toxicol. Chem. 2010, 29, 19-26.

(192) Muir, D. C. G.; Kwan, M.; Evans, M. Temporal trends of persistent organic pollutants and metals in ringed seals from the Canadian Arctic. In Synopsis of research conducted under the 2006-2007 Northern Contaminants Program; Smith, S., Stow, J., Eds.; Department of Indian Affairs and Northern Development: Ottawa 2007; pp 211-218.

(193) Muir, D. C. G.; Kwan, M.; Evans, M. Temporal trends of persistent organic pollutants and metals in ringed seals from the Canadian Arctic. In Synopsis of research conducted under the 2006-2007 Northern Contaminants Program; Smith, S., Stow, J., Edwards, J., Eds.; Department of Indian Affairs and Northern Development: Ottawa 2009; pp 76-84.

(194) Helgason, L. B.; Polder, A.; Foreid, S.; Baek, K.; Lie, E.; Gabrielsen, G. W.; Barrett, R. T.; Skaare, J. U. Levels and temporal trends (1983-2003) of polybrominated diphenyl ethers and hexabromocyclododecanes in seabird eggs from North Norway Environ. Toxicol. Chem. 2009, 28, 1096-1103.

(195) Sandholm, A.; Emanuelsson, B. M.; Wehler, E. K. Bioavailability and half-life of decabromodiphenyl ether (BDE-209) in rat Xenobiotica 2003, 33, 1149-1158.

(196) La Guardia, M. J.; Hale, R. C.; Harvey, E. Detailed polybrominated diphenyl ether (PBDE) congener composition of the widely used Penta-, Octa-, and Deca-PBDE technical flame-retardant mixtures Environ. Sci. Technol. 2006, 40, 6247-6254.

(197) Shaw, S. D.; Kannan, K. Polybrominated diphenyl ethers in marine ecosystems of the American continents: foresight from current knowledge Rev. Environ. Health 2009, 24, 157-229.

(198) Thuresson, K.; Hoglund, P.; Hagmar, L.; Sjodin, A.; Bergman, A.; Jakobsson, K. Apparent half-lives of hepta- to decabrominated diphenyl ethers in human serum as 
determined in occupationally exposed workers Environ. Health Perspect. 2006, 114, 176-181.

(199) Watanabe, I.; Sakai, S. Environmental release and behavior of brominated flame retardants Environ. Int. 2003, 29, 665-682.

(200) Shi, T.; Chen, S. J.; Luo, X. J.; Zhang, X. L.; Tang, C. M.; Luo, Y.; Ma, Y. J.; Wu, J. P.; Peng, X. Z.; Mai, B. X. Occurrence of brominated flame retardants other than polybrominated diphenyl ethers in environmental and biota samples from southern China Chemosphere 2009, 74, 910-916.

(201) Gauthier, L. T.; Potter, D.; Hebert, C. E.; Letcher, R. J. Temporal trends and spatial distribution of non-polybrominated diphenyl ether flame retardants in the eggs of colonial populations of Great Lakes herring gulls Environ. Sci. Technol. 2009, 43, 312-317.

(202) Hu, G. C.; Luo, X. J.; Dai, J. Y.; Zhang, X. L.; Wu, H.; Zhang, C. L.; Guo, W.; Xu, M. Q.; Mai, B. X.; Wei, F. W. Brominated flame retardants, polychlorinated biphenyls, and organochlorine pesticides in captive giant panda (Ailuropoda melanoleuca) and red panda (Ailurus fulgens) from China Environ. Sci. Technol. 2008, 42, 4704-4709.

(203) Law, K.; Halldorson, T.; Danell, R.; Stern, G.; Gewurtz, S.; Alaee, M.; Marvin, C.; Whittle, M.; Tomy, G. Bioaccumulation and trophic transfer of some brominated flame retardants in a Lake Winnipeg (Canada) food web Environ. Toxicol. Chem. 2006, 25, 2177-2186.

(204) Luo, X. J.; Zhang, X. L.; Liu, J.; Wu, J. P.; Luo, Y.; Chen, S. J.; Mai, B. X.; Yang, Z. Y. Persistent halogenated compounds in waterbirds from an e-waste recycling region in South China Environ. Sci. Technol. 2009, 43, 306-311.

(205) Tomy, G. T.; Pleskach, K.; Ferguson, S. H.; Hare, J.; Stern, G. A.; MacInnis, G.; Marvin, C. H.; Loseto, L. L. Trophodynamics of some PFCs and BFRs in a western Canadian Arctic marine food web Environ. Sci. Technol. 2009, 43, 4076-4081.

(206) Letcher, R. J.; Klasson-Wehler, E.; Bergman, A. Methyl sulfone and hydroxylated metabolites of polychlorinated biphenyls. In The Handbook of Environmental Chemistry Vol. 3 part K. New types of persistent halogenated compounds; Paasivirta, J., Ed.; Springer-Verlag: Berlin 2000; pp 315-359.

(207) Chen, L. J.; Lebetkin, E. H.; Sanders, J. M.; Burka, L. T. Metabolism and disposition of 2,2',4,4',5-pentabromodiphenyl ether (BDE99) following a single or repeated administration to rats or mice Xenobiotica 2006, 36, 515-534.

(208) Hakk, H.; Letcher, R. J. Metabolism in the toxicokinetics and fate of brominated flame retardants- a review Environ. Int. 2003, 29, 801-828.

(209) Benedict, R. T.; Stapleton, H. M.; Letcher, R. J.; Mitchelmore, C. L. Debromination of polybrominated diphenyl ether-99 (BDE-99) in carp (Cyprinus carpio) microflora and microsomes Chemosphere 2007, 69, 987-993.

(210) Browne, E. P.; Stapleton, H. M.; Kelly, S. M.; Tilton, S. C.; Gallagher, E. P. In vitro hepatic metabolism of 2,2',4,4',5-pentabromodiphenyl ether (BDE 99) in Chinook Salmon (Onchorhynchus tshawytscha) Aquat. Toxicol. 2009, 92, 281-287. 
(211) Routti, H.; Letcher, R. J.; Arukwe, A.; van Bavel, B.; Yoccoz, N. G.; Chu, S. G.; Gabrielsen, G. W. Biotransformation of PCBs in relation to Phase I and II xenobioticmetabolizing enzyme activities in ringed seals (Phoca hispida) from Svalbard and the Baltic Sea Environ. Sci. Technol. 2008, 42, 8952-8958.

(212) Sandala, G. M.; Sonne-Hansen, C.; Dietz, R.; Muir, D. C. G.; Valters, K.; Bennett, E. R.; Born, E. W.; Letcher, R. J. Hydroxylated and methyl sulfone PCB metabolites in adipose and whole blood of polar bear (Ursus maritimus) from east Greenland Sci. Total Environ. 2004, 331, 125-141.

(213) Wang, F.; Wang, J.; Dai, J. Y.; Hu, G. C.; Wang, J. S.; Luo, X. J.; Mai, B. X. Comparative Tissue Distribution, Biotransformation and Associated Biological Effects by Decabromodiphenyl Ethane and Decabrominated Diphenyl Ether in Male Rats after a 90-Day Oral Exposure Study Environ. Sci. Technol. 2010, 44, 5655-5660.

(214) Yamaguchi, Y.; Kawano, M.; Tatsukawa, R. Tissue distribution and excretion of hexabromobenzene and its debrominated metabolites in the rat Arch. Environ. Contam. Toxicol. 1988, 17, 807-812.

(215) de Boer, J.; Wester, P. G.; Rodriguez, D. P. I.; Lewis, W. E.; Boon, J. P. Polybrominated biphenyls and diphenylethers in sperm whale and other marine mammals- a new threat to ocean life? Organohalog. Compd. 1998, 21, 383-386.

(216) Stapleton, H. M.; Kelly, S. M.; Pei, R.; Letcher, R. J.; Gunsch, C. Metabolism of polybrominated diphenyl ethers (PBDEs) by human hepatocytes in vitro Environ. Health Perspect. 2009, 117, 197-202.

(217) Hakk, H.; Larsen, G.; Bowers, J. Metabolism, tissue disposition, and excretion of 1,2-bis(2,4,6-tribromophenoxy)ethane (BTBPE) in male Sprague-Dawley rats Chemosphere 2004, 54, 1367-1374.

(218) Ross, P. S.; Couillard, C. M.; Ikonomou, M. G.; Johannessen, S. C.; Lebeuf, M.; Macdonald, R. W.; Tomy, G. T. Large and growing environmental reservoirs of Deca-BDE present an emerging health risk for fish and marine mammals Mar. Pollut. Bull. 2009, 58, 7-10. 


\section{Appendices}

Appendix A

Analytical Details for Stable Isotopes Determinations from EIL

Summary: Solid samples are run for Nitrogen and Carbon analysis on one of 2 systems;

1. A Delta Plus Continuous Flow Stable Isotope Ratio Mass Spectrometer (Thermo Finnigan / Bremen-Germany) coupled to a Carlo Erba Elemental Analyzer (CHNS-O EA1108 - Italy).

2. An Isochrom Continuous Flow Stable Isotope Ratio Mass Spectrometer (GVInstruments / Micromass-UK) coupled to a Carlo Erba Elemental Analyzer (CHNSO EA1108 - Italy).

${ }^{15}$ Nitrogen and ${ }^{13}$ Carbon:

-Results are generally corrected to Nitrogen standards IAEA-N1 and IAEA-N2 (both Ammonium Sulphate) and Carbon standards IAEA-CH6 (sugar), EIL-72 (cellulose) and EIL-32 (graphite).

-The error for clean ball-milled standard material is $+/-0.2 \%$ for Carbon and $+/-0.3 \%$ for Nitrogen. This error can be expected to increase depending on the homogeneity, type and amount of sample used in analysis. A truer representation of sample reproducibility can be gained through sample repeats.

-Standards are placed throughout each run at a range of weights to allow for an additional linearity correction, when necessary, due to machine fluctuations or samples of varying signal peak areas. 
-Nitrogen and Carbon compositions are calculated based on Carlo Erba Elemental Standards B2005, B2035 and B2036 with an error of $+/-1 \%$.

-Other NIST organic materials are being run at EIL and cross-checked with other labs in hopes of producing a collection of Organic Reference materials for use in stable isotope research. At present these materials are not used in correction but rather as monitoring material.

\section{EQUIPMENT}

Balances- The two high precision analytical balances are checked monthly with NIST traceable calibrated weights.

Mass Spectrometer- The Micromass Isochrom EA-IRMS system is checked each day before analyzing samples by running the peak shape program. With the standard gas flowing, the mass spectrometer scans from peak 43 to 47 . The operator checks to make sure the peak shape is correct and that the collectors are set in the center of the peaks. The standard is then introduced 10 times to check stability and reproducibility. If the reproducibility is less than 0.01 , the peak shape is adjusted and the standard check is repeated. The mass spectrometer sample run program performs an analysis on the gas standard with each sample to confirm stability. The performance of the complete sample run can be checked by the reproducibility of this analysis.

Sample Runs- In each group of 100 samples, standards are run to check and allow for bias and linearity corrections. Four replicates of different weights are placed at the beginning and end of each run. This set allows for linearity corrections. Two sets of three 
or four replicates of NIST or EIL carbon and nitrogen standards are analyzed in each group. Two sets of replicates of element standards are also run in each group. EIL has accumulated a set of data on a number of NIST elemental standards with respect to their isotope content. This set of control standards is used to confirm that the EA is combusting and transporting gases with the correct isotope ratio to the mass spectrometer. A sample replicate is run at least every eight samples and duplicates are run from previous groups. The overall average number of repeats is about one every eight samples. A few sample replicates of different weights are analyzed to check linearity of the sample matrix. EIL recommends that each client establish a statistical population of 30 or more analysis of one sample to confirm the error associated with the natural variation of that sample type. 


\section{Appendix B}

Fig. B1. Temporal comparisons of legacy contaminants and metabolites in 10 polar bear subpopulations from 1989-1993 (adult female (AF), adult male (AM); ref 26), 1996-2002 (age-adjusted female (F-Adj), age-unadjusted female (F); ref 39) and 2005-2008 (current study). BS samples were from SBS and NBS. $\sum \mathrm{MeSO}_{2}-\mathrm{PCB}, \sum \mathrm{HCH}$ and $\sum \mathrm{CHL}$ levels in 2005-2008 were normalized to a $7 \mathrm{yr}$ old female. Blank values denoted a contaminant not analyzed from that location/time point, with the exceptions in which the contaminant was not detected in a majority of samples: OCS in 1996-2002 in BS, GB, LJS, BB, DS, WHB; mirex in 1996-2002 in EG; 3-MeSO $2-p, p^{\prime}-\mathrm{DDE}$ in 1996-2002 in $\mathrm{BB}, \mathrm{SV}$ and in 2005-2008 in all except BB and SHB. 

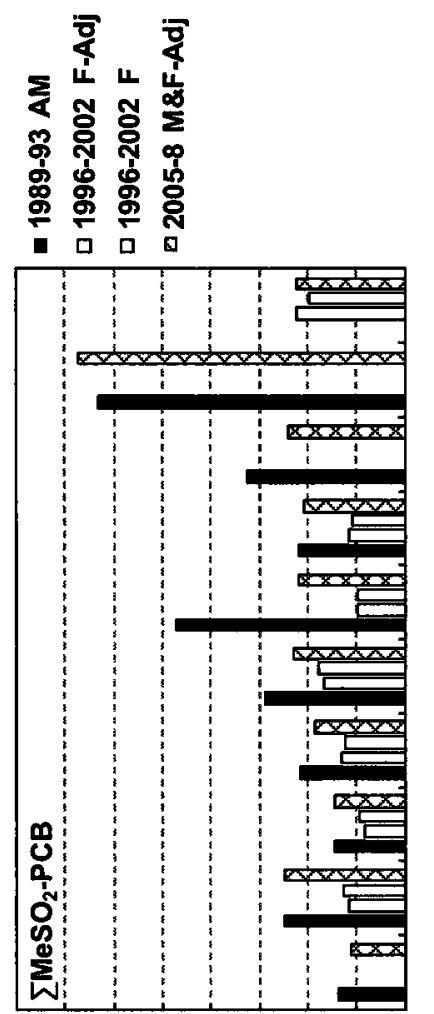

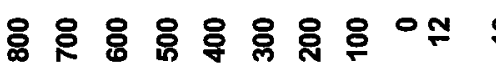
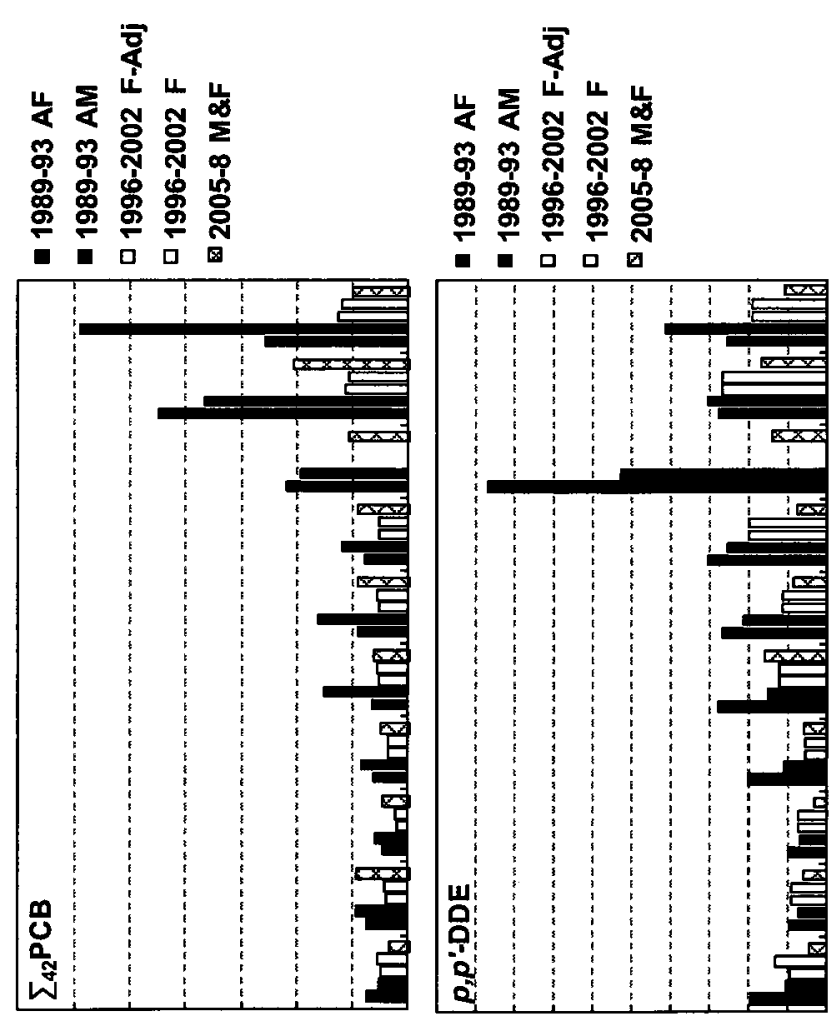

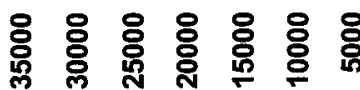

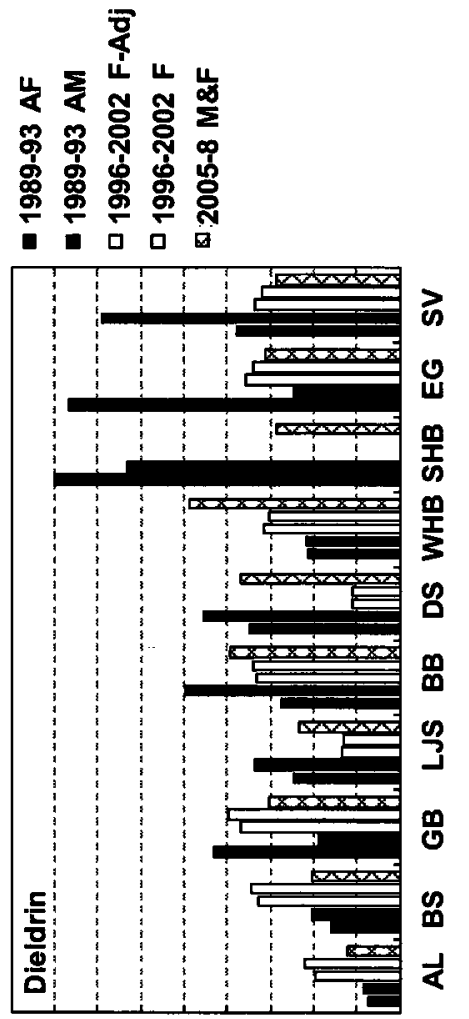

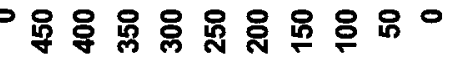

199

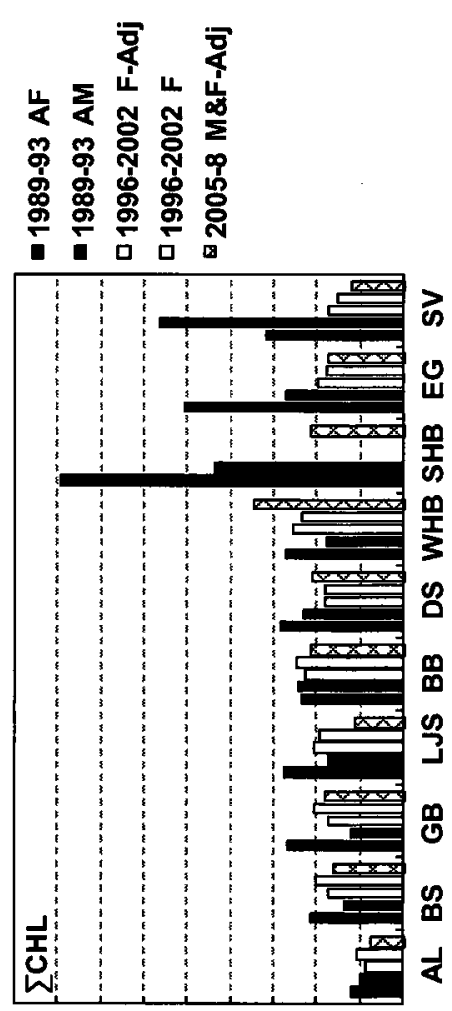

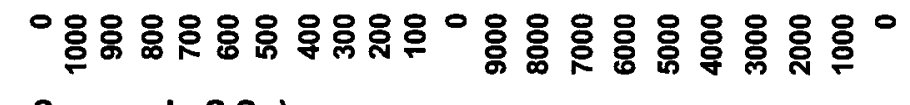




\section{Appendix C}

Table C1. Mean $( \pm 95 \% \mathrm{CI})$ nitrogen $\left(\delta^{15} \mathrm{~N}\right)$ and carbon $\left(\delta^{13} \mathrm{C}\right)$ stable isotope ratios in 2005-2008 polar bear muscle from 11 subpopulations from Alaska east to Svalbard

\begin{tabular}{lcc}
\hline \multicolumn{1}{c}{ Polar bear subpopulation } & $\boldsymbol{\delta}^{15} \mathbf{N}(\%)$ & $\boldsymbol{\delta}^{13} \mathbf{C}(\%)$ \\
Alaska- Bering-Chukchi Sea (AL) & $21.08(0.29)$ & $-16.81(0.19)$ \\
S. Beaufort Sea (SBS) & $20.77(0.56)$ & $-19.28(0.30)$ \\
N. Beaufort Sea (NBS) & $21.63(0.28)$ & $-19.18(0.22)$ \\
Gulf of Boothia (GB) & $21.51(0.52)$ & $-17.38(0.37)$ \\
Lancaster/Jones Sound (LJS) & $21.28(0.26)$ & $-17.53(0.28)$ \\
Baffin Bay- N.E. Baffin Island (BB) & $20.23(0.36)$ & $-17.45(0.27)$ \\
Davis Strait- S.E. Baffin Island (DS) & $19.58(0.59)$ & $-16.49(0.40)$ \\
W. Hudson Bay (WHB) & $18.88(0.96)$ & $-18.76(0.32)$ \\
S. Hudson Bay (SHB) & $19.22(0.30)$ & $-18.85(0.12)$ \\
E. Greenland- Scoresby Sound (EG) & $18.31(0.18)$ & $-18.66(0.15)$ \\
Svalbard- Barents Sea (SV) & not available & not available \\
\hline
\end{tabular}

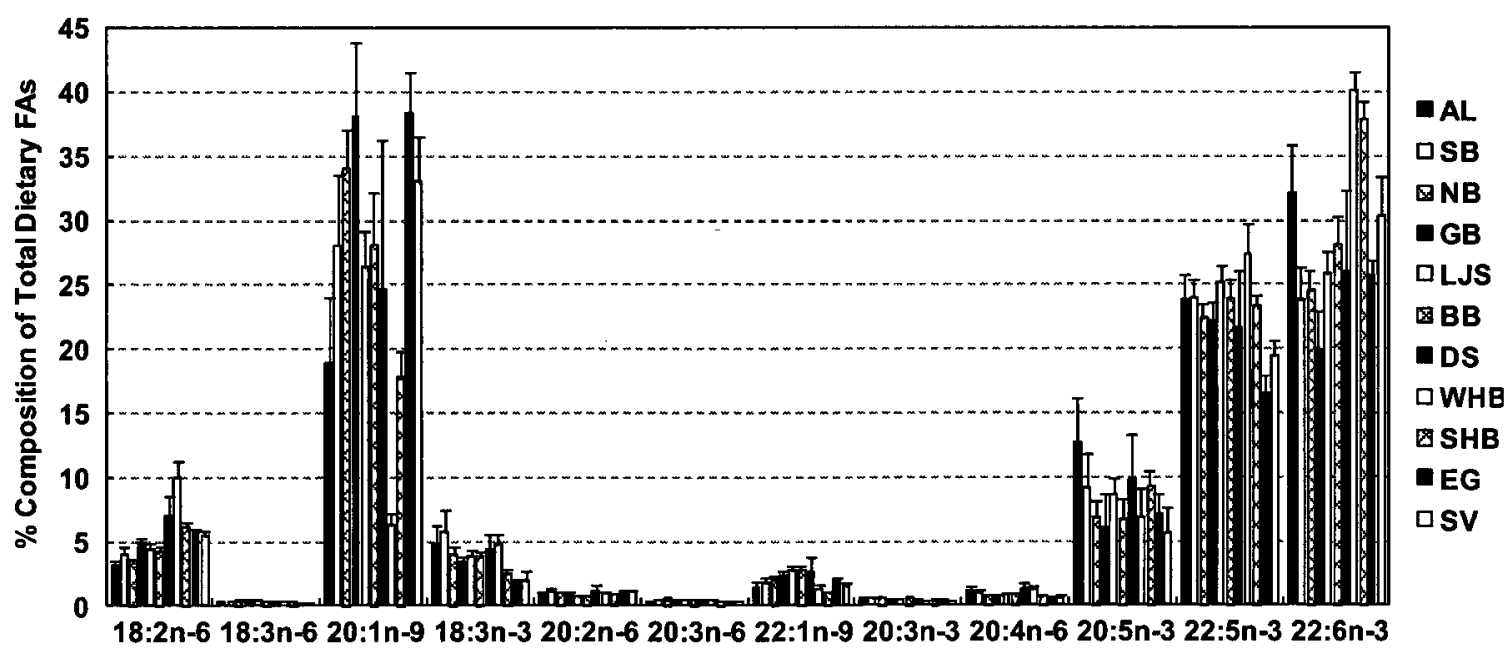

Fig. C1. Mean $( \pm 95 \% \mathrm{CI})$ dietary FA composition in 2005-2008 polar bear adipose from 11 subpopulations (left to right): AL, SBS, NBS, GB,LJS, BB, DS, WHB, SHB, EG and SV. 


\section{Appendix D}

Table D1. Results of the ranked correlation analysis of WHB polar bear dietary tracers with ice breakup date in western Hudson Bay

\begin{tabular}{lcccc}
\hline & & $\boldsymbol{\delta}^{\mathbf{1 3}} \mathbf{C ~ ( \% o ) ~}$ & FA-Index1 & FA-Index2 \\
Ice Breakup Date & Spearman $r$ & 0.86 & -0.54 & -0.68 \\
(Ordinal Date) & $p$-value & 0.01 & 0.21 & 0.09 \\
\hline
\end{tabular}




\section{Appendix E}

Table E1. Geometric means (GM), 95\% CI, medians (M) and ranges (R) (ng/g lipid weight) of brominated and chlorinated contaminant and metabolite concentrations in adipose tissue of adult male (AM), adult female (AF) and subadult (S) polar bears from 11 subpopulations sampled in 2005-2008 


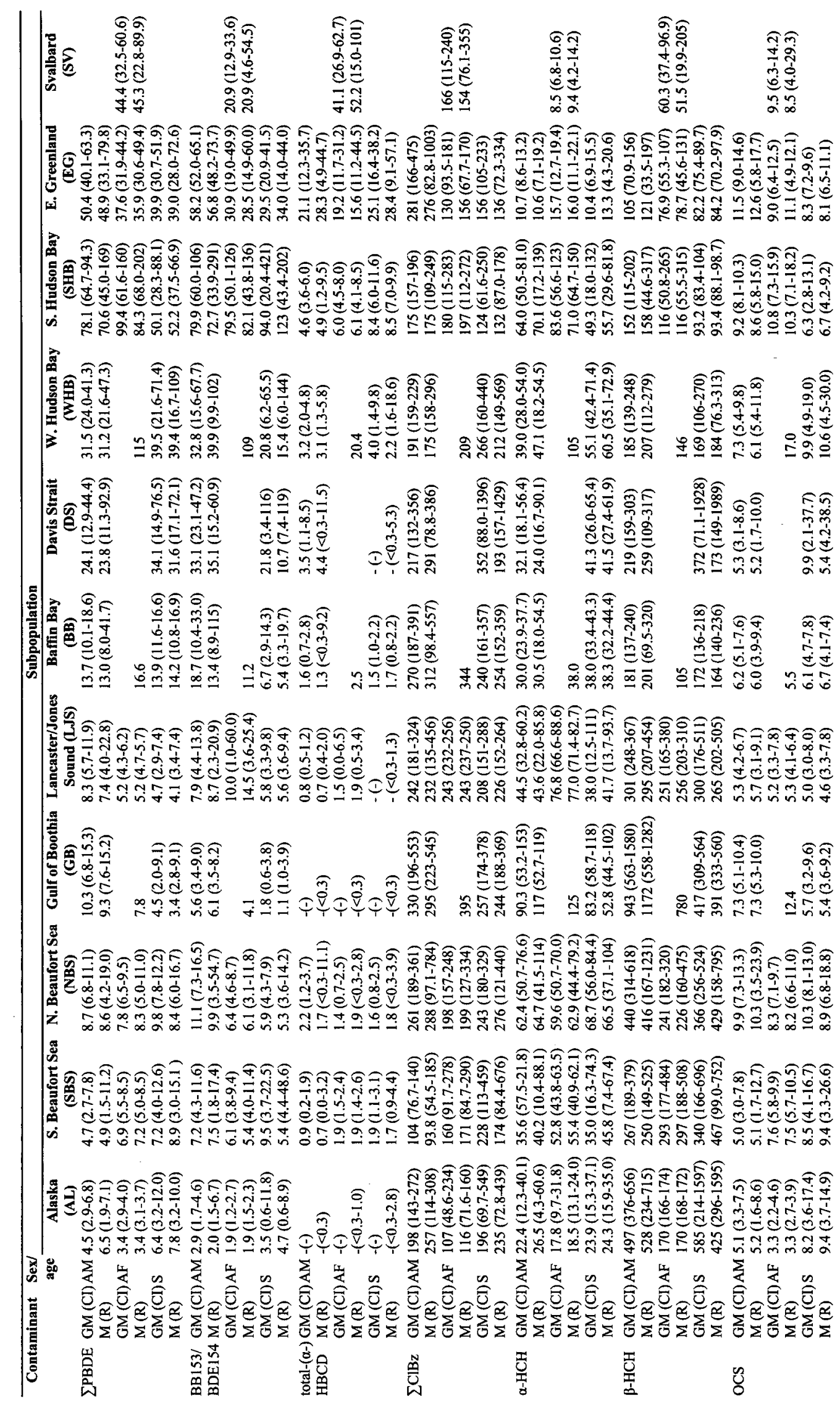




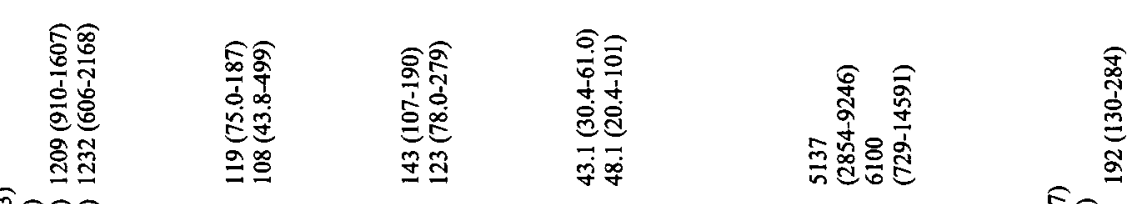

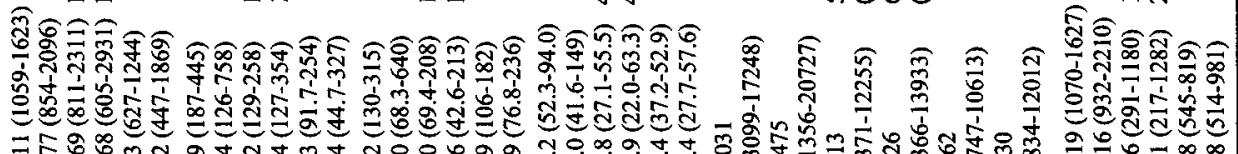

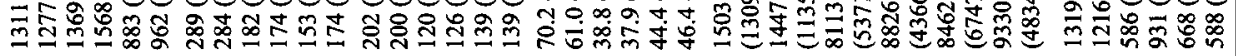

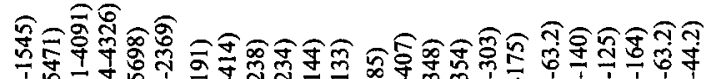

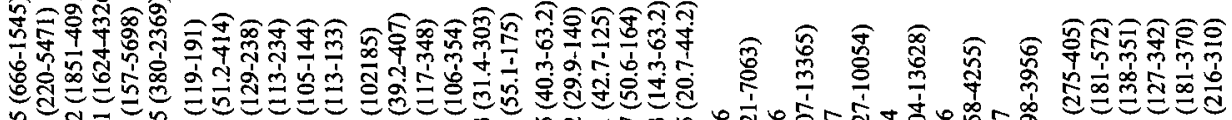

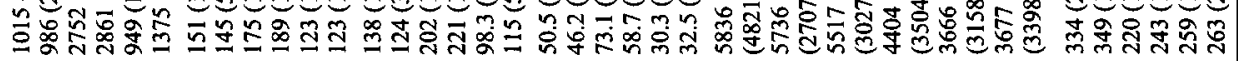

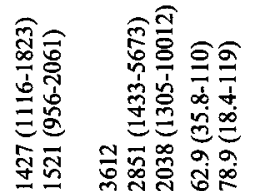

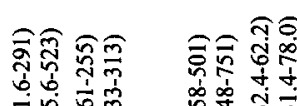

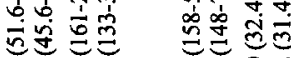

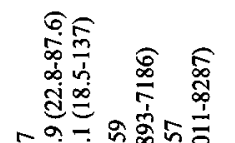

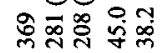

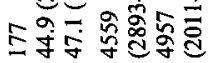

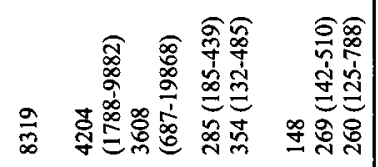

商商

สิธิธี

ป ป

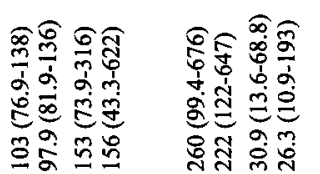

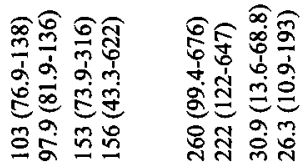

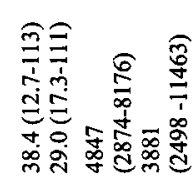

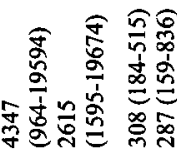

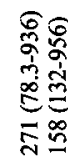

ลิธิธีิ

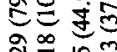

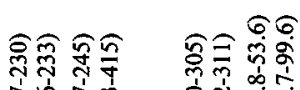

तิ

हैं 今े

范啇

莺守穷

อั己

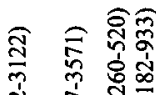

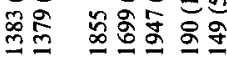

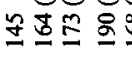

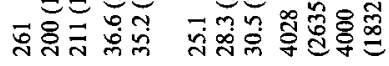

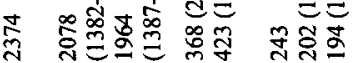

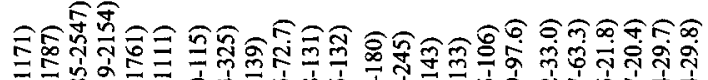

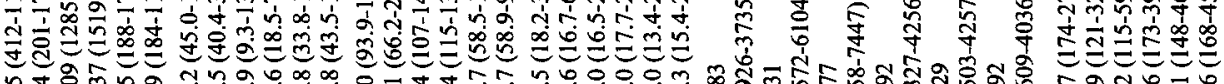

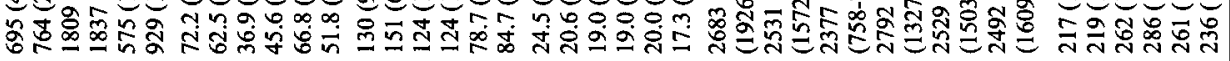

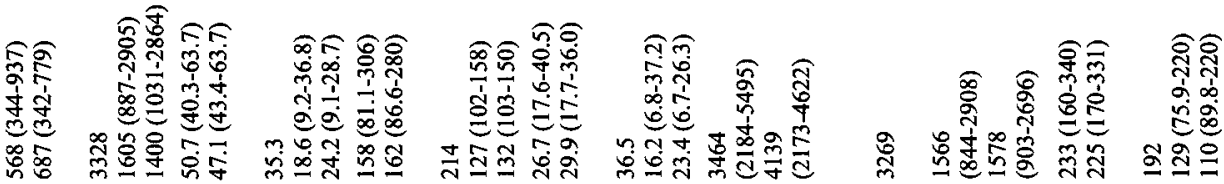

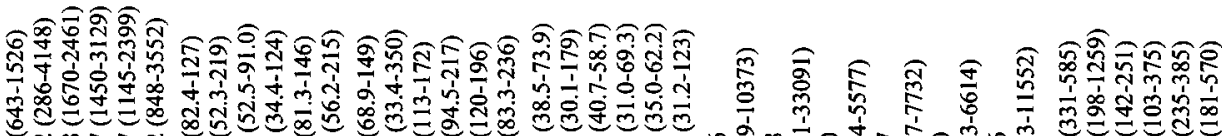

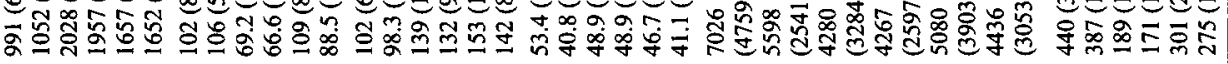

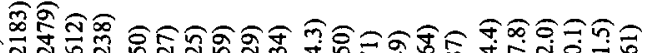

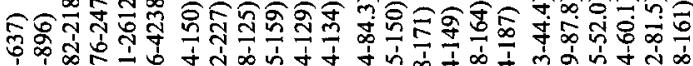

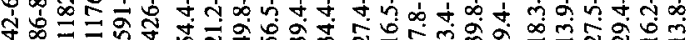

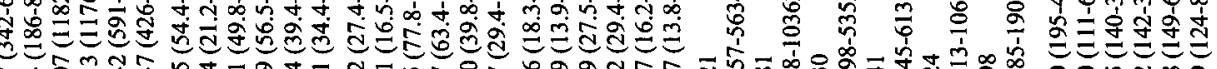

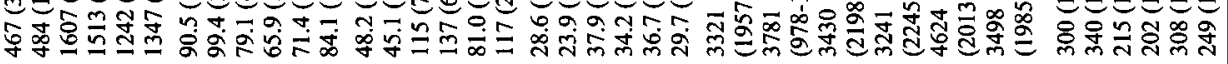

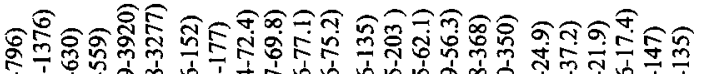

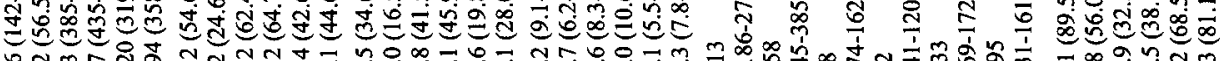

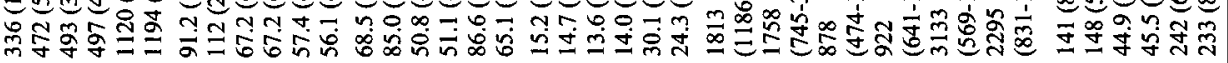

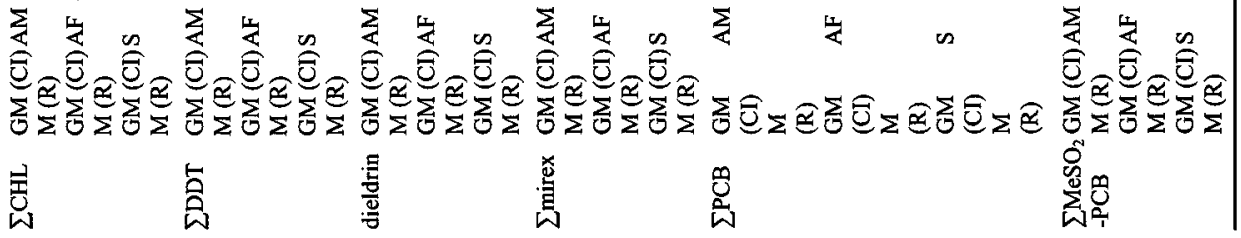




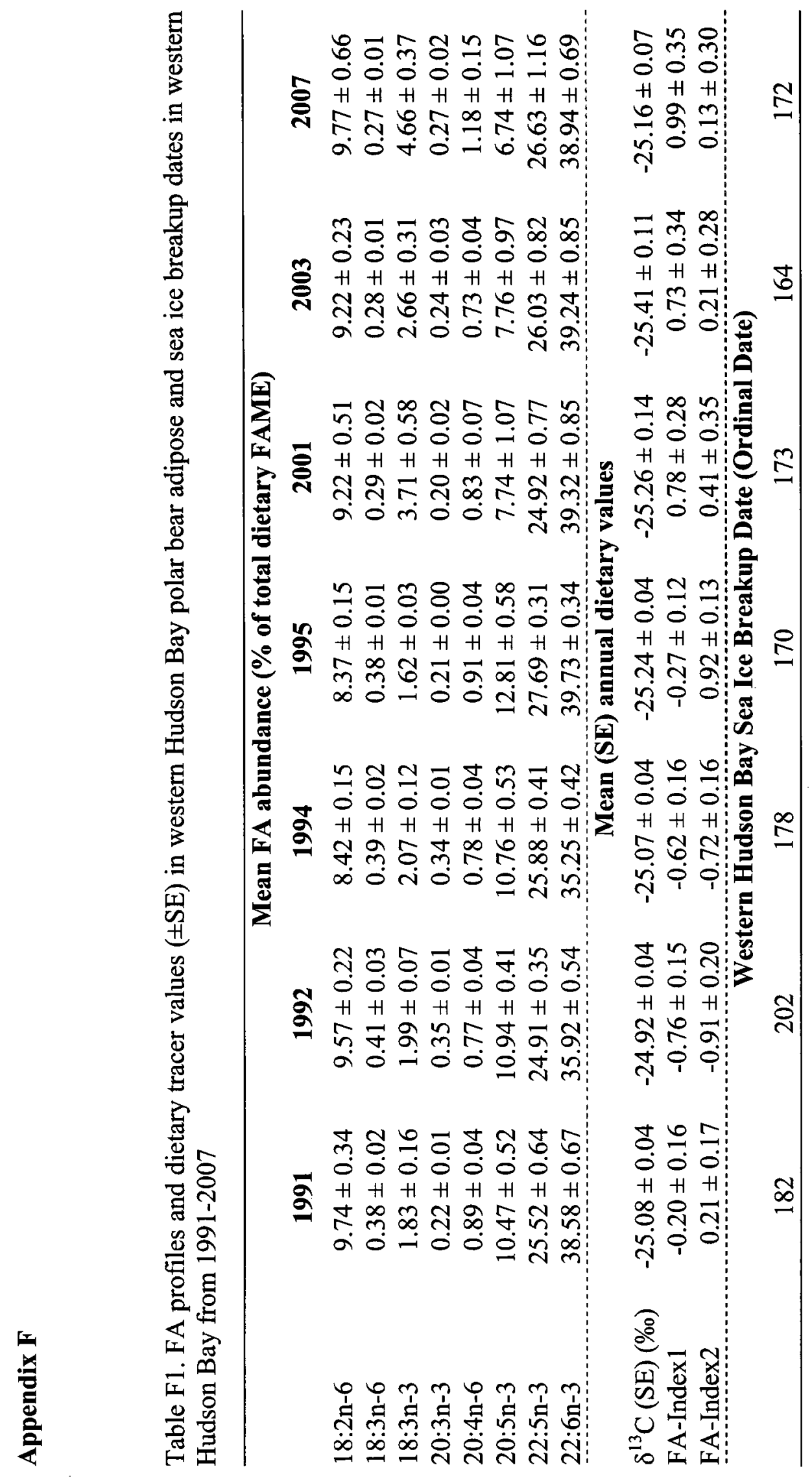

